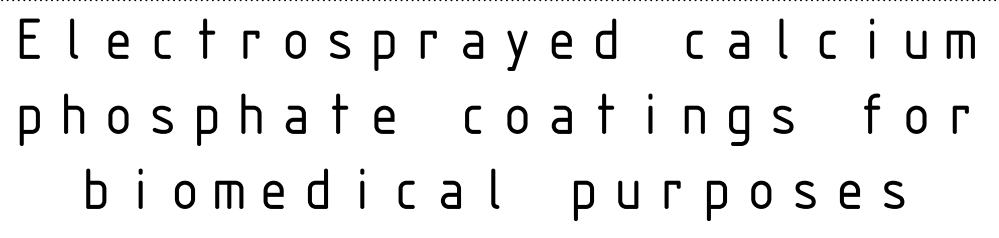


Sponsoring of this thesis was kindly provided by:

The Foundation for the Advancement in Research in Medicine (FARM)

Bonesmart $^{\mathrm{TM}}$

PANalytical

Biomet Nederland BV

CAM Implants BV

Stichting Annafonds Leiden

Stichting Prothese en Orthesemakerij Nijmegen (POM)

Dutch Society for Biomaterials and Tissue Engineering (NBTE)

Nederlandse Keramische Vereniging (NKV)

Advanced Surface Technology (AST)

BioComp Industries BV

Collof 0 o

Thesis Radboud University Nijmegen Medical Center, with summary in Dutch.

Electrosprayed calcium phosphate coatings for biomedical purposes.

Sander Cornelis Gerardus Leeuwenburgh, Nijmegen, 2006.

All rights reserved.

ISBN-10

ISBN-13

Cover design

Lay-out interior

Printing
90-9020705-8

978-90-9020705-6

Henk Looij

Martijn Prins

Print Partners Ipskamp BV, Enschede 


\section{Electrosprayed calcium phosphate coatings for biomedical purposes}

Een wetenschappelijke proeve op het gebied van de medische wetenschappen

$$
\text { Ргоеfschrift }
$$

ter verkrijging van de graad van doctor aan de Radboud Universiteit Nijmegen op gezag van de Rector Magnificus, prof. dr. C.W.P.M. Blom, volgens besluit van het College van Decanen in het openbaar te verdedigen op woensdag 8 november 2006, des namiddags om 3.30 uur precies

door

Sander Cornelis Gerardus Leeuwenburgh

geboren op 22 juli 1977

te Gouda 
Promotores

Prof. dr. John A. Jansen

Prof. dr. Joop Schoonman, Technische Universiteit Delft

Copromotor

Dr. Joop G.C. Wolke

Manuscriptcommissie

Prof. dr. Jan C.M. van Hest (voorzitter)

Prof. dr. Elias Vlieg

Dr. Arjen M. Vredenberg, Universiteit Utrecht

Р аг а п i m f e n

Ir. Roel J. Schierbeek

Ir. Bastiaan van Meeteren 
"A $\mathrm{A}$, und es hatte dies ganze Leben doch nur dann einen Sinn, wenn beides sich erringen ließ, wenn das Leben nicht durch dies dürre Entweder-Oder gespalten war ! Schaffen, ohne dafür den Preis des Lebens zu bezahlen ! Leben, ohne doch auf den Adel des Schöpfertums zu verzichten! War denn das nicht möglich ?"

(Hermann Hesse, "Narziß und Goldmund") 


\section{$C O N T E N T S$}

\section{GENERAL INTRODUCTION}

1. BIOMATERIALS 12

2. THE BONE-IMPLANT INTERFACE 12

2.1 Bone 12

2.2 Bioactivity and bone-bonding 13

2.3 Cellular interactions with implant surfaces 13

3. CALCIUM PHOSPHATE CERAMICS 14

3.1 Apatites 15

3.2 Carbonate apatite 15

4. CALCIUM PHOSPHATE COATINGS 16

4.1 Deposition techniques 17

$\begin{array}{ll}\text { 4.2 Electrostatic Spray Deposition (ESD) } & 17\end{array}$

5. ELECTROSPRAYING 18

$\begin{array}{ll}5.1 \text { Conventional spraying } & 19\end{array}$

$\begin{array}{ll}5.2 \text { Electrospraying } & 19\end{array}$

5.3 Electrospraying modes $\quad 19$

5.4 Cone-jet mode 20

5.5 Upscaling of electrospraying $\quad 22$

6. ELECTROSPRAYED COATINGS 23

6.1 Inorganic coatings 23

6.2 Organic coatings 23

7. OBJECTIVES OF THIS THESIS $\quad 24$

8. REFERENCES 25

2. ELECTROSTATIC SPRAY DEPOSITION (ESD) OF CALCIUM PHOSPHATE COATINGS FOR BIOMEDICAL PURPOSES: A FEASIBILITY STUDY

$\begin{array}{ll}\text { 1. INTRODUCTION } & 32 \\ \text { 2. MATERIALS AND METHODS } & 33 \\ \text { 2.1 Substrates } & 33 \\ \text { 2.2 Electrostatic Spray Deposition (ESD) process } & 33 \\ \text { 2.3 Coating characterization } & 33 \\ \text { 3. RESULTS } & 34 \\ \text { 4. DISCUSSION } & 36 \\ \text { 5. CONCLUSIONS } & 37 \\ \text { 6. REFERENCES } & 37\end{array}$

\section{INFLUENCE OF PRECURSOR SOLUTION PARAMETERS ON CHEMICAL CHARACTERISTICS OF ELECTROSPRAYED CALCIUM PHOSPHATE COATINGS}

1. INTRODUCTION 40

2. MATERIALS AND METHODS 41

2.1 Electrostatic Spray Deposition (ESD) process $\quad 41$ 
2.2 Coating deposition parameters $\quad 41$

2.3 Coating characterization $\quad 42$

3. RESULTS 43

3.1 Influence of relative $\mathrm{Ca} / \mathrm{P}$ ratio of the precursor solution 43

3.2 Influence of the absolute precursor solute concentration $\quad 45$

3.3 Influence of acidity of the precursor solution $\quad 45$

3.4 Influence of the type of Ca precursor salt $\quad 48$

4. DISCUSSION 48

4.1 Influence of relative $\mathrm{Ca} / \mathrm{P}$ ratio of the precursor solution $\quad 48$

4.2 Influence of the absolute precursor solute concentration $\quad 50$

4.3 Influence of acidity of the precursor solution $\quad 51$

4.4 Influence of the type of Ca precursor salt $\quad 51$

5. CONCLUSIONS

6. REFERENCES $\quad 52$

\section{INFLUENCE OF APPARATUS-RELATED DEPOSITION PARAMETERS ON CHEMICAL CHARACTERISTICS OF ELECTROSPRAYED CALCIUM PHOSPHATE COATINGS}

1. INTRODUCTION 56

2. MATERIALS AND METHODS 56

2.1 Electrostatic Spray Deposition (ESD) process 56

2.2 Coating deposition parameters $\quad 57$

2.3 Coating characterization $\quad 58$

3. RESULTS 58

3.1 Influence of deposition temperature $\quad 58$

3.2 Influence of nozzle-to-substrate distance $\quad 59$

3.3 Influence of spraying nozzle geometry $\quad 61$

3.4 Influence of liquid flow rate $\quad 62$

4. DISCUSSION 63

4.1 Influence of deposition temperature $\quad 63$

4.2 Influence of nozzle-to-substrate distance $\quad 63$

4.3 Influence of spraying nozzle geometry $\quad 64$

$\begin{array}{ll}4.4 \text { Influence of liquid flow rate } & 64\end{array}$

5. CONCLUSIONS $\quad 65$

6. REFERENCES $\quad 65$

\section{INFLUENCE OF APPARATUS-RELATED DEPOSITION PARAMETERS ON MORPHOLOGICAL CHARACTERISTICS OF ELECTROSPRAYED CALCIUM PHOSPHATE COATINGS}

1. INTRODUCTION 68

2. MATERIALS AND METHODS 68

2.1 Electrostatic Spray Deposition (ESD) process $\quad 68$

$\begin{array}{ll}2.2 \text { Coating deposition parameters } & 69\end{array}$

$\begin{array}{ll}2.3 \text { Coating characterization } & 69\end{array}$ 
3. RESULTS $\quad 70$

3.1 Coating crystal phase and molecular structure $\quad 70$

3.2 Influence of nozzle-to-substrate distance on coating morphology 71

3.3 Influence of precursor liquid flow rate on coating morphology 74

3.4 Influence of deposition temperature on coating morphology $\quad 74$

4. DISCUSSION

4.1 Coating crystal and molecular structure $\quad 76$

4.2 Influence of nozzle-to-substrate distance on coating morphology 76

4.3 Influence of precursor liquid flow rate on coating morphology 77

4.4 Influence of deposition temperature on coating morphology $\quad 77$

$\begin{array}{ll}\text { 5. CONCLUSIONS } & 78\end{array}$

$\begin{array}{ll}\text { 6. REFERENCES } & 78\end{array}$

\section{CORRELATING SPRAY CHARACTERISTICS WITH SURFACE} MORPHOLOGY OF ELECTROSPRAYED CALCIUM PHOSPHATE COATINGS

1. INTRODUCTION 82

2. MATERIALS AND METHODS 83

2.1 Electrostatic Spray Deposition (ESD) process 83

2.2 Coating deposition parameters $\quad 83$

2.3 Characterization $\quad 85$

3. RESULTS 85

3.1 PDA measurements $\quad 85$

3.2 Surface morphology of deposited coatings $\quad 89$

3.3 Deposition of porous, reticular coatings $\quad 89$

4. DISCUSSION 91

4.1 Influence of physical, apparatus-related parameters $\quad 91$

4.2 Influence of composition of precursor solutions 93

4.3 Deposition of porous, reticular coatings 93

5. CONCLUSIONS 94

6. REFERENCES 95

\section{MECHANICAL PROPERTIES OF ELECTROSPRAYED CALCIUM}

\section{PHOSPHATE COATINGS}

1. INTRODUCTION

2. MATERIALS AND METHODS 98

2.1 Electrostatic Spray Deposition (ESD) process 98

$\begin{array}{ll}2.2 \text { Test specimens } & 99\end{array}$

2.3 Fatigue testing $\quad 100$

$\begin{array}{ll}2.4 \text { Scratch testing } & 100\end{array}$

$\begin{array}{ll}2.5 \text { Explantation of dental screw implants } & 101\end{array}$

3. RESULTS 101

$\begin{array}{ll}3.1 \text { Fatigue testing } & 101\end{array}$

$\begin{array}{ll}3.2 \text { Scratch testing } & 104\end{array}$

$\begin{array}{ll}3.3 \text { Explantation of dental screw implants } & 107\end{array}$ 
4. DISCUSSION 109

4.1 Fatigue testing 109

4.2 Scratch testing 109

4.3 Explantation of dental screw implants $\quad 110$

5. CONCLUSIONS 111

6. REFERENCES 112

\section{IN VITRO AND IN VIVO REACTIVITY OF POROUS ELECTROSPRAYED} CALCIUM PHOSPHATE COATINGS

1. INTRODUCTION 116

2. MATERIALS AND METHODS 116

2.1 Specimen preparation $\quad 116$

$\begin{array}{ll}2.2 \text { In vitro soaking experiment } & 117\end{array}$

$\begin{array}{ll}2.3 \text { In vivo subcutaneous implantation } & 117\end{array}$

3. RESULTS 118

3.1 CaP coating characterization before in vitro/vivo testing 118

$\begin{array}{ll}3.2 \text { In vitro soaking experiment } & 121\end{array}$

3.3 In vivo subcutaneous implantation $\quad 123$

4. DISCUSSION 126

4.1 CaP coating characterization before in vitro/vivo testing $\quad 126$

4.2 In vitro soaking experiment $\quad 126$

$\begin{array}{ll}4.3 \text { In vivo subcutaneous implantation } & 128\end{array}$

4.4 Comparison between in vitro and in vivo studies $\quad 129$

5. CONCLUSIONS 129

$\begin{array}{lr}\text { 6. REFERENCES } & 130\end{array}$

\section{GENERAL CONCLUSIONS AND FUTURE PERSPECTIVE}

1. SUMMARY 134

2. CLOSING REMARKS AND FUTURE PERSPECTIVE 137

3. SAMENVATTING 139

4. SLOTOPMERKINGEN EN TOEKOMSTPERSPECTIEF 142

5. REFERENCES | REFERENTIES 144

DANKWOORD 146

$\begin{array}{lr}\text { CURRICULUM VITAE } & 148\end{array}$

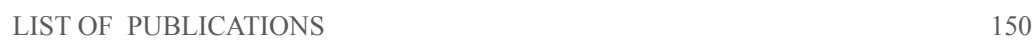

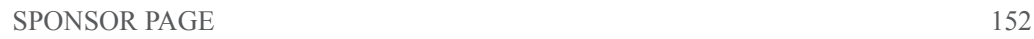




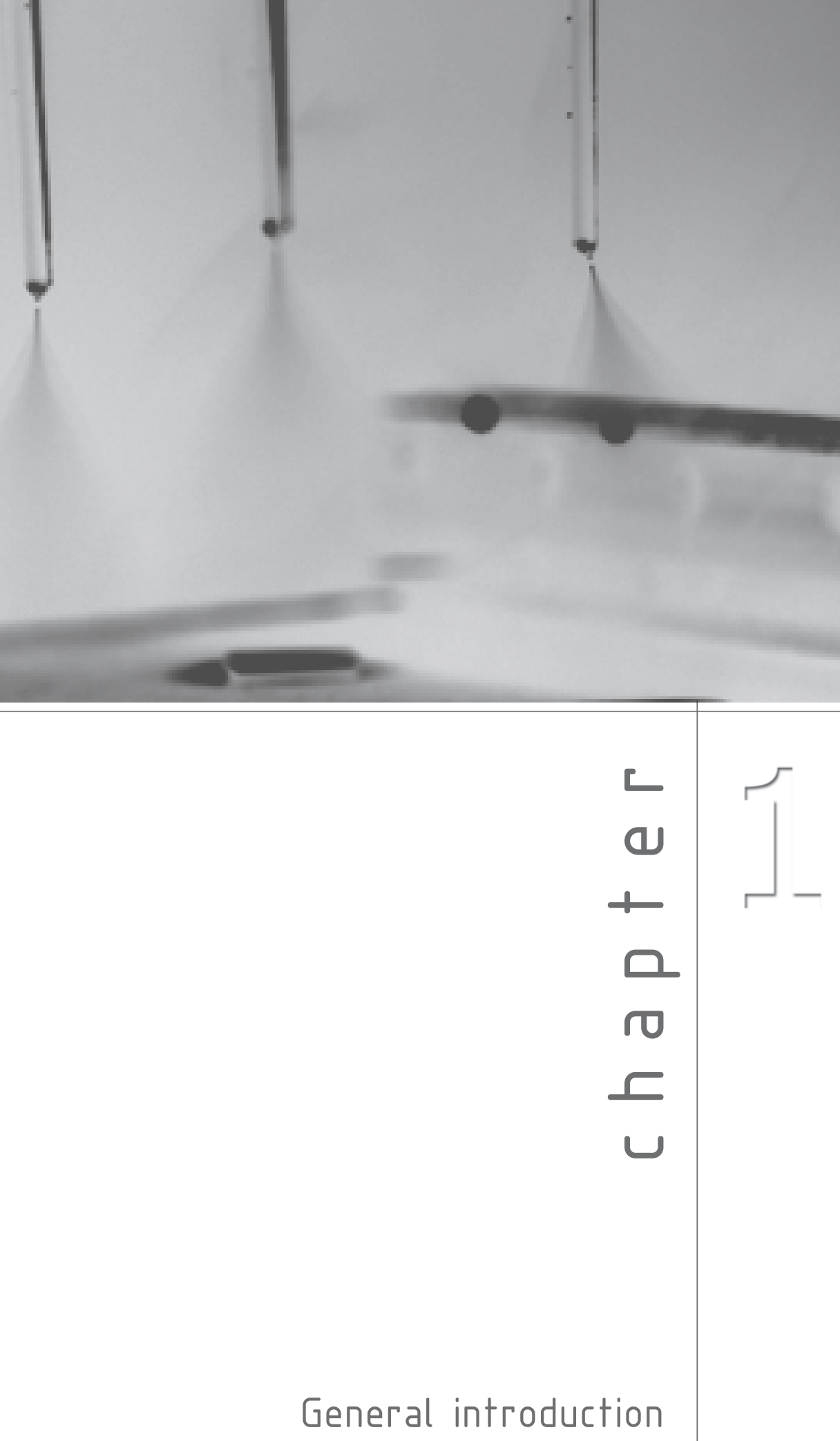




\section{Biomaterials}

During the second consensus conference on definitions in biomaterials ${ }^{1}$, biomaterials were defined as "materials intended to interface with biological systems to evaluate, treat, augment, or replace any tissue, organ or function of the body". These materials are capable of being in contact with body fluids and tissues for prolonged periods of time, whilst eliciting little if any adverse reactions. However, no foreign material placed within a living body can be completely compatible to the biological surroundings, with the notable exception of autogeneous materials (autografts), which are retrieved from the body itself. Any other foreign substance initiates a specific host-tissue response.

With respect to bone-substituting biomaterials, Osborn and Newesely ${ }^{2}$ classified three categories of biocompatibility based on the various reactions to surrounding bone tissue:

" Biotolerant materials, such as stainless steel and Co-Cr alloys, are characterized by distant osteogenesis, which means that the implant surface is separated from adjacent bone by an intervening fibrous tissue layer.

" Bioinert materials, such as titanium and aluminum oxide, do not provoke the formation of fibrous tissue and display contact osteogenesis, i.e., the creation of a direct contact to osseous tissue.

" Bioactive materials, such as calcium phosphate (further abbreviated as CaP throughout this thesis) ceramics and silica-based bioglasses, are truly bone-bonding materials, which are characterized by the formation of a very tight, chemical bond with bone (bonding osteogenesis). Bioactive materials enhance bone tissue forming reactions starting from the implant surface, and induce the formation of a continuous transition from tissue to implant surface, i.e., bonding ${ }^{3}$.

\section{The bone-implant interface}

In order to clarify the above mentioned concept of bone-bonding, first of all a brief outline will be given on the structure of bone tissue.

\subsection{BONE}

Bone is a mineralized tissue, which can be described as a natural composite material consisting of an organic matrix strengthened by an inorganic $\mathrm{CaP}$ phase. The extracellular organic matrix of bone consists of $90 \%$ collagenic proteins (type I collagen $97 \%$ and type $\mathrm{V}$ collagen $3 \%$ ) and of $10 \%$ non-collagenic proteins (osteocalcin $20 \%$, osteonectin $20 \%$, bone sialoproteins $12 \%$, proteoglycans $10 \%$, osteopontin, fibronectin, growth factors, bone morphogenetic proteins, etc. $)^{4}$. Regarding the inorganic phase, the most abundant mineral in human bone is apatite. The similarity between bone mineral and hydroxyapatite was first noticed by de Jong ${ }^{5}$. Investigations by LeGeros ${ }^{6}$ revealed that the crystal structure of bone mineral is more similar to the structure of carbonated apatites. Besides apatite, other phases are thought to exist in bone mineral ${ }^{7}$.

This calcified matrix embeds bone cells, which participate in the maintenance and organization of bone. Bone is a dynamic tissue subject to constant remodeling by osteoblasts and osteoclasts, i.e. bone-forming and bone-resorbing cells. Osteoblasts are responsible for the synthesis, deposition, and mineralization of bone matrix. They are located at bone 
surfaces and form a continuous layer. Upon embedding in this matrix, osteoblasts finally transform into quiescent osteocytes. Osteoclasts are large multinuclear cells that are involved in bone resorption. A main feature of this bone cell type is its ruffled border, which acts as a high surface area interface for excretion of proteins and (hydrochloric) acid. This acid decreases the local $\mathrm{pH}$ and dissolves $\mathrm{CaP}$ bone mineral. Generally, two types of bone tissue can be distinguished. Cortical (compact) bone is found at the external surfaces of bones, which is constructed of about $90 \%$ of dense bone. Trabecular (spongy) bone is found in the interior of bones, and is composed of a highly porous, spongeous network of so-called bone trabeculae. The intervening cavities are filled with blood vessels and bone marrow.

\subsection{BIOACTIVITY AND BONE-BONDING}

Until the early 1970s, basic clinical concepts for anchoring load-bearing implants within the skeletal system (such as impaction into bone, mechanical interlocking of the implants with bone through screws and other surface macrostructures, and polymerization of methylmethacrylate bone cement) had in common that a soft tissue layer was formed between the implant and bone at retrieval ${ }^{8}$. The lack of chemical intertness of the applied metallic and polymeric materials was suggested to be responsible for this unfavorable tissue reaction. On the contrary, Hulbert ${ }^{9}$ introduced a new concept of so-called biological fixation of skeletal implants by active bone growth onto the implant surface. These materials were oxidic ceramics and carbon materials, as well as metals which were covered with stable oxide layers.

At the same time, however, the principle of bioactive materials (mainly $\mathrm{CaP}$ ceramics and silicate-based glasses and glass-ceramics) was explored ${ }^{10-14}$. As mentioned before, bioactivity refers to a material which interacts with the surrounding bone and forms a chemical bond to this tissue ("bone-bonding"). This occurs through a time-dependent kinetic modification of the surface, triggered by their implantation within the living bone ${ }^{15-18}$. An ion-exchange reaction between the bioactive implant and surrounding body fluids results in the formation of a carbonate apatite layer on the implant that is chemically and crystallographically equivalent to the mineral phase in bone. This correlation between bioactivity and the formation of a carbonate apatite layer is often inverted for preliminary in vitro testing of the potential bioactivity of biomaterials. The capacity to nucleate $\mathrm{CaP}$ formation under in vitro conditions is then interpretated as a first indication of possible bioactivity in vivo.

\subsection{CELLULAR INTERACTIONS WITH IMPLANT SURFACES}

A sequence of complex and strongly interrelated interactions takes place at the implant surface after installation of a prosthesis ${ }^{15}$. First, ions and proteins adsorb onto the surface ${ }^{19}$. This adsorption process is strongly dependent on the physicochemical characteristics of the implant surface, such as its topography (in terms of roughness, porosity, morphology, etc.), chemistry, energy, and charge ${ }^{20}$. As a result, both the amount and functionality of the adsorbed proteins are largely controlled by the biomaterial surface. This adsorbed biofilm subsequently determines cell adhesion, since proteins act as contact for the attachment of cells. This is accomplished by means of integrins, which are specific transmembrane receptors. These integrins bind to adhesive proteins on the biomaterial's surface and to components of the cytoskeleton through their extra- and intracellular domains, respectively ${ }^{21}$. Although the biological side of the interface is more dynamic than the material side ${ }^{8}$, it 
should be stressed that the material's surface can also undergo significant alterations due to the physicochemical interaction between the surface and surrounding body fluids.

In general, the biocompatibility of bone-replacing biomaterials is closely related to osteoblast adhesion onto their surface ${ }^{22-26}$. Osteoblast attachment, adhesion and spreading will influence the capacity of these cells to proliferate and to differentiate itself upon contact with the implant. These latter processes are quintessential for the establishment of a mechanically solid interface with complete fusion between the implant surface and bone tissue without any intervening fibrous tissue layer.

\section{Calcium phosphate ceramics}

Calcium orthophosphates are salts of the tribasic phosphoric acid $\mathrm{H}_{3} \mathrm{PO}_{4}$ and thus can form compounds that contain $\mathrm{H}_{2} \mathrm{PO}_{4}^{-}, \mathrm{HPO}_{4}{ }^{2-}$ and/or $\mathrm{PO}_{4}^{3-}$ ions. Those with $\mathrm{H}_{2} \mathrm{PO}_{4}^{-}$ions only form under rather acidic conditions and are, therefore, usually not found in biological systems. However, both $\mathrm{HPO}_{4}{ }^{2-}$ and $\mathrm{PO}_{4}{ }^{3-}$ ions are incorporated into the mineral phase of bones and teeth ${ }^{27}$. Pyrophosphates $\left(\mathrm{P}_{2} \mathrm{O}_{7}^{4-}\right.$, dipolyphosphates), which contain P-O-P bonds, are of less biological importance than the orthophosphates. Nevertheless, calcium pyrophosphates occur in some pathological calcifications. Pyrophosphates are inhibitors of nucleation and crystal growth of $\mathrm{CaP}$ in aqueous systems ${ }^{27}$. Table 1 gives chemical names, compositions, and frequently used abbreviations of the most important $\mathrm{CaP}$ compounds ${ }^{27}$.

\begin{tabular}{|c|c|c|c|}
\hline $\mathrm{Ca} / \mathrm{P}$ ratio & Formula & Name & Abbreviation \\
\hline 0.5 & $\mathrm{Ca}\left(\mathrm{H}_{2} \mathrm{PO}_{4}\right)_{2} \cdot \mathrm{H}_{2} \mathrm{O}$ & Monocalcium phosphate monohydrate & MCPM \\
\hline 0.5 & $\mathrm{Ca}\left(\mathrm{H}_{2} \mathrm{PO}_{4}\right)_{2}$ & Monocalcium phosphate anhydrous & MCPA \\
\hline 1.0 & $\mathrm{CaHPO}_{4} \cdot 2 \mathrm{H}_{2} \mathrm{O}$ & Dicalcium phosphate dihydrate & DCPD \\
\hline 1.0 & $\mathrm{CaHPO}_{4}$ & Dicalcium phosphate anhydrous & DCPA \\
\hline 1.33 & $\mathrm{Ca}_{8} \mathrm{H}_{2}\left(\mathrm{PO}_{4}\right)_{6} .5 \mathrm{H}_{2} \mathrm{O}$ & Octacalcium phosphate & OCP \\
\hline 1.5 & $\mathrm{Ca}_{3}\left(\mathrm{PO}_{4}\right)_{2}$ & Tricalcium phosphate & TCP \\
\hline 1.67 & $\mathrm{Ca}_{5}\left(\mathrm{PO}_{4}\right)_{3}(\mathrm{OH})$ & Hydroxyapatite & HA/OHAp \\
\hline 1.67 & $\mathrm{Ca}_{5}\left(\mathrm{PO}_{4}\right)_{3} \mathrm{~F}$ & Fluorapatite & $\mathrm{FA} / \mathrm{FAp}$ \\
\hline$\geq 1.67$ & $\mathrm{Ca}_{5}\left(\mathrm{PO}_{4}\right)_{\mathrm{x}}\left(\mathrm{CO}_{3}\right)_{\mathrm{y} . .}$ & Carbonate apatite & $\mathrm{CA} / \mathrm{CO}_{3} \mathrm{Ap}$ \\
\hline 2.0 & $\mathrm{CaO} . \mathrm{Ca}_{3}\left(\mathrm{PO}_{4}\right)_{2}$ & Tetracalcium phosphate & TetCP \\
\hline
\end{tabular}

Table 1: Ca/P ratios, composition, names, and abbreviations for various calcium phosphates

Phase diagrams show thermodynamically stable phases and give an indication of the likely conditions required for synthesis. However, the actual phase that forms under any given conditions is often dictated by kinetic rather than thermodynamic considerations ${ }^{27}$. The calculated phase diagram for the system $\mathrm{Ca}(\mathrm{OH})_{2}-\mathrm{H}_{3} \mathrm{PO}_{4}-\mathrm{H}_{2} \mathrm{O}$ at normal temperatures and pressures is given in Figure 1, which shows that hydroxyapatite is the most stable phase at $\mathrm{pH}$-values between 5 to 8 from a thermodynamical point of view ${ }^{27}$. 


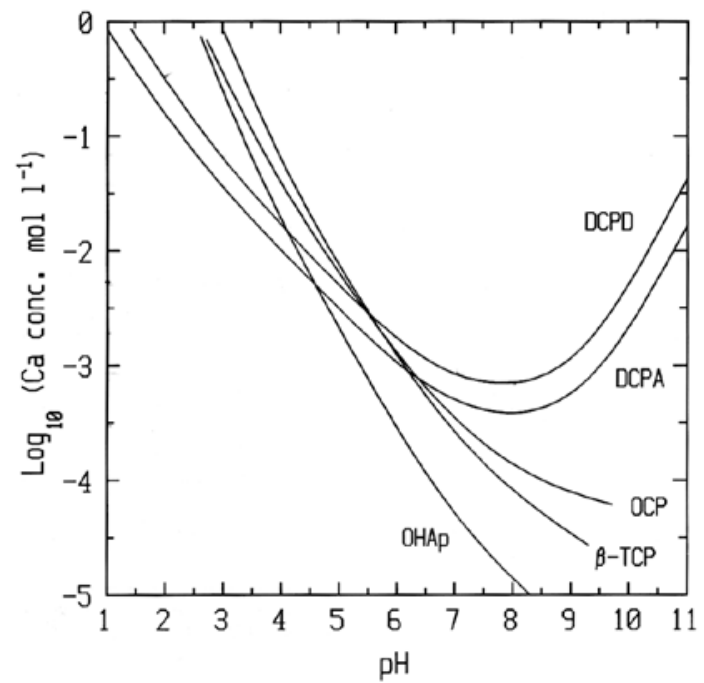

Figure 1: Solubility isotherms of CaP phases in the system $\mathrm{Ca}(\mathrm{OH})_{2}-\mathrm{H}_{3} \mathrm{PO}_{4}-\mathrm{H}_{2} \mathrm{O}$ at $37^{\circ} \mathrm{C}^{27}$.

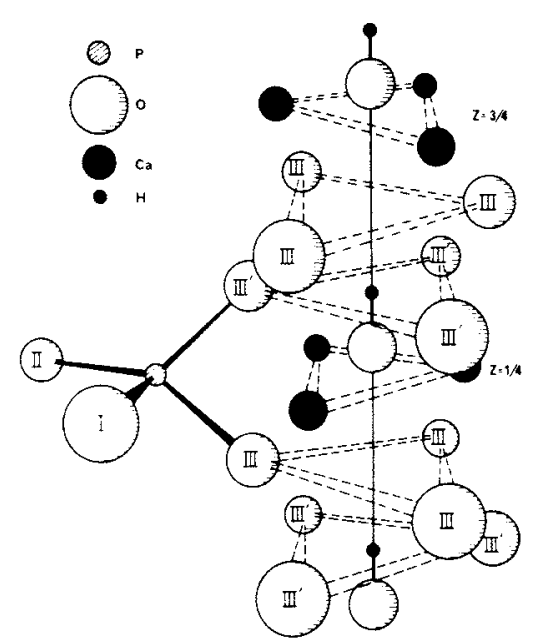

Figure 2: Arrangement of ions in and around the $\mathrm{OH}$-ion containing c-axis tunnel in hydroxyapatite ${ }^{28}$.

\subsection{APATITES}

Calcium phosphates are often used in the biomedical field due to their similarity with the mineral phase as present in bone and teeth. Hydroxyapatite, or more specifically carbonate apatite, is by far the most abundant inorganic phase in the human body. Apatites have the formula $\mathrm{Ca}_{5}\left(\mathrm{PO}_{4}\right) \mathrm{X}$, where $\mathrm{X}$ may represent several mono- and/or divalent anions such as $\mathrm{F}^{-}(\mathrm{FA}), \mathrm{OH}^{-}(\mathrm{HA})$, or carbonate (CA). The name apatite has been taken from the Greek $\alpha \pi \alpha \tau \alpha \omega$ (Eng. "to deceive"), because the mineral was frequently confused with other compounds such as aquamarine, amethyst, etc. The apatite structure is very tolerant for ionic substitutions. For example, $\mathrm{Ca}^{2+}$ ions can be partly or completely replaced by $\mathrm{Ba}^{2+}$, $\mathrm{Sr}^{2+}$ or $\mathrm{Pb}^{2+}$. Stoichiometric hydroxyapatite has a hexagonal lattice with space group $\mathrm{P} 6_{3} / \mathrm{m}$ $\left(\mathrm{a}=\mathrm{b} \neq \mathrm{c}, \gamma=120^{\circ}, \mathrm{a}=9.421\right.$ and $\left.\mathrm{c}=6.881 \AA\right)$. The exact lattice parameters - and many other properties of apatites - depend slightly on the mode of preparation because of the frequent occurrence of nonstoichiometry. Some lattice substitutions cause a lowering of the symmetry, so that the unit cell may be slightly distorted. $\mathrm{OH}^{-}$ions are positioned along the c-axis of the unit cell in tunnels that are formed by calcium ions. These cations are arranged in triangular co-ordinated groups around the c-axis, thus forming the "tunnels" (Figure 2).

\subsection{CARBONATE APATITE}

Carbonate apatite comprises a chemical composition closer to bone or dental enamel than that of hydroxyapatite. The relation between carbonate apatite and hydroxyapatite is important, because carbonate increases the chemical reactivity of apatites. This occurs by an increase of the solubility product and rate of dissolution in acids ${ }^{29}$, and by reducing the thermal stability. Carbonate apatite is more similar to bone mineral and more soluble than hydroxyapatite. As carbonate is known as an effective crystal growth inhibitor ${ }^{6}$, carbonate apatite consists of smaller crystals. Carbonate apatite gives an X-ray Diffraction (XRD) pattern of poorly crystallized apatite, which makes it difficult to distinguish carbonate apatite from hydroxyapatite. Therefore, XRD-analysis only is not sufficient to characterize 
carbonate apatite. Fourier-transform Infrared Spectroscopy (FTIR) is a suitable technique to study the chemistry of the carbonate apatites, since changes in the chemical environment of an ion will alter its vibrational frequency. Two types of carbonate sites have been characterized $^{30-32}$ :

A-type carbonate, corresponding to a location of carbonate ions on monovalent, anionic $\mathrm{OH}^{-}$sites.

" B-type carbonate, corresponding to a substitution of phosphate ions by carbonate ions.

A-type carbonated apatites are obtained at high temperatures and are more stable than Btype carbonate apatites. The complex and variable infrared spectra of synthetic carbonate apatites prove that the carbonate substitution is a highly complex phenomenon ${ }^{6,27,30-32}$.

In the range between $400-4000 \mathrm{~cm}^{-1}$, the infrared spectra of carbonate (hydroxy)apatite have bands due to phosphate and carbonate ions. The vibrations of these ions are influenced by neighboring ions in the lattice. The undistorted carbonate ion is a planar ion with three equal, symmetrically placed C-O bonds and four normal modes of vibration of which $v_{2}$ at $879 \mathrm{~cm}^{-1}$ (out of plane bending), $v_{3}$ at $1415 \mathrm{~cm}^{-1}$ (asymmetric stretching), and $v_{4}$ at $680 \mathrm{~cm}^{-1}$ (planar bending) are infrared active ${ }^{27}$. The symmetry of the carbonate ion will be lowered if it is surrounded by calcium ions located in an apatite crystal lattice. Consequently, there is a loss of degeneracy. The carbonate bands at 1535 and $1458 \mathrm{~cm}^{-1}$ in A-type carbonate apatite have been assigned to the $v_{3 \mathrm{~b}}$ and $v_{3 \mathrm{a}}$ bands that result from this loss of the degeneracy of $v_{3}$. The frequencies of $v_{3 a}$ and $v_{2}$ are almost independent of the degree of substitution of $\mathrm{OH}^{-}$by $\mathrm{CO}_{3}{ }^{2-}$ ions (A-type), but $v_{3 \mathrm{~b}}$ decreases in a nonlinear way from about 1565 to $1527 \mathrm{~cm}^{-1}$ as the substitution increases. However, the absence of the $v_{3} \mathrm{OH}$-stretching band $\left(3570 \mathrm{~cm}^{-1}\right)$ has been reported for various preparations, which did not show any absorption peaks for A-type carbonate substitutions either ${ }^{31}$. The B-type substitution is often associated with a peak at $1430 \mathrm{~cm}^{-1}$. Other frequently reported absorptions are found at 1465, 1412, and 873 $\mathrm{cm}^{-1}$. Generally, A-sites are favored for a small carbonate content, but with increasing carbonate incorporation, B-sites become favored and the A-site content becomes less.

The amount of carbonate incorporated into carbonate apatite has a direct influence on the lattice parameters of AB-type carbonate apatites. As the $\mathrm{CO}_{3}{ }^{2-}$ concentration increases to about 3 to $4 \mathrm{wt} \%$, the a-axis parameter increases and the c-axis parameter decreases, which has been attributed to an initial preferred A-type substitution. For precipitated carbonate apatite with a $\mathrm{CO}_{3}{ }^{2-}$ concentration exceeding 3 to $4 \mathrm{wt} \%$, the a-axis parameter decreases markedly and the c-axis increases, as expected for the B-type substitutions ${ }^{27}$.

\section{Calcium phosphate coatings}

Bulk CaP products are currently marketed as bone fillers in dense or porous forms, which have been clinically applied in many areas of dentistry and orthopedics ${ }^{33,34}$, whereas injectable $\mathrm{CaP}$ bone graft substitutes represent another branch of bulk $\mathrm{CaP}$ ceramics $^{35-37}$. As bulk material, however, $\mathrm{CaP}$ ceramics are intrinsically brittle and relatively weak in comparison to other implant metals, like titanium and its alloys, and high-strength ceramics, e.g. alumina and zirconia. Consequently, calcium phosphates are applied as coatings on mechanically strong implant materials in load-bearing implant applications in order to combine the mechanical strength of metals with the excellent biological properties of $\mathrm{CaP}$ ceramics. 


\subsection{DEPOSITION TECHNIQUES}

The most successful method to apply CaP coatings to implants has been the plasmaspraying technique until now due to its high deposition rate and the ability to coat large areas. Although the osteoconductive and bone-bonding behavior of plasma-sprayed coatings is confirmed by numerous studies ${ }^{38-41}$, still some serious concerns are related to the plasma-spraying technique ${ }^{42}$ :

- Plasma-sprayed coatings must be at least $50 \mu \mathrm{m}$ thick to completely cover the implant. As a consequence, the adhesion of the thick plasma-sprayed coatings tends to be quite weak, which necessitates a pre-treatment of the substrates such as grit blasting to roughen the substrate and to increase the mechanical interlocking of the coatingsubstrate system.

- Phase changes in the CaP powder particles during the coating process are unpredictable due to the high temperature differences in the plasma, leading to the formation of undesired phases such as tetracalcium phosphate, calcium oxide, and $\alpha$-tricalcium phosphate. Moreover, particularly promising phases such as carbonate apatite (which is close to bone composition ${ }^{43}$ ) and biological agents such as growth factors can not be deposited using plasma-spraying.

- Particle release and delamination are specific drawbacks for the plasma-spraying technique. The crystallinity of plasma-sprayed coatings is not uniform, as the coatings consist of crystalline and amorphous regions. When $\mathrm{CaP}$ material is released from these heterogeneous coatings, the resultant particles may initiate inflammation in surrounding tissues.

- Poor control over thickness and surface morphology.

Therefore, researchers have been continuously inspired in the past two decades to explore alternative or complementary techniques for deposition of $\mathrm{CaP}$ coatings onto implant surfaces. In order to overcome the above mentioned drawbacks of plasma-sprayed coatings, various deposition methods have been proposed, including magnetron sputtering ${ }^{44,45}$, electrophoretic deposition ${ }^{46}$, hot isostatic pressing ${ }^{47}$, sol-gel deposition ${ }^{48}$, pulsed laser deposition $^{49}$, ion beam deposition ${ }^{50}$, molecular precursor method ${ }^{51}$, biomimetic deposition ${ }^{52}$, and electrolytic deposition ${ }^{53}$. In the current thesis, a novel deposition technique referred to as Electrostatic Spray Deposition (ESD) was investigated, since this technique offers some specific advantages compared to many other coating deposition techniques. The process and its advantages will be discussed in more detail in the next paragraph.

\subsection{ELECTROSTATIC SPRAY DEPOSITION (ESD)}

At the Laboratory for Inorganic Chemistry of the Delft University of Technology, the synthesis technique called Electrostatic Spray Deposition (ESD) was developed in the $1990 \mathrm{~s}^{54}$ in order to be able to fabricate porous, thin ceramic films with a controlled morphology for solid electrolytes and lithium battery electrode materials. Briefly, the basic principle of ESD is the generation of an aerosol out of organic solvents containing inorganic precursors under the influence of a high voltage. An aerosol is defined as a dispersion of solid or liquid particles in a gas. This is accomplished by pumping this liquid through a nozzle. Usually a spherical droplet is then formed at the tip of the nozzle, but if a high voltage is applied between the nozzle and substrate, this droplet transforms into a conical shape and fans out to form a spray of highly charged droplets. The generated spray droplets are attracted by the grounded and heated substrate as a result of the applied potential differ- 


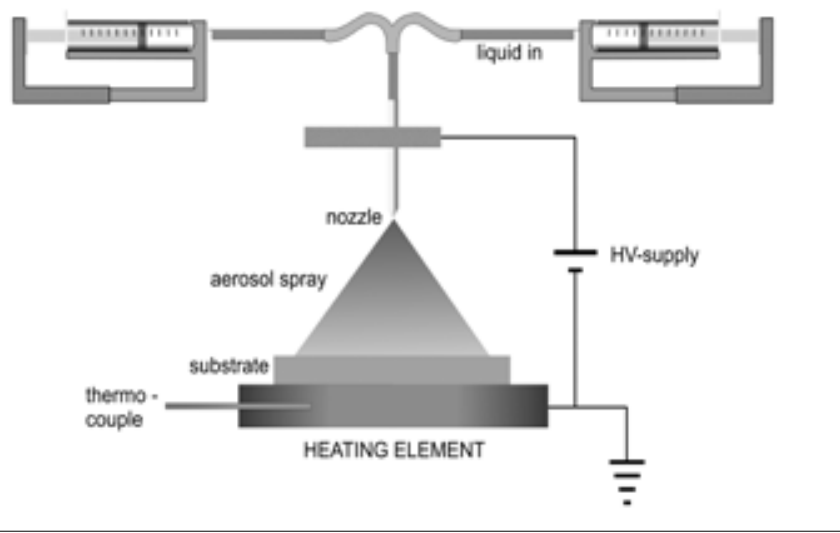

Figure 3: Experimental setup of the Electrostatic Spray Deposition (ESD) technique.

ence. Consequently, the droplets impinge onto the heated substrate, where they lose their charge. After complete solvent evaporation, a thin layer is left onto the substrate surface. Figure 3 shows a schematic view of such an experimental set-up.

This coating technique can have several advantages over conventional deposition techniques:

A very simple and cheap set-up.

- A wide choice of sprayable precursor solutions (dissolved salts, suspensions, sols) and coatable substrates.

" Large control over surface properties. In view of the above mentioned relationship between physicochemical characteristics of biomaterial's surfaces and their biological performance in vitro and in vivo (section 2.3), the flexibility of the ESD-technique regarding deposition of coatings with a wide variety of surface chemical and morphological properties offers a specific advantage over many deposition techniques which lack this freedom.

" Control over coating thickness. In contrast to plasma-spraying, the thickness of electrosprayed thin films can be controlled easily from several nanometers to more than $30 \mu \mathrm{m}$.

- A high deposition efficiency as compared to conventional spraying processes without any applied electric field. The trajectory of electrosprayed droplets is well-defined due to the external electric field, which can be modified by means of additional external electrodes in order to conform the electric field to the desired shape. Moreover, droplet coagulation cannot occur since droplets are equally charged, yielding homogeneous and controllable sprays.

\section{Electrospraying}

In the current thesis, the ESD technique has been used to deposit thin $\mathrm{CaP}$ layers onto titanium substrates. Therefore, the principles of electrospraying will be elucidated in the next paragraphs. 


\subsection{CONVENTIONAL SPRAYING}

A high number of spraying techniques has been developed for various technical applications. In most cases, bulk liquid is atomized by means of mechanical energy, which disintegrates the liquid body into small droplets ${ }^{55}$. This mechanical energy can be added to the liquid by applying high pressure, (ultrasonic) vibration, kinetic acceleration, etc. The mechanism of atomization is mainly based on a high relative velocity difference between the liquid and surrounding gas medium, as a result of which the liquid jet disintegrates into droplets.

\subsection{ELECTROSPRAYING}

As compared to uncharged sprays, charged droplets and sprays offer the possibility to control droplet transport, evaporation, and lifetime by applying external electric fields. The droplet trajectory can be directed towards the desired location by tailoring the external electric field, which enhances deposition efficiency significantly ${ }^{56}$. Charging of sprays can be obtained by means of various droplet charging mechanisms. The charging by induction is based on the ionic bombardment of the droplets by ionized molecules, whereas the sprays are still generated by mechanical forces (ultrasonic, pressure, etc.) ${ }^{57}$. On the contrary, by applying a high voltage directly to the spray-generating nozzle, the processes of spray generation and charging of the droplets are not separated anymore. In that case, the liquid is disintegrated by the disrupting influence of the applied electric potential only. In literature, this phenomenon is referred to as electrohydrodynamic or electrostatic atomization $^{58}$. For the production of charged droplets the purely electrostatic spraying method is used most frequently, but hybrid electrosprays are applied also, e.g. for production of charged fuel sprays ${ }^{59}$ where an electric field is applied in combination with a conventional pressure nozzle.

Electrostatic atomizers make us of electric force to overcome the surface tension of the liquid. Liquid acceleration and droplet breakup are induced by the electric field acting onto the droplet surface. Lord Rayleigh ${ }^{60}$ was the first to describe the instabilities of an electrically charged droplet when the outward electrostatic forces are balancing the surface tension forces, resulting in emission of a narrow liquid jet. Electrospraying in a capillaryplate configuration is based on this effect. The liquid is flowing through the capillary outlet, where the high electric field accelerates the liquid resulting in jets that break up into droplets. Depending on the strength of the electric stresses at the liquid surface relative to the surface tension stress and the kinetic energy of the flowing liquid, different electrospraying modes are obtained. Cloupeau and Prunet-Foch ${ }^{61}$, Grace and Marijnissen ${ }^{62}$, and Jaworek and $\mathrm{Krupa}^{63}$ reviewed these spraying modes, which will be discussed in more detail in the next section.

\subsection{ELECTROSPRAYING MODES}

When a liquid is slowly flowing through a thin circular capillary without an electric field applied over the droplet hanging down from the capillary, droplets are produced ${ }^{55}$ with a droplet diameter $\mathrm{d}$ of:

$$
d=\left(\frac{6 d_{0} \gamma}{\rho_{L} g}\right)^{\frac{1}{3}}
$$


where $d_{0}$ is the outlet diameter, $\gamma$ the liquid surface tension, $\rho_{L}$ the liquid density, and $g$ the gravity constant. Generally, these droplets are millimeter-sized and not suitable for most industrial applications. Application of an electric field produces a surface charge in the droplet, resulting in an electric stress which reduces the effective surface tension stress in the droplet surface. A small droplet will be ejected when the electric stresses and gravitational pressure overcome the surface tension. Subsequently, the large droplet at the capillary relaxes to its original shape and starts growing until a new droplet can be ejected. These so-called dripping and microdripping modes occur at low electric field strengths and produce narrow size distributions. The intermittent cone-jet mode occurs at higher electric field strengths than microdripping. The droplet at the capillary outlet is transformed into a conical shape, at the apex of which a jet emerges. This jet breaks up into a large number of small and charged droplets. Since the charged aerosol reduces the electric field at the liquid cone, the surface tension stress is still able to overcome the electric stresses, resulting into a periodical relaxation of the liquid cone to a normal droplet shape. Consequently, the shape of the liquid at the capillary exit continuously alternates between a cone-shape (emitting a jet) and a rounded drop. The intermittent cone-jet mode produces a relatively broad droplet size distribution.

By increasing the electric field strength, the liquid cone does not relax anymore at a certain voltage to re-establish a normal droplet shape, which stabilizes the process of droplet production in time. This so-called cone-jet mode, sometimes referred to as the Taylor-cone, can be considered as a process producing an aerosol with a continuous flow. The jet-breakup process yields micrometer-sized droplets, even if the capillary outlet diameter is in the order of millimeters. This means that the electrospray mechanism serves as jet miniaturization apparatus. With increasing potential difference, the liquid cone of the cone-jet mode continuously decreases in size until the liquid cone has become too small for the capillary diameter. The cone moves from the center of the capillary towards the edge. When the potential difference increases further, a second cone will appear. With increasing potential difference, the number of jets increases. The cone-shaped bases of these jets are still attached, comprising an electrically deformed droplet which feeds multiple spraying points. At even higher field strengths, electrospraying modes such as the ramified-jet mode appear, where emitted jets become highly charged and unstable. The jet breakup mechanism is of mechanical nature for cone-jet and multi-jet modes, whereas the charge density for ramified-jets is so high that the jet disintegrates by mutual repulsion of charges.

The electrospraying mode that has been investigated most extensively in the past is the cone-jet mode. Therefore, the following paragraph will summarize the processes that occur during electrospraying in the cone-jet mode.

\subsection{CONE-JET MODE}

Three separate processes occur during cone-jet mode of electrospraying: cone formation, breakup of the jet into an aerosol, and spray evolution.

\subsubsection{Cone formation}

Taylor $^{64}$ was the first to describe the balance between the surface tension stress and the normal electrical stress in a liquid cone. However, Taylor's solution is only valid for the extreme case where there is no jet and no tangential stress. In reality, the process is much more complex. Figure 4 shows the various processes that occur in the liquid cone. 


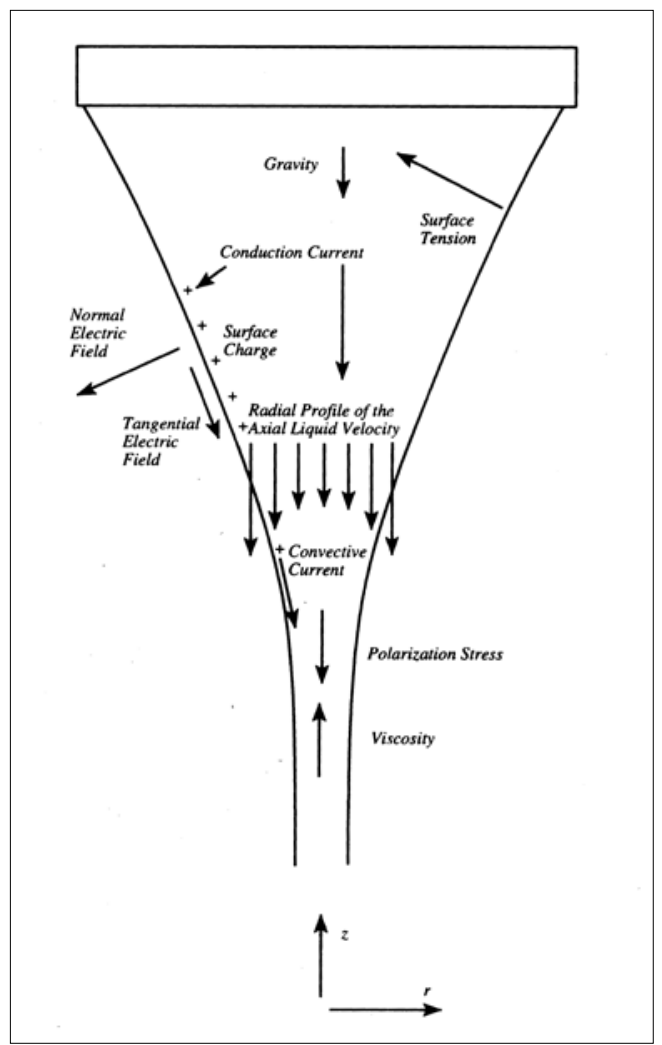

Figure 4: Schematic representation of the processes inside the liquid cone during electrospraying ${ }^{65}$.

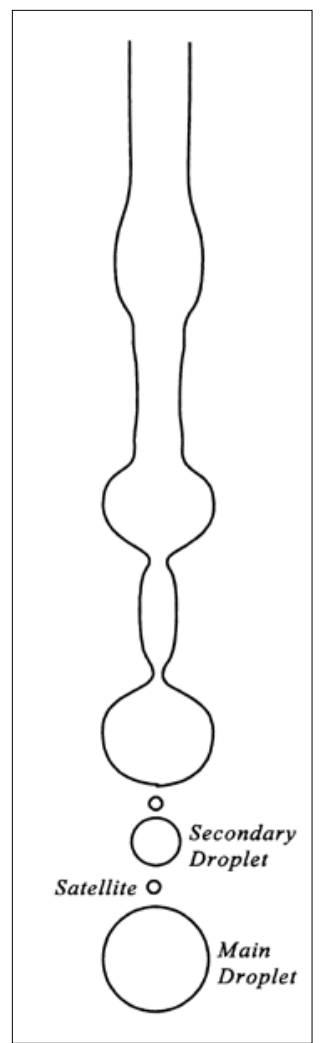

Figure 5: Jet breakup by axisymmetric varicose instabilities ${ }^{65}$.

The electric field induces a free surface charge in the cone surface. This free surface charge mainly consists of ions, since charge is mainly transported by ions in a liquid. The tangential electric field accelerates the ions at the liquid surface towards the cone apex. These ions accelerate the surrounding liquid. As a result, a thin jet emerges at the cone apex. This acceleration process and the shape of the liquid cone are a result of the balance between the liquid pressure, liquid surface tension, gravity, and electric stresses in the liquid surface. Correspondingly, cone formation is strongly dependent on physical properties of the liquid, such as the electrical conductivity, surface tension, and viscosity.

\subsubsection{Jet breakup}

Due to the acceleration of the surface charge, a jet with a high charge density is formed at the cone apex. This jet breaks up into primary main droplets and small secondary droplets (satellites). Every liquid has a minimum flow rate, below which a stable cone-jet mode cannot exist. Above the minimum flow rate the jet breaks up due to axisymmetric instabilites, which are also called varicose instabilities (see Figure 5).

At higher flow rates, the current through the liquid cone increases. With increasing current, the surface charge on the jet increases. Above a certain surface charge the jet breakup will also be influenced by lateral instabilities of the jet. These instabilities are also called 
kink instabilities. When the influence of these kink instabilities increases, the size distribution of main droplets becomes wider.

\subsubsection{Spray transport and evaporation}

Gaňán-Calvo et al. ${ }^{66}$ developed a transport model based on a force balance according to Newton's second law for transport of a droplet in a conventional capillary-plate electrospraying configuration. This model accounts for the electric force imposed on the droplet by the external electric field between the nozzle and grounded substrate, the drag force acting on the droplet by the surrounding gas, the mutual electric forces between charged droplets, and the inductive charge on the conductive substrate by the charged droplets (image force). Tang and Gomez ${ }^{67}$ found that the axial velocity of electrospray droplets is mainly determined by the external electric field, whereas the radial spread of electrosprays derives from mutual repulsion of charged droplets.

Wilhelm et al. ${ }^{68}$ developed a theoretical model for droplet transport and evaporation in a cone-jet mode of electrospraying on a heated plate by Lagrangian tracking of single droplets. The model enables prediction of droplet salt concentrations of electrosprayed solution droplets and describes the mechanism of size segregation of primary and secondary droplets. Using this theoretical model, a deposition diagram was developed which predicts film morphology of electrosprayed yttria-stabilized zirconia (YSZ) coatings as function of droplet size, precursor concentration, and substrate temperature ${ }^{69}$. The model was validated experimentally by means of measurements of droplet size and velocity using Phase Doppler Anemometry (PDA), and by means of Scanning Electron Microscopy (SEM) of deposited coatings. The most important parameters for the film morphology were reported to be the substrate temperature and the initial droplet size.

\subsection{UPSCALING OF ELECTROSPRAYING}

Although electrospraying is a versatile technique with many possible applications, the low flow rates at which the cone-jet mode generally operates have limited the use of electrosprays. Currently, no practical applications of purely electrohydrodynamic electrosprays are in widespread use with the exception of mass spectrometry. Electrospray ionization has emerged as a powerful tool for mass spectrometry of large and complex molecules, as reflected by the fact that the 2002 Chemistry Nobel Prize was awarded to John B. Fenn for his pioneering work in this field ${ }^{70}$.

Several researchers have been trying to increase the liquid thoughput for electrospray atomization by increasing the number of spraying cones. Flagran and Rulison deviced linear arrays of six Taylor cones on capillary electrode tubes ${ }^{71}$. Throughout the experiments of the current thesis, a square array of four nozzles was developed to increase the number of substrates that could be coated within a certain time period. Almekinders and Jones designed a multiple-jet electrospray atomizer of $15 \mathrm{~cm}$ width based on a continuous liquid feed line without single spraying nozzles ${ }^{72}$.

Recently, investigators at Yale University (USA) reported interesting developments regarding multiplexed electrospraying systems. Deng et al. ${ }^{73}$ developed a compact system of electrospray distributors by microfabrication of an array of nozzles $\left(250 \mathrm{sources} / \mathrm{cm}^{2}\right)$ in silicon wafers using deep reactive ion etch techniques. Nozzles were protruding from 150 to $450 \mu \mathrm{m}$ and were patterned with outer diameters ranging from 180 to $240 \mu \mathrm{m}$. By using an extractor electrode at about $0.5 \mathrm{~mm}$ distance from the spray sources, uniform droplets were electrosprayed simultaneously from all parallelized electrosprays, each one operating 
Figure 6:

Microfabricated

electrospray distri-

butor (left), with the

penny as standard

(middle), and system

in operation with a

multitude of sprays $^{73}$.

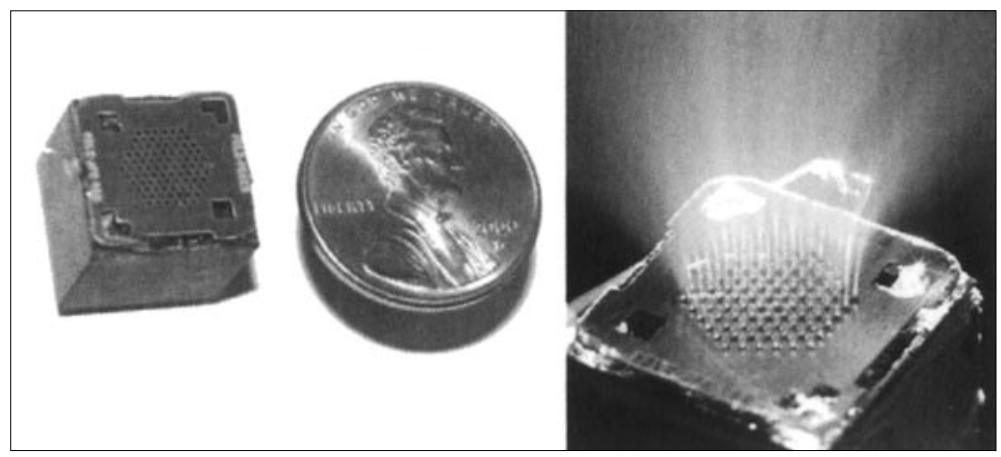

as an isolated spray on the quasi-monodisperse cone-jet mode (see Figure 6).

Duby et al. ${ }^{74}$ reported a novel approach to multiplexing single electrosprays based on the multi-jet mode of electrospraying. Sharp features (grooves, ridges, etc.) were machined at the nozzle outlet to intensify the local electric field and to anchor the single cone-jets at these features. Stable modes of operation were reported over several hundreds of volts and a broad range of flow rates. The grooved atomizer was found to be a simple and easily controllable means of multiplexing an electrospray by one or two orders of magnitude, yielding a density on the order of 50 cone-jets per $\mathrm{cm}^{2}$.

\section{Electrosprayed coatings}

\subsection{INORGANIC COATINGS}

The first application of ESD for the synthesis of inorganic coatings was reported by van Zomeren et al. ${ }^{54}$, who deposited $\mathrm{LiMn}_{2} \mathrm{O}_{4}$ thin films by means of electrospraying. This synthesis technique was researched extensively by Chen et al. ${ }^{75-78}$ for the fabrication of various thin electroceramic films of solid electrolytes and lithium battery electrode materials such as $\mathrm{Li}_{3} \mathrm{PO}_{4}, \mathrm{LiCoO}_{2}$, and $\mathrm{LiMn}_{2} \mathrm{O}_{4}$. Amongst the various morphologies that could be obtained, unique reticular layers with interconnected porosity were given special atten$\operatorname{tion}^{77,78}$. Since then, several other authors have used the ESD-technique for the deposition of inorganic coatings such as $\mathrm{NiCo}_{2} \mathrm{O}_{4}{ }^{79}$, yttria-stabilized zirconia (YSZ) ${ }^{80,81}$, indium tin oxide ${ }^{82}, \mathrm{La}_{1-\mathrm{x}} \mathrm{Sr}_{\mathrm{x}} \mathrm{Co}_{1-\mathrm{y}} \mathrm{Fe}_{\mathrm{y}} \mathrm{O}_{3}^{83}, \mathrm{MgO}^{84}, \mathrm{CdS}, \mathrm{CdSe}$, and $\mathrm{ZnS}^{85}$.

Instead of using dissolved precursor salts, another approach towards ESD involves electrospraying of stable suspensions and sols. Chen et al. ${ }^{86}$ combined the advantages of both sol-gel and ESD-technology by electrospraying titania sols using the ESD technique. Recently, stable nano-hydroxyapatite suspensions have been electrosprayed onto glass and alumina substrates ${ }^{87}$.

\subsection{ORGANIC COATINGS}

Besides inorganic coatings, several types of protein and polymer films have been deposited by means of electrospray deposition at relatively low deposition temperatures. Uematsu et al. ${ }^{88}$ prepared electrosprayed protein thin films on aluminum-coated poly(ethylene terephthalate) (PET) substrates from aqueous solutions of $\alpha$-lactalbumin. These coatings had a fine porous structure with pore diameters ranging from 40 to $600 \mathrm{~nm}$, and the biological activities of the cross-linked protein films were preserved upon deposition. Using 
identical ESD-equipment, Lee et al.$^{89}$ deposited transparant protein films of iron-free cytochrome onto ITO-glass plates. Moerman et al.$^{90}$ produced arrays of micron-sized protein spots from aqueous solution. Morozov et al. ${ }^{91,92}$ have been using electrospray deposition as a method to fabricate functionally active protein films from a wide variety of proteins such as alkaline phosphatase ${ }^{91}$, bovine/human serum albumin, human hemoglobin, chicken ovalbumin, horseradish peroxidase, etc. ${ }^{92}$. Moreover, $\lambda$-DNA layers were successfully electrosprayed onto carbon-coated membranes ${ }^{92}$. Recently, Pareta et al. ${ }^{93}$ used the electrospray deposition method to atomize bovine serum albumin solutions. It was concluded that electrospraying of bovine serum albumin did not result into significant structural changes under specific conditions.

Regarding polymer thin films, Sanders et al. ${ }^{94}$ used the electrospraying technique to deposit polymeric Nafion coatings on a rotating teflon-coated cylinder. Berkland et al. ${ }^{95}$ deposited poly(D,L-lactide-co-glycolide) coatings with a wide variety of surface (nano)morphologies (ranging from porous to smooth surfaces) using an advanced field-injection electrostatic spraying technique. Morota et al. ${ }^{96}$ obtained thin films of poly(ethylene oxide) on aluminum-sheets by means of the ESD-technique. Morphology of these coatings was shown to depend on apparatus-related parameters such as the applied voltage and on solution-related properties (polymer molecular weight, viscosity, conductivity, surface tension).

\section{Objectives of this thesis}

Since 1994, the Electrostatic Spray Deposition technique ${ }^{54}$ has been used extensively for the synthesis of several types of electroceramic thin films. The aim of the current thesis was to investigate the feasibility of this ESD technique for biomedical applications, i.e., deposition of CaP coatings onto titanium substrates. Therefore, physicochemical as well as biological properties of electrosprayed $\mathrm{CaP}$ coatings have been studied in order to obtain insight into the following phenomena:

" The influence of various deposition parameters on the chemical and morphological characteristics of electrosprayed $\mathrm{CaP}$ coatings.

- The chemical formation mechanism of these CaP coatings.

- The physical formation mechanism of typical ESD-derived coating morphologies.

" The adhesion and mechanical strength of electrosprayed CaP-coatings.

- The reactivity of these CaP coatings under in vitro and in vivo conditions.

In chapter 2, the feasibility of the ESD techniqe was investigated for the deposition of $\mathrm{CaP}$ coatings onto titanium substrates. Chapters 3 and 4 describe the influence of various process parameters on the chemical characteristics of electrosprayed $\mathrm{CaP}$ coatings, whereas chapters 5 and 6 focus on the morphological properties of these $\mathrm{CaP}$ coatings. Chapter 7 deals with the mechanical properties of ESD-derived coatings in terms of coating adhesion and mechanical strength. Finally, the biological performance (in vitro and in vivo) of electrosprayed $\mathrm{CaP}$ coatings is described in chapter 8 . 


\section{References}

1. Williams DF, Black J, Doherty PJ. Second consensus conference on definitions in biomaterials, Chester, England. In: Doherty PJ, Williams RF, Williams DF, Lee AJC, eds. Biomaterial-Tissue Interfaces. Advances in Biomaterials, Vol. 10. Amsterdam: Elsevier, 1992. p. 525-533.

2. Osborn JF, Newesely H. Dynamic aspects of implant/bone interface. In: Heimke G, ed. Dental Implants. Munich: Carl Hansen Verlag, 1980. p. 111-123.

3. Ducheyne P, Bianco P, Radin S, Schepers E. Bioactive materials: mechanisms and bioengineering considerations. In: Ducheyne P, van Blitterswijk CA, Kokubo T, eds. Bone-bonding biomaterials. Leiderdorp: Reed Healthcare Communications, 1993. p. 1-12.

4. Anselme K. Osteoblast adhesion on biomaterials. Biomaterials 2000;21:667-681.

5. de Jong WF. Le sustance mineral dans le os. Rec Trav Chim 1926;45:445-448.

6. LeGeros RZ. Calcium phosphates in oral biology and medicine. Basel: Karger, 1991.

7. Driessens FCM. Formation and stability of calcium phosphates in relation to the phase composition of the mineral in calcified tissue. In: de Groot K, ed. Bioceramics of calcium phosphates. Boca Raton: CRC Press, 1983.

8. Plenk H. Prosthesis-bone interface. J Biomed Mater Res (Appl Biomater) 1998;43:350-355.

9. Hulbert SF, Cooke F, Klawitter JJ. Attachment of prostheses to the musculoskeletal system by tissue ingrowth and mechanical interlocking. J Biomed Mater Res Symp 1973;4:1-23.

10. Hench LL, Splinter RJ, Allen WC. Bonding mechanism at the interface if ceramic prosthetic materials. $J$ Biomed Mater Res Symp 1971;2:117-141.

11. Hench LL, Paschall HA. Direct chemical bond of bioactive glass-ceramic materials to bone and muscle. J Biomed Mater Res 1973;7:25-42.

12. Piotrowski G, Hench LL, Allen WC, Miller GJ. Mechanical studies of the bone bioglass interfacial bond. J Biomed Mater Res 1975;9:47-61.

13. Greenspan DC, Hench LL. Chemical and mechanical behavior of bioglass-coated alumina. J Biomed Mater Res 1976;10:503-509.

14. Gross U, Brandes J, Strunz V, Bab I, Sela J. The ultrastructure of the interface between a glass ceramic and bone. J Biomed Mater Res 1981;15:291-305.

15. Hench LL. Bioceramics. J Am Ceram Soc 1998;81:1705-1728.

16. Saravanapavan P, Jones JR, Pryce RS, Hench LL. Bioactivity of gel-glass powders in the CaO-SiO2 system: a comparison with ternary (CaO-P2O5-SiO2) and quaternary glasses ( $\mathrm{SiO} 2-\mathrm{CaO}-\mathrm{P} 2 \mathrm{O} 5-\mathrm{Na} 2 \mathrm{O}$ ). J Biomed Mater Res 2003;66:110-119.

17. Sepulveda P, Jones JR, Hench LL. In vitro dissolution of melt-derived $45 S 5$ and sol-gel derived $58 S$ bioactive glasses. J Biomed Mater Res 2002;61:301-311.

18. Ducheyne P, Qiu Q. Bioactive ceramics: the effect of surface reactivity on bone formation and bone cell function. Biomaterials 1999;20:2287-2303.

19. Vroman L, Adams AL. Identification of rapid changes at plasma-solid interfaces. J Biomed Mater Res $1969 ; 3: 43-67$. 
20. Kasemo B, Lausmaa J. Surface science aspects on inorganic biomaterials. CRC Crit Rev Biocomp $1986 ; 2: 335-380$.

21. Siebers MC, ter Brugge PJ, Walboomers XF, Jansen JA. Integrins as linker proteins between osteoblasts and bone replacing materials. A critical review. Biomaterials 2005; 26:137-146.

22. Anselme K, Noel B, Hardouin P. Human osteoblast adhesion on titanium alloy, stainless steel, glass and plastic substrates with same surface topography. J Mater Sci Mater Med 1999;10:815-819.

23. Bigerelle M, Anselme K, Noel B, Ruderman I, Hardouin P, Iost A. Improvement in the morphology of Ti-based surfaces: a new process to increase in vitro human osteoblast response. Biomaterials 2002;23:1563-1577.

24. Zinger $O$, Anselme K, Denzer A, Habersetzer P, Wieland P, Wieland M, Jeanfils J, Hardouin P, Landolt D. Time-dependent morphology and adhesion of osteoblastic cells on titanium model surfaces featuring scale-resolved topography. Biomaterials 2004;25:2695-2711.

25. Keller JC, Collins JG, Niederauer GG, McGee TD. In vitro attachment of osteoblast-like cells to osteoceramic materials. Dent Mater 1997;13-62-68.

26. Webb K, Hlady V, Tresco PA. Relationships among cell attachment, spreading, cytoskeletal organization, and migration rate for anchorage-dependent cells on model surfaces. J Biomed Mater Res 2000;49:362368 .

27. Elliott JC. Structure and chemsitry of the apatites and other claicum orthophosphates. Amsterdam: Elsevier, 1994.

28. Young RA. Dependence of apatite properties on crystal structural details. Trans NYAcad Sci 1967;29:949959.

29. LeGeros RZ, Tung M. Chemical stability of carbonate- and fluoride-containing apatites. Caries Res 1983;17:419-429.

30. Redey SA, Nardin M, Bernache-Assolant D, Rey C, Delannoy P, Sedel L, Marie PJ. Behavior of human osteoblastic cells on stoichiometric hydroxyapatite and type A carbonate apatite: role of surface energy. J Biomed Mater Res 2000;50:353-364.

31. Labarthe JC, Bonel G, Montel G. Sur la localisation des ions carbonate dans le réseau des apatites calciques. Compt Rend Acad Sci 1971;273:349-351.

32. Vignoles $M$, Bonel $G$, Holcomb DW, Young RA. Influence of preparation conditions on the composition of type $B$ carbonated hydroxyapatite and on the localization of the carbonate ions. Calcif Tissue Int 1988;43:33-40.

33. Nery EB, Kenneth $L L$, Rooney GE. Alveolar ridge augmentation with tricalcium phosphate ceramic. $J$ Prosth Dent 1978;40:668-675.

34. Daculsi G, Passuti N, Martin S, Deudon C, LeGeros RZ, Raher S. Macroporous calcium phosphate ceramic for long bone surgery in humans and dogs. Clinical and histological study. J Biomed Mater Res 1990;24:379-396.

35. Chow LC. Calcium phosphate cements. Monogr Oral Sci 2001;18:148-163.

36. Schmitz JP, Hollinger JO, Milam SB. Reconstruction of bone using calcium phosphate bone cements; a critical review. J Oral Maxillofac Surg 1999;57:1122-1126.

37. Ooms EM, Wolke JG, van de Heuvel MT, Jeschke B, Jansen JA. Histological evaluation of the bone response to calcium phosphate cement implanted in cortical bone. Biomaterials 2003;24:989-1000. 
38. Dhert WJA. Retrieval studies on calcium phosphate-coated implants. Med Prog Technol. 1994;20:143154.

39. Lacefield WR, Materials characteristics of uncoated/ceramic-coated implant materials. Adv Dent Res $1999 ; 13: 21-26$

40. Lacefield WR. Current status of ceramic coatings for dental implants. Implant Dent 1998;7:315-322.

41. Geesink RGT. Osteoconductive coatings for total joint arthroplasty. Clin Orthop Relat Res 2002;395:5365.

42. Lusquinos F, De Carlos A, Pou J, Arias JL, Boutinguiza M, Leon B, Perez-Amor M, Driessens FC, Hinh K, Gibson I, Best $S$, Bonfield W. Calcium phosphate coatings obtained by Nd:YAG laser cladding: physicochemical and biologic properties. J Biomed Mater Res 2003;64:630-637.

43. Rey C. Calcium phosphate biomaterials and bone mineral. Differences in composition, structure and properties. Biomaterials 1990;11:13-15.

44. Wolke JGC, van Dijk K, Schaeken HG, de Groot K, Jansen JA. Study of the surface characteristics of magnetron-sputter calcium phosphate coatings. J Biomed Mater Res 1994;28:1477-1484.

45. Yang Y, Kim KH, Ong JL. A review on calcium phosphate coatings produced using a sputtering processan alternative to plasma spraying. Biomaterials 2005;26:327-337.

46. Ducheyne P, Radin S, Heughebaert M, Heughebaert JC. Calcium phosphate ceramic coatings on porous titanium: effect of structure and composition on electrophoretic deposition, vacuum sintering and in vitro dissolution. Biomaterials 1990;11:244-254.

47. Hero H, Wie H, Jorgenson RB, Ruyter IE. Hydroxyapatite coatings on Ti produced by hot isostatic pressing. J Biomed Mater Res 1994;28:343-348.

48. Yang C. Effect of calcium phosphate surface coating on bone ingrowth onto porous-surfaced titanium alloy implants in rabbit tibiae. J Oral Maxillofac Surg 2002;60:422-426.

49. Cotell CM, Chrisey DB, Grabowski KS, Sprague JA, Grossett CR. Pulsed laser deposition of hydroxylapatite thin films on Ti-6Al-4V. J Appl Biomater 1992;3:87-93.

50. Chen TS, Lacefield WR. Crystallization of ion beam deposited calcium phosphate coatings. J Mater Res 1994;9:1284-1290.

51. Takahashi K, Hayakawa T, Yoshinari T, Hara H, Mochizuki C, Sato M, Nemoto K. Molecular precursor method for thin calcium phosphate coating on titanium. Thin Solid Films 2005;484:1-9.

52. Barrere F, van Blitterswijk CA, de Groot K, Layrolle P. Influence of ionic strength and carbonate on the Ca-P coating formation from SBFX5 solution. Biomaterials 2002 23:1921-1930.

53. Wang J, de Boer J, de Groot K. Preparation and characterization of electrodeposited calcium phosphate/ chitosan coating on Ti6Al4V plates. J Dent Res 2004;83:296-301.

54. van Zomeren AA, Kelder EM, Marijnissen JCM, Schoonman J. The production of thin films of LiMn $\mathrm{O}_{4}$ by electrospraying. J Aerosol Sci 1994;25:1229-1235.

55. Lefebvre AH. Atomization and sprays. New York: Hemisphere Publishing Corporation, 1989.

56. Siefert W. Corona spray pyrolysis: a new coating technique with an extremely enhanced deposition efficiency. Thin Solid Films 1984;120:267-274.

57. Bailey AG. Electrostatic spraying of liquids. New York: John Wiley and Sons, 1988. 
58. Hartman RPA, Borra JP, Brunner DJ, Marijnissen JCM, Scarlett B. The evolution of electrohydrodynamic sprays produced in the cone-jet mode, a physical model. J Electrostat 1999;47:143-170.

59. Romat H, Badri A. Internal electrification of diesel oil injectors. J Electrostat 2001;51/52:481-487.

60. Lord Rayleigh. On the conditions of instability of electrified drops. Proc $R$ Soc 1879;29:71-83.

61. Cloupeau M, Prunet-Foch B. Electrohydrodynamic spraying functioning modes: a critical review. J Aerosol Sci 1994;25:1021-1036.

62. Grace JM, Marijnissen JCM. A review of liquid atomization by electrical means. J Aerosol Sci 1994;25:1005-1019.

63. Jaworek A, Krupa A. Classification of the modes of EHD spraying. J Aerosol Sci 1999;30:873-893.

64. Taylor GI. Disintegration of water drops in an electric field. Proc R Soc Lon A 1964;280:383-397.

65. Hartman R. Electrohydrodynamic atomization in the conejet mode. PhD Thesis. Delft University of Technology, Delft, 1998.

66. Gañán-Calvo AM, Lasheras JC, Davila J, Barrero A. The electrostatic spray emitted from an electrified conical meniscus. J Aerosol Sci 1994;25:1121-1142.

67. Tang K, Gomez A. On the structure of an electrostatic spray of monodisperse droplets. Phys Fluids 1994;6:2317-2332.

68. Wilhelm O, Madler L, Pratsinis SE. Electrospray evaporation and deposition. J Aerosol Sci 2003;34:815836 .

69. Wilhelm O, Pratsinis SE, Perednis D, Gauckler LJ. Electrospray and pressurized spray deposition of yttria-stabilized zirconia films. Thin Solid Films 2005;479:121-129.

70. Fenn JB, Mann M, Meng CK, Wong SF, Whitehouse CM. Electrospray ionization for mass spectrometry of large biomolecules. Science 1989;246:64-71.

71. Rulison AJ, Flagan RC. Scale up of electrospray atomization using linear arrays of Taylor cones. Rev Sci Instrum 1993;64:683-686.

72. Almekinders JC, Jones C. Multiple jet electrohydrodynamic spraying and applications, J Aerosol Sci 1999;30:969-971.

73. Deng W, Klemic JF, Li X, Reed MA, Gomez A. Increase of electrospray throughput using multiplexed microfabricated sources for the scalable generation of monodisperse droplets. J Aerosol Sci 2006;37:696714.

74. Duby MH, Deng W, Kim K, Gomez T, Gomez A. Stabilization of monodisperse electrosprays in the multi-jet mode via electric field enhancement. J Aerosol Sci 2006;37:306-322.

75. Chen CH. Thin film components for lithium-ion batteries. PhD Thesis. Delft University of Technology, Delft, 1998.

76. Zhang SQ, Xie $\mathrm{S}$, Chen $\mathrm{CH}$. Fabrication and electrical properties of $\mathrm{Li}_{3} \mathrm{PO}_{4}$-based composite electrolyte films. Mater Sci Eng B 2005;121:160-165.

77. Chen $\mathrm{CH}$, Kelder EM, Schoonman J. Unique porous $\mathrm{LiCoO}_{2}$ thin layers prepared by electrostatic spray deposition. J Mater Sci 1996;31;5437-5442.

78. $Y u$ Y, Shui JL, Xie S, Chen CH. Highly porous spongelike ceramic films with bimodal pore structure prepared by electrostatic spray deposition technique. Aerosol Sci Technol 2005;39:276-281. 
79. Lapham DP, Colbeck I, Schoonman J, Kamlag Y. The preparation of $\mathrm{NiCo}_{2} \mathrm{O}_{4}$ films by electrostatic spray deposition. Thin Solid Films 2001;391:17-20.

80. Nguyen T, Djurado E. Deposition and characterization of nanocrystalline tetragonal zirconia films using electrostatic spray deposition. Solid State Ionics 2001;138:191-197.

81. Perednis D, Wilhelm O, Pratsinis SE, Gauckler LJ. Morphology and deposition of thin yttria-stabilized zirconia films using spray pyrolysis. Thin Solid Films 2005;474:84-95.

82. Chandrasekhar R, Choy KL. Innovative and cost-effective synthesis of indium tin oxide films. Thin Solid Films 2001;398/399:69-64.

83. Taniguchi I, van Landschoot $\mathrm{RC}$, Schoonman J. Fabrication of $\mathrm{La}_{1-\mathrm{x}} \mathrm{Sr}_{x} \mathrm{Co}_{1-y} \mathrm{Fe}_{y} \mathrm{O}_{3}$ thin films by electrostatic spray deposition. Solid State Ionics 2003;156:1-13.

84. Kim SG, Choi KH, Eun JH, Kim HJ, Hwang CS. Effects of additives on properties of MgO thin films by electrostatic spray deposition. Thin Solid Films 2000;377/378:694-698.

85. Su B, Choy KL. Electrostatic assisted aerosol jet deposition of CdS, CdSe, and ZnS thin films. Thin Solid Films 2000;361/362:102-106.

86. Chen CH, Kelder EM, Schoonman J. Electrostatic sol-spray deposition (ESSD) and characterisation of nanostructured $\mathrm{TiO}_{2}$ films. Thin Solid Films 1999;342:35-41.

87. Huang J, Jayasinghe SN, Best SM, Edirisinghe MJ, Brooks RA, Bonfield W. Electrospraying of a nanohydroxyapatite suspension. J Mater Sci 2004;39:1029-1032.

88. Uematsu I, Matsumoto H, Morota K, Minagawa M, Tanioka A, Yamagata Y, Inoue K. Surface morphology and biological activity of protein thin films produced by electrospray deposition. J Colloid Interface Sci 2004;269:336-340.

89. Lee B, Kamiya N, Machida S, Yamagata Y, Horie K, Nagamune T. Fabrication of a protein film by electrospray deposition method and investigation of photochemical properties by persistent spectral hole burning. Biomaterials 2003;24:2045-2051.

90. Moerman R, Frank J, Marijnissen JCM, Schalkhammer TGM, van Dedem GWK. Miniaturized electrospraying as a technique for the production of microarrays of reproducible micrometer-sized protein spots. Anal Chem 2001;73:2183-2189.

91. Morozov VN, Morozova TY. Electrospray deposition as a method to fabricate functionally active protein films. Anal Chem 1999;71:1415-1420.

92. Morozov VN, Morozova TY. Electrospray deposition as a method for mass fabrication of mono- and multicomponent microarrays of biological and biologically active substances. Anal Chem 1999;71:31103117 .

93. Pareta R, Brindley A, Edirisinghe MJ, Jayasinghe $S N$, Luklinska ZB. Electrohydrodynamic atomization of protein (bovine serum albumin). J Mater Sci Mater Med 2005;16:919-925.

94. Sanders EH, McGrady KA, Wnek GE, Edmondson CA, Mueller JM, Fontanella JJ, Suarez S, Greenbaum SG. Characterization of electrosprayed Nafion films. J Power Sources 2004:129;55-61.

95. Berkland C, Park DW, Kim K. Controlling surface nano-structure using flow-limited field-injection electrostatic spraying (FFESS) of poly(D,L-lactide-co-glycolide). Biomaterials 2004;25:5649-5658.

96. Morota K, Matsumoto H, Mizukoshi T, Konosu Y, Minagawa M, Tanioka A, Yamagata Y, Inoue K. Poly(ethylene oxide) thin films produced by electrospray deposition: morphology control and additive effects of alcohols on nanostructure. J Colloid Interface Sci 2004:279;484-492. 
Electrostatic Spгay Deposition (ESD) of calcium phosphate coatings fог biomedical puгposes: a feasibility study 


\section{Introduction}

Titanium (Ti) and its alloys are widely used to manufacture orthopedic and dental implants. In order to improve the biological performance of these metals, ceramic calcium phosphate $(\mathrm{CaP})$ coatings are frequently applied onto the implant surface. Wolke ${ }^{1}$ reported an overview of the techniques that have been used in the past to deposit CaP coatings. Various approaches have been used, including electrophoretic deposition, immersion coating, hot isostatic pressing, sol-gel deposition, pulsed laser deposition, biomimetic deposition, RF magnetron sputter deposition and plasma-spraying. Each of these methods produces coatings that are several micrometers to a few millimeters thick. Currently, the most widely applied method to deposit such a synthetic $\mathrm{CaP}$ coating onto $\mathrm{Ti}$ is the plasma-spraying technique $^{2}$. However, this complex and expensive technique has several drawbacks. For example, phase changes in the $\mathrm{CaP}$ powder particles during the coating process are unpredictable due to the high temperature differences. Consequently, promising $\mathrm{CaP}$ phases like carbonate apatite, which is close to bone composition ${ }^{3}$, cannot be deposited using plasma-spraying. Moreover, plasma-sprayed coatings must be relatively thick in order to completely cover the implant. In view of this, the coated surface may not have the same surface morphology as the underlying metal. Finally, the occurrence of particle release and delamination ${ }^{4}$ may initiate an inflammatory reaction in the surrounding tissues, which eventually can lead to implant failure ${ }^{5}$.

To overcome these problems, new coating techniques are being researched. Recently, a coating technique referred to as Electrostatic Spray Deposition (ESD) was developed in order to synthesize thin ceramic films for solid electrolytes and lithium battery materials ${ }^{6,7}$. It was shown that using this technique, various types of ceramic materials could be deposited as thin films with a great variety in surface morphology depending on process conditions.

The basic principle of ESD is the generation of an aerosol using organic solvents containing inorganic or organometallic precursors under the influence of a high voltage. An aerosol is defined as a dispersion of solid particles or liquid droplets in a gaseous ambient. In order to obtain such an aerosol of micron-sized droplets, the precursor liquid is pumped through a metal nozzle. Usually a spherical droplet is formed at the tip of a nozzle, but if a high voltage is applied (typically between $6-15 \mathrm{kV}$ ) between the nozzle and a grounded substrate, this droplet at the tip of the nozzle transforms into a conical shape and fans out to form a spray of highly charged droplets. The generated spray droplets are attracted by the grounded and heated substrate as a result of the applied potential difference. Consequently, the droplets impinge onto the heated substrate, where they lose their charge. After complete solvent evaporation, a thin layer consisting of the inorganic product is left onto the substrate surface.

The main advantages of the ESD-technique for application in the biomedical field $\operatorname{are}^{7-11}$ :

" The possibility to tailor the surface morphology of the deposited coatings.

" The possibility to control the chemical composition of the deposited coatings.

" A very simple set-up.

- A high deposition efficiency, since the electric field directs the charged droplets to the substrate.

The objective of this first study was to investigate the feasibility of the ESD technique in order to deposit ceramic $\mathrm{CaP}$ layers onto Ti substrates. 


\section{Materials and Methods}

\subsection{SUBSTRATES}

Machined commercially pure Ti discs (diameter $12 \mathrm{~mm}$, thickness $1.5 \mathrm{~mm}$ ) were used as substrate material for application of ESD-deposited CaP coatings. The substrates were cleaned ultrasonically in acetone (15 minutes) and ethanol (15 minutes) prior to the depositions.

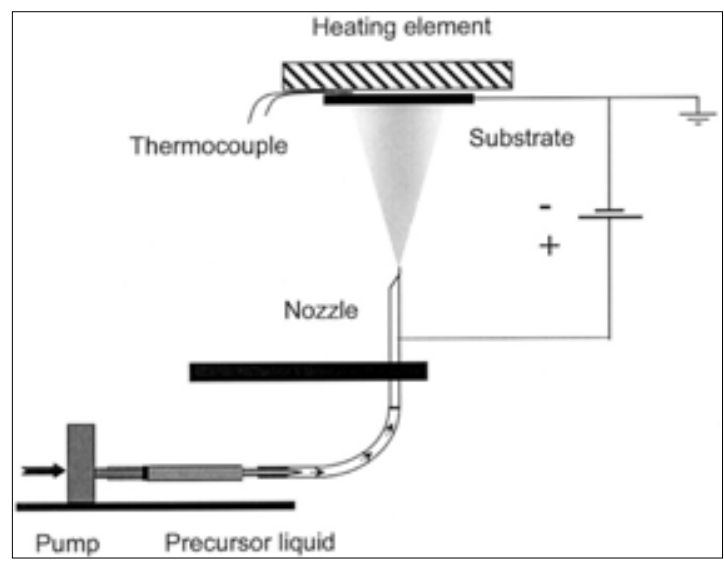

Figure 1: Electrostatic Spray Deposition (ESD) set-up in upwards-facing configuration.

\subsection{ELECTROSTATIC SPRAY DEPOSITION (ESD) PROCESS}

A vertical ESD set-up (ESD-ACT-XY03, TU Delft) was used in this study to deposit inorganic coatings. Figure 1 gives a schematic view of the set-up, which is operated in a fume hood. In this unit, the spray is directed upwards from the nozzle to the substrate holder. A DC voltage supply (Fug, HCN 14-20000) was used in order to generate a positive high potential difference between the nozzle and the grounded substrate holder in the range from 6.5 to $8.0 \mathrm{kV}$. A stainless steel nozzle with a tilted outlet (apex angle $30^{\circ}$ ) was used. The inner and outer diameters of this nozzle were 0.6 and $0.8 \mathrm{~mm}$, respectively. Heating of the substrates was determined by a temperature-controlling unit (Eurotherm Controls model 2216), including a heating element and temperature controller. The precursor solutions were delivered to the metal nozzle by a syringe pump (Kd Scientific 100-3113). $\mathrm{Ca}\left(\mathrm{NO}_{3}\right)_{2} \cdot 4 \mathrm{H}_{2} \mathrm{O}$ (Merck) and $\mathrm{H}_{3} \mathrm{PO}_{4}(85 \mathrm{wt} \%$, J.T. Baker) in a fixed $\mathrm{Ca} / \mathrm{P}$ ratio of 1.67 were used as precursors for calcium and phosphate. These precursors were dissolved at $\mathrm{Ca}^{2+}$ concentrations between 0.005 and $0.01 \mathrm{M}$ into pure ethanol or butyl carbitol $\left(\mathrm{C}_{8} \mathrm{H}_{18} \mathrm{O}_{3}\right.$, $99 \%$, Aldrich) as low- and high-boiling point solvents, respectively. The precursor flow rate was varied between 0.5 and $2 \mathrm{ml} / \mathrm{h}$, whereas the substrate temperature was changed between 300 and $450{ }^{\circ} \mathrm{C}$. The distance between the spray nozzle and the substrate was varied between 2.5 and $3.5 \mathrm{~cm}$ and typical deposition times were 30 to 120 minutes. After deposition, coatings were left as-deposited or subjected to additional heat-treatments in air at temperatures of $500{ }^{\circ} \mathrm{C}$ to $730{ }^{\circ} \mathrm{C}$ in an infrared furnace (E4-10-P, Research Inc.) $)^{12}$.

\subsection{COATING CHARACTERIZATION}

The deposited ESD-coatings were characterized using the following techniques:

- Scanning Electron Microscopy (SEM): the surface morphology of the ESD-coatings was investigated using a JEOL JSM-35. 
- X-ray diffraction (XRD): the crystallographic structure of the ESD-coatings was characterized by means of a Panalytical thin-film X-Ray Diffractometer using CuK $\alpha$-radiation (PW 3710, $40 \mathrm{kV}, 40 \mathrm{~mA}$ ). Coatings were analyzed by fixing the coated substrates to a position of $2.5^{\circ}$ and scanning the detector between $20^{\circ} 2 \theta$ and $50^{\circ} 2 \theta$ with a step-size of $0.02^{\circ} 2 \theta$, a scanning speed of $0.01^{\circ} 2 \theta / \mathrm{s}$, and a sample time of $2 \mathrm{~s} / \mathrm{step}$. " reflection Fourier-Transform Infrared Spectrometry (FTIR, Perkin-Elmer): the molecular structure of the ESD-coatings was characterized by obtaining infrared spectra of the deposited coatings in the range from 4000 to $400 \mathrm{~cm}^{-1}$.

\section{Results}

Figure 2 shows scanning electron micrographs of three representative coating morphologies that can be obtained using the ESD-technique. The corresponding deposition parameters are summarized in Table 1. Porous films made of fractal agglomerates of tiny particles (Figure 2a) were deposited at a large nozzle-to-substrate distance of $3.5 \mathrm{~cm}$ and a high deposition temperature of $450{ }^{\circ} \mathrm{C}$ using ethanol as a solvent. On the contrary, a unique reticular coating morphology characterized by a three-dimensional interconnected, porous network of random orientation (Figure $2 \mathrm{~b}$ ) could be obtained on top of polished $\mathrm{Ti}$ substrates. This particular surface morphology was obtained at a relatively small nozzleto-substrate-distance of $2.5 \mathrm{~cm}$ and a low deposition temperature of $300{ }^{\circ} \mathrm{C}$ using butyl carbitol as a solvent. Large machining grooves were clearly observed in the morphology of the deposited ESD-coatings on top of unpolished, machined Ti substrates (Figure 2c).

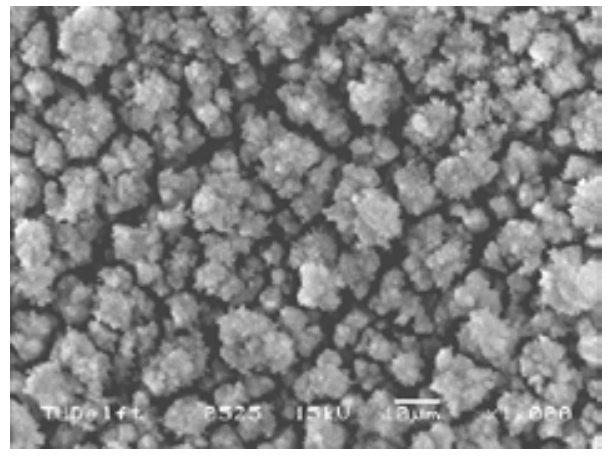

$2 \mathrm{a}$

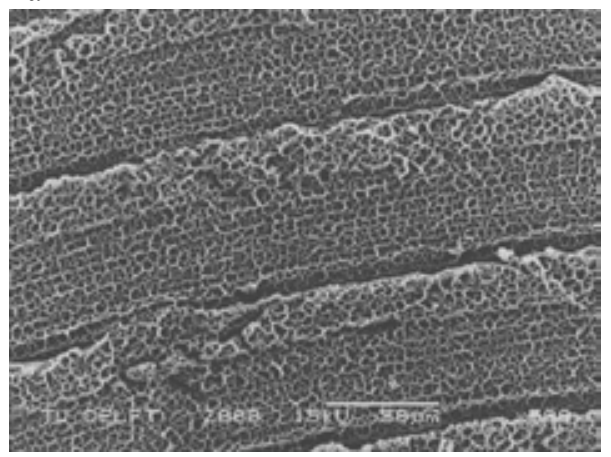

$2 \mathrm{c}$

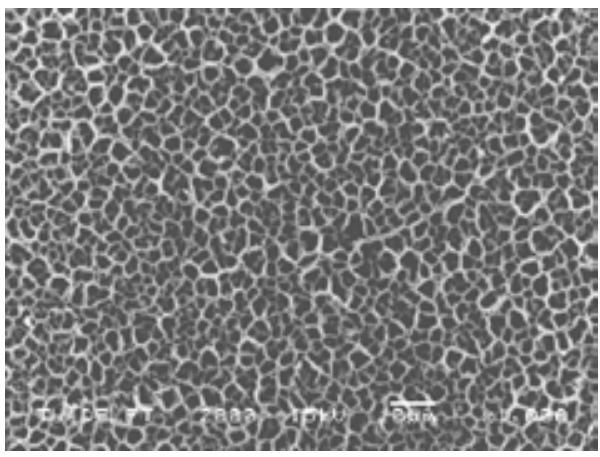

$2 b$

Figure 2: Scanning electron micrographs of electrosprayed CaP coatings. [a] Porous films made of fractal agglomerates of tiny particles; [b] reticular coating morphology characterized by a three-dimensional interconnected porous network; and $[c] \mathrm{re}$ ticular coating morphology with machining grooves resulting from the substrate topography. Bar size 10 $\mu \mathrm{m}[a+b]$ or $50 \mu \mathrm{m}[c]$. 


\begin{tabular}{|c|c|c|}
\hline & ESD-fractal & ESD-reticular \\
\hline $\mathrm{Ca}^{2+}$ concentration $[\mathrm{M}]$ & 0.01 & 0.005 \\
\hline $\mathrm{H}_{3} \mathrm{PO}_{4}$ concentration $[\mathrm{M}]$ & 0.006 & 0.003 \\
\hline Solvent & ethanol & butyl carbitol \\
\hline Deposition temperature $\left[{ }^{\circ} \mathrm{C}\right]$ & 450 & 300 \\
\hline Liquid flow rate $[\mathrm{ml} / \mathrm{h}]$ & 0.5 & 2.0 \\
\hline Deposition time [hours] & 2 & 1 \\
\hline Nozzle-to-substrate distance [mm] & 35 & 25 \\
\hline
\end{tabular}

Table 1: Synthesis conditions for the deposition of fractal-like and reticular CaP coating morphologies.

The XRD surface patterns of a reticular ESD-coating heat-treated at different temperatures are shown in Figure 3. The XRD patterns show the development from an amorphous as-deposited coating towards a poorly crystalline apatitic $\mathrm{CaP}$ phase characterized by reflection peaks at $2 \theta=25.9^{\circ}(002), 31.8^{\circ}(211), 32.4^{\circ}(112)$ and $32.7^{\circ}(300)^{13}$. Oxidation of the Ti substrate, reflected by rutile peaks as indicated in Figure 3, was the result of the high heating intensity of the rapid IR heat-treatment.

The FTIR spectrum (Figure 4) of the as-deposited coating shows broad absorption bands around 3440 and $1630 \mathrm{~cm}^{-1}$, corresponding to $\mathrm{OH}$-stretching and bending of $\mathrm{H}_{2} \mathrm{O}$, respectively. Furthermore, broad and intense absorption bands between $1300-1500 \mathrm{~cm}^{-1}$ and $900-1200 \mathrm{~cm}^{-1}$ correspond to $v_{3}$ absorptions of carbonate and phosphate, respectively.

After heat-treatment at $500{ }^{\circ} \mathrm{C}$, two broad $v_{3}$ carbonate absorptions were measured at $1494 \mathrm{~cm}^{-1}$ and $1426 \mathrm{~cm}^{-1}$. Also, a $v_{2}$ carbonate peak at $874 \mathrm{~cm}^{-1}$ was observed. These vibrations correspond to carbonate groups engaged in an amorphous solid ${ }^{14}$. No absorption bands due to $\mathrm{OH}$ and $\mathrm{H}_{2} \mathrm{O}$ groups were observed anymore. Phosphate bands at 1050 $\mathrm{cm}^{-1}$ and $570 \mathrm{~cm}^{-1}\left(v_{3}\right.$ and $v_{4}$, respectively) remained broad single-phase bands, indicating a disordered environment.

At $650{ }^{\circ} \mathrm{C}$, both carbonate and phosphate bands split into more defined absorption

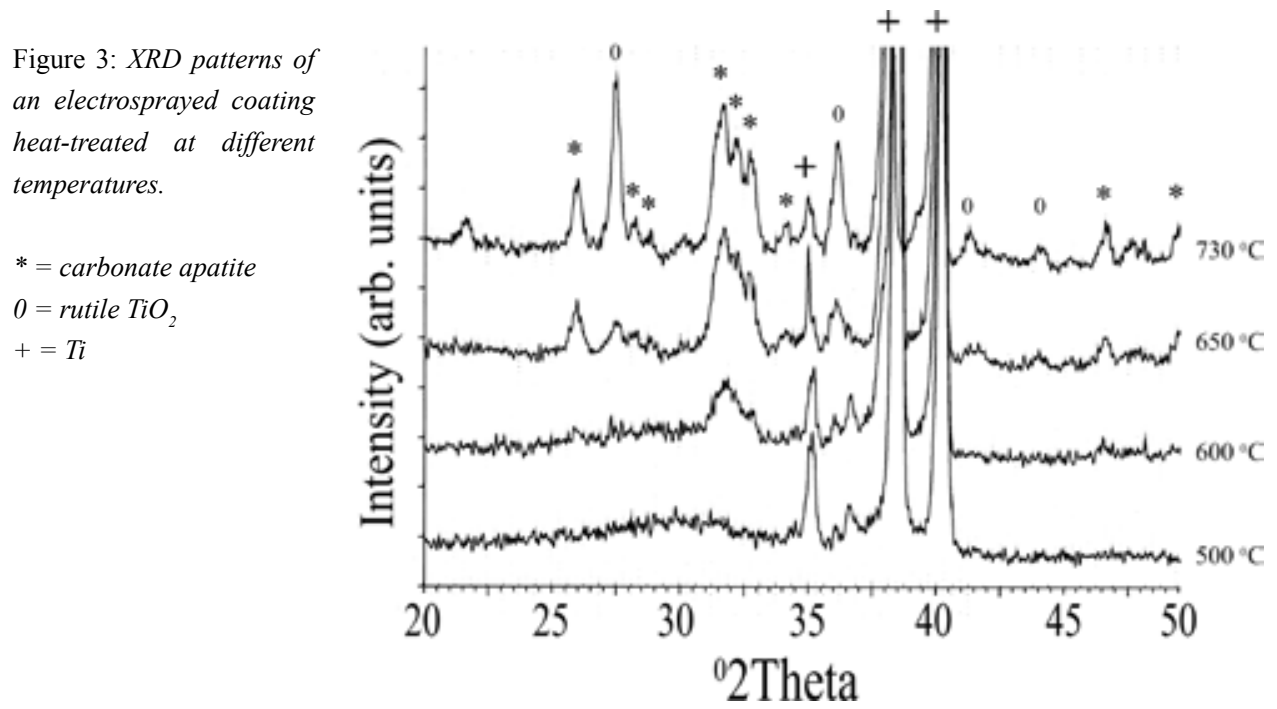




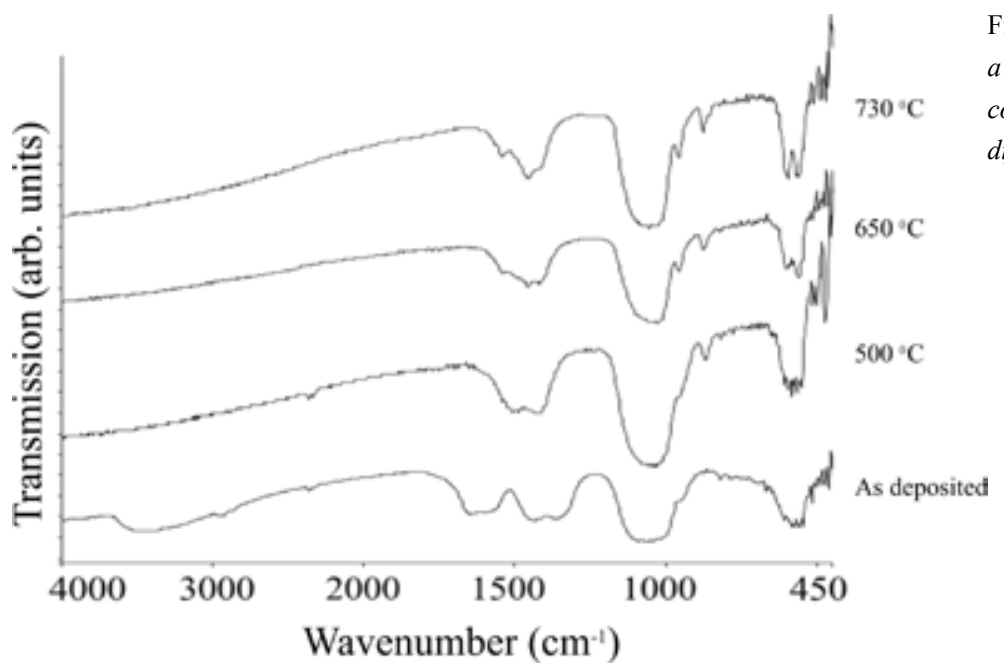

Figure 4: FTIR spectra of a carbonate apatite ESD coating heat-treated at different temperatures.

peaks, corresponding to the observed increase in crystallinity measured by XRD. The coating converted to a mixed-type $\mathrm{AB}$ carbonate apatite, as revealed by the $v_{3}$ carbonate bands at 1542 and $1460 \mathrm{~cm}^{-1}$, which correspond to type A carbonate, and those at 1460 and 1413 $\mathrm{cm}^{-1}$, corresponding to type B carbonate ${ }^{15}$. A $v_{1}$ phosphate peak at $960 \mathrm{~cm}^{-1}$ next to a broad $v_{3}$ peak at $1050 \mathrm{~cm}^{-1}$ and $v_{4}$ peaks at 600 and $563 \mathrm{~cm}^{-1}$ correspond to phosphate groups in carbonate apatite containing type A-substitutions ${ }^{16}$. The broad, featureless phosphate $v_{3}$ band at $1050 \mathrm{~cm}^{-1}$ instead of a collection of sharply defined $v_{3}$ absorptions is characteristic for poorly crystalline carbonate apatite. At $730^{\circ} \mathrm{C}$, the transformation towards type ABcarbonate apatite was completed.

\section{Discussion}

The aim of this study was to investigate the applicability of the Electrostatic Spray Deposition (ESD) technique for the synthesis of ceramic CaP coatings on Ti substrates. The results demonstrate that it is possible to deposit $\mathrm{CaP}$ coatings with a tailored surface morphology by choosing the appropriate deposition parameters.

Rough, fractal-like thin films are formed when solvent evaporation of the solute containing droplets is extensive. Using a high deposition temperature of $450{ }^{\circ} \mathrm{C}$ and a low boiling point solvent like ethanol, the micron-sized spray droplets evaporate at a very fast rate. Moreover, a large nozzle-to-substrate distance corresponds to a longer flight time of the aerosol droplets. As a consequence, severe droplet drying takes place during droplet flight and the particles reach the substrate in almost dry condition. This leads to the formation of rough, fractal-like coating morphologies. Solvent evaporation is suppressed by making use of a high boiling point solvent like butyl carbitol, which has a boiling point of $231{ }^{\circ} \mathrm{C}$. Moreover, the flight time of the spray droplets can be reduced by choosing a small nozzleto-substrate distance. Consequently, droplet drying during flight of the aerosol droplets is strongly reduced by an appropriate choice of deposition parameters. As a result, reticular ESD-coatings are formed under wet conditions. ESD-coatings may clearly reflect the topography of the underlying substrate due to preferential landing of the charged spray 
droplets onto regions of positive curvature. Therefore, reticular coating morphologies were aligned along the machining grooves of the Ti substrate. These findings are in line with results obtained earlier by $\mathrm{Chen}^{7}$.

XRD analysis showed that as-deposited CaP coatings were amorphous. After infrared heat-treatment in air, these amorphous coatings were transformed into a crystalline apatitic CaP phase. FTIR analysis confirmed that carbonate anions were incorporated into the asdeposited coatings. The only possible source of carbonate ions is the solvent butyl carbitol, since it is the only organic component in the precursor solution. During deposition with pure butyl carbitol, smoke development was observed at the heated substrate holder. Due to a burning/decomposition reaction of butyl carbitol, carbonate ions were formed that were subsequently incorporated into the $\mathrm{CaP}$ coatings. After heat-treatments, the amorphous carbonate containing $\mathrm{CaP}$ coatings were transformed into mixed $\mathrm{AB}$-type carbonate apatite with carbonate anions replacing both hydroxyl and phosphate groups. The crystallinity of these carbonate apatite coatings was low as compared to highly crystalline hydroxyapatite coatings ${ }^{16,17}$. This can be attributed to the fact that carbonate is known as an effective crystal growth inhibitor ${ }^{18}$. Using the plasma-spraying technique, it is impossible to synthesize carbonate containing $\mathrm{CaP}$ phases as a result of the very high process temperatures.

\section{Conclusions}

$\mathrm{CaP}$ thin films have been successfully deposited onto commercially pure Ti substrates by means of the ESD-technique. Various surface morphologies were obtained by varying the deposition parameters, ranging from porous films made of fractal agglomerates to unique reticular coating morphologies with a three-dimensional interconnected porous network. Crystalline carbonate apatite thin films were formed after heat-treatment. This $\mathrm{CaP}$ phase is particularly interesting due to its chemical resemblence to bone mineral. The current study shows the feasibility of the Electrostatic Spray Deposition technique for the production of thin $\mathrm{CaP}$ coatings with a defined surface morphology onto Ti substrates. The biological efficacy of the ESD-coatings has to be proven in future in vitro and in vivo studies.

\section{References}

1. Wolke JGC. Sprayed and sputtered calcium phosphate coatings for medical implants. PhD Thesis. University of Nijmegen, Nijmegen, 1997.

2. de Groot K. Calcium phosphate coatings: Alternatives to plasma spray. Bioceramics 1998;11:41-43.

3. Rey C. Calcium phosphate biomaterials and bone mineral. Differences in composition, structure and properties. Biomaterials 1990;11:13-15.

4. Layrolle P, de Groot K, van Blitterswijk CA. Biomimetic hydroxyapatite coating on Ti6A14V induced by pre-calcification. Bioceramics 1998;11:465-468.

5. Berger G, Ploska U, Willmann G. Hydroxyapatite's solubility may cause loosening of coated implants. Bioceramics 2000;13:111-114. 
6. van Zomeren AA, Kelder EM, Marijnissen JCM, Schoonman J. The production of thin films of LiMn ${ }_{2} \mathrm{O}_{4}$ by electrospraying. J Aerosol Sci 1994;25:1229-1235.

7. Chen CH. Thin film components for lithium-ion batteries. PhD Thesis. Delft University of Technology, Delft, 1998 .

8. Lapham DP, Colbeck I, Schoonman J, Kamlag Y. The preparation of $\mathrm{NiCo}_{2} \mathrm{O}_{4}$ films by electrostatic spray deposition. Thin Solid Films 2001;391:17-20.

9. Nguyen T, Djurado E. Deposition and characterization of nanocrystalline tetragonal zirconia films using electrostatic spray deposition. Solid State Ionics 2001;138:191-197.

10. Kim SG, Choi KH, Eun JH, Kim HJ, Hwang CS. Effects of additives on properties of MgO thin films by electrostatic spray deposition. Thin Solid Films 2000;377-378:694-698.

11. Mohamedi M, Takahashi D, Uchiyama T, Itoh T, Nishizawa M, Uchida I. Explicit analysis of impedance spectra related to thin films of spinel $\mathrm{LiMn}_{2} \mathrm{O}_{4}$. J Power Sources 2001;93:93-103.

12. Yoshinari M, Hayakawa T, Wolke JGC, Nemote $K$, Jansen JA. Influence of rapid heating with infrared radiation on $R F$ magnetron-sputtered calcium phosphate coatings. J Biomed Mater Res 1997;37:60-67.

13. Elliott JC. Structure and chemistry of the apatites and other calcium orthophosphates. Amsterdam: Elsevier, 1994.

14. Layrolle P, Ito A, Tateishi T. Sol-gel synthesis of amorphous calcium phosphate and sintering into microporous hydroxyapatite bioceramics. J Am Ceram Soc 1998;81:1421-1428.

15. Nadal M, Trombe JC, Bonel G, Montel G. Etude par spectrométrie d'absorption dans l'infrarouge de quelques substitutions dans les apatites carbonatées. J Chimie Phys 1970;67:1161-1167.

16. de Bruijn JD, Flach JS, Leenders H, van den Brink J, van Blitterswijk CA. Degradation and interface characteristics of plasma-sprayed hydroxyapatite coatings with different crystallinities. Bioceramics 1992;5:291-298.

17. Wolke JGC, de Blieck-Hogervorst JMA, Dhert WJA, Klein CPAT, de Groot K. Studies on thermal spraying of apatite bioceramics. J Thermal Spray Technol 1992;1:75-82.

18. LeGeros RZ. Calcium phosphates in oral biology and medicine. Basel: Karger, 1991 . 



\section{Introduction}

In the biomedical field, coatings are frequently applied onto the surface of metallic dental and orthopedic implants in order to improve their biological performance. Because of its similarity to the inorganic component of bone and teeth, calcium phosphate $(\mathrm{CaP})$ ceramics were considered early as a suitable class of materials for use as a surface coating on top of metals like titanium (Ti) and its alloys ${ }^{1}$. CaP materials are categorized as bioactive ceramics, which implies that the implant material bonds to surrounding osseous tissue, resulting in a strong interface between bone and the implant surface ${ }^{2}$. Generally, the phenomenon of bioactivity is characterized by the formation of an intermediate $\mathrm{CaP}$ layer at this interface. The capacity of biomaterial surfaces to initiate the formation of this intermediate $\mathrm{CaP}$ layer is indicative for their bioactivity. This capacity is strongly related to the chemical stability - and accordingly to the physicochemical properties - of the implant material surface in vitro and in vivo upon exposure to body fluids ${ }^{3-5}$. Specifically, the osteogenic capacity of $\mathrm{CaP}$ coatings was shown to be dependent on chemical properties, such as the coating composition, coating crystal as well as molecular structure, and coating crystallinity.

Currently, the most frequently applied method to coat Ti implants with synthetic CaP films is the plasma-spraying technique. However, this complex technique has several drawbacks, which are mainly related to extremely high processing temperatures and its lineof-sight application ${ }^{6,7}$. Consequently, promising $\mathrm{CaP}$ phases like carbonate apatite, which resembles the composition and crystallinity of bone mineral, cannot be deposited using plasma-spraying. Therefore, research has focused on the development of new coating techniques that overcome the above mentioned drawbacks.

Recently, the feasibility of a novel coating technique, referred to as Electrostatic Spray Deposition (ESD), was investigated ${ }^{8}$. Briefly, the basic principle of ESD is the generation of a spray of charged, micron-sized droplets. This is accomplished by means of electrostatic atomization ${ }^{9}$ of precursor solutions that contain inorganic precursor salts. These spray droplets are directed towards a grounded and heated substrate as a result of the applied potential difference. After complete solvent evaporation, a thin inorganic layer is left onto the substrate surface. This technique has been shown to enable the deposition of inorganic coatings with a defined surface morphology onto Ti substrates ${ }^{8,10}$.

In our previous study, the feasibility of the ESD-technique was proven for the production of thin $\mathrm{CaP}$ coatings ${ }^{8}$. In order to deposit ESD-coatings with defined chemical properties (in terms of coating crystallinity, crystal phase and molecular structure), the objective of the current study was to investigate the influence of several deposition parameters on these chemical properties. Since the synthesis of the various $\mathrm{CaP}$ phases in solutions is strongly dependent on factors like solution composition, supersaturation and acidity ${ }^{11}$, precursor solution parameters were expected to have a strong impact on the chemical characteristics of the deposited coatings. Therefore, four relevant precursor solution parameters (relative and absolute precursor solute concentrations, solution acidity, and the type of precursor salt) were selected and examined in this study. 


\section{Materials and Methods}

\subsection{ELECTROSTATIC SPRAY DEPOSITION (ESD) PROCESS}

In the current study, a commercially available, upwards-facing ESD set-up (ESD-ACTXY03, TU Delft/AST, Bleiswijk, The Netherlands) was used to deposit CaP coatings. Figure 1 gives a schematic view of the experimental set-up. Further details of the technique were described previously ${ }^{8,10}$. Machined, commercially pure (cp) Ti substrates (diameter $12 \mathrm{~mm}$, thickness $1.5 \mathrm{~mm}$ ) were used as substrate material for the deposition of the CaP coatings. The substrates were cleaned ultrasonically in acetone (15 minutes) and ethanol (15 minutes) prior to deposition.

Figure 1: Experimental set-up of the Electrostatic Spray Deposition (ESD) technique in upwards-facing configuration.

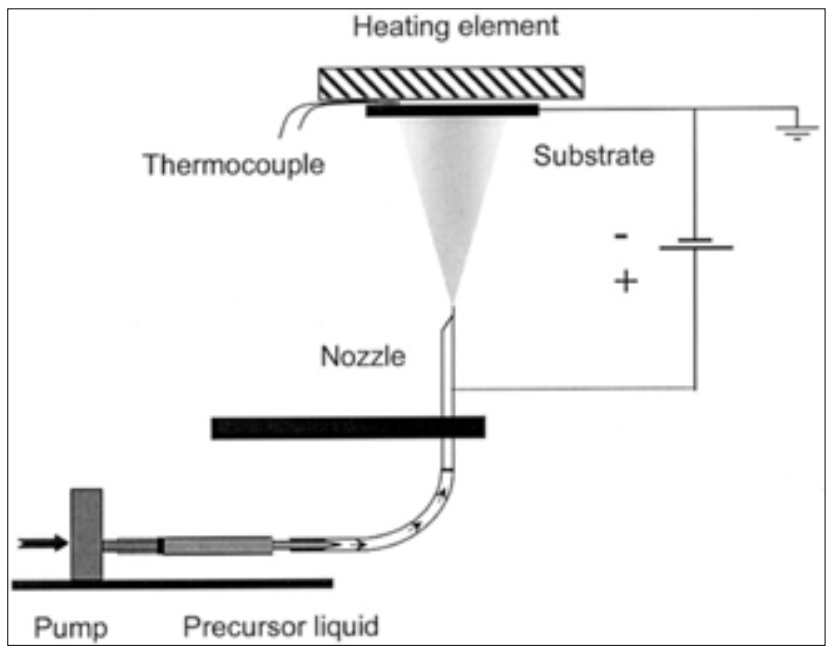

\subsection{COATING DEPOSITION PARAMETERS}

Four precursor solution parameters (type of $\mathrm{Ca}$ precursor salt, relative $\mathrm{Ca} / \mathrm{P}$ ratio, absolute precursor concentration, and solution acidity) were varied in order to investigate the relationship between the chemical coating characteristics and precursor solution properties. Coatings were deposited using $\mathrm{Ca}\left(\mathrm{NO}_{3}\right)_{2} \cdot 4 \mathrm{H}_{2} \mathrm{O}$ (Merck) or $\mathrm{CaCl}_{2} \cdot 2 \mathrm{H}_{2} \mathrm{O}$ (Merck) and $\mathrm{H}_{3} \mathrm{PO}_{4}\left(85 \mathrm{wt} \%\right.$, J.T. Baker) as precursor solutes and pure butyl carbitol $\left(\mathrm{BC}, \mathrm{C}_{8} \mathrm{H}_{18} \mathrm{O}_{3}\right.$, $99 \%$, Aldrich) or pure ethanol as organic solvents. Relevant precursor solution parameters of the depositions are summarized in Table 1. The distance between the stainless steel spraying nozzle (flat outlet, inner and outer diameter 1.0 and $1.4 \mathrm{~mm}$, respectively) and the substrate was set at $1.5 \mathrm{~cm}$. A stable electrospray was generated by adjusting the potential difference between the spraying nozzle and the substrate to values between 5.5 and $8.0 \mathrm{kV}$, depending on the composition of the precursor solution. All depositions were carried out at a fixed substrate temperature of $300^{\circ} \mathrm{C}$. Deposition time was varied between 15 minutes and 1 hour. No fixed deposition time could be chosen, since the growth rate of ESD-deposited thin films is strongly dependent on factors such as acidity and precursor concentration of the spraying solutions ${ }^{10}$. As a result, the coating thickness varied between 0.5 and 2.0 $\mu \mathrm{m}$. The precursor liquid flow rate was $2.0 \mathrm{ml} / \mathrm{h}$ (standard) or $1.0 \mathrm{ml} / \mathrm{h}$ (using precursor solution number II-x with varying absolute precursor concentration), since electrospraying in a stable cone-jet mode is only possible at lower flow rates for concentrated precursor 


\begin{tabular}{|c|c|c|c|c|c|}
\hline Study & $\begin{array}{l}\text { Solution } \\
\text { number }\end{array}$ & $\begin{array}{l}\mathrm{Ca}^{2+} \text { concentration }{ }^{\mathrm{a}, \mathrm{b}} \\
{[\mathrm{mM}]}\end{array}$ & $\begin{array}{l}\mathrm{H}_{3} \mathrm{PO}_{4} \text { concen- } \\
\text { tration }^{\mathrm{a}}[\mathrm{mM}]\end{array}$ & $\begin{array}{l}\mathrm{Ca} / \mathrm{P} \\
\text { ratio }\end{array}$ & $\begin{array}{l}\mathrm{HNO}_{3} \text { addi- } \\
\text { tion [vol\%] }\end{array}$ \\
\hline \multirow{7}{*}{$\begin{array}{l}\mathrm{Ca} / \mathrm{P} \text { ratio } \\
\text { (relative) }\end{array}$} & $\mathrm{I}-1$ & 2.5 & 2.5 & 1 & 0 \\
\hline & $\mathrm{I}-2$ & 2.7 & 2.3 & 1.17 & 0 \\
\hline & $\mathrm{I}-3$ & 2.9 & 2.2 & 1.33 & 0 \\
\hline & $\mathrm{I}-4$ & 3.0 & 2.0 & 1.5 & 0 \\
\hline & $\mathrm{I}-5$ & 3.1 & 1.9 & 1.67 & 0 \\
\hline & I-6 & 3.2 & 1.8 & 1.83 & 0 \\
\hline & $\mathrm{I}-7$ & 3.3 & 1.7 & 2.0 & 0 \\
\hline \multirow{4}{*}{$\begin{array}{l}\text { Concentration } \\
\text { (absolute) }\end{array}$} & II-1 & 1.25 & 1.25 & 1.0 & 0 \\
\hline & II-2 & 2.5 & 2.5 & 1.0 & 0 \\
\hline & II-3 & 5 & 5 & 1.0 & 0 \\
\hline & II-4 & 50 & 50 & 1.0 & 0 \\
\hline \multirow{6}{*}{ Acidity } & III-1 & 3.1 & 1.9 & 1.67 & 0 \\
\hline & III-2 & 3.1 & 1.9 & 1.67 & 0.1 \\
\hline & III-3 & 3.1 & 1.9 & 1.67 & 0.25 \\
\hline & III-4 & 3.1 & 1.9 & 1.67 & 0.5 \\
\hline & III-5 & 3.1 & 1.9 & 1.67 & 1.0 \\
\hline & III-6 & 3.1 & 1.9 & 1.67 & 2.0 \\
\hline \multirow{2}{*}{$\mathrm{Ca}$ precursor } & IV-1 & $0.0031 \mathrm{Ca}\left(\mathrm{NO}_{3}\right)_{2} \cdot 4 \mathrm{H}_{2} \mathrm{O}$ & 0.0019 & 1.67 & 0 \\
\hline & IV-2 & $0.0031 \mathrm{CaCl}_{2} .2 \mathrm{H}_{2} \mathrm{O}$ & 0.0019 & 1.67 & 0 \\
\hline
\end{tabular}

Table 1: Deposition settings used for the study of the influence of four precursor solution parameters (relative Ca/P ratio, absolute precursor concentration, acidity and type of Ca precursor) on chemical properties of electrosprayed CaP coatings.
${ }^{a}$ All precursor solutions listed in this table were prepared using the organic solvent butyl carbitol.

${ }^{b} \mathrm{Ca}\left(\mathrm{NO}_{3}\right)_{2} \cdot 4 \mathrm{H}_{2} \mathrm{O}$ was used as standard precursor salt for solution number I-x (Ca/P ratio), II-x (absolute concentration), and III-x (acidity).

solutions ${ }^{9,12}$. After deposition and subsequent characterization by means of FTIR and XRD, all coatings were subjected to additional heat-treatments of 15 seconds in air at final heating temperatures of up to $650^{\circ} \mathrm{C}$ in an infrared furnace (E4-10-P, Research Inc. $)^{13}$.

\subsection{COATING CHARACTERIZATION}

The as-deposited and heat-treated ESD-coatings were characterized using the following techniques:

" X-Ray Diffraction (XRD): CaP coatings were subjected to X-Ray Diffraction (XRD) analysis on a thin-film Panalytical X-Ray Diffractometer using CuK $\alpha$-radiation (PW $3710,40 \mathrm{kV}, 40 \mathrm{~mA}$ ) in order to characterize the crystal structure of the deposited coatings. Coatings were analyzed by fixing the sample to a position of $2.5^{\circ}$ and scanning the detector between $20^{\circ} 2 \theta$ and $50^{\circ} 2 \theta$ with a step-size of $0.02^{\circ} 2 \theta$, a scanning speed of $0.01^{\circ} 2 \theta / \mathrm{s}$, and a sample time of $2 \mathrm{~s} / \mathrm{step}$.

- Fourier-Transform Infrared Spectrometry (FTIR): in order to characterize the molecular structure of the deposited coatings, infrared spectra of the films on the substrates 
were obtained from 4000 to $400 \mathrm{~cm}^{-1}$ by reflection Fourier-Transform Infrared Spectrometry (Spectrum One, Perkin-Elmer), since infrared radiation cannot pass through the Ti substrate.

" Energy Dispersive Spectroscopy (EDS): the above described scanning electron microsope was equipped with an energy-dispersive X-ray microanalyzer (Voyager). EDS was carried out at a magnification of $500 \mathrm{x}$ at an accelerating voltage of $10 \mathrm{kV}$ in order to determine the elemental composition of the deposited coatings. Stoichiometric hydroxyapatite discs of known $\mathrm{Ca} / \mathrm{P}$ ratio and of equal thickness to the coated Ti-substrates $(1.5 \mathrm{~mm})$ were used as a reference for the determination of $\mathrm{Ca} / \mathrm{P}$ ratios of the deposited ESD-coatings.

\section{Results}

\subsection{INFLUENCE OF RELATIVE CA/P RATIO OF THE PRECURSOR SOLUTION}

Regarding the influence of the initial $\mathrm{Ca} / \mathrm{P}$ solution ratio on the chemical structure of ESD-coatings, XRD and FTIR analysis revealed that all CaP coatings were amorphous after deposition, irrespective of the initial $\mathrm{Ca} / \mathrm{P}$ solution ratio. After heat-treatment at $650{ }^{\circ} \mathrm{C}$, these amorphous coatings crystallized into different crystalline phases. Figure 2 shows the XRD patterns of three heat-treated coatings, synthesized with different initial $\mathrm{Ca} / \mathrm{P}$ solution ratios. Using a low relative $\mathrm{Ca} / \mathrm{P}$ solution ratio of 1.0 (spectrum $\mathrm{A}$, precursor solution $\mathrm{I}-1$ ), crystalline $\beta$-tricalcium phosphate $(\beta$-TCP) was synthesized with main reflection lines at $27.8^{\circ}, 31.0^{\circ}$ and $34.3^{\circ} 2 \theta$, corresponding to JCPDS File No. 9-169. At a higher relative $\mathrm{Ca} / \mathrm{P}$ solution ratio of 1.67 (spectrum $\mathrm{B}$, precursor solution $\mathrm{I}-5$ ), the crystal phase of the deposited coating was apatitic $\left(\mathrm{Ca}_{5}\left(\mathrm{PO}_{4}\right)_{3} \mathrm{X}\right)$. Main reflection lines were located at $25.8^{\circ}$, $31.8^{\circ}$ and $32.9^{\circ} 2 \theta$, which correspond to (002), (211), and (300) reflections of synthetic hydroxyapatite (JCPDS File No. 9-432). At a relative $\mathrm{Ca} / \mathrm{P}$ solution ratio of 2.0 (spectrum C, precursor solution I-7), the deposited crystal phase was also apatitic. However, presence

Figure 2: XRD patterns of electrosprayed CaP coatings, prepared with different relative $C a / P$ ratios of the precursor solution. [A] relative Ca/P solution ratio of 1.0 (solution I-1); [B] relative $C a / P$ solution ratio of 1.67 (solution I-5); [C] relative Ca/P solution ratio of 2.0 (solution I-7). All coatings were heat-treated at $650{ }^{\circ} \mathrm{C}$.

$*=\beta-T C P$

$+=$ carbonate apatite

$\checkmark$ calcite

$\mathrm{x}=$ calcium oxide

$0=T i$

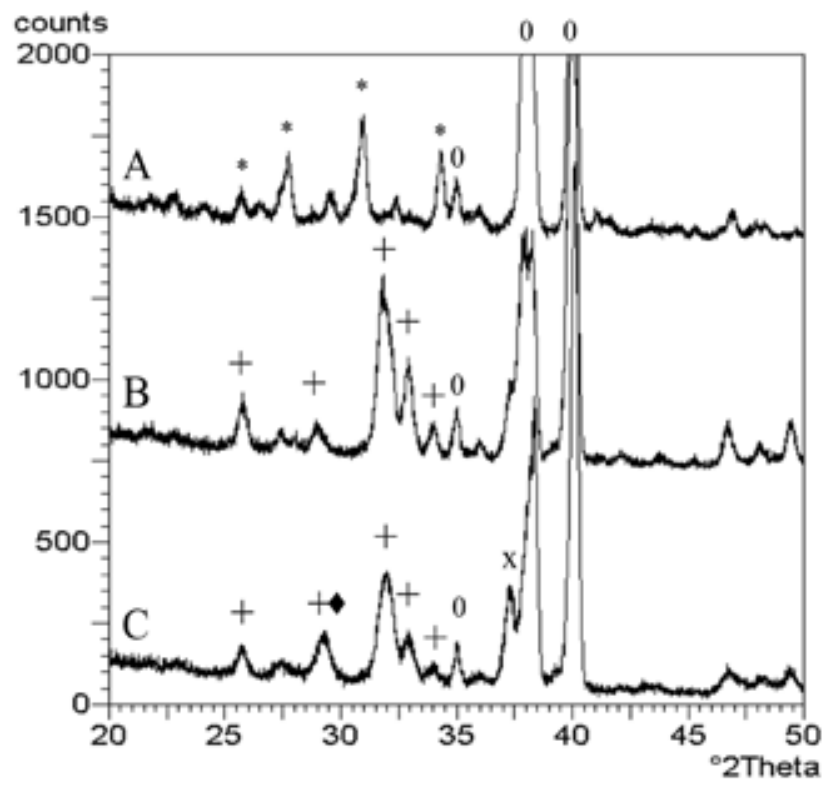




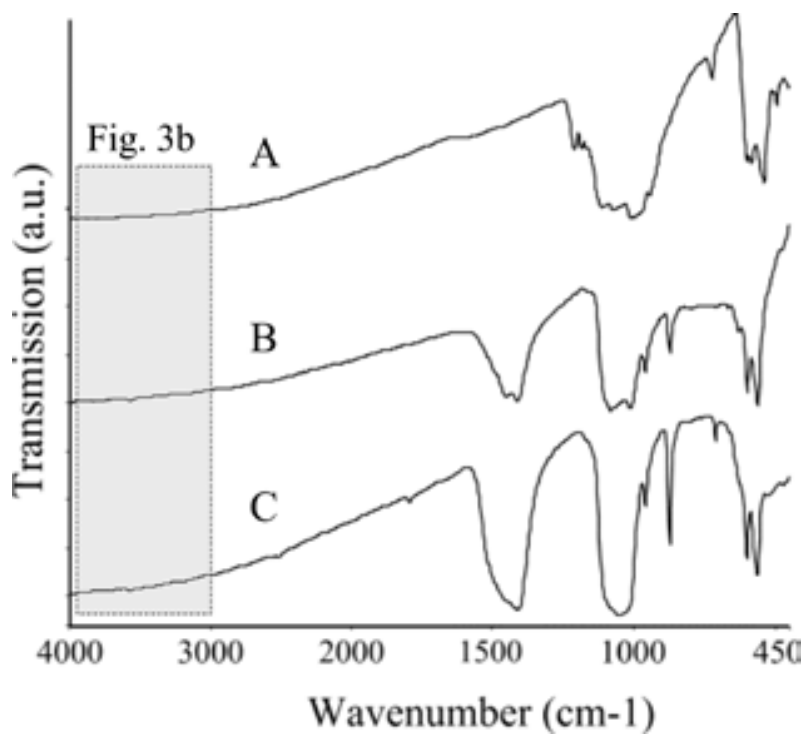

Figure 3 [a]: FTIR spectra (4000-450 $\left.\mathrm{cm}^{-1}\right)$ of electrosprayed CaP coatings, prepared with different relative $C a / P$ solution ratios 1.0 (A, solution I-1); 1.67 (B, solution I-5); 2.0 (C, solution I-7). All coatings were heattreated at $650{ }^{\circ} \mathrm{C}$.

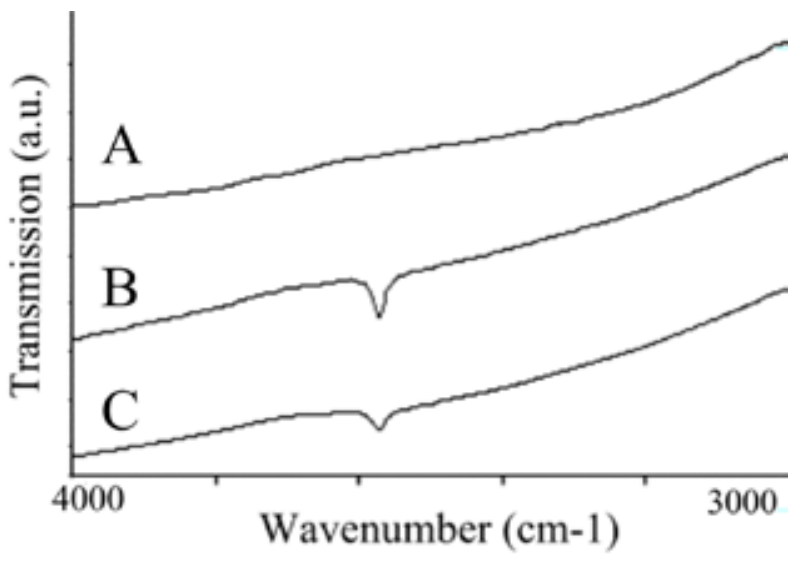

Figure 3 [b]: zoomed FTIR spectra (4000-3000 $\left.\mathrm{cm}^{-1}\right)$ of electrosprayed CaP coatings, prepared with different relative $\mathrm{Ca} / \mathrm{P}$ solution ratios of 1.0 ( $\mathrm{A}$, solution I-1); 1.67 (B, solution I-5); 2.0 (C, solution I-7). All coatings were heat-treated at $650^{\circ} \mathrm{C}$.

of calcite was detected by a reflection peak at $29.3^{\circ} 2 \theta$ (superimposed onto a weak, neighbouring apatite reflection at $28.9^{\circ} 2 \theta$ ). Moreover, a considerable shoulder at $37.4^{\circ} 2 \theta$ could be related to calcium oxide as an impurity phase.

Figure 3a shows the corresponding FTIR spectra after heat-treatment at $650{ }^{\circ} \mathrm{C}$. In the spectrum, belonging to the coatings deposited at a low relative $\mathrm{Ca} / \mathrm{P}$ solution ratio of 1.0 (spectrum A, precursor solution I-1), two intense absorption bands between $1250-900$ $\mathrm{cm}^{-1}\left(v_{3}\right)$ and $650-450 \mathrm{~cm}^{-1}\left(v_{4}\right)$ were observed, which match with crystalline $\beta$-TCP ${ }^{14}$. Still, slight differences were observed in the positions of the various small P-O absorption bands. The FTIR-spectrum of the apatitic $\mathrm{CaP}$ coatings, deposited at a relative $\mathrm{Ca} / \mathrm{P}$ ratios of 1.67 (spectrum B, precursor solution I-5), revealed that carbonate was incorporated into the apatite lattice. Carbonate bands $\left(v_{3}\right)$ at 1454 and $1413 \mathrm{~cm}^{-1}$ indicated that carbonate was mainly substituting for phosphate anions (type B substitutions) ${ }^{14-16}$. A sharp carbonate peak at $874 \mathrm{~cm}^{-1}\left(v_{2}\right)$ was also observed. Sharp phosphate absorption peaks were located at 1015, 
$1084 \mathrm{~cm}^{-1}\left(v_{3}\right), 962\left(v_{1}\right)$, and 600 as well as $563 \mathrm{~cm}^{-1}\left(v_{4}\right)$. Small but sharp absorption peaks were assigned to $\mathrm{OH}^{-}$stretch $\left(3570 \mathrm{~cm}^{-1}\right.$, Figure $\left.3 \mathrm{~b}\right)$ and $\mathrm{OH}^{-}$libration modes (shoulder at $630 \mathrm{~cm}^{-1}$, Figure 3a). At a relative $\mathrm{Ca} / \mathrm{P}$ solution ratio of 2.0 (spectrum $\mathrm{C}$, precursor solution I-7), carbonate absorption peaks were more intense. The doubly degenerate $v_{3}$ mode at $1414 \mathrm{~cm}^{-1}$ and calcite absorptions at 1796 and $712 \mathrm{~cm}^{-1}$ revealed that carbonate was also present as calcium carbonate. A broad, featureless phosphate $v_{3}$ absorption band between 900 and $1200 \mathrm{~cm}^{-1}$ instead of two sharply defined P-O absorption peaks was characteristic for poorly crystalline carbonate apatite (CA).

As shown in Table 2, EDS analysis revealed that the $\mathrm{Ca} / \mathrm{P}$ ratio of the deposited coatings were substantially higher than the initial $\mathrm{Ca} / \mathrm{P}$ solution ratios.

\begin{tabular}{|c|c|c|c|c|}
\hline $\begin{array}{l}\text { Solution } \\
\text { number }\end{array}$ & $\begin{array}{l}\text { HNO }{ }_{3} \text { addition } \\
{[\text { vol\%] }}\end{array}$ & $\mathrm{Ca}^{2+}$ concentration $[\mathrm{M}]$ & $\mathrm{Ca} / \mathrm{P}$ solution & $\mathrm{Ca} / \mathrm{P}$ coating \\
\hline $\mathrm{I}-1$ & 0 & 0.0025 & 1.0 & 1.5 \\
\hline $\mathrm{I}-5$ & 0 & 0.0031 & 1.67 & 3.4 \\
\hline $\mathrm{I}-7$ & 0 & 0.0033 & 2.0 & 4.3 \\
\hline II-2 & 0 & 0.0025 & 1.0 & 1.5 \\
\hline II-4 & 0 & 0.05 & 1.0 & 1.1 \\
\hline III-1 & 0 & 0.0031 & 1.67 & 3.4 \\
\hline III-2 & 0.1 & 0.0031 & 1.67 & 2.0 \\
\hline III-5 & 1.0 & 0.0031 & 1.67 & 1.3 \\
\hline III-6 & 2.0 & 0.0031 & 1.67 & 1.1 \\
\hline IV-1 & 0 & $0.0031 \mathrm{Ca}\left(\mathrm{NO}_{3}\right)_{2} \cdot 4 \mathrm{H}_{2} \mathrm{O}$ & 1.67 & 3.4 \\
\hline IV-2 & 0 & $0.0031 \mathrm{CaCl}_{2} .2 \mathrm{H}_{2} \mathrm{O}$ & 1.67 & 2.1 \\
\hline
\end{tabular}

Table 2: Ca/P ratios of initial precursor solutions and deposited CaP coatings (after heat-treatment) as measured by EDS.

\subsection{INFLUENCE OF THE ABSOLUTE PRECURSOR SOLUTE CONCENTRATION}

Figure 4a shows the XRD patterns of two as-deposited coatings, which were deposited by electrospraying precursor solutions with low $(2.5 \mathrm{mM}$, precursor solution II-2) and high (50 mM, precursor solution II-4) absolute $\mathrm{Ca}^{2+}$ and $\mathrm{H}_{3} \mathrm{PO}_{4}$ concentrations. Amorphous coatings were deposited using a low precursor concentration. On the contrary, crystalline monetite (matching to JCPDS File No. 9-80) was obtained using a highly concentrated precursor solution. After heat-treatment at $650{ }^{\circ} \mathrm{C}$, the amorphous coating transformed into crystalline $\beta$-TCP (Figure 4b), corresponding to JCPDS File No. 9-169. On the contrary, monetite coatings transformed completely into $\gamma$-pyrophosphate $\left(\gamma-\mathrm{Ca}_{2} \mathrm{P}_{2} \mathrm{O}_{7}\right.$, matching to JCPDS File No. 15-197) with main reflection peaks at $29.2^{\circ}$ and $30.7^{\circ} 2 \theta$. EDS measurements (Table 2) showed that the $\mathrm{Ca} / \mathrm{P}$ ratio of the $\beta$-TCP coating was equal to 1.5 , whereas the crystalline monetite coating had a $\mathrm{Ca} / \mathrm{P}$ ratio of 1.1 .

\subsection{INFLUENCE OF ACIDITY OF THE PRECURSOR SOLUTION}

All as-deposited coatings were amorphous. After heat-treatment at $650{ }^{\circ} \mathrm{C}$, various $\mathrm{CaP}$ crystal phases were obtained, depending on the acidity of the precursor solutions. 

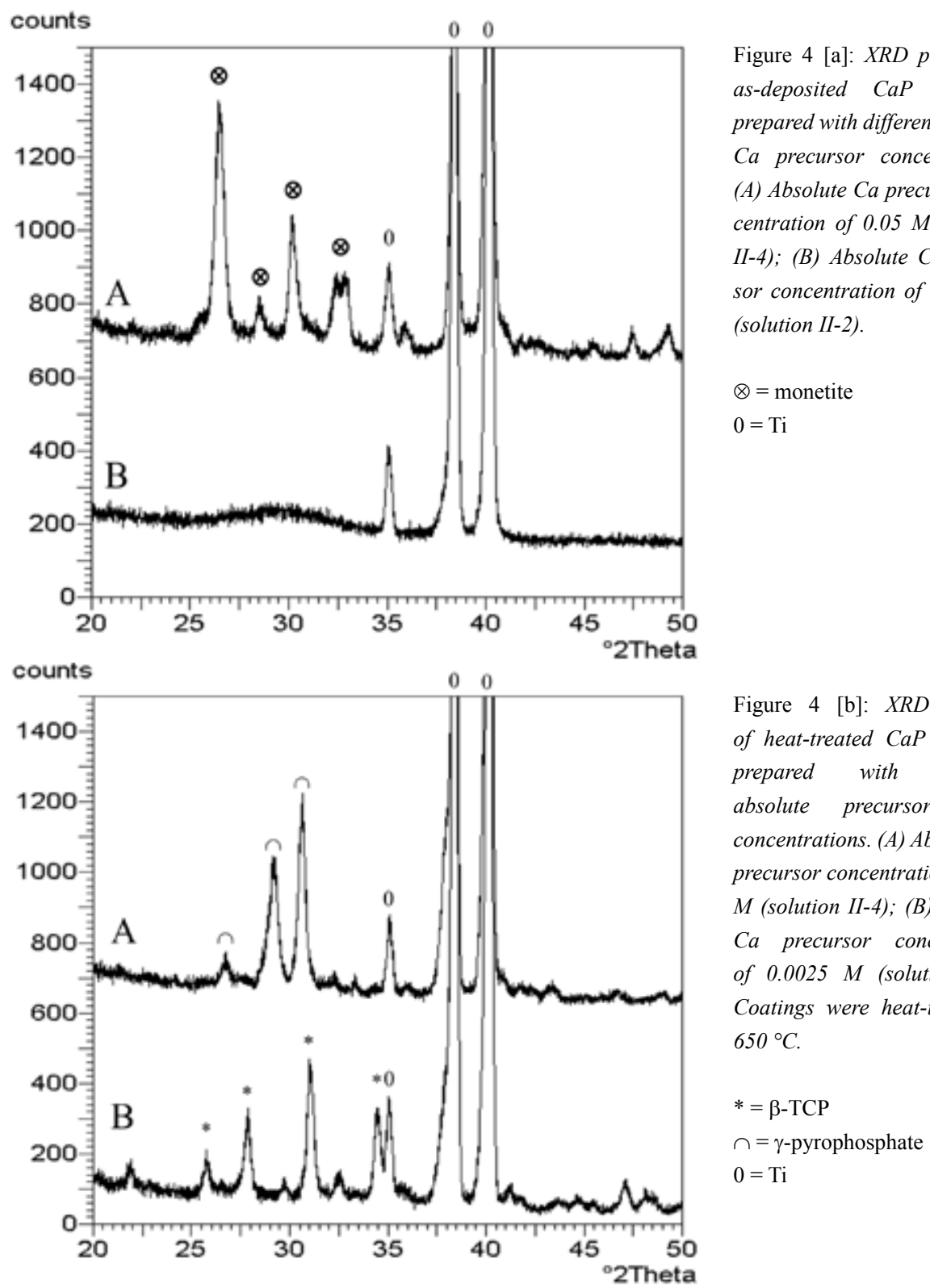

Figure 5 shows XRD patterns of four coatings, which were deposited using precursor solutions supplemented with varying amounts of nitric acid. Using the most acidic precursor solution $\left(2 \% \mathrm{HNO}_{3}\right.$, spectrum A, precursor solution III-6), $\beta$-pyrophosphate was the main crystal phase (JCPDS File No. 9-346). However, diffraction peaks at $31.2^{\circ}$ and $34.8^{\circ}$ $2 \theta$ were assigned to whitlockite (corresponding to JCPDS File No. 13-404). Using less acidic precursor solutions $\left(1 \% \mathrm{HNO}_{3}\right.$, spectrum $\mathrm{B}$, precursor solution III-5), whitlockite was deposited with main reflections at $31.3^{\circ}$ and $34.8^{\circ} 2 \theta$. A small peak at $31.8^{\circ} 2 \theta$ could be related to a minor contamination of apatitic nature. The XRD pattern of the coating, deposited using a slightly acidic solution $\left(0.1 \% \mathrm{HNO}_{3}\right.$, spectrum $\mathrm{C}$, precursor solution III-2), 
can be characterized as a poorly crystalline apatite phase. Without any addition of $\mathrm{HNO}_{3}$ (spectrum D, precursor solution III-1), the crystal phase was also apatitic, but a shoulder at $37.5^{\circ} 2 \theta$ was indicative for calcium oxide as an impurity phase.

FTIR spectra of the heat-treated coatings are shown in Figure 6. The spectrum, belonging to the most acidic deposition with $2 \% \mathrm{HNO}_{3}$ (spectrum A, precursor solution III-6), resembled the FTIR spectrum of $\beta$-pyrophosphate. Broad, feature-rich absorption bands between $900-1250 \mathrm{~cm}^{-1}$ and $450-650 \mathrm{~cm}^{-1}$ corresponded to $v_{3}$ and $v_{4}$ phosphate absorption modes, respectively. Small carbonate absorption peaks at 1482 and $1424 \mathrm{~cm}^{-1}$ were found

Figure 5: XRD patterns of electrosprayed CaP coatings, prepared using different amounts of $\mathrm{HNO}_{3}$ addition in the precursor solution. (A) $2 \%$ of $\mathrm{HNO}_{3}$ addition (solution III6); (B) $1 \%$ of $\mathrm{HNO}_{3}$ addition (solution III-5); (C) $0.1 \%$ of $\mathrm{HNO}_{3}$ addition (solution III2); (D) $0 \%$ of $\mathrm{HNO}_{3}$ addition (solution III-1). All coatings were heat-treated at $650^{\circ} \mathrm{C}$.

^ $=\beta$-pyrophosphate

$\wedge=$ whitlockite

$+=$ carbonate apatite

$\#=$ rutile $\mathrm{TiO}_{2}$

$\mathrm{x}=$ calcium oxide

$0=\mathrm{Ti}$

Figure 6: FTIR spectra of ESDdeposited calcium phosphate coatings, prepared using different amounts of $\mathrm{HNO}_{3}$ addition in the precursor solution. (A) 2 $\%$ of $\mathrm{HNO}_{3}$ addition (solution III-6); (B) $1 \%$ of $\mathrm{HNO}_{3}$ addition (solution III-5); (C) $0.1 \%$ of $\mathrm{HNO}_{3}$ addition (solution III2); (D) $0 \%$ of $\mathrm{HNO}_{3}$ addition (solution III-1). All coatings were heat-treated at $650^{\circ} \mathrm{C}$.
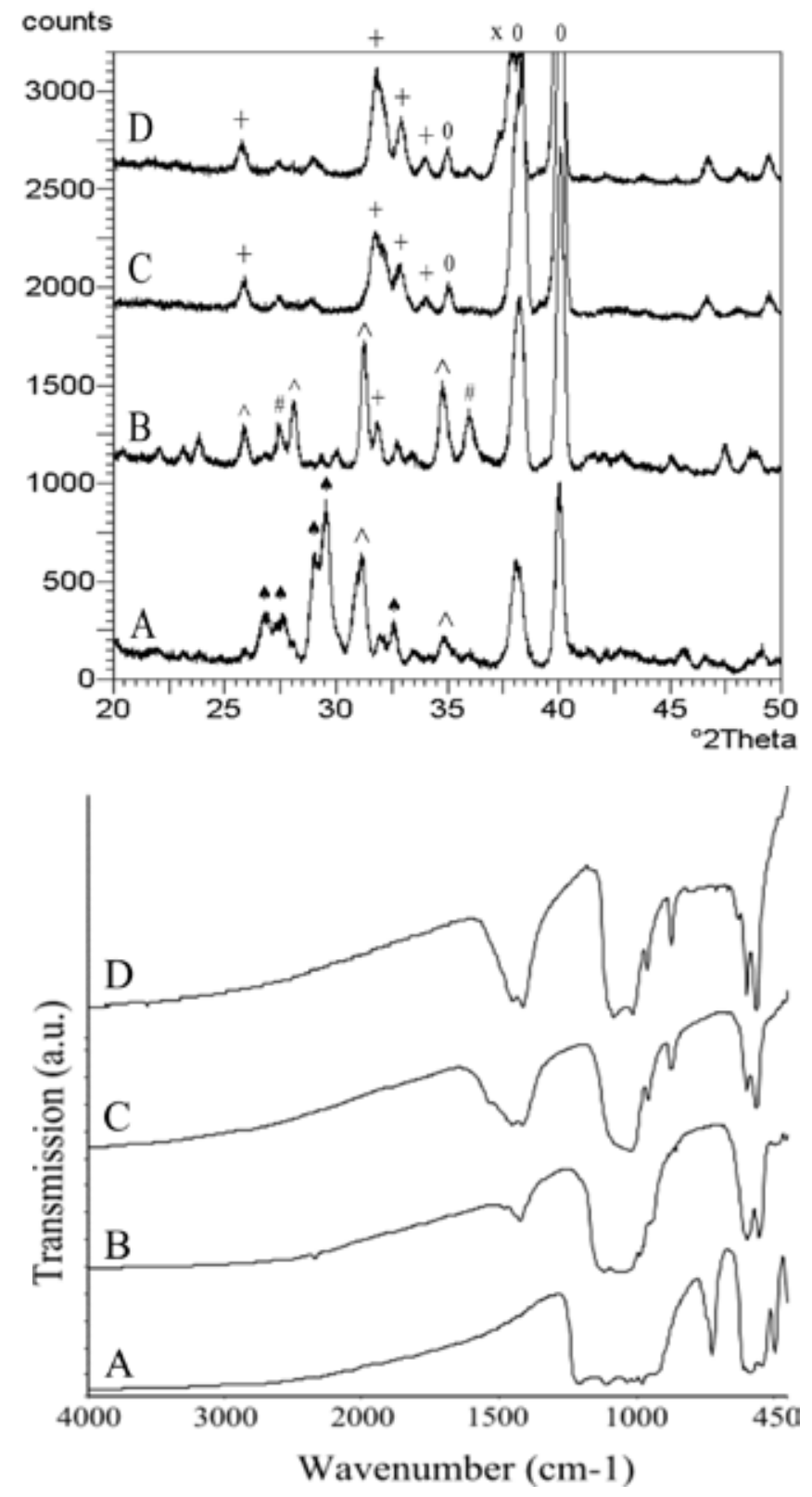
in the infrared spectrum of coatings deposited with $1 \%$ of $\mathrm{HNO}_{3}$ (spectrum $\mathrm{B}$, precursor solution III-5). The $v_{3}$ phosphate absorption band was less broad and feature-rich, and resembled the infrared spectrum of precipitated, Mg-containing whitlockite ${ }^{14}$. Using $0.1 \%$ of $\mathrm{HNO}_{3}$, intense $\mathrm{CO}_{3}$ absorption peaks at $878\left(v_{2}\right), 1415,1453$, and $1533\left(v_{3}\right) \mathrm{cm}^{-1}$ indicated a considerable increase of carbonate incorporation (spectrum $\mathrm{C}$, precursor solution III-2). These $v_{3}$ peaks indicated that carbonate anions were substituted for both phosphate (Btype) and hydroxyl groups (A-type) in a crystalline apatite lattice. The broad, featureless phosphate $v_{3}$ band at $1050 \mathrm{~cm}^{-1}$ instead of a collection of sharply defined $v_{3}$ absorptions was characteristic for poorly crystalline carbonate apatite. Absorption peaks at $960\left(v_{1}\right)$, 600 , and $563 \mathrm{~cm}^{-1}\left(\mathrm{v}_{4}\right)$ were assigned to phosphate groups. Without any $\mathrm{HNO}_{3}$ (spectrum $\mathrm{D}$, precursor solution III-1), intense carbonate absorptions peaks at 874, 1414 and $1454 \mathrm{~cm}^{-1}$ corresponded to a high carbonate content (B-type). Further, small absorptions at 3570 and $630 \mathrm{~cm}^{-1}$ were assigned to $\mathrm{OH}^{-}$stretch and libration absorption modes.

EDS analysis showed that $\mathrm{Mg}$ was present in the deposited coatings as a minor impurity element next to the main elements $\mathrm{Ca}$ and $\mathrm{P}$. Further, EDS revealed that $\mathrm{Ca} / \mathrm{P}$ ratios of the deposited coatings were strongly dependent on the amount of $\mathrm{HNO}_{3}$ added to the precursor solutions. Without any $\mathrm{HNO}_{3}$, a very high $\mathrm{Ca} / \mathrm{P}$ ratio of 3.4 was measured, whereas this value decreased to 1.1 for coatings deposited using precursor solutions supplemented with $2 \%$ of nitric acid (Table 2 ).

\subsection{INFLUENCE OF THE TYPE OF CA PRECURSOR SALT}

Figure 7 shows the XRD patterns of apatite coatings after a heat-treatment of $650{ }^{\circ} \mathrm{C}$, which were deposited using either $\mathrm{CaCl}_{2} \cdot 2 \mathrm{H}_{2} \mathrm{O}$ or $\mathrm{Ca}\left(\mathrm{NO}_{3}\right)_{2} \cdot 4 \mathrm{H}_{2} \mathrm{O}$ (spectrum $\mathrm{A}$ and $\mathrm{B}$, respectively). Using $\mathrm{CaCl}_{2} \cdot 2 \mathrm{H}_{2} \mathrm{O}$, both (211) and (122) apatite reflections were observed at $31.6^{\circ}$ and $32.2^{\circ} 2 \theta$, respectively, whereas only one broad, unresolved peak at $31.8^{\circ} 2 \theta$ was found for coatings, prepared using $\mathrm{Ca}\left(\mathrm{NO}_{3}\right)_{2} \cdot 4 \mathrm{H}_{2} \mathrm{O}$.

FTIR analysis (Figure 8) revealed that carbonate absorption peaks at $873\left(v_{2}\right), 1455$ and $1411 \mathrm{~cm}^{-1}$ (corresponding to B-type CA) were less intense for calcium chloride derived coatings (spectrum A), as compared to coatings prepared using calcium nitrate (spectrum B). Small absorption peaks at 3570 and $630 \mathrm{~cm}^{-1}$ were caused by $\mathrm{OH}^{-}$groups incorporated into calcium nitrate derived apatite. On the contrary, $\mathrm{OH}^{-}$absorptions were almost absent using calcium chloride.

$\mathrm{Ca}, \mathrm{P}$, and $\mathrm{Cl}$ were detected by means of $\mathrm{EDS}$. $\mathrm{Ca} / \mathrm{P}$ ratios of apatite coatings, prepared using $\mathrm{CaCl}_{2} \cdot 2 \mathrm{H}_{2} \mathrm{O}$, were lower than CA coatings synthesized using calcium nitrate (Table 2).

\section{Discussion}

The aim of this study was to investigate the influence of various precursor solution parameters on the chemical properties of $\mathrm{CaP}$ coatings deposited by means of the Electrostatic Spray Deposition (ESD) technique. The results clearly demonstrate that the crystal and molecular structure of ESD-deposited coatings are strongly dependent on the composition of the precursor solutions.

\subsection{INFLUENCE OF RELATIVE CA/P RATIO OF THE PRECURSOR SOLUTION}

XRD revealed that three different crystal phases could be obtained after heat-treat- 
Figure 7: XRD patterns of electrosprayed CaP coatings, prepared using different $\mathrm{Ca}$ precursor salts in the precursor solution. (A) Calcium chloride ( $\left.\mathrm{CaCl}_{2} .2 \mathrm{H}_{2} \mathrm{O}\right)$ (solution $\mathrm{IV}-2$ ); (B) Calcium nitrate $\left(\mathrm{Ca}\left(\mathrm{NO}_{3}\right)_{2} \cdot 4 \mathrm{H}_{2} \mathrm{O}\right)$ (solution $I V-1)$. All coatings were heat-treated at $650{ }^{\circ} \mathrm{C}$.

$+=$ carbonate apatite

$0=T i$

Figure 8: FTIR spectra of electrosprayed CaP coatings, prepared using different $\mathrm{Ca}$ precursor salts in the precursor solution. (A) Calcium chloride $\left(\mathrm{CaCl}_{2} .2 \mathrm{H}_{2} \mathrm{O}\right)$ (solution $\left.\mathrm{IV}-2\right) ; \quad(B)$ Calcium nitrate $\left(\mathrm{Ca}\left(\mathrm{NO}_{3}\right)_{2} \cdot 4 \mathrm{H}_{2} \mathrm{O}\right)$ (solution $I V-1)$. All coatings were heat-treated at $650^{\circ} \mathrm{C}$.
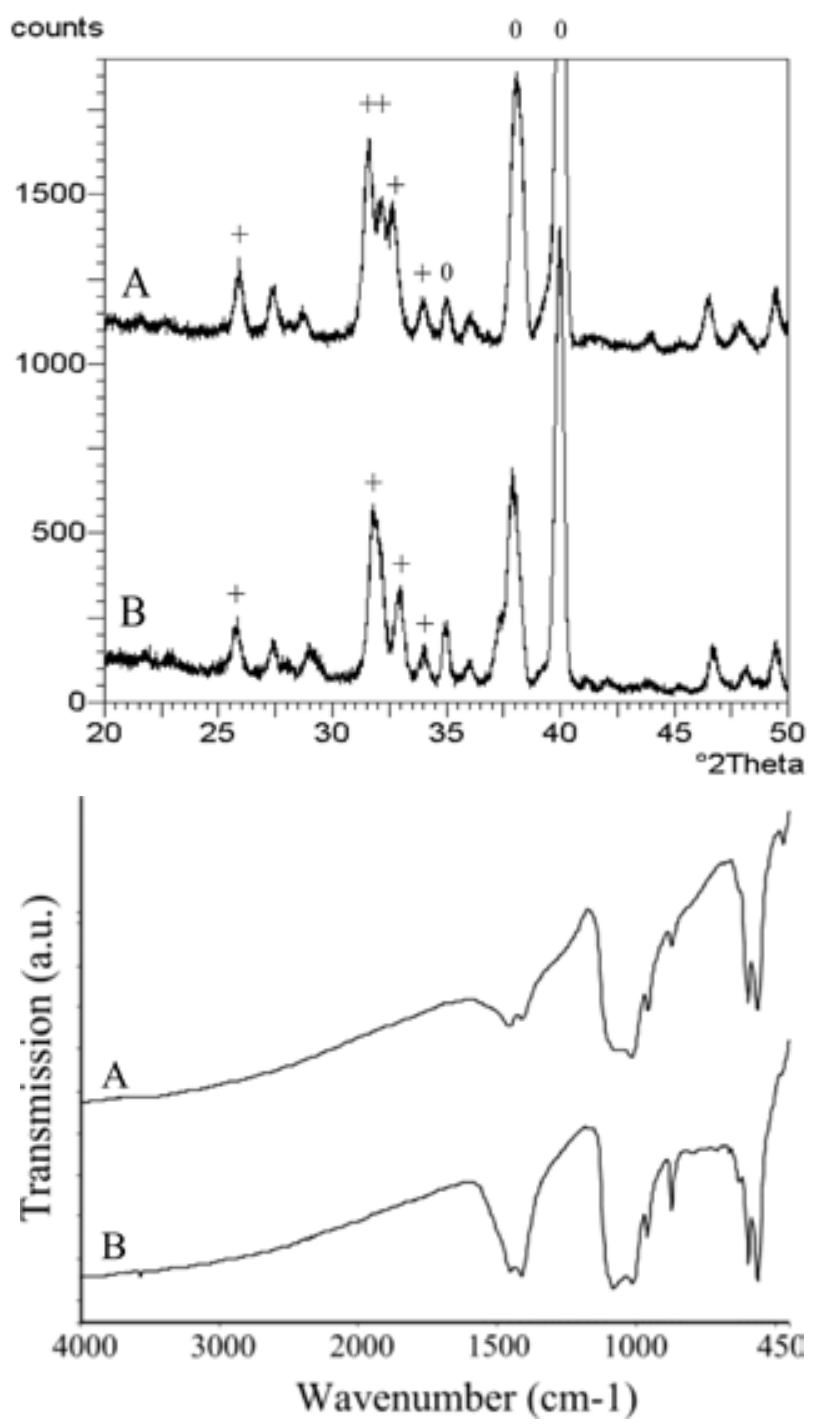

ment with infrared radiation at $650{ }^{\circ} \mathrm{C}$, depending on the $\mathrm{Ca} / \mathrm{P}$ precursor solution ratio. At a low $\mathrm{Ca} / \mathrm{P}$ solution ratio, $\beta$-TCP $\left(\mathrm{Ca}_{3}\left(\mathrm{PO}_{4}\right)_{2}\right)$ was deposited, whereas B-type carbonate apatite $\left(\mathrm{CA}\right.$, simplified as $\left.\mathrm{Ca}_{5}\left(\mathrm{PO}_{4}\right)_{\mathrm{x}}\left(\mathrm{CO}_{3}\right)_{\mathrm{y}}\right)$ was formed at intermediate $\mathrm{Ca} / \mathrm{P}$ ratios. Using solutions with a high $\mathrm{Ca} / \mathrm{P}$ ratio, a phase mixture of $\mathrm{CA}$, calcite $\left(\mathrm{CaCO}_{3}\right)$, and calcium oxide $(\mathrm{CaO})$ was observed. However, after less intense heat-treatments at temperatures below $550{ }^{\circ} \mathrm{C}$ (not shown), $\mathrm{CaO}$ reflections were absent for these high $\mathrm{Ca} / \mathrm{P}$ solution ratios, whereas the main calcite peak at $29.3^{\circ} 2 \theta$ was considerably more intense. Thus, calcium oxide is formed by thermal decomposition of calcite ${ }^{11}$ :

$$
\mathrm{CaCO}_{3} \rightarrow \mathrm{CaO}+\mathrm{CO}_{2}
$$

All carbonate-containing apatite coatings were less crystalline than synthetic hydroxyapatite, since carbonate is known as an effective crystal growth inhibitor ${ }^{14}$. 
FTIR analysis showed that the amount of carbonate incorporation in CA increased with increasing $\mathrm{Ca} / \mathrm{P}$ solution ratio. Carbonate replaced mainly phosphate groups (type $\mathrm{B}$ substitution), which indicated that the lack of phosphate anions at high $\mathrm{Ca} / \mathrm{P}$ solution ratios was compensated by extra carbonate anions. $\mathrm{OH}^{-}$groups occupied A-sites after heat-treating coatings of higher $\mathrm{Ca} / \mathrm{P}$ solution ratios. These results are in line with observations of $\mathrm{El}$ Feki et al. ${ }^{16}$, who found that $\mathrm{OH}^{-}$ions are formed and occupied A-sites after partial decomposition of type $\mathrm{B}$ carbonate ions:

$$
\begin{array}{ll}
\mathrm{CO}_{3}{ }^{2-} & \rightarrow \mathrm{CO}_{2}+\mathrm{O}^{2-} \\
\mathrm{O}^{2-}+\mathrm{H}_{2} \mathrm{O} & \rightarrow 2 \mathrm{OH}^{-}
\end{array}
$$

$\mathrm{Ca} / \mathrm{P}$ ratios of deposited coatings were higher than the initial $\mathrm{Ca} / \mathrm{P}$ ratios in the corresponding precursor solutions, as observed by means of EDS. However, one should realize that, using this technique, no distinction can be made between the phosphate-bounded calcium and other calcium compounds like calcite and/or calcium oxide. Moreover, B-type substitutions in $\mathrm{CA}$ result into increased $\mathrm{Ca} / \mathrm{P}$ ratios of the apatite phase.

Generally, precipitation reactions between precursor solutes are an essential step in the process of coating formation by means of $\mathrm{ESD}^{10}$. Therefore, the chemical nature of the precipitate, which forms upon precipitation in $\mathrm{CaP}$ containing precursor solutions, was investigated in more detail. This was accomplished by precipitating and centrifuging precipitation powders from several supersaturated $\mathrm{CaP}$ precursor solutions, followed by characterization by means of XRD and FTIR ${ }^{17}$. It was concluded that calcium and phosphate precursor solutes precipitated into the monetite phase $\left(\mathrm{CaHPO}_{4}\right)$ using the apolar, organic solvent butyl carbitol. This observation was confirmed by the fact that the interior of all spraying nozzles was covered with a thin layer of monetite after several tenths of hours of operation, as characterized by means of FTIR ${ }^{18}$. Consequently, formation of $\beta$-TCP $\left(\mathrm{Ca}_{3}\left(\mathrm{PO}_{4}\right)_{2}\right)$ and $\mathrm{CA}\left(\mathrm{Ca}_{5}\left(\mathrm{PO}_{4}\right)_{\mathrm{x}}\left(\mathrm{CO}_{3}\right)_{\mathrm{y}}\right)$ coatings without any $\mathrm{H}^{+}$incorporation was enabled by the following acid-base reaction between basic $\mathrm{CO}_{3}{ }^{2-}$ and acidic $\mathrm{HPO}_{4}{ }^{2-}$ groups from the intermediate $\mathrm{CaHPO}_{4}$ phase of the precipitate ${ }^{11}$ :

$$
2 \mathrm{HPO}_{4}^{2-}+\mathrm{CO}_{3}^{2-} \rightarrow 2 \mathrm{PO}_{4}^{3-}+\mathrm{CO}_{2}+\mathrm{H}_{2} \mathrm{O}
$$

LeGeros also found that monetite reacts in hot carbonate solutions yielding an apatite phase, often with simultaneous formation of calcite ${ }^{19}$. We suggest that this acid-base reaction essentially determined the final $\mathrm{Ca} / \mathrm{P}$ ratio of the deposited coatings.

The only possible source of carbonate was the solvent (butyl carbitol, ethanol), since it is the only organic component in the precursor solutions. Organic solvents like butyl carbitol produce gaseous $\mathrm{CO}$ and $\mathrm{CO}_{2}$ upon (partial) decomposition at higher temperatures, and $\mathrm{CO}_{3}{ }^{2-}$ might be formed afterwards. Nitrate ions are expected to play an important role in this latter reaction, since nitrate salts are strong oxidizers under acidic conditions ${ }^{20}$. Nitrate decomposes into gaseous oxides of nitrogen $\left(\mathrm{NO}_{\mathrm{x}}\right.$ ) and reactive $\mathrm{O}^{2-}$, which subsequently may react with $\mathrm{H}^{+}, \mathrm{CO}$, and $\mathrm{CO}_{2}$. For this purpose, calcium nitrate is also used in explosives as oxygen supplier.

\subsection{INFLUENCE OF THE ABSOLUTE PRECURSOR SOLUTE CONCENTRATION}

The absolute concentration of precursor solutions was shown to have a strong effect 
on coating chemistry. Using highly concentrated precursor solution $\left(\left[\mathrm{Ca}^{2+}\right]=50 \mathrm{mM}\right)$, crystalline monetite coatings were obtained upon deposition without any additional heattreatment. As precipitation experiments showed that this CaP phase was also formed upon precipitation in comparably supersaturated precursor solutions, it was concluded that this monetite coating was formed by a precipitation reaction without any reaction with carbonate ions. After heat-treatment, monetite coatings transformed into $\gamma$-pyrophosphate, a modification of pyrophosphate which can be formed when monetite is heated in air below $750{ }^{\circ} \mathrm{C}$ due to condensation of acidic phosphate groups into pyrophosphate ions $\left(\mathrm{P}_{2} \mathrm{O}_{7}^{4-}\right)^{21}$. At lower precursor concentrations, $\beta$-TCP was formed, indicating that protons were removed from phosphate groups by the above mentioned acid-base reaction between hydrogenated phosphate $\mathrm{HPO}_{4}{ }^{2-}$ and $\mathrm{CO}_{3}{ }^{2-}$. We suggest that the precipitation reaction, which yields monetite, is competitive to the acid-base reaction between carbonate and hydrogenated phosphate, that accounts for the formation of $\beta$-TCP. Using highly concentrated and Cadeficient precursor solutions, the fast precipitation reaction is expected to dominate the phosphate deprotonation reaction by carbonate anions.

\subsection{INFLUENCE OF ACIDITY OF THE PRECURSOR SOLUTION}

The acidity of precursor solutions was also shown to have a great influence on the chemical properties of ESD-deposited CaP coatings. XRD analysis displayed the formation of $\beta$-pyrophosphate with traces of whitlockite contamination for highly acidic deposition conditions $\left(2 \% \mathrm{HNO}_{3}\right)$. Whitlockite with traces of CA was formed under moderately acidic preparation conditions $\left(1 \% \mathrm{HNO}_{3}\right)$, whereas CA was observed for less acidic precursor solutions. Generally, FTIR-analysis revealed that the carbonate content increased with decreasing acidity. $\mathrm{HNO}_{3}$ is a strong acid which effectively eliminates basic carbonate according to the reaction:

$$
2 \mathrm{H}^{+}+\mathrm{CO}_{3}^{2-} \rightarrow \mathrm{CO}_{2}+\mathrm{H}_{2} \mathrm{O}
$$

Mixed AB-type $\mathrm{CA}$ without $\mathrm{OH}^{-}$incorporation was synthesized using slightly acidic precursor solutions $\left(0.1 \% \mathrm{HNO}_{3}\right)$. A-type carbonate anions were suggested to impede incorporation of hydroxyl ions in the channel along the c-axis. Without any addition of $\mathrm{HNO}_{3}$, B-type CA with $\mathrm{OH}^{-}$incorporation at A-sites was observed next to traces of calcite and calcium oxide. Several authors have shown also that carbonation in B-sites at a higher carbonate content induces a decrease in the ion content in monovalent A-sites, which are favored for a small carbonate content ${ }^{15,16,22}$. EDS showed that $\mathrm{Ca} / \mathrm{P}$ ratios of deposited coatings decreased with increasing acidity. Lower carbonate contents due to acidification of the precursor solutions can explain this effect. Furthermore, extra addition of nitric acid shifted the phosphate equilibrium into the acidic direction. In other words, the concentration of monovalent $\mathrm{H}_{2} \mathrm{PO}_{4}$ - increased and the concentration of divalent $\mathrm{HPO}_{4}{ }^{2-}$ decreased. Generally, $\mathrm{Ca} / \mathrm{P}$ ratios of precipitated $\mathrm{CaP}$ compounds decrease with increasing acidity ${ }^{11}$. This is the result of a reduced total negative charge of phosphate anions due to an increased amount of protons attached to the phosphate anions. Correspondingly, calcium and phosphate react at lower $\mathrm{Ca} / \mathrm{P}$ ratios and more phosphate is incorporated into the $\mathrm{CaP}$ coatings.

\subsection{INFLUENCE OF THE TYPE OF CA PRECURSOR SALT}

FTIR showed that the carbonate content was smaller for coatings prepared with calcium chloride, as compared to coatings prepared using calcium nitrate. Consequently, $\mathrm{Ca} / \mathrm{P}$ 
ratios were lower and crystallinity was higher since carbonate is known as an effective inihibitor of crystal growth. $\mathrm{OH}^{-}$incorporation was observed by means of FTIR for calcium nitrate derived coatings. Probably, these hydroxyl groups were formed after partial decomposition of type $\mathrm{B}$ carbonate and calcium carbonate into reactive $\mathrm{O}^{2-}$, as described earlier. Another source of $\mathrm{O}^{2-}$ might be the decomposition of $\mathrm{NO}_{3}^{-}$into $\mathrm{O}^{2-}$ and gaseous nitrogen oxides $\mathrm{NO}_{\mathrm{x}}$. These highly reactive oxygen anions are suggested to react with $\mathrm{H}_{2} \mathrm{O}$ and $\mathrm{CO}_{2}$ according to the following reactions:

$$
\begin{array}{ll}
\mathrm{O}^{2-}+\mathrm{H}_{2} \mathrm{O} & \rightarrow 2 \mathrm{OH}^{-} \\
\mathrm{OH}^{-}+\mathrm{CO}_{2} & \rightarrow \mathrm{HCO}_{3}^{-} \\
\mathrm{HCO}_{3}^{-} & \rightarrow \mathrm{CO}_{3}{ }^{-2}+\mathrm{H}^{+}
\end{array}
$$

\section{Conclusions}

Our results showed that the chemical properties of CaP coatings, deposited using the ESD-technique, are strongly dependent on the composition of the precursor solutions. Various crystal phases and phase mixtures were deposited (carbonate apatite, $\beta-\mathrm{TCP}, \mathrm{Mg}-$ substituted whitlockite, monetite, $\beta / \gamma$-pyrophosphate, calcite) by varying the relative $\mathrm{Ca} / \mathrm{P}$ solution ratio, the absolute precursor concentration, the acidity of the precursor solution and the type of $\mathrm{Ca}$ precursor salt. By means of precipitation experiments, it was shown that monetite $\left(\mathrm{CaHPO}_{4}\right)$ acts as an intermediate $\mathrm{CaP}$ compound during the formation of ESD-deposited CaP coatings. Subsequently, carbonate anions play an essential role in controlling the chemical properties of the final $\mathrm{CaP}$ coating. Basically, carbonate has three functions. First of all, it acts as a base that eliminates protons from acidic, hydrogenated phosphate groups. With increasing carbonate content, carbonate is incorporated into apatitic $\mathrm{CaP}$ phases on A- and B-type substitution sites. Finally, carbonate anions react with excessive $\mathrm{Ca}^{2+}$ cations towards calcite in the case of phosphate-deficient precursor solutions of high $\mathrm{Ca} / \mathrm{P}$ solution ratios.

\section{References}

1. Lacefield WR. Hydroxylapatite coatings. In: Hench LL, Wilson J, eds. An introduction to bioceramics. Singapore: World Scientific Publishing Co., 1993. p223-238.

2. Hench LL, Ethridge EC. Biomaterials. New York: Academic Press, 1982.

3. Ducheyne P, Qiu Q. Bioactive ceramics: the effect of surface reactivity on bone formation and bone cell function. Biomaterials 1999;20:2287-2303.

4. LeGeros RZ. Biodegradation and bioresorption of calcium phosphate ceramics. Clin Mater 1993;14:6588 .

5. de Bruijn JD. Calcium phosphate biomaterials: bone-bonding and biodegradation properties. PhD Thesis. University of Leiden, Leiden, 1993. 
sis. University of Twente, Enschede, 2002.

7. Layrolle P, de Groot K, van Blitterswijk CA. Biomimetic hydroxyapatite coating on Ti6Al4V induced by pre-calcification. Bioceramics 1998;11:465-468.

8. Leeuwenburgh S, Wolke J, Schoonman J, Jansen J. Electrostatic Spray Deposition (ESD) of calcium phosphate coatings. J Biomed Mater Res 2003;66:330-334.

9. Hartman R. Electrohydrodynamic atomization in the cone-jet mode. PhD Thesis. Delft University of Technology, Delft, 1998.

10. Chen $\mathrm{CH}$. Thin film components for lithium-ion batteries. PhD Thesis. Delft University of Technology, Delft, 1998 .

11. Elliott JC. Structure and chemistry of the apatites and other calcium orthophosphates. Amsterdam: Elsevier, 1994.

12. Grace JM, Marijnissen JCM. A review of liquid atomization by electrical means. J Aerosol Sci 1994;25:1005-1019.

13. Yoshinari M, Hayakawa T, Wolke JGC, Nemoto K, Jansen JA. Influence of rapid heating with infrared radiation on RF magnetron-sputtered calcium phosphate coatings. J Biomed Mater Res 1997;37:60-67.

14. LeGeros RZ. Calcium phosphate in oral biology and medicine. Basel: Karger, 1991.

15. Nelson DGA, Featherstone JDB. Preparation, analysis and characterization of carbonated apatites. Calcif Tissue Int 1982;34:S69-S81.

16. El Feki H, Rey C, Vignoles M. Carbonate ions in apatites: Infrared investigations in the $v_{4} \mathrm{CO}_{3}$ domain. Calcif Tissue Int 1991;49:269-274.

17. Leeuwenburgh SCG, Wolke JGC, Schoonman J, Jansen JA. Unpublished results 2001.

18. Leeuwenburgh SCG, Wolke JGC, Schoonman J, Jansen JA. Deposition of calcium phosphate coatings with defined chemical properties using the Electrostatic Spray Deposition technique. J Europ Ceram Soc $2006 ; 26: 487-493$..

19. LeGeros RZ. Crystallographic studies of the carbonate substitution in the apatite structure. PhD Thesis. University of London, London, 1967.

20. Atkins PW. Physical chemistry. Oxford: Oxford University Press, 1995.

21. Skinner HCW. Transition of calcium phosphate to pyrophosphate at elevated pressures. Mat Res Bull 1970;5:437-448.

22. Vignoles $M$, Bonel G, Holcomb DW, Young RA. Influence of preparation conditions on the composition of type $B$ carbonated hydroxyapatite and on the localization of the carbonate ions. Calcif Tissue Int 1988;43:33-40. 



\section{Introduction}

Calcium phosphate $(\mathrm{CaP})$ ceramics are categorized as bioactive materials, which implies that the implant material bonds to surrounding osseous tissue, resulting in a strong interface between bone and the implant surface ${ }^{1}$. This bone-bonding capacity is strongly related to the reactivity and thus the chemical stability of the implant material surface in vitro and in vivo upon exposure to body fluids ${ }^{2-6}$. Specifically, the osteogenic capacity of $\mathrm{CaP}$ coatings was shown to be dependent on chemical properties, such as the coating composition, coating crystal as well as molecular structure, and coating crystallinity ${ }^{2,6,7}$.

In order to produce electrosprayed $\mathrm{CaP}$ coatings with defined chemical properties (in terms of crystallinity, crystal phase and molecular structure of the coating), the relationship between various processing parameters of the technique and chemical characteristics of the deposited coatings has to be understood. In a previous study, the influence of the composition of the precursor solutions on the chemical properties of ESD-derived CaP coatings was investigated ${ }^{8}$. The main objective of the current study was to study the influence of physical, apparatus-related deposition parameters on these chemical properties. Therefore, four relevant apparatus-related deposition parameters (deposition temperature, nozzle-tosubstrate distance, liquid flow rate, and the geometry of the spraying nozzle) were selected and investigated in this study. The deposition temperature and nozzle-to-substrate distance were chosen for their influence on solvent evaporation. The liquid flow rate and the geometry of the spraying nozzle were expected to influence the mixing characteristics of the precursor solutions.

\section{Materials and Methods}

\subsection{ELECTROSTATIC SPRAY DEPOSITION (ESD) PROCESS}

In the current study, a commercially available, vertical ESD set-up (Advanced Surface Technology, Bleiswijk, The Netherlands) was used to deposit CaP coatings. Figure 1 gives a schematic view of the set-up. In this unit, the spray is directed downwards from the nozzle to the heated substrate. A DC voltage supply (Fug, HCN 14-20000, Rosenheim, Germany) was used in order to generate a positive high potential difference between the nozzle and the grounded substrate. Heating of the substrates was regulated by a temperature-controlling unit (Eurotherm Controls model 2216). The precursor solutions containing $\mathrm{Ca}$ and $\mathrm{P}$ precursor salts were pumped towards the spraying nozzle by means of a syringe pump (Kd Scientific 220, New Hope, USA).

$\mathrm{Ca}$ and $\mathrm{P}$ precursor solutions were prepared by dissolving $\mathrm{Ca}\left(\mathrm{NO}_{3}\right)_{2} \cdot 4 \mathrm{H}_{2} \mathrm{O}(5 \mathrm{mM}$, Merck) and $\mathrm{H}_{3} \mathrm{PO}_{4}\left(3.57 \mathrm{mM}, 85 \mathrm{wt} \%\right.$, J.T. Baker) in butyl carbitol $\left(\mathrm{C}_{8} \mathrm{H}_{18} \mathrm{O}_{3}, 99 \%\right.$, Aldrich) at a fixed $\mathrm{Ca} / \mathrm{P}$ ratio of 1.4 . A stable cone-jet mode of electrospraying ${ }^{9}$ was generated by adjusting the potential difference between the spraying nozzle and the substrate to values between 4.0 and $8.5 \mathrm{kV}$, depending on the specific set of deposition parameters. The deposition time was varied between 15 minutes and 3 hours in order to obtain coatings with comparable thicknesses, depending on the liquid flow rate and the nozzle-to-substrate distance. Machined, commercially pure titanium (Ti) discs (diameter $12 \mathrm{~mm}$, thickness $1.5 \mathrm{~mm}$ ) were used as the substrate material for the deposition of the CaP coatings. The substrates were cleaned ultrasonically in acetone (15 minutes) prior to deposition. 
Figure 1: Experimental set-up of the Electrostatic Spray Deposition (ESD) technique.

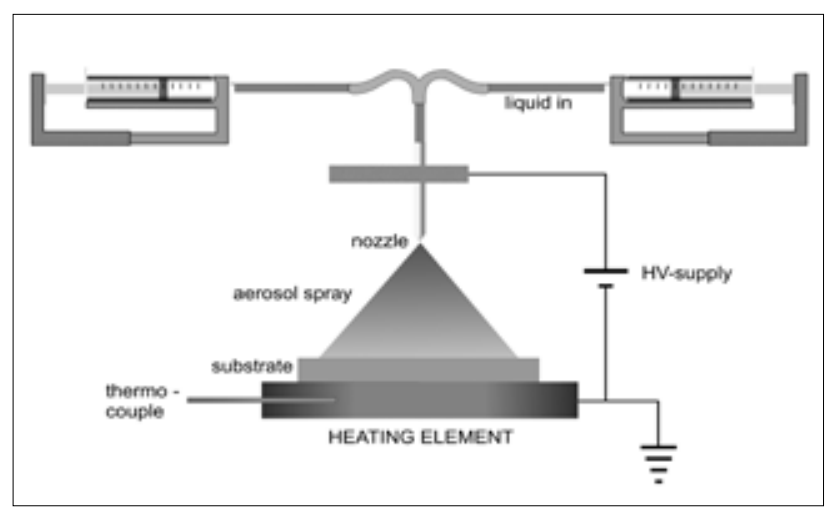

\subsection{COATING DEPOSITION PARAMETERS}

The substrate temperature was changed between 300 and $600{ }^{\circ} \mathrm{C}$, whereas the distance between the spraying nozzle and the substrate was varied between 5 and $40 \mathrm{~mm}$. Regarding the geometry of the spraying nozzle, a two-component nozzle with separate inlet for $\mathrm{Ca}$ and $\mathrm{P}$ precursor solutions was used as standard nozzle (stainless steel, flat outlet, inner and outer diameter of 0.9 and $1.4 \mathrm{~mm}$, respectively) in order to avoid premature precipitation of the precursor solutions prior to spray generation. This novel nozzle geometry was compared with a conventional one-component nozzle geometry using premixed precursor solutions. Both nozzle geometries are depicted in Figure 2.

Using the standard two-component nozzle, the precursor flow rate was varied between

Figure 2: Novel two-component and conventional one-component spraying nozzle geometries.

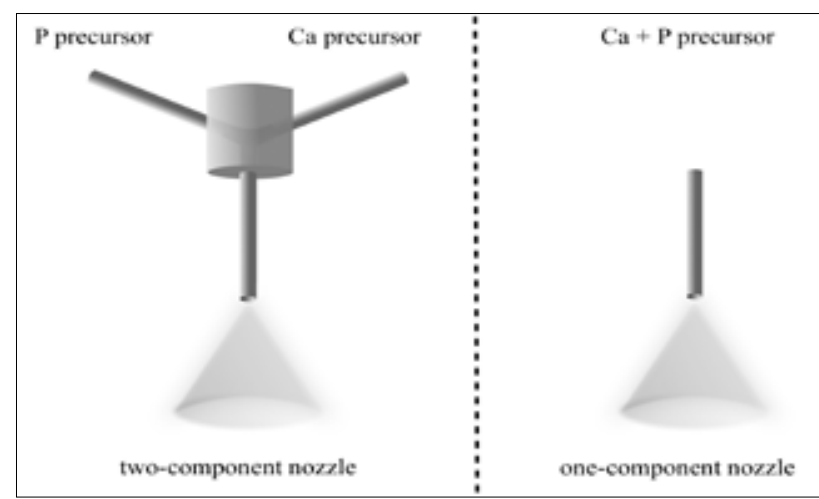

0.5 and $2.0 \mathrm{ml} / \mathrm{h}$ (equal flow rate for both $\mathrm{Ca}$ and $\mathrm{P}$ precursor solutions), whereas the flow rate was fixed at $2.0 \mathrm{ml} / \mathrm{h}$ for the one-component nozzle. The thickness of the deposited coatings varied between 0.5 and $10 \mu \mathrm{m}$, depending on the nozzle-to-substrate distance and the liquid flow rate. After deposition, some of the coatings were subjected to additional heat-treatments in air at a temperature of $650{ }^{\circ} \mathrm{C}$ in an infrared furnace $(\mathrm{E} 4-10-\mathrm{P}$, Research Inc., Minneapolis, USA) in order to study the crystallization behavior of the $\mathrm{CaP}$ ceramic coatings ${ }^{10}$. 


\subsection{COATING CHARACTERIZATION}

The as-deposited and heat-treated ESD-coatings were characterized using the following techniques:

" X-Ray Diffraction (XRD): CaP coatings were subjected to X-Ray Diffraction analysis on a thin-film Panalytical X-Ray Diffractometer using CuK $\alpha$-radiation (PW 3710, 40 $\mathrm{kV}, 40 \mathrm{~mA}$ ) in order to characterize the crystal structure of the deposited coatings. Coatings were analyzed by fixing the sample to a position of $2.5^{\circ}$ and scanning the detector between $20^{\circ} 2 \theta$ and $50^{\circ} 2 \theta$ with a step-size of $0.02^{\circ} 2 \theta$, a scanning speed of $0.01^{\circ} 2 \theta / \mathrm{s}$ and a sample time of $2 \mathrm{~s} /$ step.

" Fourier-Transform Infrared Spectrometry (FTIR): in order to characterize the molecular structure of the deposited coatings, infrared spectra of the films on the substrates were obtained from 4000 to $400 \mathrm{~cm}^{-1}$ by reflection Fourier-Transform Infrared Spectrometry (Spectrum One, Perkin-Elmer), since infrared radiation cannot pass through the Ti substrate.

- Energy Dispersive Spectroscopy (EDS): EDS was performed using an energy dispersive X-ray microanalyzer (Voyager) connected to a scanning electron microscope (Jeol, SEM6310). EDS was carried out at a magnification of 500x at an accelerating voltage of $10 \mathrm{kV}$ in order to determine the chemical composition of the deposited coatings. Stoichiometric hydroxyapatite discs of known $\mathrm{Ca} / \mathrm{P}$ ratio and of equal thickness to the coated Ti substrates $(1.5 \mathrm{~mm})$ were used as a reference for the determination of $\mathrm{Ca} / \mathrm{P}$ ratios of the deposited ESD-coatings.

\section{Results}

\subsection{INFLUENCE OF DEPOSITION TEMPERATURE}

The minimum deposition temperature for the formation of CaP coatings by means of ESD appeared to be $300{ }^{\circ} \mathrm{C}$; at lower temperatures it was impossible to obtain solid, ceramic coatings. Figure 3 shows the FTIR spectra of as-deposited coatings, synthesized at different deposition temperatures. At $300{ }^{\circ} \mathrm{C}$, two broad and unresolved phosphate absorption bands were observed between $1250-900 \mathrm{~cm}^{-1}\left(v_{3}\right)$ and $650-500 \mathrm{~cm}^{-1}\left(v_{4}\right)$. However, remnants of the organic solvent were still present at $300{ }^{\circ} \mathrm{C}$. Several absorption peaks were assigned to organic groups ${ }^{11}$, such as intense $\mathrm{CH}$ stretch absorptions (between 2850-2940 $\mathrm{cm}^{-1}$ ), a $\mathrm{CH}$ bending band at $1460 \mathrm{~cm}^{-1}$, a symmetric $\mathrm{CH}$ bending band of the $\mathrm{CH}_{3}$ group at $1376 \mathrm{~cm}^{-1}$, and $\mathrm{CH}_{2}$ rocking absorption at $722 \mathrm{~cm}^{-1}$. Moreover, absorption peaks at 1713 and $1598 \mathrm{~cm}^{-1}$ were assigned to $\mathrm{C}=\mathrm{O}^{11}$ and nitrate groups ${ }^{12}$. However, some authors have reported a bending mode of water $\left(v_{2}\right)^{13}$ at $1595 \mathrm{~cm}^{-1}$. At a deposition temperature of 350 ${ }^{\circ} \mathrm{C}$, the organic remnants and $\mathrm{C}=\mathrm{O}$ groups were absent and two broad $\mathrm{v}_{3}$ carbonate absorptions were observed at $1487 \mathrm{~cm}^{-1}$ and $1425 \mathrm{~cm}^{-1}$. Also, a small $v_{2}$ carbonate peak at $870 \mathrm{~cm}^{-1}$ was found. These vibrations correspond to carbonate groups engaged in an amorphous $\mathrm{CaP}$ environment ${ }^{14}$. Absorption peaks at 782,1323 , and $1646 \mathrm{~cm}^{-1}$ corresponded to the presence of hydrated calcium oxalate ${ }^{15}$. At a deposition temperature of $450{ }^{\circ} \mathrm{C}$, the nitrate and/or water absorption band around $1600 \mathrm{~cm}^{-1}$ had completely disappeared, whereas the oxalate absorption peaks were also hardly visible anymore. On the contrary, the carbonate bands at 1487,1425 , and $870 \mathrm{~cm}^{-1}$ were still present. Phosphate absorptions between $1250-900$ $\mathrm{cm}^{-1}\left(v_{3}\right)$ and $650-500 \mathrm{~cm}^{-1}\left(v_{4}\right)$ remained broad and unresolved up to deposition temperatures of $550{ }^{\circ} \mathrm{C}$, but at $600{ }^{\circ} \mathrm{C}$ these two absorption bands split up into sharper bands 
Figure 3: FTIR spectra of as-deposited, electrosprayed CaP coatings, prepared at different deposition temperatures. [I] $300^{\circ} \mathrm{C}$, [II] $350^{\circ} \mathrm{C}$, [III] $450^{\circ} \mathrm{C}$, and [IV] $600^{\circ} \mathrm{C}$.

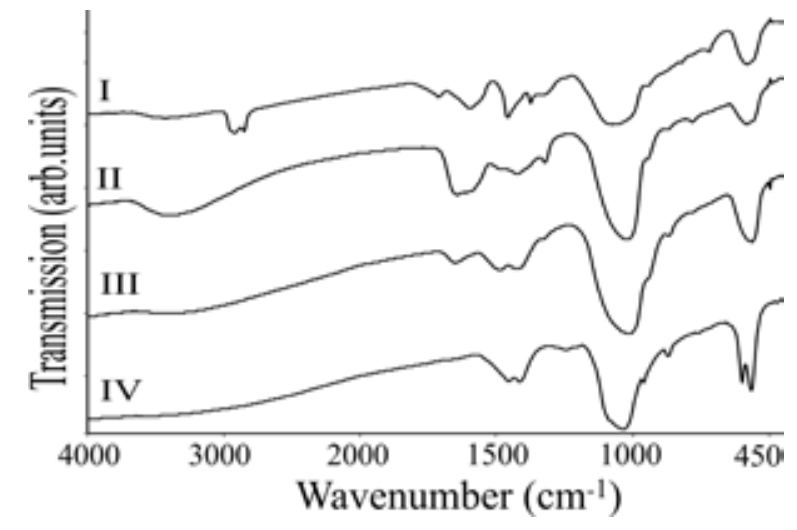

at 1087, $1032\left(v_{3}\right), 962\left(v_{1}\right), 602$, and $567 \mathrm{~cm}^{-1}\left(v_{4}\right)$. Furthermore, sharp carbonate bands $\left(v_{3}\right)$ at 1455 and $1416 \mathrm{~cm}^{-1}$ revealed that carbonate was mainly substituting for phosphate anions (type $\mathrm{B}$ substitutions) in a crystalline $\mathrm{CaP}$ environment. By means of XRD analysis, the crystalline apatitic structure of these coatings was confirmed (data not shown); main reflection lines were located at $25.8^{\circ}, 31.9^{\circ}$, and $32.9^{\circ} 2 \theta$, which correspond to (002), (211) and (300) reflections of the apatite structure ${ }^{16}$. This indicated that the as-deposited coatings remained amorphous up to deposition temperatures of $600{ }^{\circ} \mathrm{C}$, which was the temperature for crystallization of these B-type carbonate apatite (CA) coatings.

After an additional heat-treatment of the various as-deposited coatings at $650{ }^{\circ} \mathrm{C}$, all coatings transformed into crystalline CA coatings, irrespective of the original substrate temperature during coating deposition. No chemical differences were observed after heattreatment between the various deposition temperatures. As shown in Table 1, EDS analysis revealed that $\mathrm{Ca} / \mathrm{P}$ ratios of deposited coatings were higher than the initial $\mathrm{Ca} / \mathrm{P}$ solution ratio of 1.4 .

\begin{tabular}{|c|c|c|c|c|}
\hline Temperature $\left[{ }^{\circ} \mathrm{C}\right]$ & $\begin{array}{l}\text { Nozzle-to-substrate } \\
\text { distance }[\mathrm{mm}]\end{array}$ & $\begin{array}{l}\text { Flow rate } \\
{[\mathrm{ml} / \mathrm{h}]}\end{array}$ & Nozzle geometry & $\begin{array}{l}\text { Ca/P ratio of } \\
\text { coating }\end{array}$ \\
\hline 300 & 20 & 1.0 & two-component & $1.9-2.0$ \\
\hline 350 & 20 & 1.0 & two-component & $1.9-2.0$ \\
\hline 450 & 20 & 1.0 & two-component & $1.9-2.0$ \\
\hline 600 & 20 & 1.0 & two-component & $2.0-2.1$ \\
\hline 340 & 5 & 1.0 & two-component & $2.2-2.3$ \\
\hline 340 & 10 & 1.0 & two-component & $1.7-1.8$ \\
\hline 340 & 40 & 1.0 & two-component & $1.6-1.7$ \\
\hline 340 & 20 & 0.5 & two-component & $2.0-2.1$ \\
\hline 340 & 20 & 1.0 & two-component & $1.7-1.8$ \\
\hline 340 & 20 & 1.0 & one-component & $2.1-2.2$ \\
\hline 340 & 20 & 1.0 & two-component & $1.8-1.9$ \\
\hline
\end{tabular}

Table 1: Ca/P ratios of deposited coatings (after heat-treatment) as measured by EDS.

\subsection{INFLUENCE OF NOZZLE-TO-SUBSTRATE DISTANCE}

Figure $4 \mathrm{a}$ shows the FTIR spectra of heat-treated coatings, synthesized at different nozzle-to-substrate distances. At a high distance of $40 \mathrm{~mm}$, the FTIR spectrum revealed 

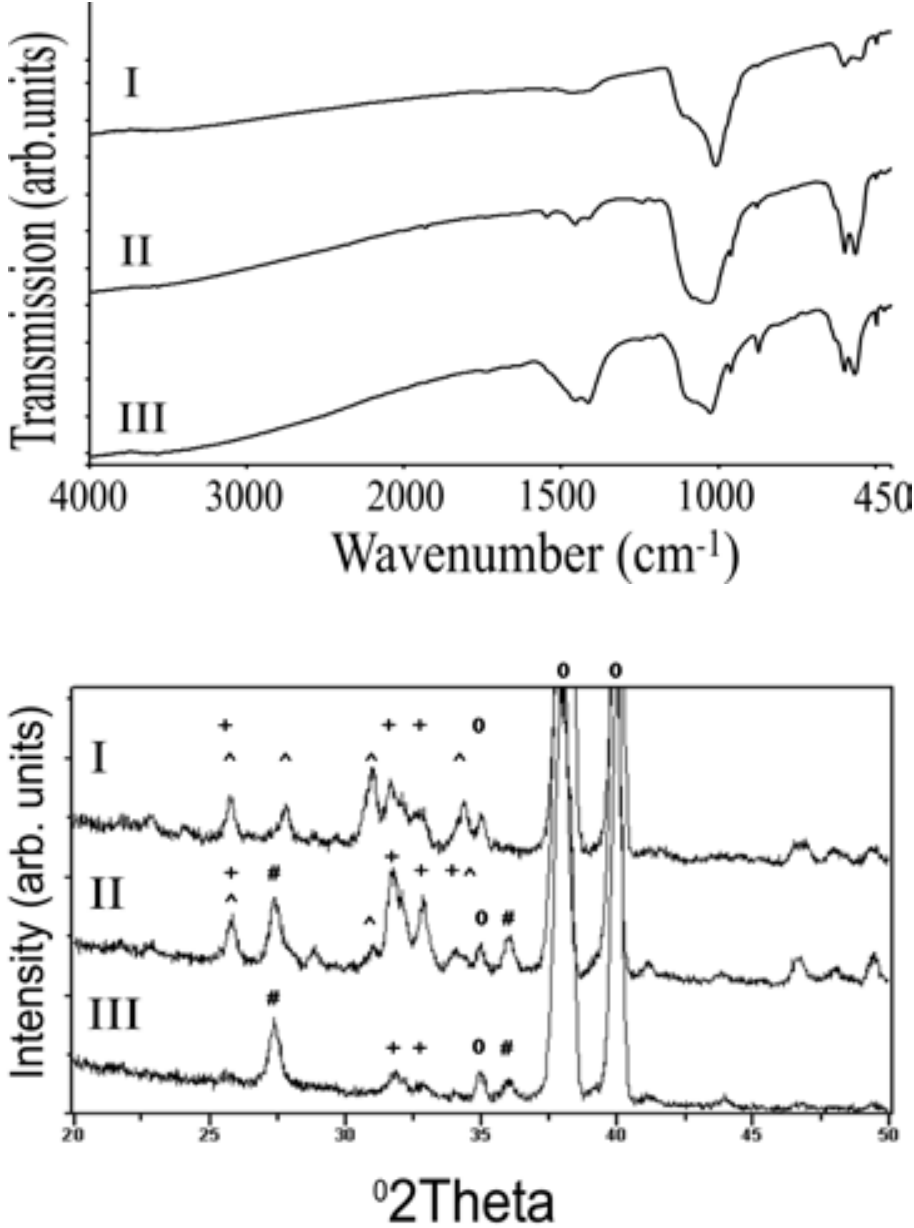

Figure 4 [a]: FTIR spectra of heat-treated CaP coatings, prepared by using ESD at different nozzle-to-substrate distances. [I] $40 \mathrm{~mm}$, [II] $10 \mathrm{~mm}$, and [III] $5 \mathrm{~mm}$. All coatings were heat-treated at $650^{\circ} \mathrm{C}$.
Figure $4[\mathrm{~b}]:$ XRD patterns of heat-treated CaP coatings, prepared by using ESD at different nozzle-to-substrate distances. [I] $40 \mathrm{~mm}$, [II] $10 \mathrm{~mm}$, and [III] $5 \mathrm{~mm}$. All coatings were heat-treated at $650^{\circ} \mathrm{C}$.

$+=$ carbonate apatite

$\wedge=\beta-T C P$

$0=T i$

$\#=$ rutile $\mathrm{TiO}_{2}$

characteristics of the $\beta$-tricalcium phosphate $\left(\beta\right.$-TCP) phase $\mathrm{e}^{13,16}$, such as phosphate absorptions (shoulders) at 1115, 972, and $945 \mathrm{~cm}^{-1}\left(v_{3}\right)$ and relatively broad $v_{4}$ phosphate absorptions at 602 and $551 \mathrm{~cm}^{-1}$. Hardly any carbonate was detected by means of FTIR. On the contrary, at a smaller distance of $10 \mathrm{~mm}, \mathrm{CO}_{3}$ absorption peaks at $879\left(v_{2}\right), 1414,1456$, and $1546\left(\mathrm{v}_{3}\right) \mathrm{cm}^{-1}$ indicated a considerable increase of carbonate incorporation. Absorption peaks at 1086, $1035\left(v_{3}\right), 962\left(v_{1}\right), 602$, and $567 \mathrm{~cm}^{-1}\left(v_{4}\right)$ were assigned to phosphate groups in a crystalline apatite lattice. Carbonate anions were substituted for both phosphate (B-type) and hydroxyl groups (A-type) in a crystalline apatite lattice ${ }^{13,16,17}$. At a small distance of $5 \mathrm{~mm}$, the intensity of the carbonate absorptions had increased significantly. Moreover, the absorption peak at $1546 \mathrm{~cm}^{-1}$ had disappeared, which corresponds to A-type carbonate-for-hydroxyl substitutions. This indicated that carbonate ions were substituting for phosphate groups only (B-type substitutions).

The corresponding XRD diffractograms are depicted in Figure 4b. At a high distance of $40 \mathrm{~mm}$, a phase mixture of $\beta$-TCP and CA was observed. Main reflection lines were located at $25.8^{\circ}, 27.8^{\circ}, 31.0^{\circ}$ and $34.3^{\circ} 2 \theta$ (matching with JCPDS File No. 9-169 of the $\beta$-TCP phase), and $25.8^{\circ}, 31.6^{\circ}, 32.1^{\circ}$ and $32.8^{\circ} 2 \theta$, which correspond to (002), (211), 
(112), and (300) reflections of the apatite structure ${ }^{13,16,17}$. At a smaller distance of $10 \mathrm{~mm}$, the heat-treated coatings consisted mainly of CA (main reflections located at $25.8^{\circ}, 31.7^{\circ}$, $32.1^{\circ}$ and $32.8^{\circ} 2 \theta$ ). However, a small shoulder at $31.0^{\circ} 2 \theta$ indicated that there was still a minor contamination of $\beta$-TCP. The reflections at 27.4 and $36.0^{\circ} 2 \theta$ corresponded to rutile $\left(\mathrm{TiO}_{2}\right)$ due to oxidation of the underlying substrate. At small distances of 5 and $10 \mathrm{~mm}$, the Ti substrates were not completely covered with $\mathrm{CaP}$ material. At a distance of $40 \mathrm{~mm}$, no bare $\mathrm{Ti}$ was left due to complete coating coverage and consequently less $\mathrm{TiO}_{2}$ was detected. At $5 \mathrm{~mm}$, the XRD pattern corresponded to CA (main reflections at $31.8^{\circ}, 32.1^{\circ}, 32.9^{\circ} 2 \theta$ ) without any impurity phases, except $\mathrm{TiO}_{2}$. The intensity of the diffraction peaks of the $\mathrm{CaP}$ coating was relatively low as a result of the small dimensions of the deposited CaP spot. EDS measurements showed that the $\mathrm{Ca} / \mathrm{P}$ ratio of the deposited coatings increased with decreasing nozzle-to-substrate distance (Table 1).

\subsection{INFLUENCE OF SPRAYING NOZZLE GEOMETRY}

FTIR spectra of heat-treated coatings, deposited using one- or two-component nozzle geometries, are shown in Figure 5a. Using a two-component nozzle, a small $v_{2}$ absorption at $879 \mathrm{~cm}^{-1}$ and three $v_{3}$ absorptions at 1411,1456 and $1547 \mathrm{~cm}^{-1}$ were assigned to carbonate groups substituting for hydroxyl (A-type) and phosphate groups (B-type). Phosphate

Figure 5 [a]: FTIR spectra of heat-treated CaP coatings, prepared by using ESD with different nozzle geometries: [I] two-component nozzle geometry and [II] onecomponent nozzle geometry. All coatings were heattreated at $650^{\circ} \mathrm{C}$.

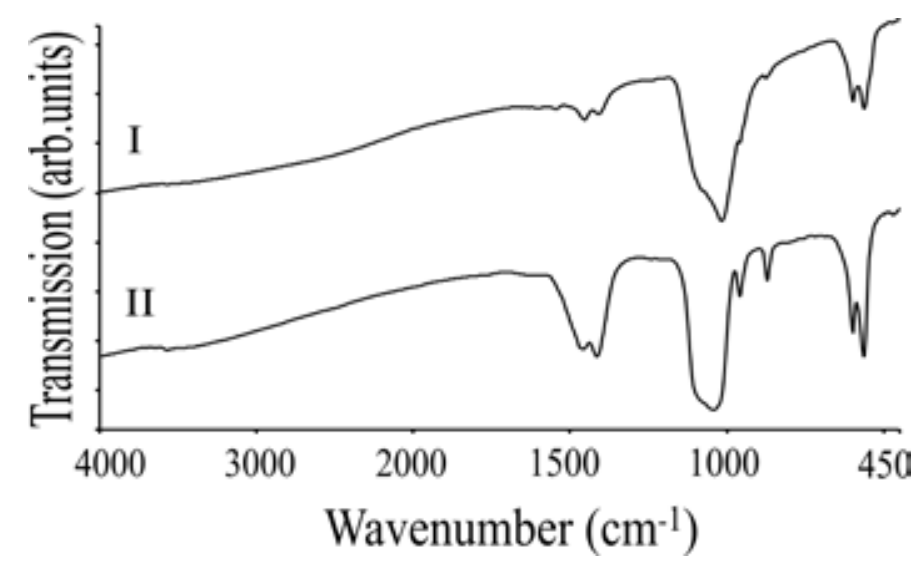

Figure $5[\mathrm{~b}]$ : XRD patterns of heat-treated CaP coatings, prepared by using ESD with different nozzle geometries: [I] two-component nozzle geometry and [II] onecomponent nozzle geometry. All coatings were heattreated at $650^{\circ} \mathrm{C}$.

$+=$ carbonate apatite
$\wedge=\beta-T C P$
$0=T i$

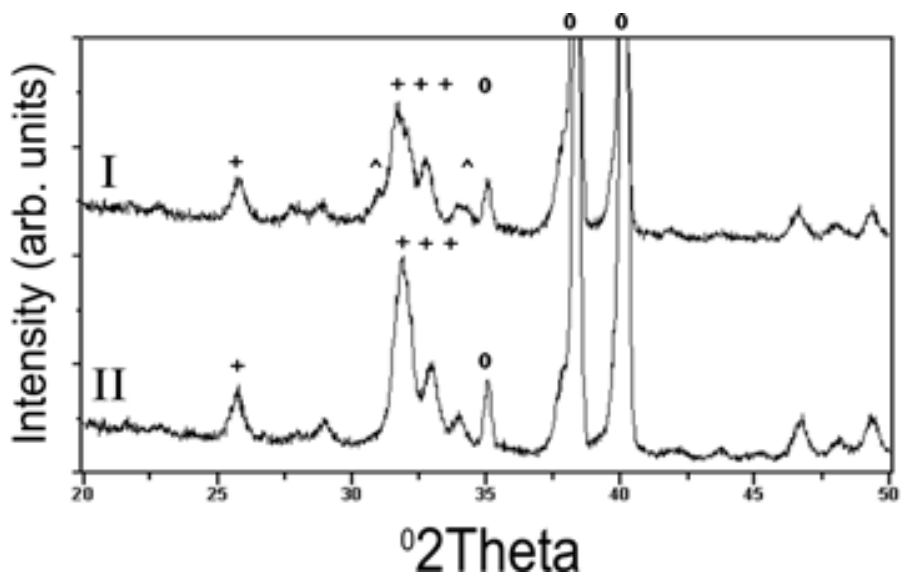


peaks were located at $1089\left(v_{3}\right), 1020\left(v_{3}\right), 961\left(v_{1}\right), 600\left(v_{4}\right)$, and $565 \mathrm{~cm}^{-1}\left(v_{4}\right)$. On the contrary, carbonate peaks were significantly more intense using a conventional one-component spraying nozzle. Further, only B-type substitutions were left (peaks at 1456 and 1416 $\mathrm{cm}^{-1}$ ), whereas absorption peaks corresponding to A-type substitutions were not detected. Phosphate absorptions were comparable to the two-component nozzle. The corresponding XRD diffractograms are shown in Figure 5b. Both patterns revealed main reflection lines at $25.8^{\circ}, 31.9^{\circ}, 32.8^{\circ}$ and $34.0^{\circ} 2 \theta$ of (carbonate) apatite. However, using the two-component nozzle, extra reflection peaks at $31.0^{\circ}$ and $34.3^{\circ} 2 \theta$ were assigned to the presence of a minor second phase: $\beta$-TCP. $\mathrm{Ca} / \mathrm{P}$ ratios of the deposited coatings were higher using one-component nozzles as compared to two-component nozzle geometries, as shown in Table 1.

\subsection{INFLUENCE OF LIQUID FLOW RATE}

Regarding the influence of the liquid flow rate on the molecular structure of deposited coatings, relevant FTIR spectra of heat-treated coatings are shown in Figure 6a.

At a flow rate of $1.0 \mathrm{ml} / \mathrm{h}$, a small $v_{2}$ absorption at $879 \mathrm{~cm}^{-1}$ and three $v_{3}$ absorptions at 1414,1456 and $1546 \mathrm{~cm}^{-1}$ were related to carbonate ions substituting for hydroxyl (A-type) and phosphate groups (B-type). Phosphate peaks were located at $1055\left(v_{3}\right), 961\left(v_{1}\right), 600$ $\left(v_{4}\right)$, and $567 \mathrm{~cm}^{-1}\left(v_{4}\right)$. At a lower flow rate of $0.5 \mathrm{ml} / \mathrm{h}$, carbonate peaks were consider-
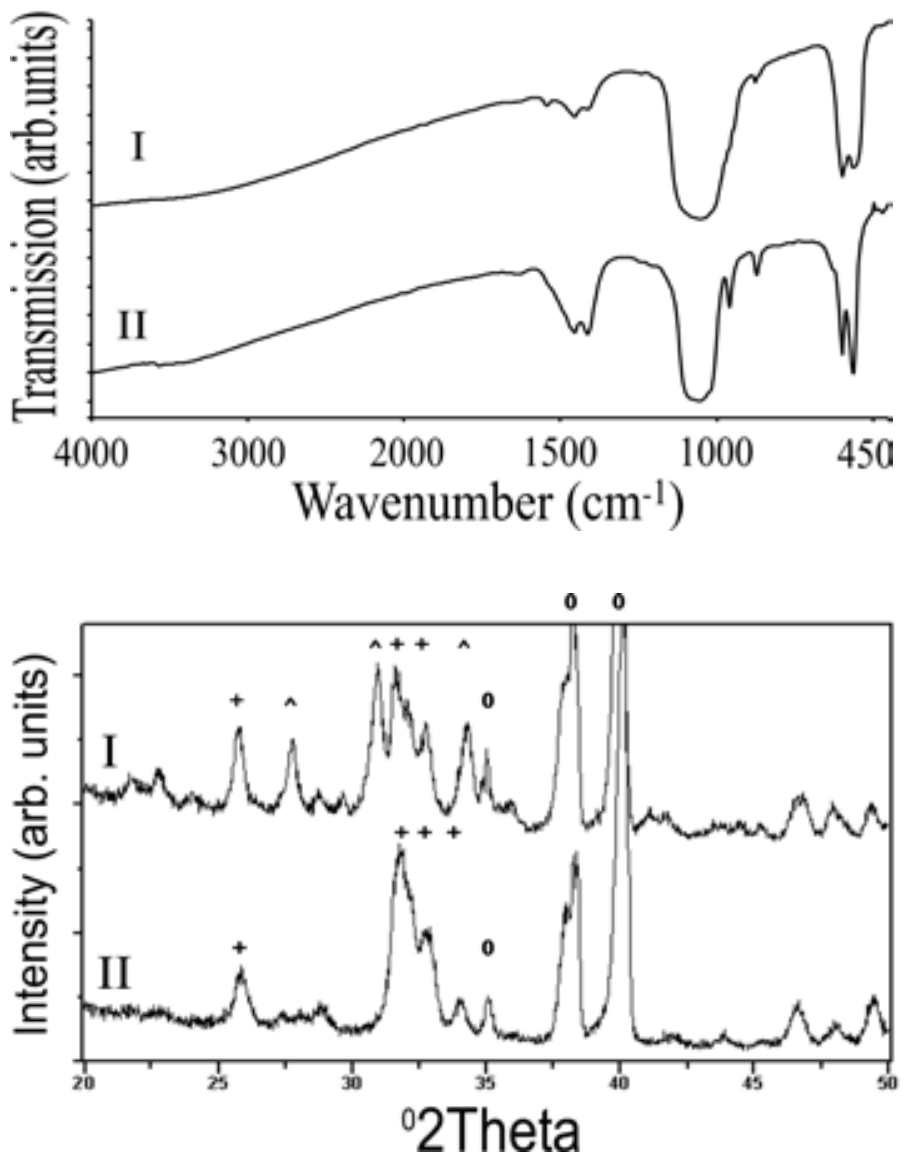

Figure 6 [a]: FTIR spectra of heat-treated CaP coatings, prepared by using ESD at different liquid flow rates: [I] $1.0 \mathrm{~mL} / \mathrm{h}$, and [II] 0.5 $\mathrm{mL} / \mathrm{h}$. All coatings were heattreated at $650^{\circ} \mathrm{C}$.

Figure $6[\mathrm{~b}]$ : XRD patterns of heat-treated CaP coatings, prepared by using ESD at different liquid flow rates: [I] $1.0 \mathrm{~mL} / \mathrm{h}$ and [II] 0.5 $\mathrm{mL} / \mathrm{h}$. All coatings were heattreated at $650^{\circ} \mathrm{C}$.

$+=$ carbonate apatite

$\wedge=\beta-T C P$

$0=T i$ 
ably more intense. Only B-type substitutions were left (peaks at 1456 and $1416 \mathrm{~cm}^{-1}$ ) and absorption peaks corresponding to A-type substitutions were not detected. At $0.5 \mathrm{ml} / \mathrm{h}$, phosphate absorptions were sharper than at the higher flow rate of $1.0 \mathrm{ml} / \mathrm{h}$.

$\mathrm{XRD}$ revealed that a phase mixture was deposited consisting of CA and a considerable amount of $\beta$-TCP using a flow rate of $1.0 \mathrm{ml} / \mathrm{h}$, whereas phase pure CA without any trace of $\beta$-TCP was deposited at a flow rate of $0.5 \mathrm{ml} / \mathrm{h}$ (Figure $6 \mathrm{~b}$ ). Correspondingly, $\mathrm{Ca} / \mathrm{P}$ ratios of deposited coatings were higher using low flow rates (Table 1).

\section{Discussion}

The main objective of the current study was to study the influence of several apparatusrelated deposition parameters on the chemical characteristics of $\mathrm{CaP}$ coatings deposited by means of the Electrostatic Spray Deposition (ESD) technique. The results clearly demonstrate that the crystal and molecular structure of ESD-deposited coatings are dependent on all selected apparatus-related deposition parameters.

\subsection{INFLUENCE OF DEPOSITION TEMPERATURE}

Information on the chemical formation mechanism of electrosprayed $\mathrm{CaP}$ coatings could be obtained by means of characterization of ESD-coatings, which were deposited at various deposition temperatures. Formation of electrosprayed $\mathrm{CaP}$ coatings was not just the result of solvent evaporation. At the minimum temperature of $300^{\circ} \mathrm{C}$, organic remnants of the solvent were still present. These remnants were absent at a deposition temperature of $350{ }^{\circ} \mathrm{C}$, whereas both oxalate $\left(\mathrm{C}_{2} \mathrm{O}_{4}{ }^{2-}\right)$ and carbonate $\left(\mathrm{CO}_{3}{ }^{2-}\right)$ anions were formed simultaneously. At a higher deposition temperature of $450{ }^{\circ} \mathrm{C}$, only carbonate ions were present and hardly any oxalate was left anymore. In a previous study, it was shown that carbonate anions play an essential role in controlling the chemical properties of ESD-derived CaP coatings ${ }^{8}$. Here, it was concluded that carbonate ions were formed via intermediate oxalate groups as the result of thermal decomposition of the organic solvent butyl carbitol. From literature, it is known that oxalate decomposes to carbonate around $425^{\circ} \mathrm{C}$ according to the following reaction ${ }^{18}$ :

$$
\mathrm{C}_{2} \mathrm{O}_{4}{ }^{2-} \rightarrow \mathrm{CO}_{3}^{2-}+\mathrm{CO}
$$

At a deposition temperature of $450{ }^{\circ} \mathrm{C}$, carbonate was still engaged in an amorphous environment. From XRD and FTIR analyses, it was concluded that these CaP coatings became crystalline upon deposition (B-type CA) at a temperature of $600{ }^{\circ} \mathrm{C}$. Generally, all coatings transformed into crystalline $\mathrm{CA}$ after an additional heat-treatment, irrespective of their initial deposition temperature, indicating that the deposition temperature did not influence the final chemical structure of heat-treated coatings.

\subsection{INFLUENCE OF NOZZLE-TO-SUBSTRATE DISTANCE}

From XRD and FTIR analyses it can be concluded that the chemical characteristics of ESD-derived CaP coatings are dependent on the nozzle-to-substrate distance at which the coatings were deposited. At a high distance of $40 \mathrm{~mm}$, a phase mixture of CA and $\beta$-TCP was formed with hardly any carbonate incorporation. At a smaller distance of $10 \mathrm{~mm}$, the carbonate content had increased and both A-type and B-type substitutions were detected 
by means of FTIR spectroscopy. At the smallest distance of $5 \mathrm{~mm}$, the intensity of carbonate absorptions had increased significantly and only B-type substitutions were detected. Several authors have shown also that carbonation in B-sites is favored at higher carbonate concentrations, whereas A-type substitutions occur mainly in slightly carbonated samples with carbonate contents of about 3 to $4 \mathrm{wt} \% 0^{17,19,20}$. Generally, the amount of carbonate incorporation decreased with increasing nozzle-to-substrate distance, resulting into lower $\mathrm{Ca} / \mathrm{P}$ ratios. Since carbonate was shown to derive from solvent decomposition reactions, it is suggested that solvent evaporation was more pronounced for large nozzle-to-substrate distances, resulting into lower amounts of carbonate incorporation.

\subsection{INFLUENCE OF SPRAYING NOZZLE GEOMETRY}

CaP coatings, deposited using a conventional one-component spraying nozzle, were characterized by a phase-pure CA crystal phase and a high carbonate content. On the contrary, low carbonate concentrations and low $\mathrm{Ca} / \mathrm{P}$ ratios were observed for coatings, deposited using a two-component nozzle, resulting into the presence of traces of $\beta$-TCP.

It is suggested that the observed chemical differences were caused by different precursor mixing times for both nozzle geometries. The two-component nozzle was designed to reduce the mixing time of the $\mathrm{Ca}$ and $\mathrm{P}$-precursors to a constant value of about 60 seconds at a flow rate of $1.0 \mathrm{ml} / \mathrm{h}$, whereas mixing times were equal to or even longer than the coating deposition times (typically 45 minutes) using a conventional one-component nozzle. In order to study the mixing behavior of the precursor solutions, experiments were carried out in which the $\mathrm{pH}$ of stirred and unstirred precursor solution mixtures was monitored during mixing. Generally, a pronounced and time-dependent $\mathrm{pH}$-drop of several $\mathrm{pH}$-values was observed for both stirred and unstirred precursor solution mixtures within the first few minutes of mixing ${ }^{21}$. In other words, the $\mathrm{H}^{+}$concentration increased upon mixing due to dissociation of protons from the polyprotic phosphoric acid. Consequently, the total negative charge of the (protonated) phosphate anions gradually increased upon mixing of both precursor solutions as a result of a time-dependent shift of the phosphate equilibrium towards the basic direction by transferring protons to the organic solvent butyl carbitol (BC):

$$
\mathrm{H}_{3} \mathrm{PO}_{4} \rightarrow \mathrm{PO}_{4}^{3-}+3 \mathrm{HBC}^{+}
$$

Due to the time-dependent equilibrium position of this reaction, the average negative charge of the phosphate ions in the spraying cone was expected to be larger using a onecomponent nozzle with a long mixing time as compared to a two-component nozzle with a short mixing time. This was confirmed by the observation that higher potential differences (about $1 \mathrm{kV}$ ) were needed for the one-component nozzle in order to obtain a stable cone-jet spraying mode. Thus, calcium and phosphate ions reacted at higher $\mathrm{Ca} / \mathrm{P}$ ratios using the one-component nozzle, since less phosphate ions were incorporated into the $\mathrm{CaP}$ coating due to their relatively high average charge.

\subsection{INFLUENCE OF LIQUID FLOW RATE}

CaP coatings, deposited using a low flow rate of $0.5 \mathrm{ml} / \mathrm{h}$, were characterized by a phase-pure CA crystal structure and more carbonate incorporation as compared to coatings, deposited using a higher flow rate of $1.0 \mathrm{ml} / \mathrm{h}$, which consisted of a phase mixture of CA and a considerable amount of $\beta$-TCP. As a result, $\mathrm{Ca} / \mathrm{P}$ ratios were lower at the higher flow rate. Again, the aforementioned time-dependent $\mathrm{pH}$-drop, occurring upon mixing of the 
two precursor solution components, was suggested to be responsible for this phenomenon. At a high flow rate of $1.0 \mathrm{ml} / \mathrm{h}$, the mixing time of the precursors (about $60 \mathrm{~s}$ ) was twice as short as compared to a flow rate of $0.5 \mathrm{ml} / \mathrm{h}$. As a consequence, the dissociation reaction yielding $\mathrm{H}^{+}$and acidic, negatively charged phosphate ions might not be completed yet in the spraying cone at a flow rate of $1.0 \mathrm{ml} / \mathrm{h}$, which could lead to a relatively low average charge of the phosphate anions. Consequently, calcium and phosphate ions reacted at lower $\mathrm{Ca} / \mathrm{P}$ ratios using high flow rates (Table 1 ).

\section{Conclusions}

Our results showed that the chemical characteristics of $\mathrm{CaP}$ coatings, deposited using the ESD technique, are strongly dependent on physical, apparatus-related parameters. By investigating the influence of the deposition temperature, information could be obtained on the formation mechanism of CaP coatings by means of the ESD-technique. Formation of $\mathrm{CaP}$ coatings was not just the result of solvent evaporation, and a chemical reaction was needed to synthesize the coatings. This reaction involved the thermal decomposition of the organic solvent butyl carbitol into carbonate ions via formation of intermediate oxalate ions. The influence of the nozzle-to-substrate distance on coating chemistry was unambiguous: carbonate incorporation and $\mathrm{Ca} / \mathrm{P}$ ratios decreased with increasing nozzle-to-substrate distance. Regarding the influence of nozzle geometry and liquid flow rate, it was concluded that the mixing characteristics of the calcium and phosphate precursor solutions are an important factor in controlling coating properties. Long mixing times at low flow rates and/or a one-component nozzle geometry using premixed precursor solutions resulted into more carbonate incorporation and higher $\mathrm{Ca} / \mathrm{P}$ ratios as compared to short mixing times. This effect could be explained by the time-dependent equilibrium position of the dissociation reaction, by which protons are removed from the polyprotic phosphoric acid yielding negatively charged, protonated phosphate groups. As a consequence, long mixing times were expected to correspond to a higher average negative charge of the phosphate ions in the spraying cone, resulting into less phosphate incorporation and higher $\mathrm{Ca} / \mathrm{P}$ ratios as compared to shorter mixing times.

In general, it was concluded that ESD is especially suitable in research focused on the fundamental relationship between $\mathrm{CaP}$ coating characteristics and biological coating performance due to the versatility of the technique regarding deposition of coatings with tailored chemical characteristics.

\section{References}

1. Osborn JF, Newesely H. Dynamic aspects of implant/bone interface. In: Heimke G, ed. Dental Implants. Munich: Carl Hansen Verlag, 1980. p. 111-123.

2. Lacefield WR. Hydroxylapatite coatings. In: Hench LL, Wilson J, eds. An introduction to bioceramics. Singapore: World Scientific Publishing Co., 1993. p. 223-238.

3. Hench LL, Ethridge EC. Biomaterials. New York: Academic Press, 1982.

4. Ducheyne P, Qiu Q. Bioactive ceramics: the effect of surface reactivity on bone formation and bone cell 
function. Biomaterials 1999;20:2287-2303.

5. LeGeros RZ. Biodegradation and bioresorption of calcium phosphate ceramics. Clin Mater 1993;14:6588 .

6. de Bruijn JD. Calcium phosphate biomaterials: bone-bonding and biodegradation properties. PhD Thesis. University of Leiden, Leiden, 1993.

7. Lacefield WR. Current status of ceramic coatings for dental implants. Implant Dent 1998;7:315-322.

8. Leeuwenburgh SCG, Wolke JGC, Schoonman J, Jansen JA. Influence of precursor solution parameters on chemical properties of calcium phosphate coatings prepared using Electrostatic Spray Deposition (ESD). Biomaterials 2004;25:641-649.

9. Cloupeau M, Prunet-Foch B. Electrohydrodynamic spraying functioning modes: a critical review. $J$ Aerosol Sci 1994;25:1021-1036.

10. Yoshinari M, Hayakawa T, Wolke JGC, Nemoto K, Jansen JA. Influence of rapid heating with infrared radiation on RF magnetron-sputtered calcium phosphate coatings. J Biomed Mater Res 1997;37:60-67.

11. Pouchert CJ. The Aldrich library of infrared spectra - Edition 3. Milwaukee: Aldrich Chemical company, 1981.

12. Hadjiivanov KI. Identification of neutral and charged $N_{x} O_{y}$ surface species by IR spectroscopy. Catal Rev Sci Eng 2000;42:71-144.

13. Koutsopoulos S. Synthesis and characterization of hydroxyapatite crystals: a review study on the analytical methods. J Biomed Mater Res 2002;62:600-612.

14. Layrolle P, Ito A, Tateishi T. Sol-gel synthesis of amorphous calcium phosphate and sintering into microporous hydroxyapatite bioceramics. J Am Ceram Soc 1998;81:1421-1428.

15. Kingsley RJ, van Gilder R, LeGeros RZ, Watabe N. Multimineral calcareous deposits in the marine alga acetabularia acetabulum (chlorophyta;dasycladaceae). J Phycol 2003;39:937-947.

16. LeGeros RZ. Calcium phosphates in oral biology and medicine. Basel: Karger, 1991.

17. Elliott JC. Structure and chemistry of the apatites and other calcium orthophosphates. Amsterdam: Elsevier, 1994.

18. Kloprogge JT, Boström TE, Weier ML. In situ observation of the thermal decomposition of weddelite by heating stage and environmental scanning electron microscopy. Amer Mineral 2004;89:245-248.

19. Nelson DGA, Featherstone JDB. Preparation, analysis and characterization of carbonated apatites. Calcif Tissue Int 1982;34:S69-S81.

20. El Feki H, Rey C, Vignoles M. Carbonate ions in apatites: infrared investigations in the $v_{4} \mathrm{CO}_{3}$ domain. Calcif Tissue Int 1991;49:269-274.

21. Leeuwenburgh SCG, Wolke JGC, Schoonman J, Jansen JA. Unpublished results 2002. 



\section{Introduction}

Bioactive materials such as calcium phosphate $(\mathrm{CaP})$ ceramics induce the formation of a strong interface between bone and the surface of orthopedic and dental implants, thereby creating a tight bonding to the surrounding osseous tissue ${ }^{1}$. As bulk material, however, $\mathrm{CaP}$ ceramics are intrinsically brittle and relatively weak in comparison to other implant metals, like titanium (Ti) and its alloys, and high strength ceramics, e.g. alumina and zirconia. Consequently, calcium phosphates are applied as coatings on mechanically strong implant materials in load-bearing implant applications in order to combine the mechanical strength of metals with the excellent biological properties of $\mathrm{CaP}$ ceramics ${ }^{2}$.

The bioactivity of $\mathrm{CaP}$ coatings is strongly related to the physicochemical properties of the implant material surface in vitro and in vivo upon exposure to body fluids. Considering the physical properties of biomaterial surfaces, a large number of in vitro studies show that increased surface roughness enhances attachment, proliferation and expression of different markers in osteogenic cells ${ }^{3-8}$. However, reports that do not show beneficial effects of increased surface roughness are also published ${ }^{9,10}$, indicating the controversy existing around this subject.

In order to study the influence of surface architecture of CaP coatings on the biological performance of osteogenic cells in vitro and in vivo, a new deposition technique, referred to as Electrostatic Spray Deposition (ESD), offers the possibility to deposit ceramic coatings with a variety of coating morphologies ${ }^{11,12}$. Briefly, the basic principle of ESD is the generation of a spray of charged, micron-sized droplets. This is accomplished by means of electrostatic atomization ${ }^{13}$ of precursor solutions that contain inorganic precursor salts. These spray droplets are directed towards a grounded and heated substrate as a result of the applied potential difference. After complete solvent evaporation, a thin inorganic layer is left onto the substrate surface.

In order to deposit biomedical CaP coatings with a defined surface morphology, the objective of the current study was to investigate the influence of three physical, apparatusrelated deposition parameters (nozzle-to-substrate distance, precursor liquid flow rate, and deposition temperature) on the morphology of electrosprayed $\mathrm{CaP}$ coatings. The selected parameters are supposed to influence the final properties of the coatings as follows: droplet size scaling laws predict that the average diameter of the generated aerosol droplets increases with increasing flow rate ${ }^{14}$. After droplet generation, evaporation rate and evaporation time are expected to depend on the deposition temperature and the nozzle-to-substrate distance, respectively.

\section{Materials and Methods}

\subsection{ELECTROSTATIC SPRAY DEPOSITION (ESD) PROCESS}

In the current study, a commercially available, vertical ESD set-up (Advanced Surface Technology, Bleiswijk, The Netherlands) was used to deposit CaP coatings. Figure 1 gives a schematic view of the set-up. In this unit, the spray is directed downwards from the nozzle to the heated substrate. A DC voltage supply (Fug, HCN 14-20000, Rosenheim, Germany) was used in order to generate a positive high potential difference between the nozzle and the grounded substrate. Heating of the substrates was regulated by a temperature-control- 
Figure 1: Experimental set-up of the Electrostatic Spray Deposition (ESD) technique.

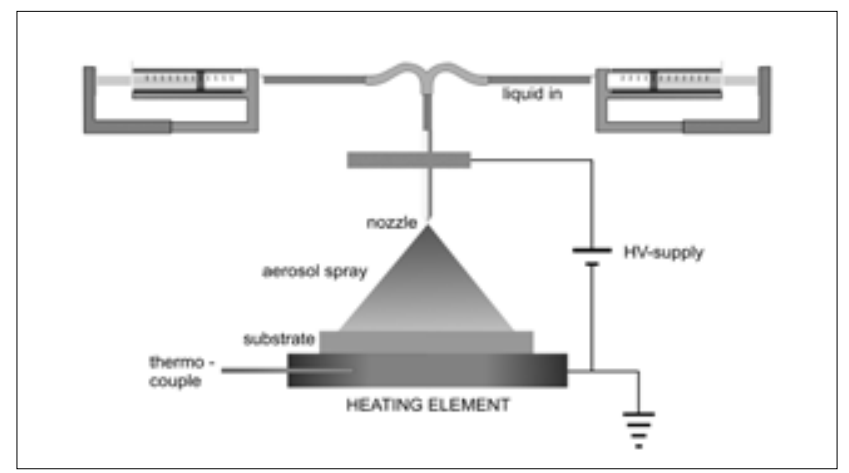

ling unit (Eurotherm Controls model 2216). Two precursor solutions containing $\mathrm{Ca}$ and $\mathrm{P}$ precursor salts were pumped separately towards a two-component stainless steel spraying nozzle (flat outlet, inner and outer diameter of 0.9 and $1.4 \mathrm{~mm}$, respectively) by means of a single syringe pump (Kd Scientific 220, New Hope, USA). This two-component nozzle with separate inlet for $\mathrm{Ca}$ and $\mathrm{P}$ precursors was used in order to avoid premature precipitation of the precursor solution prior to spray generation.

$\mathrm{Ca}$ and $\mathrm{P}$ precursor solutions were prepared by dissolving $\mathrm{Ca}\left(\mathrm{NO}_{3}\right)_{2} \cdot 4 \mathrm{H}_{2} \mathrm{O}(5 \mathrm{mM}$, Merck) and $\mathrm{H}_{3} \mathrm{PO}_{4}(3 \mathrm{mM}, 85 \mathrm{wt} \%$, J.T. Baker $)$ in butyl carbitol $\left(\mathrm{C}_{8} \mathrm{H}_{18} \mathrm{O}_{3}, 99 \%\right.$, Aldrich) at a fixed $\mathrm{Ca} / \mathrm{P}$ ratio of 1.67 . The deposition time was 60 minutes. A stable cone-jet mode of electrospraying was generated by adjusting the potential difference between the spraying nozzle and the substrate to values between 5.5 and $8.0 \mathrm{kV}$, depending on the specific set of deposition parameters. Machined, commercially pure Ti discs (diameter $12 \mathrm{~mm}$, thickness $1.5 \mathrm{~mm}$ ) were used as the substrate material for the deposition of the CaP coatings. The substrates were cleaned ultrasonically in acetone (15 minutes) and ethanol (15 minutes) prior to deposition.

\subsection{COATING DEPOSITION PARAMETERS}

The distance between the spraying nozzle and the substrate was varied between 10 and $30 \mathrm{~mm}$. The precursor flow rate was varied between 0.5 and $2.0 \mathrm{ml} / \mathrm{h}$ (equal flow rate for both $\mathrm{Ca}$ and $\mathrm{P}$ precursor solutions), whereas the substrate temperature was changed between 325 and $400{ }^{\circ} \mathrm{C}$. Relevant precursor solution parameters of the depositions are summarized in Table 1.

The thickness of the deposited coatings varied between 0.5 and $10 \mu \mathrm{m}$, depending on the nozzle-to-substrate distance and the liquid flow rate. After deposition, some of the coatings were subjected to additional heat-treatments in air at a temperature of $650{ }^{\circ} \mathrm{C}$ in an infrared furnace (E4-10-P, Research Inc., Minneapolis, USA ${ }^{15}$ in order to study the crystallization behavior of the $\mathrm{CaP}$ ceramic coatings.

\subsection{COATING CHARACTERIZATION}

The as-deposited and heat-treated ESD-coatings were characterized using the following techniques:

" Scanning Electron Microscopy (SEM): the surface morphology of the ESD-coatings was investigated using a JEOL 6310 SEM.

" Universal Surface Tester (UST): average surface roughness values $\left(\mathrm{R}_{\mathrm{a}}\right.$ ) were determined according to DIN standards (Deutsches Institut für Normung) using a Universal 
Surface Tester (UST, Innowep ${ }^{\circledR}$, Würzburg, Germany).

" X-Ray Diffraction (XRD): CaP coatings were subjected to X-Ray Diffraction (XRD) analysis on a thin-film Panalytical X-Ray Diffractometer using CuK $\alpha$-radiation (PW $3710,40 \mathrm{kV}, 40 \mathrm{~mA}$ ) in order to characterize the crystal structure of the deposited coatings. Coatings were analyzed by fixing the sample to a position of $2.5^{\circ}$ and scanning the detector between $20^{\circ} 2 \theta$ and $50^{\circ} 2 \theta$ with a step-size of $0.02^{\circ} 2 \theta$, a scanning speed of $0.01^{\circ} 2 \theta / \mathrm{s}$, and a sample time of $2 \mathrm{~s} / \mathrm{step}$.

- $\quad$ Fourier-Transform Infrared Spectrometry (FTIR): in order to characterize the molecular structure of the deposited coatings, infrared spectra of the films on the substrates were obtained from 4000 to $400 \mathrm{~cm}^{-1}$ by reflection Fourier-Transform Infrared Spectrometry (Spectrum One, Perkin-Elmer), since infrared radiation cannot pass through the Ti substrate.

\begin{tabular}{|c|c|c|c|}
\hline Study & $\begin{array}{l}\text { Nozzle-to-substrate } \\
\text { distance }[\mathrm{mm}]\end{array}$ & $\begin{array}{l}\text { Liquid flow rate } \\
{[\mathrm{ml} / \mathrm{h}]}\end{array}$ & $\begin{array}{l}\text { Deposition temperature } \\
{\left[{ }^{\circ} \mathrm{C}\right]}\end{array}$ \\
\hline \multirow{4}{*}{$\begin{array}{l}\text { Nozzle-to-substrate } \\
\text { distance }\end{array}$} & 10 & 1.0 & 400 \\
\hline & 15 & 1.0 & 400 \\
\hline & 20 & 1.0 & 400 \\
\hline & 30 & 1.0 & 400 \\
\hline \multirow{4}{*}{ Liquid flow rate } & 20 & 0.5 & 400 \\
\hline & 20 & 0.75 & 400 \\
\hline & 20 & 1.0 & 400 \\
\hline & 20 & 2.0 & 400 \\
\hline \multirow{4}{*}{$\begin{array}{l}\text { Deposition } \\
\text { temperature }\end{array}$} & 20 & 1.0 & 325 \\
\hline & 20 & 1.0 & 350 \\
\hline & 20 & 1.0 & 375 \\
\hline & 20 & 1.0 & 400 \\
\hline
\end{tabular}

Table 1: Deposition conditions used for the study of the influence of three deposition parameters (nozzle-to-substrate distance, precursor liquid flow rate, and deposition temperature) on morphological properties of electrosprayed CaP coatings.

\section{Results}

\subsection{COATING CRYSTAL PHASE AND MOLECULAR STRUCTURE}

$\mathrm{XRD}$ analysis showed that all as-deposited $\mathrm{CaP}$ coatings were amorphous. After infrared heat-treatment in air at $650^{\circ} \mathrm{C}$, these amorphous coatings were transformed into a crystalline apatitic $\mathrm{CaP}$ phase $\left(\mathrm{Ca}_{5}\left(\mathrm{PO}_{4}\right)_{3} \mathrm{X}\right)$, as shown in Figure 2. Main reflection lines were located at $25.8^{\circ}, 31.9^{\circ}$ and $32.9^{\circ} 2 \theta$, which correspond to (002), (211), and (300) reflections of the apatite structure.

The FTIR spectrum of the same heat-treated coating is shown in Figure 3. This spectrum also corresponds to a crystalline apatitic phase, indicated by the presence of degenerated bending modes $\left(v_{4}\right)$ of the phosphate group at 600 and $565 \mathrm{~cm}^{-1}$. Other phosphate absorption peaks were located at $962 \mathrm{~cm}^{-1}\left(v_{1}\right)$ next to an intense $v_{3}$ peak at $1053 \mathrm{~cm}^{-1}$. Carbonate absorption peaks at 1464 and $1418 \mathrm{~cm}^{-1}\left(v_{3}\right)$ and $873 \mathrm{~cm}^{-1}\left(v_{2}\right)$ indicated that carbonate ions were incorporated into the apatite lattice. Carbonate was mainly substitut- 
Figure 2: XRD pattern of an electrosprayed $\mathrm{CaP}$ coating after heat-treatment at $650^{\circ} \mathrm{C}$.

* = carbonate apatite

$0=$ rutile $\mathrm{TiO}_{2}$

$+=T i$
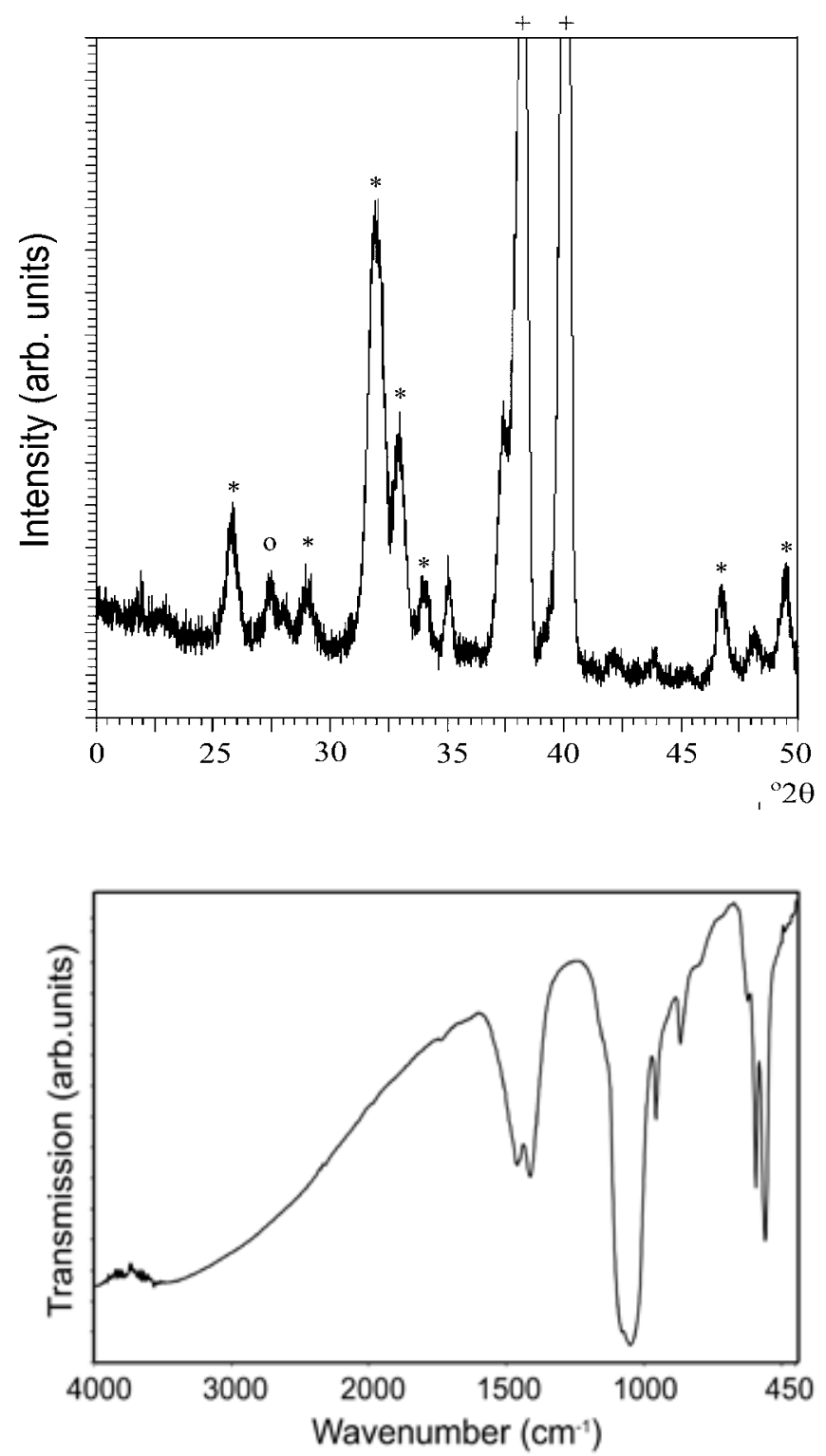

Figure 3: FTIR spectrum of an electrosprayed CaP coating after heat-treatment at $650^{\circ} \mathrm{C}$.

ing for phosphate anions (type B carbonate apatite). These carbonate ions originated from a decomposition reaction of the solvent butyl carbitol, a phenomenon that was studied in more detail in a previous study on ESD-deposited CaP coatings ${ }^{16}$.

\subsection{INFLUENCE OF NOZZLE-TO-SUBSTRATE DISTANCE ON COATING MORPHOLOGY}

Figure 4 shows the influence of various nozzle-to-substrate distances on the morphology of the deposited CaP coatings at a small (Figures 4a-d) and high (Figures 4e-h) magnification. At a short distance of $10 \mathrm{~mm}$ (Figures $4 \mathrm{a}+\mathrm{e}$ ), a rather flat, homogeneous coating containing submicron-sized pores was deposited. At a larger distance of $15 \mathrm{~mm}$ (Figures 


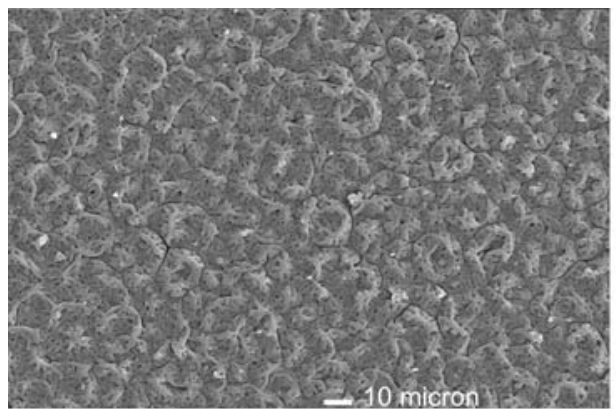

$4 \mathrm{a}$

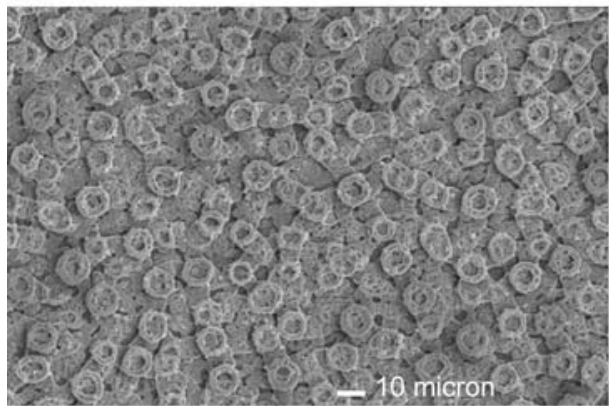

$4 \mathrm{c}$

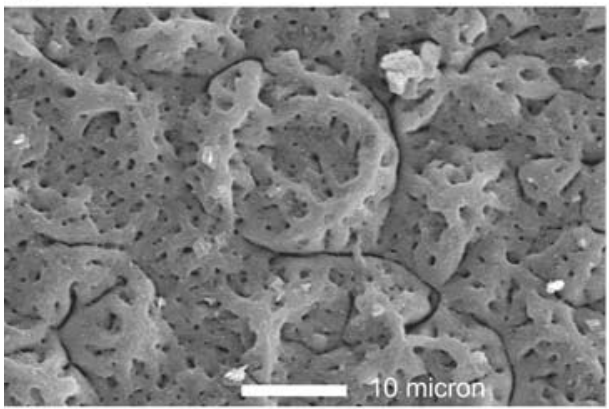

$4 \mathrm{e}$

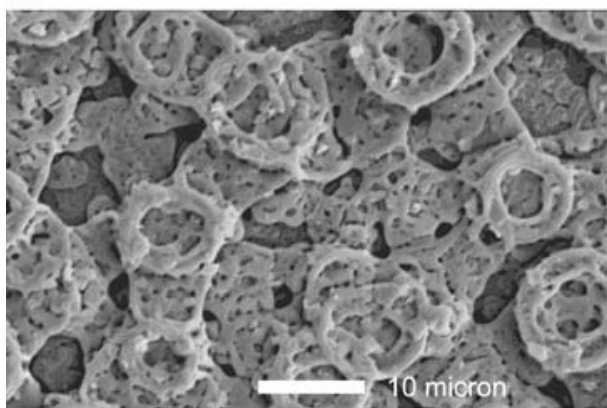

$4 \mathrm{~g}$

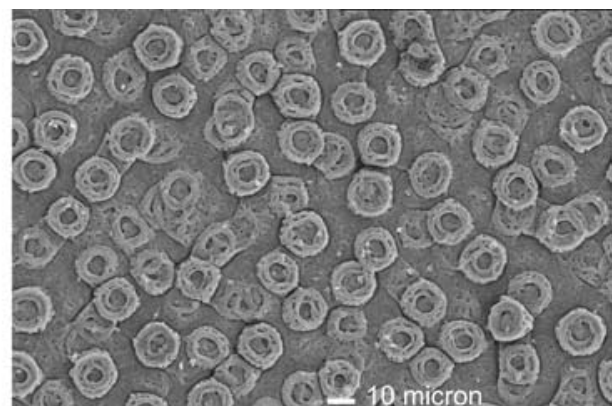

$4 \mathrm{~b}$

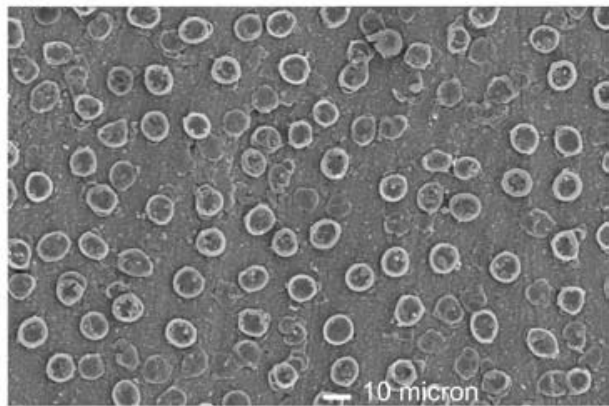

$4 \mathrm{~d}$

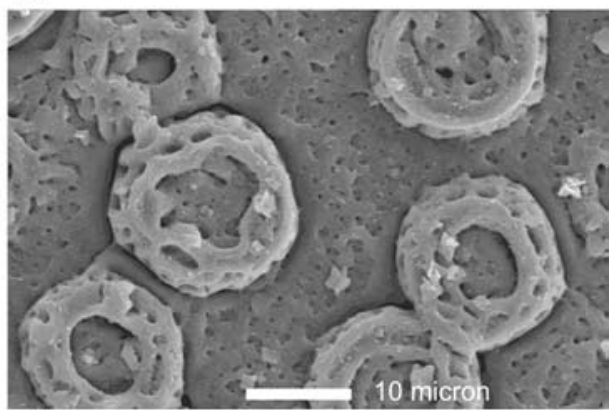

$4 \mathrm{f}$

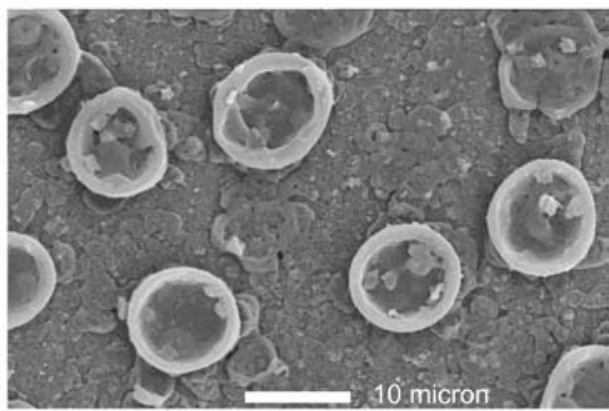

$4 \mathrm{~h}$

Figure 4: Scanning electron micrographs of electrosprayed CaP coatings at low [a-d] and high [e-h] magnification, prepared at different nozzle-to-substrate distances: [a] and [e] nozzle-to-substrate distance of $10 \mathrm{~mm} ;[\mathrm{b}]$ and [f] nozzle-to-substrate distance of $15 \mathrm{~mm}$; [c] and [g] nozzle-to-substrate distance of $20 \mathrm{~mm}$; [d] and [h] nozzle-to-substrate distance of $30 \mathrm{~mm}$. Bar size $10 \mu \mathrm{m}$. 


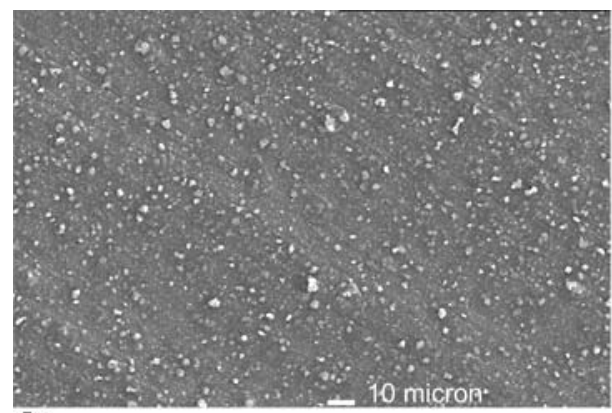

$5 \mathrm{a}$

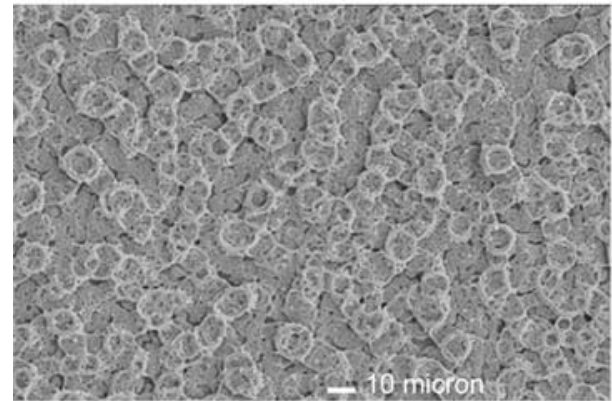

$5 \mathrm{c}$

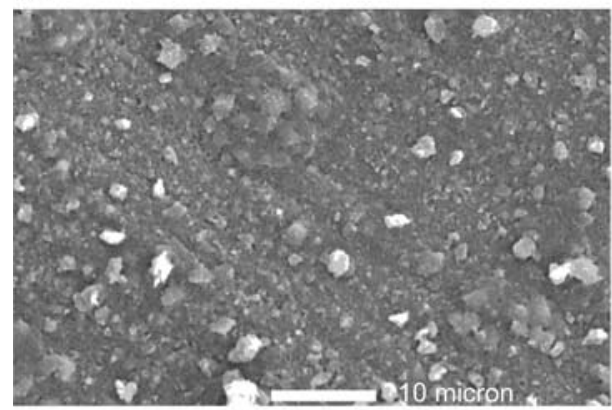

$5 \mathrm{e}$

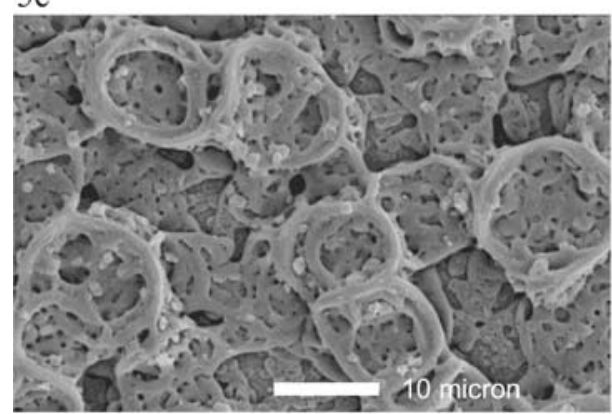

$5 \mathrm{~g}$

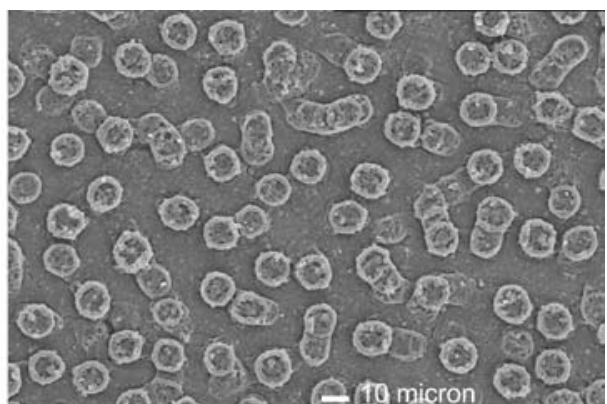

$5 b$

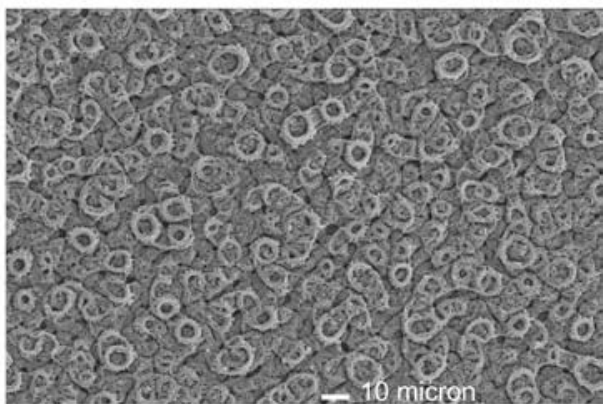

$5 \mathrm{~d}$

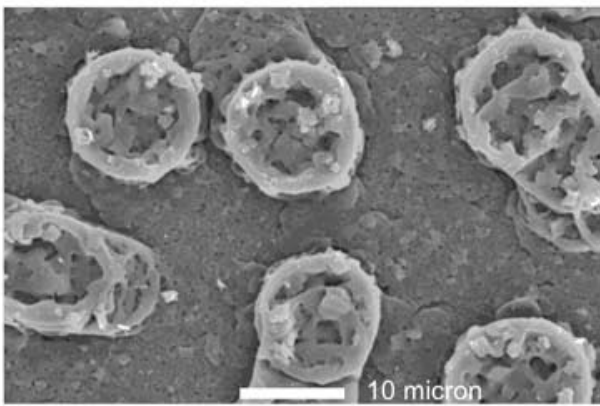

$5 \mathrm{f}$

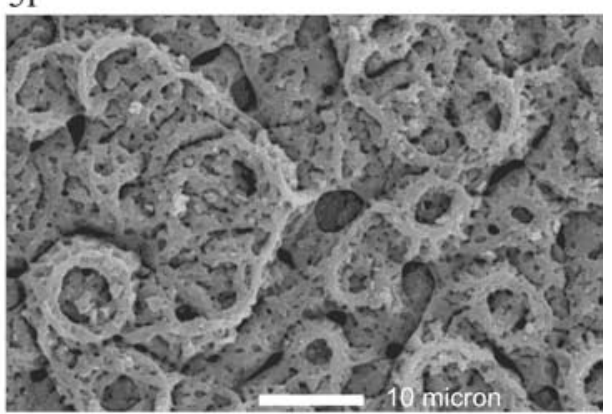

$5 \mathrm{~h}$

Figure 5: Scanning electron micrographs of electrosprayed CaP coatings at low [a-d] and high [e-h] magnification, prepared at different precursor liquid flow rates: [a] and [e] flow rate of $0.5 \mathrm{ml} / \mathrm{h} ;[\mathrm{b}]$ and $[f]$ flow rate of $0.75 \mathrm{ml} / \mathrm{h} ;[\mathrm{c}]$ and $[\mathrm{g}]$ flow rate of $1.0 \mathrm{ml} / \mathrm{h}$; [d] and [h] flow rate of $2.0 \mathrm{ml} / \mathrm{h}$. Bar size $10 \mu \mathrm{m}$. 
$4 \mathrm{~b}+\mathrm{f}$ ), ring-shaped protuberances with diameters of up to $15 \mu \mathrm{m}$ emerged from the microporous underlayer. Coatings deposited at a larger distance of $20 \mathrm{~mm}$ (Figures $4 \mathrm{c}+\mathrm{g}$ ) also revealed these circular protuberances on top of a microporous underlayer. However, their average diameter was shrunk to less than $12 \mu \mathrm{m}$. At the largest distance of $30 \mathrm{~mm}$ (Figures $4 d+h$ ), the surface morphology of the deposited coating was characterized by a low number density of dense doughnuts on top of a thin underlayer (doughnut diameters of up to 10 $\mu \mathrm{m})$. No porosity was observed in both the doughnut walls and the underlayer.

$R_{a}$ values of the flat coating morphologies, deposited at a small distance of $10 \mathrm{~mm}$, were in the same range $(0.3-0.4 \mu \mathrm{m})$ as $\mathrm{R}_{\mathrm{a}}$ values of the uncoated Ti-substrates. Higher $\mathrm{R}_{\mathrm{a}}$ values were measured for coatings, deposited at higher nozzle-to-substrate distances (0.6-1.0 $\mu \mathrm{m})$.

\subsection{INFLUENCE OF PRECURSOR LIQUID FLOW RATE ON COATING MORPHOLOGY}

Figure 5 shows the influence of various precursor liquid flow rates on the morphology of the deposited CaP coatings at small (Figures 5a-d) and high (Figures 5e-h) magnification. At a low flow rate of $0.5 \mathrm{ml} / \mathrm{h}$ (Figures $5 \mathrm{a}+\mathrm{e}$ ), a coating morphology without any particular features was observed. On the contrary, ring-shaped protuberances on top of a rather dense underlayer were deposited at a larger flow rate of $0.75 \mathrm{ml} / \mathrm{h}$ (Figures $5 \mathrm{~b}+\mathrm{f}$ ). Increasing the flow rate further to $1.0 \mathrm{ml} / \mathrm{h}$ (Figures $5 \mathrm{c}+\mathrm{g}$ ) resulted into a more flattened coating morphology, where the ring-shaped protuberances were almost sunk into a microporous underlayer. At an even larger flow rate of $2.0 \mathrm{ml} / \mathrm{h}$ (Figures $5 \mathrm{~d}+\mathrm{h}$ ), a disordered, porous coating morphology was obtained. Although some characteristics of a coating composed of circular protuberances were still recognizable, no clear separation could be made anymore between a dense/microporous underlayer and a particle-like surface toplayer. $\mathrm{R}_{\mathrm{a}}$ values of the deposited coatings varied between 0.5-0.7 $\mu \mathrm{m}$.

\subsection{INFLUENCE OF DEPOSITION TEMPERATURE ON COATING MORPHOLOGY}

Figure 6 shows the influence of various deposition temperatures on the morphology of the deposited CaP coatings at small (Figures 6a-d) and high (Figures 6e-h) magnification. At a low depositon temperature of $325^{\circ} \mathrm{C}$ (Figures $6 \mathrm{a}+\mathrm{e}$ ), a flat, homogeneous coating morphology was deposited, although this flat coating type was covered by low, linear protuberances instead of circular ones. Microcracks were induced in these dense coatings by thermal stresses due to rapid heating and cooling as a result of infrared heat-treatments. Increasing the deposition temperature to $350^{\circ} \mathrm{C}$ (Figures $6 \mathrm{~b}+\mathrm{f}$ ) yielded a reticular coating morphology characterized by an interconnected pore network resembling a sponge structure. On the contrary, doughnuts were observed on top of a homogeneous underlayer at a higher deposition temperature of $375^{\circ} \mathrm{C}$ (Figures $6 \mathrm{c}+\mathrm{g}$ ). The various doughnuts were interconnected by microporous patterns along the surface of a rather dense underlayer. At a high deposition temperature of $400{ }^{\circ} \mathrm{C}$ (Figures $6 \mathrm{~d}-\mathrm{h}$ ), the coating had a roughened morphology characterized by irregularly shaped rings on top of disordered underlayer.

$\mathrm{R}_{\mathrm{a}}$ values of the flat coating morphologies, obtained at a low temperature of $325^{\circ} \mathrm{C}$, were comparable to $R_{a}$ values of the uncoated Ti-substrates $(0.3-0.4 \mu \mathrm{m})$. Higher $\mathrm{R}_{\mathrm{a}}$ values were measured for the coatings, deposited at higher deposition temperatures $(0.5-0.6$ $\mu \mathrm{m})$. 


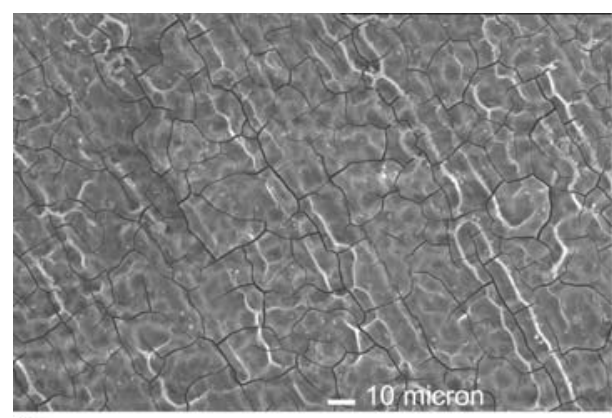

$6 \mathrm{a}$

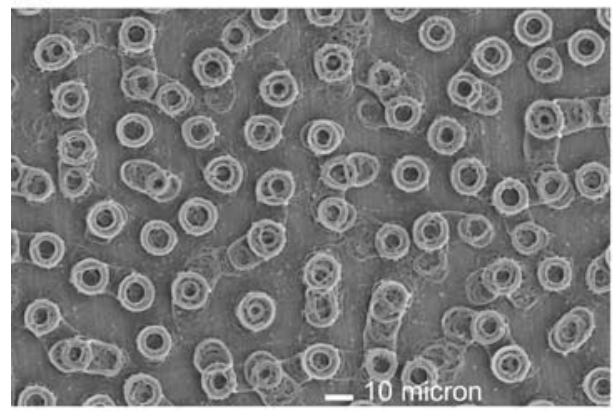

$6 \mathrm{c}$

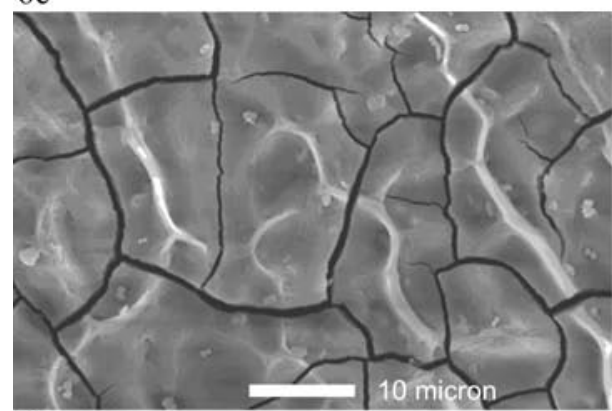

$6 \mathrm{e}$

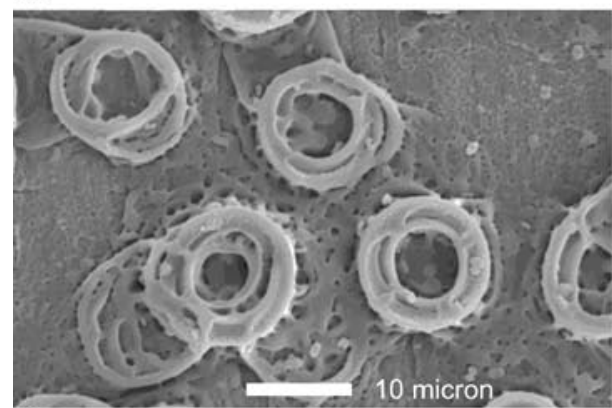

$6 \mathrm{~g}$

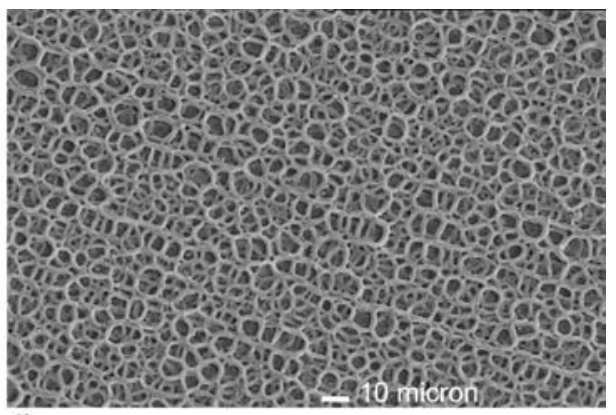

$6 \mathrm{~b}$

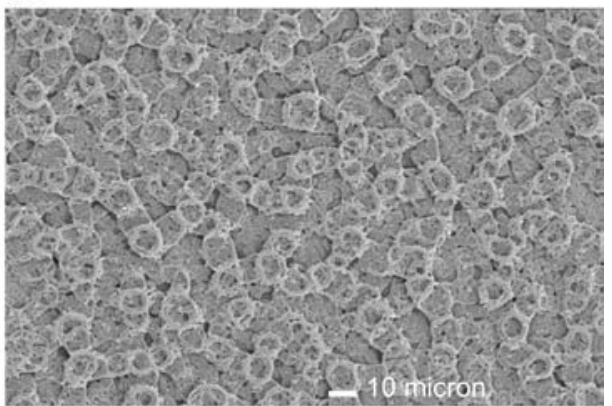

$6 \mathrm{~d}$

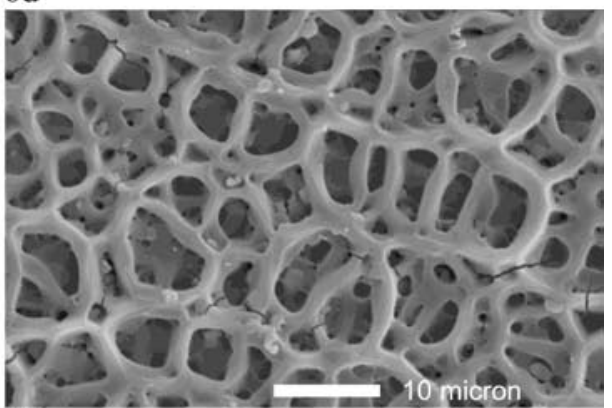

$6 f$

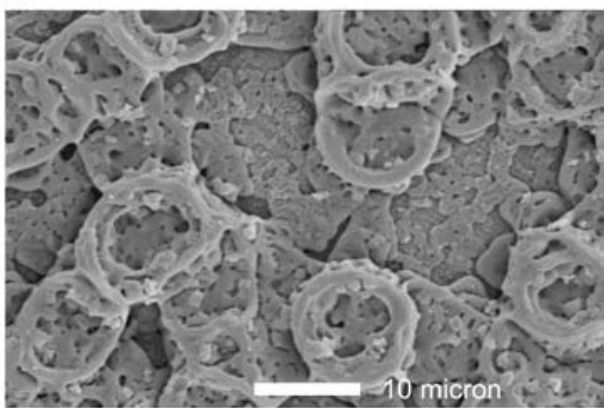

$6 \mathrm{~h}$

Figure 6: Scanning electron micrographs of electrosprayed CaP coatings at low [a-d] and high $[e-h]$ magnification, prepared at different deposition temperatures: [a] and [e] deposition temperature of $325{ }^{\circ} \mathrm{C}$; [b] and [f] deposition temperature of $350{ }^{\circ} \mathrm{C} ;[\mathrm{c}]$ and $[\mathrm{g}]$ deposition temperature of $375{ }^{\circ} \mathrm{C} ;[\mathrm{d}]$ and $[\mathrm{h}]$ deposition temperature of $400^{\circ} \mathrm{C}$. Bar size $10 \mu \mathrm{m}$. 


\section{Discussion}

The objective of the current study was to examine the influence of three specific deposition parameters on the morphological properties of electrosprayed $\mathrm{CaP}$ coatings. The results clearly demonstrate that $\mathrm{CaP}$ coatings can be deposited with a wide variety of surface morphologies using ESD as deposition technique.

\subsection{COATING CRYSTAL AND MOLECULAR STRUCTURE}

$\mathrm{XRD}$ and FTIR analysis revealed that as-deposited $\mathrm{CaP}$ coatings were transformed into crystalline carbonate apatite coatings upon heat-treatment. This $\mathrm{CaP}$ phase is particularly interesting due to its chemical resemblance to bone mineral, which is essentially a carbonatecontaining apatitic $\mathrm{CaP}$ phase.

\subsection{INFLUENCE OF NOZZLE-TO-SUBSTRATE DISTANCE ON COATING MORPHOLOGY}

The results showed that flat coating morphologies with a low surface roughness parameter $\mathrm{R}_{\mathrm{a}}$ were obtained at short distances between the nozzle and substrate, indicating that the spray droplets reached the substrate surface in a wet condition. This phenomenon can be attributed to the short flight time of the droplets and the high boiling point of the solvent butyl carbitol of $231^{\circ} \mathrm{C}$. Consequently, droplets with a long time of residence upon the substrate surface were able to spread out over large distances prior to complete solvent evaporation and solute deposition. As a result, rather smooth layers containing a considerable amount of sub-micron sized pores were deposited. We suggest that two phenomena might be responsible for this porosity. First of all, solvent boiling on the substrate surface during coating formation could yield this porosity. Secondly, in a previous study on ESDdeposited CaP coatings ${ }^{16}$, it was argued that $\mathrm{CO}_{2}$ gas is developed upon reaction between acid $\mathrm{HPO}_{4}{ }^{2-}$ and basic $\mathrm{CO}_{3}{ }^{2-}$ groups. These $\mathrm{CO}_{2}$ gas bubbles could also be responsible for the produced submicron-porosity.

However, irregular morphologies, characterized by ring-shapes or doughnuts on top of a porous or dense underlayer, were deposited at higher nozzle-to-substrate distances. Higher $\mathrm{R}_{\mathrm{a}}$ values of up to $1.0 \mu \mathrm{m}$ were measured due to the presence of these protruding irregularities. This seems to indicate that solute precipitation occurred already inside the droplets during droplet flight. The following mechanism is proposed to account for the formation of these ring- or doughnut-like shapes. From literature ${ }^{17-20}$ it is known that the solvent evaporation of aerosol droplets, which are moving relative to the ambient, is faster on the leading surface of the droplet. Therefore, the solute concentration is higher at the front surface of the droplet and crust formation starts at the frontside when the surface concentration exceeds the equilibrium saturation. Subsequently, the crust grows at the front without any precipitation at the droplet backside, since the evaporation rate is much smaller at this location. Depending on the total amount of solute and the drying conditions, the crust grows further and a cup-shaped particle is created with a certain wall thickness. A schematic representation of the formation of these ring- and doughnut-like shapes is depicted in Figure 7.

Regarding the electrosprayed CaP coatings, the droplet flight time and drying time were increased with increasing nozzle-to-substrate distance. Consequently, the size of the droplets was expected to decrease with increasing nozzle-to-substrate distance, whereas the shape of the deposited droplets changed from flat rings with thick but porous walls towards 
Figure 7: Development of doughnut shapes bymeans of solute precipitation inside spray droplets.

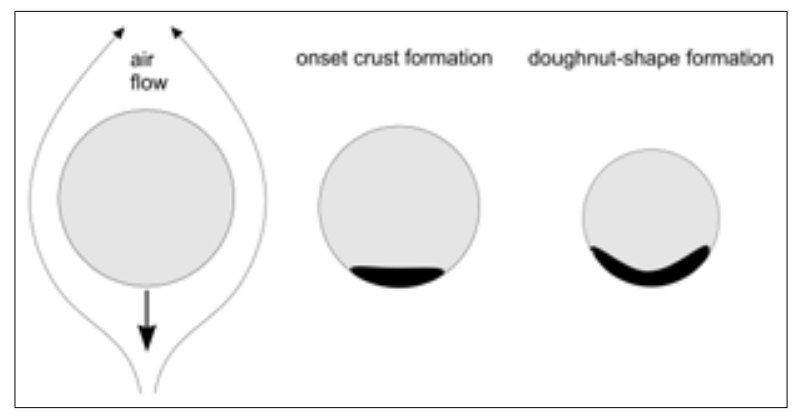

doughnut-shapes with thin but dense and relatively high walls. The number of these ringor doughnut-shapes decreased with increasing nozzle-to-substrate distance, as the spray became more diluted with increasing distance from the spray origin.

\subsection{INFLUENCE OF PRECURSOR LIQUID FLOW RATE ON COATING MORPHOLOGY}

At a low flow rate of $0.5 \mathrm{ml} / \mathrm{h}$, a coating morphology without any droplet-like features was obtained, such as ring-shapes or doughnuts. On the contrary, droplet-like features were observed again at higher flow rate of $0.75 \mathrm{ml} / \mathrm{h}$. With increasing flow rate, the size of these circular features remained about the same size. This is in contrast to the expected increase in diameter of the ring-shapes, as the diameter of the generated spray droplets theoretically increases with flow rate ${ }^{14}$. Upon further increase of the flow rate, coatings became more flattened with less protruding ring-shapes. The coating thickness is of course higher for depositions carried out at higher flow rates, since all other deposition parameters are kept constant. As a result, the circular irregularities were overgrown with an abundance of $\mathrm{CaP}$ material. Generally, the results show that the morphology of an ESD-deposited CaP coating is dependent on its layer thickness.

\subsection{INFLUENCE OF DEPOSITION TEMPERATURE ON COATING MORPHOLOGY}

Using a low deposition temperature of $325^{\circ} \mathrm{C}$, dense morphologies were obtained with a low surface roughness parameter $\mathrm{R}_{\mathrm{a}}$, indicating that solvent evaporation rate was reduced. Droplets arrived at the substrate surface in wet condition and were able to spread out intensively, thereby depositing the $\mathrm{CaP}$ solute over large distances prior to complete solvent evaporation. However, linearly protruding walls emerging from the smooth underlayer were still indicating that the concentration of the solute in the spray droplets was not uniform throughout the solvent evaporation period of the droplets prior to and after droplet landing ${ }^{18}$.

At a higher deposition temperature of $350{ }^{\circ} \mathrm{C}$, a spongy coating morphology was obtained, characterized by a homogeneous appearance without any singular droplet-like features, such as ring- or doughnuts-shapes. This means that the spray droplets were still able to spread out over the substrate surface to some extent, although the solvent evaporation rate was clearly higher. Droplet spreading seemed to be accompagnied by coalescence of the walls of the rings, yielding an interconnected pore network. At $375^{\circ} \mathrm{C}$, separated, singular ring-shapes were clearly recognizable, reflecting an increased solvent evaporation rate and reduced droplet spreading distances. At the highest temperature of $400{ }^{\circ} \mathrm{C}$, 
randomly distributed and irregularly shaped rings seemed to indicate that severe solvent evaporation occurred before droplet landing, resulting into a restricted droplet spreading mobility.

\section{Conclusions}

The results showed that the morphology of CaP coatings, deposited using the ESD technique, can be influenced to a large extent by adjusting various deposition parameters. By changing the nozzle-to-substrate distance, the precursor liquid flow rate and the deposition temperature, several coating morphologies were deposited, which varied from relatively dense to highly porous, reticular morphologies. Generally, droplet-like features were recognizable in almost all types of morphology in terms of separated rings, doughnut-shapes or interconnected pores, reflecting that droplets were the building units of the various coating morphologies using the ESD technique. The formation of various morphologies was the result of an equilibrium between the relative rates of $\mathrm{CaP}$ solute precipitation/reaction, solvent evaporation and droplet spreading on the substrate surface. Homogeneous and uniform coating morphologies were obtained under wet deposition conditions, if droplet spreading distances were large and solute precipition occurred at the substrate surface. On the contrary, coating morphologies revealing separated droplet-like features were deposited under dry conditions. Under these conditions, droplet spreading was reduced and solute precipition was suggested to start already during droplet flight.

\section{References}

1. Osborn JF, Newesely H. Dynamic aspects of implant/bone interface. In: Heimke G, ed. Dental Implants. Munich: Carl Hansen Verlag, 1980. p. 111-123.

2. Lacefield WR. Hydroxylapatite coatings. In: Hench LL, Wilson J, eds. An introduction to bioceramics. Singapore: World Scientific Publishing Co., 1993, p. 223.

3. Deligianni DD, Katsala N, Ladas S, Sotiropoloulou D, Amedee J, Missirlis YF. Effect of surface roughness of the titanium alloy Ti-6Al-4V on human bone marrow cell response and on protein adsorption. Biomaterials 2001;22:1241-1251.

4. Deligianni DD, Katsala N, Koutsoukos PG, Missirlis YF. Effect of surface roughness of hydroxyapatite on human bone marrow cell adhesion, proliferation, differentiation and detachment strength. Biomaterials 2001;22:87-96.

5. Degasne I, Baslé MF, Demais V, Huré G, Lesourd M, Grolleau G, Mercier L, Chappard D. Effects of roughness, fibronectin and vitronectin on attachment, spreading, and proliferation of human osteoblastlike cells (Saos-2) on titanium surfaces. Calcif Tissue Int 1999;64:499-507.

6. Bigerelle M, Anselme K, Noel B, Ruderman I, Hardouin P, Iost A. Improvement in the morphology of Ti-based surfaces: a new process to increase in vitro human osteoblast response. Biomaterials 2002;23:1563-1577.

7. Lincks J, Boyan BD, Blanchard CR, Lohmann CH, Liu Y, Cochran DL, Dean DD, Schwartz Z. Response of MG63 osteoblast-like cells to titanium and titanium alloy is dependent on surface roughness and composition. Biomaterials 1998;19:2219-2232. 
8. Keller JC, Schneider GB, Stanford CM, Kellogg B. Effects of implant microtopography on osteoblast cell attachment. Implant Dent 2003;12:175-181.

9. Vercaigne S, Wolke JGC, Naert I, Jansen JA. Histomorphometrical and mechanical evaluation of titanium plasma-spray-coated implants placed in the cortical bone of goats. J Biomed Mater Res 1998;41:41-48.

10. Wennerberg A, Albrektsson $T$, Andersson $B$. Bone tissue response to commercially pure titanium implants blasted with fine and coarse particles of aluminum oxide. Int J Oral Maxillofac Implants 1996;11:38-45.

11. Chen $\mathrm{CH}$. Thin film components for lithium-ion batteries. PhD Thesis. Delft University of Technology, Delft, 1998.

12. Leeuwenburgh S, Wolke J, Schoonman J, Jansen JA. Electrostatic Spray Deposition (ESD) of calcium phosphate coatings. J Biomed Mater Res 2003;66:330-334.

13. Cloupeau M, Prunet-Foch B. Electrohydrodynamic spraying functioning modes: a critical review. $J$ Aerosol Sci 1994;25:1021-1036.

14. Hartman RPA, Brunner DJ, Camelot DMA, Marijnissen JCM, Scarlett B. Electrohydrodynamic atomization in te cone-jet mode: physical modeling of the liquid cone and jet. J Aerosol Sci 1999;30:823849 .

15. Yoshinari $M$, Hayakawa $T$, Wolke $J$, Nemoto $K$, Jansen JA. Influence of rapid heating with infrared radiation on $R F$ magnetron-sputtered calcium phosphate coatings. J Biomed Mater Res 1997;37:60-67.

16. Leeuwenburgh SCG, Wolke JGC, Schoonman J, Jansen JA. Influence of precursor solution parameters on chemical properties of calcium phosphate coatings prepared using Electrostatic Spray Deposition (ESD). Biomaterials 2004;25:641-649.

17. Vercoulen PHW. Electrostatic processing of particles. A tool in particle technology. PhD Thesis. Delft University of Technology, Delft, 1995.

18. Jayanthi GV, Zhang SC, Messing GL. Modeling of solid particle formation during solution aerosol thermolysis - the evaporation stage. Aerosol Sci Technol 1993;19:478-490.

19. Messing GL, Zhang SC, Jayanthi GV. Ceramic powder synthesis by spray-pyrolysis. J Am Ceram Soc 1993;76:2707-2726.

20. Luo P, Nieh TH. Preparing hydroxyapatite powders with controlled morphology. Biomaterials 1996;17:1959-1964. 



\section{Introduction}

Calcium phosphate $(\mathrm{CaP})$ coatings are applied onto the surface of metallic implants, since these so-called bioactive ceramics are able to establish a tight, chemical bond between the implant surface and surrounding osseous tissue. This bone-bonding capacity is strongly related to the chemical properties of the coating surface upon exposure to body fluids ${ }^{1-3}$. In addition, the topography of biomaterial surfaces (in terms of physical factors such as surface roughness and porosity) is suggested to have a strong influence on biological processes such as the adsorption of proteins, cell adhesion and spreading, and consequently the overall tissue response in vivo ${ }^{4}$. In order to investigate this fundamental relationship between the chemical and physical nature of $\mathrm{CaP}$ coatings and their biological performance in vitro and in vivo, a flexible deposition technique is required which offers the possibility of varying both kinds of coating characteristics over a wide range. In that respect, the versatility of the Electrostatic Spray Deposition (ESD) technique regarding deposition of coatings with controlled surface morphology is particularly interesting. Briefly, the basic principle of ESD is the generation of a spray of charged, micron-sized droplets. This is accomplished by means of electrostatic atomization of precursor solutions. These spray droplets are directed towards a grounded and heated substrate as a result of the applied potential difference. After complete solvent evaporation, a thin layer is left onto the substrate surface.

Several studies have shown already that inorganic ${ }^{5-7}$, polymeric ${ }^{8}$, as well as protein coatings ${ }^{9}$ can be deposited using ESD with a wide variety of surface structures. Specifically, the ESD technique was shown to enable synthesis of biomedical CaP coatings with defined chemical ${ }^{10}$ and morphological ${ }^{11}$ characteristics. Under certain conditions, a unique reticular coating morphology was obtained, characterized by a three-dimensional, interconnected pore-network with variable pore size. From a biomedical point of view, this coating morphology offers the advantage of creating an implant surface with an increased and controllable specific surface area. As a result, phenomena such as $\mathrm{CaP}$ coating dissolution rate and incorporation of osteoinductive proteins might be controlled by tailoring the surface morphology.

Various formation mechanisms have been suggested in the literature to explain the characteristic surface morphologies obtained using ESD. However, these models are merely based on observations using Scanning Electron Microscopy (SEM), and in some cases the models are contradictory. For example, Chen et al. ${ }^{5}$ reported that it is necessary to use a solvent with a high boiling point (for example butyl carbitol, $\mathrm{T}_{\mathrm{b}}=231^{\circ} \mathrm{C}$ ) in order to deposit dense $\mathrm{LiCoO}_{2}$ coatings, whereas Perednis et al. ${ }^{7}$ observed the opposite effect by depositing dense yttria-stabilized zirconia (YSZ) films using a solvent with a low boiling point (1-methoxy-2-propanol, $\mathrm{T}_{\mathrm{b}}=120^{\circ} \mathrm{C}$ ). Based on a theoretical model for evaporation of electrospray droplets during transport towards a hot plate, Wilhelm et al. ${ }^{12}$ developed a deposition diagram describing the surface texture of ESD-derived YSZ coatings as a function of initial droplet size, precursor concentration, and substrate temperature. This model was in agreement with experimental results obtained using a Phase Doppler Anemometer (PDA), which enables characterization of electrospray droplet sizes and velocities ${ }^{13}$.

Here, a PDA was used to characterize the electrosprays in situ during formation of $\mathrm{CaP}$ coatings at high deposition temperatures. Morphological features of ESD-derived coatings were correlated with the corresponding droplet characteristics of the electrosprays. The influence of several physical (apparatus-related) and chemical (solution-related) deposi- 
tion parameters (deposition temperature, nozzle-to-substrate distance, nozzle geometry, and the composition of the precursor solutions) on electrospray characteristics and coating morphology was investigated. The physical, apparatus-related parameters (deposition temperature and nozzle-to-substrate distance) were chosen for their supposed influence on solvent evaporation, whereas the geometry of the spraying nozzle was supposed to affect the mixing characteristics of the precursor solutions. The influence of the chemical composition of the precursor solutions was investigated, since it is known that physical properties of the precursor solutions (such as electrical conductivity) strongly determine the initial droplet properties in the process of electrospraying ${ }^{14,15}$.

\section{Materials and Methods}

\subsection{ELECTROSTATIC SPRAY DEPOSITION (ESD) PROCESS}

In the current study, the spray was directed from the nozzle downwards to the heated substrate. A direct current voltage supply (Bertan 450, USA) was used in order to generate a positive high potential difference between the nozzle and grounded substrate, which was heated by a heating plate (Ceran 500, Type 11A, Germany). Two precursor solutions containing either $\mathrm{Ca}$ or $\mathrm{P}$ precursor salts were pumped simultaneously towards the spraying nozzle with a single syringe pump (Bioblock Scientific, A99, France). Ca and P precursor solutions were prepared by dissolving $\mathrm{Ca}\left(\mathrm{NO}_{3}\right)_{2} \cdot 4 \mathrm{H}_{2} \mathrm{O}$ (Merck) and $\mathrm{H}_{3} \mathrm{PO}_{4}(85 \mathrm{wt} \%$, J.T. Baker) in butyl carbitol $\left(\mathrm{C}_{8} \mathrm{H}_{18} \mathrm{O}_{3}, 99 \%\right.$, Aldrich). A stable cone-jet mode of electrospraying was generated by adjusting the potential difference between the spraying nozzle and substrate between 5.5 and $8.0 \mathrm{kV}$, depending on the specific set of deposition parameters. Characteristics of this cone-jet mode of electrospraying were described elsewhere ${ }^{14-16}$. Machined, commercially pure titanium (Ti) discs (diameter $12 \mathrm{~mm}$, thickness $1.5 \mathrm{~mm}$ ) and smooth silicon ( $\mathrm{Si}$ ) wafers (thickness $0.5 \mathrm{~mm}$, WaferNet GmbH, Germany) were used as substrate material for the deposition of the CaP coatings. The substrates were cleaned ultrasonically in acetone (15 minutes) and ethanol (15 minutes) prior to deposition.

\subsection{COATING DEPOSITION PARAMETERS}

Deposition temperatures ranged between $25^{\circ} \mathrm{C}$ and $400{ }^{\circ} \mathrm{C}$, whereas the distance between the spraying nozzle and the substrate was varied between $20 \mathrm{~mm}$ and $40 \mathrm{~mm}$. Regarding the geometry of the spraying nozzle, a two-component nozzle (Figure 1, left) with

Figure 1: Novel two-component (left) and conventional one-component (right) spraying nozzle geometries for Electrostatic Spray Deposition (ESD).

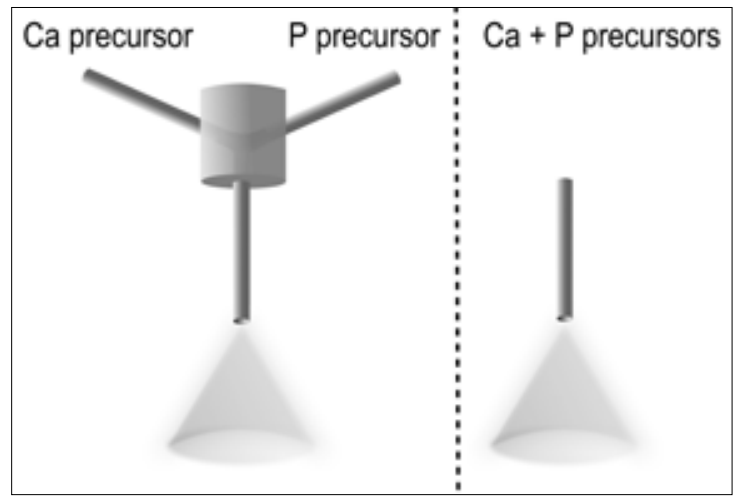


separate inlet for $\mathrm{Ca}$ and $\mathrm{P}$ precursor solutions was used as standard nozzle (stainless steel, flat outlet, inner and outer diameter of 0.9 and $1.4 \mathrm{~mm}$, respectively) in order to avoid premature precipitation of the precursor solutions within the nozzle prior to spray generation.

\begin{tabular}{|c|c|c|c|}
\hline Solution designation & $\mathbf{A}$ & B & C \\
\hline $\begin{array}{l}\text { Concentration Ca-precursor } \\
\text { solution }\left(\mathrm{Ca}\left(\mathrm{NO}_{3}\right)_{2} \cdot 4 \mathrm{H}_{2} \mathrm{O}\right)[\mathrm{mM}]\end{array}$ & 6.25 & 25.0 & 6.25 \\
\hline $\begin{array}{l}\text { Concentration P-precursor } \\
\text { solution }\left(\mathrm{H}_{3} \mathrm{PO}_{4}\right)[\mathrm{mM}]\end{array}$ & 3.5 & 14.0 & 3.5 \\
\hline $\mathrm{HNO}_{3}$ addition [vol\%] & 0 & 0 & 1.0 \\
\hline $\mathrm{Ca} / \mathrm{P}$ ratio & 1.8 & 1.8 & 1.8 \\
\hline \multirow{2}{*}{ Liquid flow rate $[\mathrm{ml} / \mathrm{h}]$} & \multirow{2}{*}{$\begin{array}{l}1.0 \\
\text { (cone-jet) }\end{array}$} & 1.0 (intermittent cone-jet) & 1.0 (intermittent cone-jet) \\
\hline & & 0.5 (continuous cone-jet) & 0.5 (continuous cone-jet) \\
\hline
\end{tabular}

Table 1: Chemical composition and spraying conditions of precursor solutions.

This two-component nozzle geometry was compared with a conventional one-component nozzle geometry (Figure 1, right) with equal dimensions using premixed precursor solutions. Using the two-component nozzle, the liquid flow rates were equal for both $\mathrm{Ca}$ and $\mathrm{P}$ precursor solutions $(1.0 \mathrm{ml} / \mathrm{h})$, whereas the flow rate was doubled for the one-component nozzle, yielding an equal effective standard flow rate of $2.0 \mathrm{ml} / \mathrm{h}$ at the nozzle outlet for both nozzle geometries.

Three different precursor solutions were used, as shown in Table 1. Precursor solution A $\left(6.25 \mathrm{mM} \mathrm{Ca}\left(\mathrm{NO}_{3}\right)_{2} \cdot 4 \mathrm{H}_{2} \mathrm{O}\right.$ and $3.50 \mathrm{mM} \mathrm{H}_{3} \mathrm{PO}_{4}$ dissolved in butyl carbitol) was sprayed at an outlet flow rate of $2.0 \mathrm{ml} / \mathrm{h}$ in a stable cone-jet mode of electrospraying. Solutions $\mathrm{B}$ (four times higher precursor concentrations) and C (supplemented with $1 \mathrm{vol} \%$ of nitric acid) were sprayed at both low $(1.0 \mathrm{ml} / \mathrm{h}$ at the nozzle outlet, continuous cone-jet mode) and high flow rates $(2.0 \mathrm{ml} / \mathrm{h}$ at the nozzle outlet, intermittent cone-jet mode $)$, since the continuous cone-jet mode was unstable at outlet flow rates higher than $1.0 \mathrm{ml} / \mathrm{h}$ for these precursor solutions of high electrical conductivity.

Standard deposition conditions are listed in Table 2. When varying specific apparatusor solution-related parameters, all other processing parameters were kept constant.

\begin{tabular}{|l|l|}
\hline Processing parameter & Standard conditions \\
\hline Substrate material & Ti \\
\hline Deposition temperature $\left[{ }^{\circ} \mathrm{C}\right]$ & 400 \\
\hline Nozzle-to-substrate distance $[\mathrm{mm}]$ & 20 \\
\hline Nozzle geometry & two-component \\
\hline Precursor solution & $\mathrm{A}$ \\
\hline Liquid flow rate $[\mathrm{ml} / \mathrm{h}]($ at nozzle outlet) & 2.0 \\
\hline Potential difference $[\mathrm{kV}]$ & 6.2 \\
\hline Electrospraying mode & continuous cone-jet mode \\
\hline Deposition time $[$ minutes] & 45 \\
\hline
\end{tabular}

Table 2: Standard electrospraying conditions. 


\subsection{CHARACTERIZATION}

A Phase Doppler Anemometer (PDA) (TSI Inc., USA) was used to measure spray droplet sizes and velocities during coating deposition. Details of this technique were described by Heine et al. ${ }^{17}$. Spatial mapping in axial direction was carried out along the central axis of the spray from $5 \mathrm{~mm}$ below the nozzle outlet until $5 \mathrm{~mm}$ above the heated substrate, which was the closest possible distance between the measuring volume and the substrate surface. At $5 \mathrm{~mm}$ above the substrate, the spray droplets were also characterized in radial direction from the center to the edge of the spray. The surface morphology of the deposited CaP-coatings was investigated using a Scanning Electron Microscope (SEM) (JEOL 6310) at an acceleration voltage of $10 \mathrm{kV}$. Moreover, the deposition rate of the ESD-technique was determined for a reticular coating morphology by means of SEM-observation of crosssectioned silicon wafers, coated at $350{ }^{\circ} \mathrm{C}$ for deposition times from 1 minute to 8 hours.

\section{Results}

\subsection{PDA MEASUREMENTS}

\subsubsection{Influence of physical, apparatus-related parameters}

Figures $2 \mathrm{a}-\mathrm{b}$ show the influence of deposition temperature and nozzle geometry on a) the number mean droplet diameter and $b$ ) the number mean axial droplet velocity along the spray axis. At room temperature (diamonds), droplet sizes between 6.5-7.0 $\mu \mathrm{m}$ were measured using the standard two-component nozzle geometry. At the highest deposition temperature $\left(\mathrm{T}_{\mathrm{d}}=400^{\circ} \mathrm{C}\right)$, comparable droplet sizes of about $7.5 \mu \mathrm{m}$ were observed using a two-component nozzle (open squares), irrespective of the axial location in the spray. Droplet sizes were between 4-5 $\mu \mathrm{m}$ when using a one-component nozzle (at equal $\mathrm{T}_{\mathrm{d}}=$ $400{ }^{\circ} \mathrm{C}$ ) with premixed $\mathrm{Ca}$ and $\mathrm{P}$ precursor solutions (filled squares). Regarding the velocity of the droplets, it was found for both nozzle geometries that the initial velocity close to the nozzle tip displayed a large variation between $6-15 \mathrm{~m} / \mathrm{s}$, as the sampling volume of the PDA-technique was at the transition between the liquid cone and jet. It is known from theoretical models on electrospraying ${ }^{12,18}$ that initial droplet velocities are high in response to the strong electric field close to the nozzle tip. Droplet velocities subsequently decrease by the reduced field intensity until an equilibrium between drag and electric forces on the
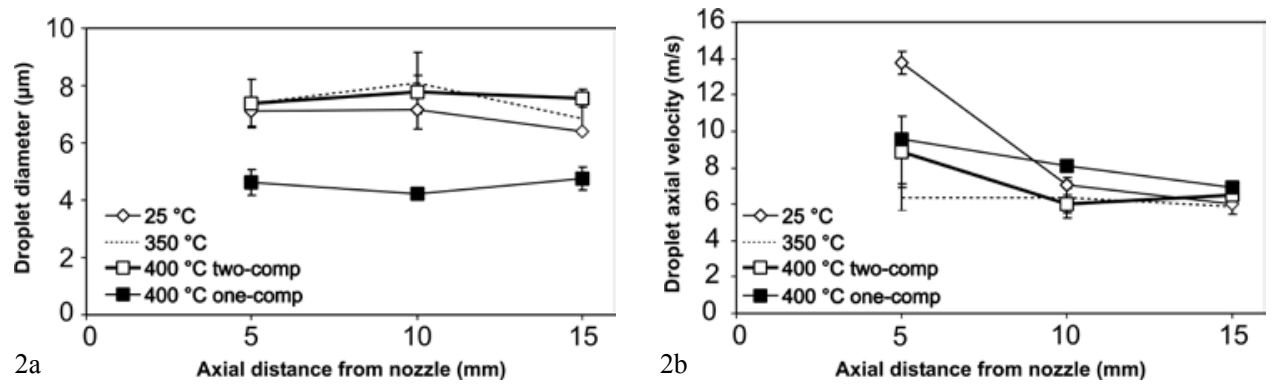

Figure 2: Axial mapping of (number) mean droplet diameter [a] and (number) mean axial droplet velocity [b] along the spray axis as a function of the deposition temperature and spraying nozzle geometry. Otherwise, standard deposition conditions were employed (Table 2). 

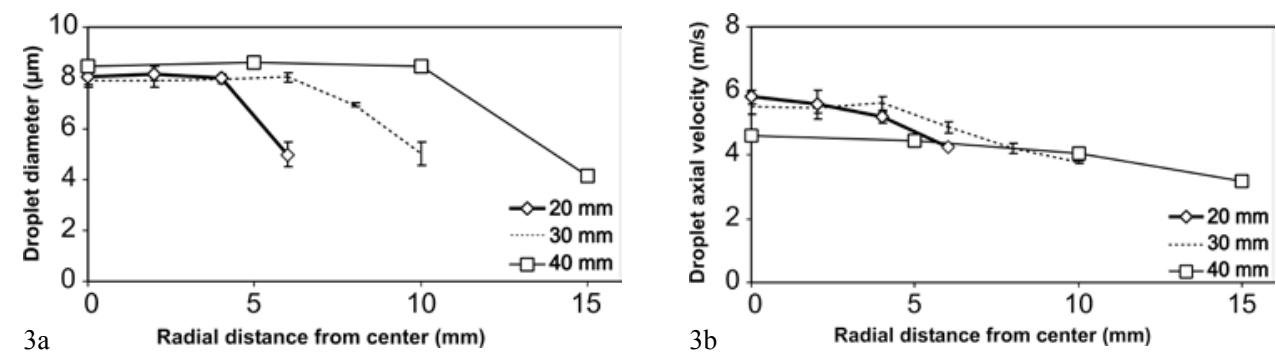

Figure 3: Radial mapping at a plane $5 \mathrm{~mm}$ above the substrate of (number) mean droplet diameters [a] and (number) mean axial velocities [b] as a function of the nozzle-to-substrate distance. Otherwise, standard deposition conditions were employed (Table 2).

droplets is established, which results in nearly constant droplet velocities of about $6 \mathrm{~m} / \mathrm{s}$ for all substrate temperatures at the vicinity of the substrate surface. The constant droplet diameters and velocities indicate that droplet shrinkage by solvent evaporation and droplet rebounding are negligible for the current ESD system.

Figures $3 a-b$ show a) the number mean droplet diameter and b) the number mean axial droplet velocity in radial direction $\left(\mathrm{T}_{\mathrm{d}}=400^{\circ} \mathrm{C}\right)$ at an axial distance of $5 \mathrm{~mm}$ above the substrate for varying distances between the nozzle and the substrate of $20 \mathrm{~mm}$ (diamonds), $30 \mathrm{~mm}$ (without marks), and $40 \mathrm{~mm}$ (squares). Droplet sizes of about $8 \mu \mathrm{m}$ were measured at the axis of the spray, irrespective of the distance between the plane of measurement (fixed at $5 \mathrm{~mm}$ above the substrate) and the nozzle tip. With increasing distance between nozzle and substrate, the diameter of the electrospray increased resulting from repulsive forces between charged droplets ${ }^{19}$. Radially, droplet diameters decreased from $8 \mu \mathrm{m}$ at the spray center down to 4-5 $\mu \mathrm{m}$ at the spray edge for all nozzle-to-substrate distances. This segregational behavior of electrospray droplets according to their sizes was consistent with Wilhelm et al. ${ }^{12}$ and Hartman et al. ${ }^{18}$. They observed that smaller secondary droplets were situated at the spray edge using a bimodal cone-jet mode of electrospraying, since these small satellite droplets with low inertia were driven to the edge of the spray, whereas the main primary droplets were distributed over the whole spray cross section. Figure $3 \mathrm{~b}$ reveals that the axial droplet velocity decreased with increasing radial distance. According to Hartman et al. ${ }^{18}$, the axial droplet velocity generally decreases with decreasing droplet size. This phenomenon was most pronounced for the broadest electrospray (nozzle-to-substrate distance of $40 \mathrm{~mm}$ ), where axial droplet velocities were reduced to $3.2 \mathrm{~m} / \mathrm{s}$ at the spray edge.

\subsubsection{Influence of composition of precursor solutions}

Figures $4 \mathrm{a}-\mathrm{b}$ show the influence of the composition of the precursor solutions on a) the number mean droplet diameter and $b$ ) the number mean axial droplet velocity in radial direction $\left(\mathrm{T}_{\mathrm{d}}=400{ }^{\circ} \mathrm{C}\right)$ at $5 \mathrm{~mm}$ above the substrate for precursor solutions $\mathrm{A}$ (diamonds), $\mathrm{B}$ (without marks), and C (squares) (Table 1). As compared to standard solution A, an increase in precursor salt concentration by factor of 4 (solution $\mathrm{B}$ ) resulted into smaller droplets with a diameter between 3.0 and $3.5 \mu \mathrm{m}$. By adding $1 \mathrm{vol} \%$ of $\mathrm{HNO}_{3}$ (solution $\mathrm{C}$ ), even smaller droplets were formed of about $2.0 \mu \mathrm{m}$ in diameter.

Both precursor solutions $\mathrm{B}$ and $\mathrm{C}$ caused a broadening of the diameter of the electrospray of 8-12 $\mathrm{mm}$ (at $5 \mathrm{~mm}$ above the substrate) due to extra mutual repulsive forces 

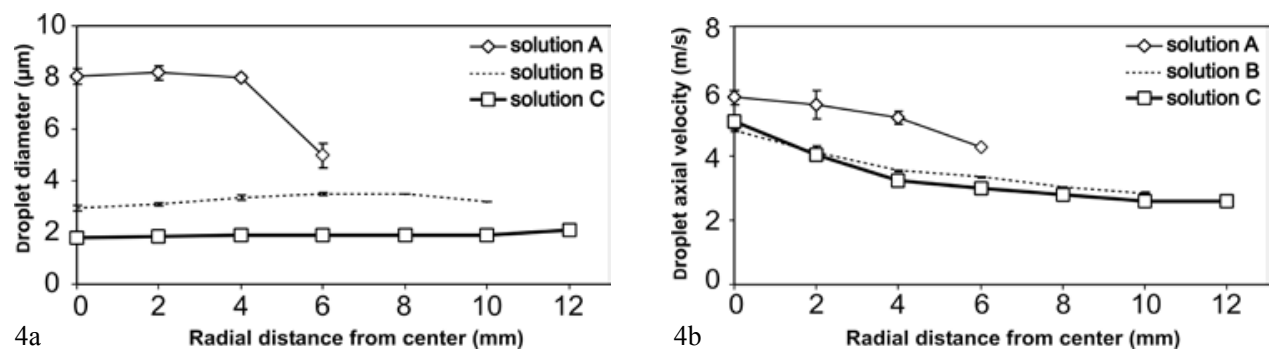

Figure 4: Radial mapping at a plane $5 \mathrm{~mm}$ above the substrate of (number) mean droplet diameters [a] and (number) mean axial droplet velocities [b] for several precursor solutions (Table 1). Otherwise, standard deposition conditions were employed (Table 2).

between the spray droplets ${ }^{19}$. These forces result from high droplet charges for highly concentrated or acidic precursor solutions ${ }^{14,15}$. In contrast to solution A, droplet segregation of smaller, secondary droplets towards the spray edges was not observed for precursor solutions B and C. Regarding the axial droplet velocities, it was observed that the droplet velocity slightly decreased with increasing radial distance for all precursor solutions (Figure 4b). Axial droplet velocities were 1 to $2 \mathrm{~m} / \mathrm{s}$ lower for the finely dispersed electrosprays consisting of small droplets (precursor solutions B and C) as compared to the spray generated from standard solution A with larger droplet sizes.

In general, number mean droplet sizes of electrosprays derived from solutions B and $\mathrm{C}$ were comparable for both electrospraying modes that were tested, irrespective of the corresponding flow rates at the nozzle outlet $(1.0$ and $2.0 \mathrm{ml} / \mathrm{h}$ for continuous and intermittent cone-jet modes, respectively). It was observed that the electrically deformed shape of the liquid cone at the nozzle outlet (emitting a cone-jet) periodically relaxed into a normal droplet shape (emitting large droplets) at a relaxation frequency of about $0.5 \mathrm{~Hz}$ for the intermittent cone-jet mode. As a consequence, volume size distributions of the intermittent cone-jet mode were broader than the corresponding ones for the continuous cone-jet modes, as shown in Figure 5 for precursor solution B. Large droplets of more than $20 \mu \mathrm{m}$ in diameter were frequently observed using the intermittent cone-jet mode, yielding a higher Sauter mean diameter for this spraying condition $(5.8 \mu \mathrm{m})$ as compared to the Sauter mean diameter of the cone-jet electrospray $(4.4 \mu \mathrm{m})$. Still, number mean droplet sizes were comparable for both spraying modes $(3.1 \mu \mathrm{m}$ vs. $3.4 \mu \mathrm{m}$ for continuous and intermittent

Figure 5: Droplet volume size distributionsforprecursorsolution $B$ (Table 1) at the continuous cone-jet mode (bold line, liquid flow rate of $1.0 \mathrm{ml} / \mathrm{h}$ ) and at the intermittent cone-jet mode (thin line, liquid flow rate of $2.0 \mathrm{ml} / \mathrm{h}$ ). Otherwise, standard deposition conditions were employed (Table 2). Measurements were performed at $5 \mathrm{~mm}$ above the substrate.

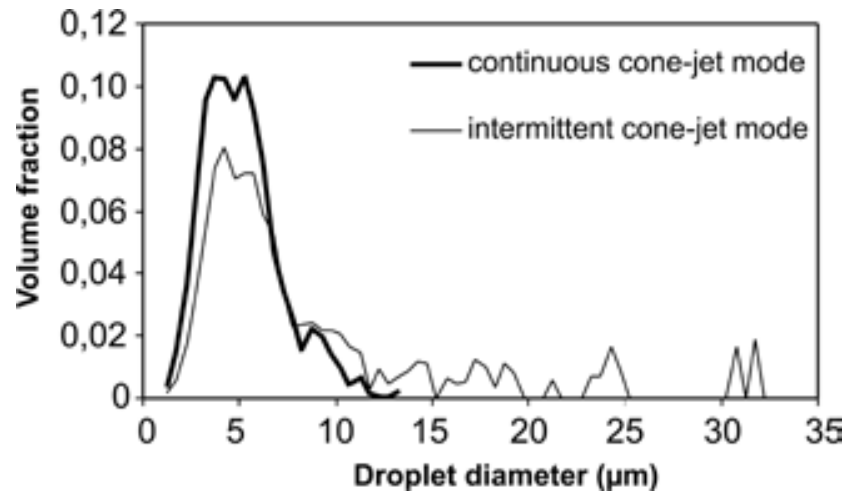




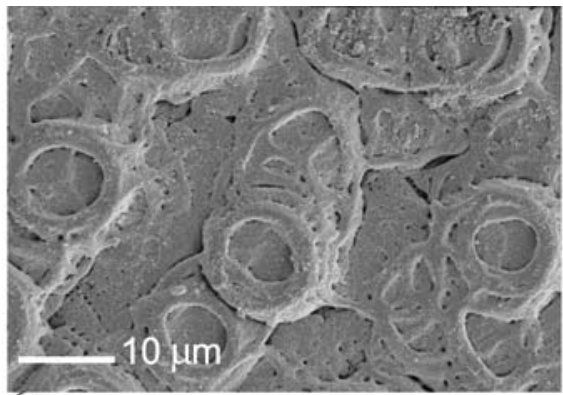

$6 a$

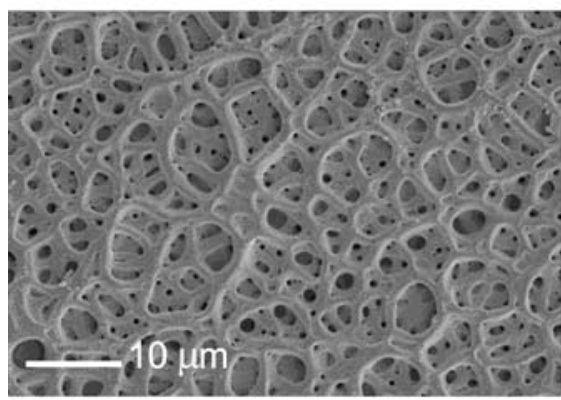

$6 \mathrm{~b}$

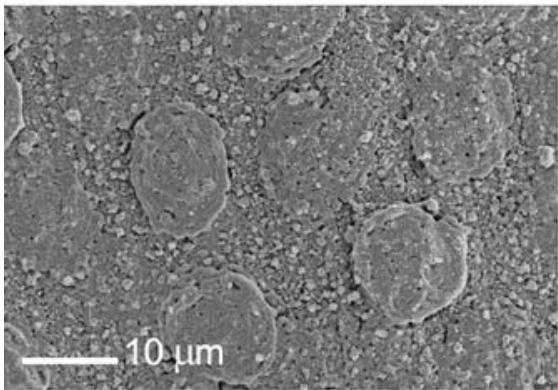

$6 d$

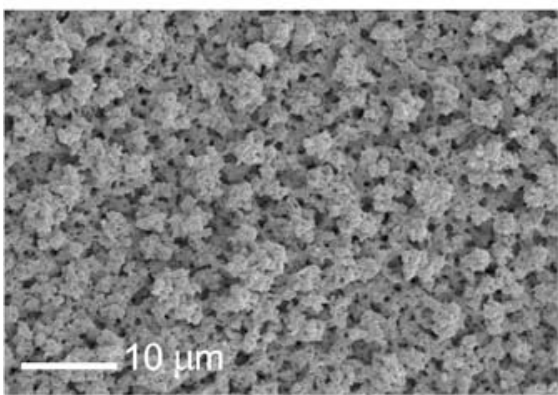

$6 f$

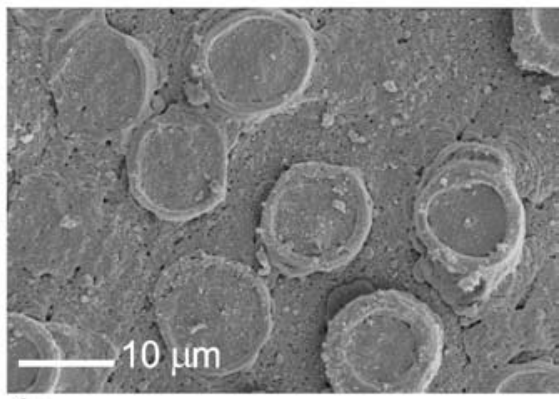

$6 \mathrm{c}$

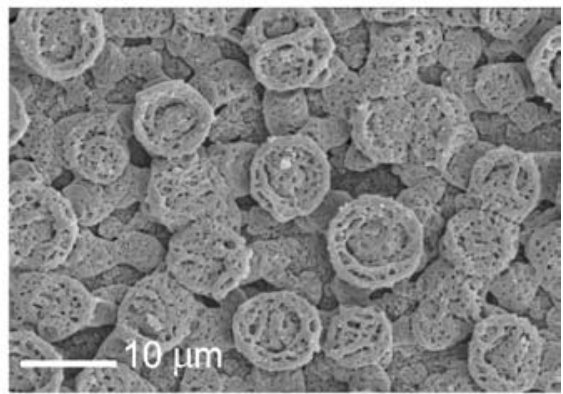

$6 \mathrm{e}$

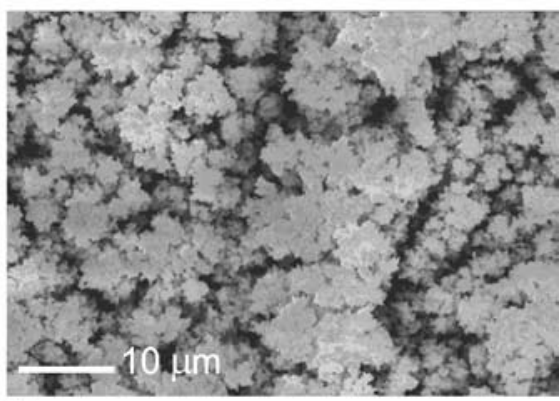

$6 \mathrm{~g}$

Figure 6: Scanning electron micrographs of ESD-derived CaP coatings which were deposited under [a] standard or [b-g] deviating conditions as compared to standard conditions (Table 2): deposition temperature of $350{ }^{\circ} \mathrm{C}$, potential difference of $6.2 \mathrm{kV}$; [c] nozzle-to-substrate distance of $30 \mathrm{~mm}$, potential difference of $6.9 \mathrm{kV}$; [d] nozzleto-substrate distance of $40 \mathrm{~mm}$, potential difference of $7.9 \mathrm{kV} ;[\mathrm{e}]$ one-component nozzle geometry, potential difference of $7.3 \mathrm{kV}[\mathrm{f}]$ highly concentrated precursor solution B, potential difference of $6.4 \mathrm{kV}$; [g] acidic precursor solution C (Table 1), potential difference of $6.6 \mathrm{kV}$. Bar size $10 \mu \mathrm{m}$. 
cone-jet modes, respectively). Geometrical number based standard deviations $\left(\sigma_{\mathrm{gn}}\right)$ of both distributions were in the same range $\left(\sigma_{\text {gn,cone-jet }}=1.5\right.$ versus $\left.\sigma_{\text {gn,intermittent }}=1.6\right)$.

\subsection{SURFACE MORPHOLOGY OF DEPOSITED COATINGS}

Figures 6a-g show scanning electron micrographs of the morphology of the CaP coatings, which were deposited during the above described PDA-measurements. Under standard conditions (Table 2), ring-shaped protuberances with external diameters of about 12-13 $\mu \mathrm{m}$ emerged from a submicron-porous underlayer (Figure 6a). Figure 6b shows a reticular structure characterized by an interconnected pore network, which was formed at a lower deposition temperature of $350{ }^{\circ} \mathrm{C}$ as compared to the standard temperature of $400{ }^{\circ} \mathrm{C}$ (Figure 6a). No separate rings could be observed under these conditions. At a larger nozzle-to-substrate distance of $30 \mathrm{~mm}$ (Figure 6c), the external diameters of these doughnut-shapes were comparable to the ones in Figure 6a, but the shape of the deposited droplet-like features had changed from rather flat rings with thick but porous walls towards doughnut-shapes with thin but dense walls. At a nozzle-to-substrate distance of $40 \mathrm{~mm}$ (Figure 6d), remnants of these circular protuberances of about $12 \mu \mathrm{m}$ in diameter were still recognizable, but the submicron-porous underlayer of Figure $6 \mathrm{a}$ had transformed into a grainy structure consisting of single particles.

Using a one-component nozzle geometry, a roughened coating morphology was formed consisting of isolated, porous doughnuts (Figure 6e). The average external diameter of these doughnuts was considerably smaller $(8-10 \mu \mathrm{m})$ than the ring-shapes with diameters between 11 and $13 \mu \mathrm{m}$, which were deposited using the two-component nozzle geometry (Figure 6a). Using the highly concentrated precursor solution combination B, a flat but microporous morphology was obtained (Figure 6f), whereas a fractal-like surface structure was formed using the acidic solution combination $\mathrm{C}$ (Figure $6 \mathrm{~g}$ ). For both conditions, the coating surface appeared to consist of single particles without droplet-like features such as rings or micron-sized pores.

\subsection{DEPOSITION OF POROUS, RETICULAR COATINGS}

Figure 7 is a high-magnification scanning electron micrograph of a reticular $\mathrm{CaP}$ coating after a deposition time of 60 minutes at a deposition temperature of $350{ }^{\circ} \mathrm{C}$. Otherwise, standard deposition conditions were employed. Clearly, two pore size regimes can be dis-

Figure 7: High-magnification scanning electron micrograph of a reticular CaP coating after 60 min of deposition at a deposition temperature of $350{ }^{\circ} \mathrm{C}$. Otherwise, standard deposition conditions were employed (Table 2). Bar size $1 \mu \mathrm{m}$.

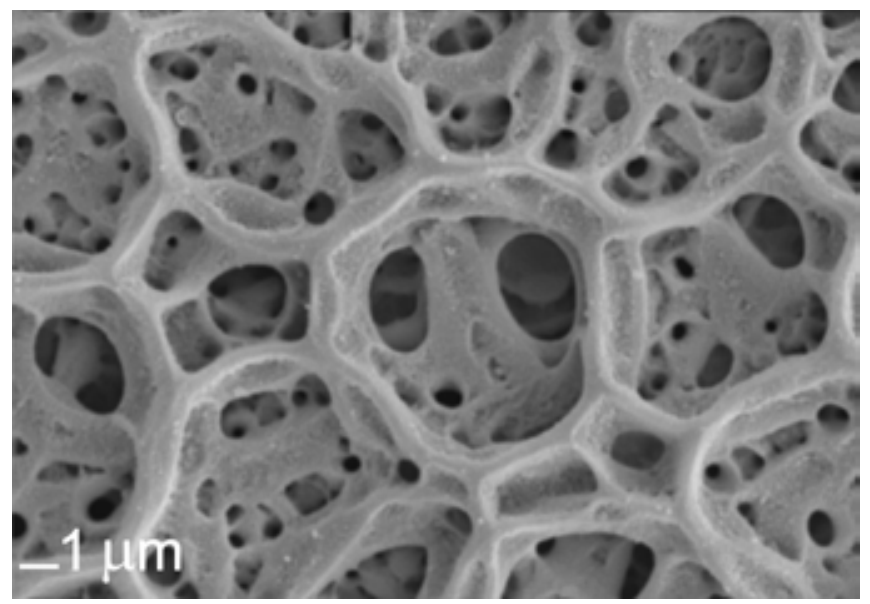




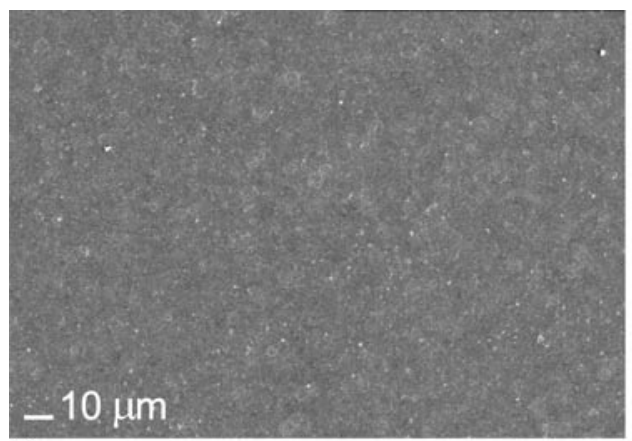

$8 \mathrm{a}$
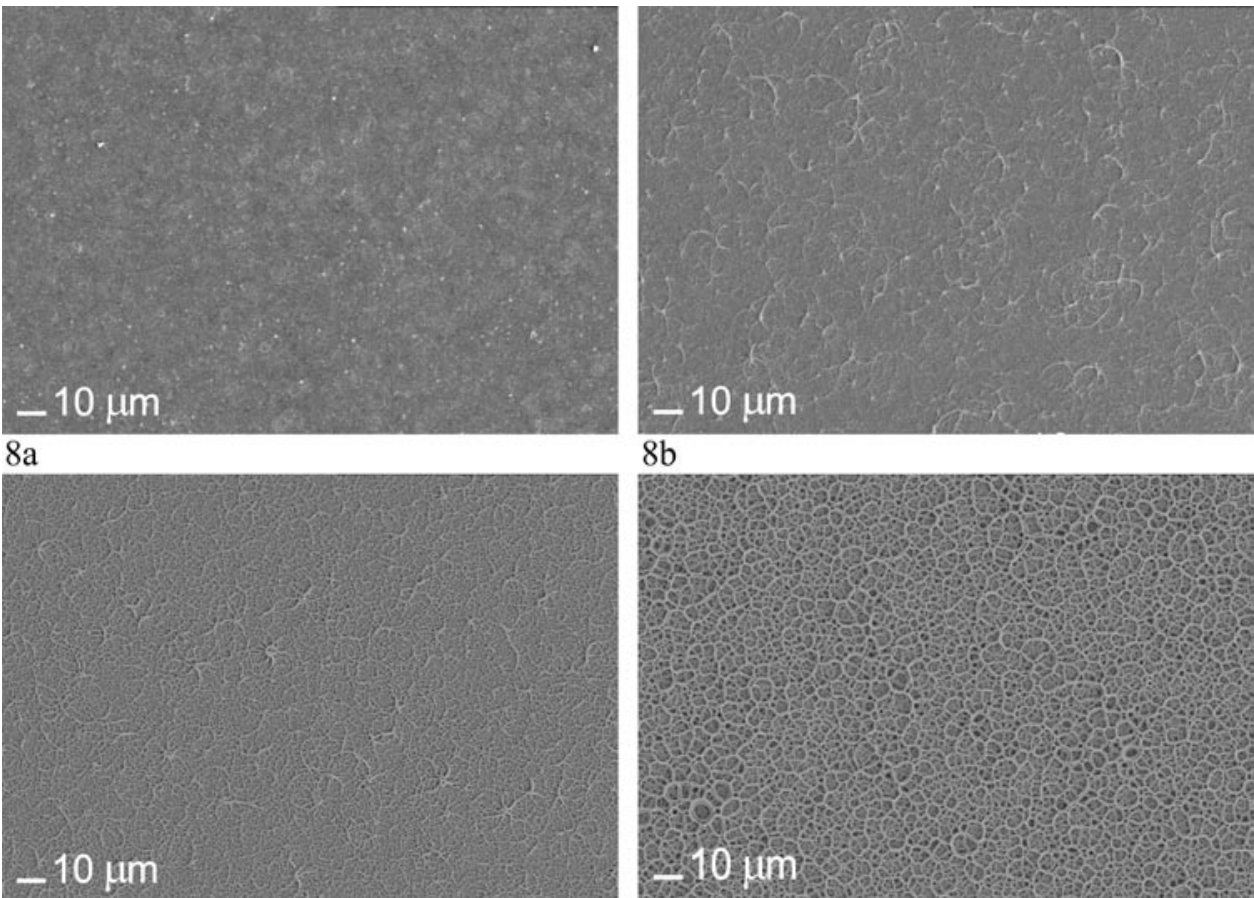

$8 \mathrm{~b}$

$8 \mathrm{c}$

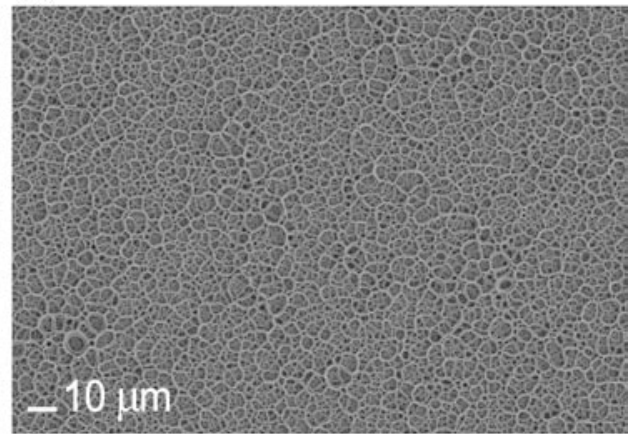

$8 \mathrm{~d}$

Figure 8: Scanning electron micrographs showing the development of a coating with a reticular surface morphology on top of Si wafers after deposition at $350{ }^{\circ} \mathrm{C}$ for 1 minute [a], 5 minutes [b], 15 minutes [c], and 45 minutes [d]. Otherwise, standard deposition conditions were employed (Table 2). Bar size $10 \mu \mathrm{m}$.

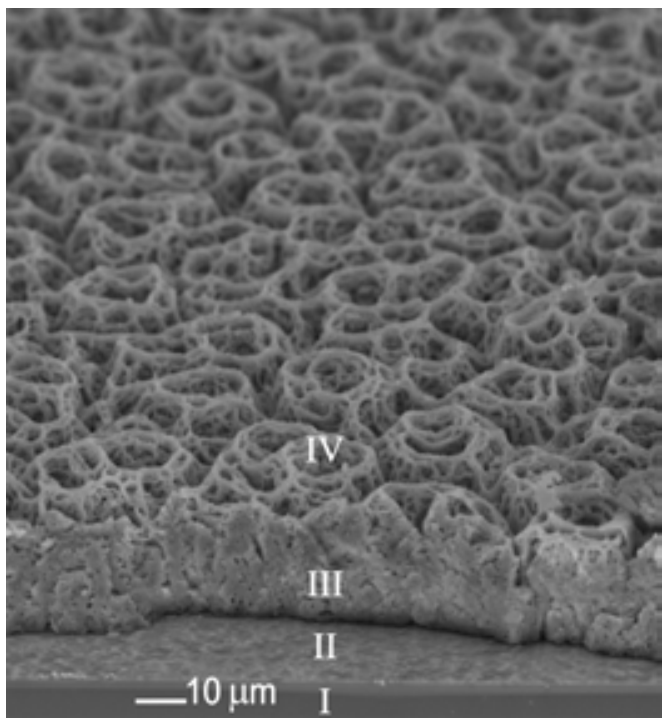

9a

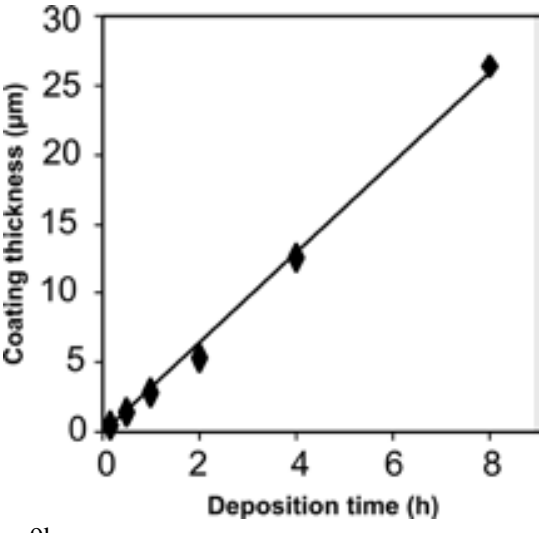

$9 b$

Figure 9: [a] Scanning electron micrograph of a cross-section of a reticular coating on top of a Si wafer after 8 hours of deposition at $350^{\circ} \mathrm{C}$ (tilted at $45^{\circ}$, bar size $10 \mu \mathrm{m}$ ). I $=$ Si substrate, II = dense underlayer, III = submicron-porous middle layer, and IV = rough top-layer. [b] Coating thicknesses of reticular coatings deposited at $350{ }^{\circ} \mathrm{C}$ onto $\mathrm{Si}$ wafers as a function of deposition time. 
tinguished: 1) micron-sized, hollow pits with diameters of at least $5 \mu \mathrm{m}$ at the surface of the coating, and 2) submicron-sized pores in the underlying coating layer.

The scanning electron micrographs of Figures $8 \mathrm{a}-\mathrm{d}$ show the development of these reticular coatings, deposited onto smooth $\mathrm{Si}$ wafers at a deposition temperature of 350 ${ }^{\circ} \mathrm{C}$, after deposition times of: a) 1 minute, b) 5 minutes, c) 15 minutes, and d) 45 minutes. Otherwise, standard conditions were employed. Coatings on Si and Ti substrate materials revealed equal morphologies. In the first minute of coating formation, a homogeneous layer was deposited without any droplet-like features (Figure 8a), but after five minutes the first pore walls were emerging from this dense underlayer (Figure 8b). Gradually, the pore network was formed on the substrate (Figure 8c), and after 45 minutes a typical reticular morphology revealing micron-sized, droplet-like features was recognizable (Figure 8d).

Figure 9 a shows the cross-section (tilted at $45^{\circ}$ ) of a reticular CaP coating deposited at $350{ }^{\circ} \mathrm{C}$ onto a Si wafer after a long deposition time of 8 hours. Otherwise, standard conditions were employed. As before, it can be clearly seen that the coating on top of the Si substrate (area I) consists of a dense underlayer (area II, see also Figure 8a), an intermediate submicron-porous layer (area III), which is covered by a rough toplayer of droplet-derived structures such as isolated ring-shapes or coalesced pores (area IV). Using untilted scanning electron micrographs of similar cross-sections, coating thicknesses were determined for several deposition times (Figure 9b). Coating thickness was defined as the maximum distance between the flat substrate and roughness peaks of the toplayer. The coating thickness was found to be linearly correlated to the deposition time, at a deposition rate of 3.2 $\mu \mathrm{m} / \mathrm{h}$.

\section{Discussion}

\subsection{INFLUENCE OF PHYSICAL, APPARATUS-RELATED PARAMETERS}

Generally, it was observed for all deposition temperatures and nozzle-to-substrate distances that electrospray droplets did not shrink by evaporation during droplet flight using the involatile solvent butyl carbitol with a high boiling point $\left(\mathrm{T}_{\mathrm{b}}=231^{\circ} \mathrm{C}\right)$. By using the same solvent, Wilhelm et al. ${ }^{13}$ also observed that droplets, generated using a downward facing, monodisperse cone-jet mode, maintained a constant (volume mean) diameter of about $12-13 \mu \mathrm{m}$ at distances between $60 \mathrm{~mm}$ to $4 \mathrm{~mm}$ above the hot substrate (heated at $192{ }^{\circ} \mathrm{C}$ ). Here, the substrate temperature was higher $\left(\mathrm{T}_{\mathrm{d}}=400{ }^{\circ} \mathrm{C}\right.$ ) and initial (volume mean) droplet diameters were smaller $(8-9 \mu \mathrm{m})$ due to higher precursor concentrations inducing higher electrical solution conductivities ${ }^{14}$, but still droplet evaporation was negligible. Although the droplet sizes and velocities close to the substrate did not depend on the intensity of substrate heating and the distance between nozzle and substrate, the resulting surface morphologies (Figures 6a-g) varied considerably from porous morphologies with coalesced droplets (Figure 6b) to morphologies revealing separated doughnuts on top of submicronporous (Figures $6 \mathrm{a}+\mathrm{c}$ ) or grainy underlayers (Figure $6 \mathrm{~d}$ ). This means that conventional models on spray and droplet drying - including phenomena such as solvent evaporation, droplet shrinkage, and crust formation during droplet flight ${ }^{20-23}$ - cannot be applied to ESD using a solvent with a high boiling point such as butyl carbitol $\left(\mathrm{T}_{\mathrm{b}}=231^{\circ} \mathrm{C}\right)$.

According to measured axial temperature profiles ${ }^{7,12}$ for a comparable ESD set-up, the air temperature is almost constant while moving from nozzle to substrate, until a very steep increase in air temperature was observed close to the heated substrate. At a substrate tem- 
perature of $400{ }^{\circ} \mathrm{C}$, it was estimated from Wilhelm et al..$^{12}$ that the air temperature exceeded the boiling point of butyl carbitol $\left(231^{\circ} \mathrm{C}\right)$ only at distances of about $5 \mathrm{~mm}$ away from the substrate. Moreover, the axial velocity of the spray droplets decreased towards a constant but positive value, indicating that the electric field of the ESD set-up helps to overcome the retarding drag forces of the surrounding gas and the thermophoretic forces as a result of substrate heating. The same effect was observed by Perednis ${ }^{24}$, which explains why spraying efficiency is larger for ESD as compared to conventional spray pyrolysis techniques without external electric fields. Thus, droplet flight times were reduced to values between 1-10 $\mathrm{ms}$ and droplets were subjected to a very fast but short heating phase close to the substrate. Therefore, ESD can be described as a surface-controlled process using involatile solvents with these high boiling points.

Droplet-derived features (such as micron-sized rings, coalesced pore walls, etc.) were formed after droplet arrival on the substrate surface as a result of spreading phenomena, since the diameter of these features was generally somewhat larger than the corresponding droplet diameters. Chen et al. ${ }^{25}$ suggested that solvent evaporation rates are higher at the edges of spreading droplets, which was confirmed by a mathematical model developed recently by $\mathrm{Ajaev}^{26}$ for the spreading of liquid droplets on a uniformly heated plate. He found that the evaporative mass flux strongly increases with decreasing thickness of the liquid film with a maximum flux near the contact line of the spreading droplet. As a result, heterogeneous concentration profiles of precursor solutes were formed for spreading droplets until $\mathrm{CaP}$ precipitation was initiated at the edges of the droplets after reaching critical supersaturation. Consequently, circular $\mathrm{CaP}$ doughnut-shapes were deposited onto the substrate as isolated rings or coalesced pores, depending on the spreading rate of the droplets and the precipitation rate of the $\mathrm{CaP}$ solute. From our results, it can be concluded that droplet spreading rates were mainly controlled by the substrate temperature. The nozzleto-substrate distance on the other hand hardly affected the droplet spreading rate, since the diameter of the doughnut-shapes on top of the underlying layers was almost equal (about $12 \mu \mathrm{m}$ ) for all nozzle-to-substrate distances.

Generally, solvent evaporation during droplet flight is suppressed using butyl carbitol until the spray droplets reach the hot zone at a distance of about $5 \mathrm{~mm}$ away from the heated substrate and evaporation starts. This phenomenon might be advantageous regarding deposition of ESD-coatings with a controllable and reproducible surface morphology onto substrates with complex geometries, since nozzle-to-substrate distances cannot be kept constant in that case. The underlying layers, however, were grainy for the largest nozzle-to-substrate distance of $40 \mathrm{~mm}$ (Figure 6d) in contrast to rather dense underlayers obtained at smaller nozzle-to-substrate distances (Figures $6 \mathrm{a}+\mathrm{c}$ ). This probably results from homogeneous precipitation in small, secondary droplets during transport after prolonged droplet flight times for large nozzle-to-substrate distances, yielding deposits in the form of particles as predicted by Wilhelm et al. ${ }^{13}$ for small droplets and high substrate temperatures. In contrast to large butyl carbitol droplets that do not shrink, these small, secondary droplets might already evaporate during droplet flight, since evaporation rate generally increases with decreasing droplet diameter. However, it should be realized that coating thickness after a constant deposition time (45 minutes) decreased with increasing nozzle-to-substrate distance due to the lower droplet number density close to the substrate. Spreading behavior of large and small droplets and subsequent layer morphology is strongly dependent on coating thickness using ESD ${ }^{5,11}$. This can also be an explanation for the morphological differences between the submicron-porous or grainy underlayers for 
various nozzle-to-substrate distances.

Regarding the influence of the nozzle geometry on coating morphology, PDA measurements revealed that the generated droplets were about $3 \mu \mathrm{m}$ smaller for a one-component nozzle as compared to the standard two-component nozzle (Figure 2). This was also reflected in the resulting surface morphology, which displayed smaller droplet-derived doughnut-shapes for the one-component nozzle (Figure 6e). In a previous study, it was proposed that the longer mixing times of the one-component nozzle were accompanied by a higher degree of dissociation of the polyprotic $\mathrm{H}_{3} \mathrm{PO}_{4}$ in the spraying cone ${ }^{27}$. As a result, the electrical conductivity of the precursor solution increased due to the higher concentration of free protons and charged protonated phosphate groups $\left(\mathrm{H}_{2} \mathrm{PO}_{4}^{-}, \mathrm{HPO}_{4}^{2-}\right)$ in the Taylor-cone. This was confirmed by the observation that higher potential differences $( \pm 1 \mathrm{kV})$ were needed for the one-component nozzle to obtain a stable cone-jet mode. Generally, electrospray droplet sizes decrease with increasing electrical conductivity of the precursor solution $^{14,15}$, which explains why smaller droplets were generated using a one-component nozzle as compared to a two-component nozzle.

\subsection{INFLUENCE OF COMPOSITION OF PRECURSOR SOLUTIONS}

The composition of the precursor solutions had a strong influence on both electrospray characteristics and resulting coating morphologies. Droplet-derived structures such as micron-sized doughnuts or pores were completely absent in the surface morphology of coatings deposited using precursor solution combinations B and $\mathrm{C}$ (Figures $6 \mathrm{f}+\mathrm{g}$ ). PDA measurements revealed that the corresponding droplet sizes were much smaller for solutions $\mathrm{B}(3-3.5 \mu \mathrm{m})$ and $\mathrm{C}(2 \mu \mathrm{m})$ as compared to the average droplet size of $8 \mu \mathrm{m}$ for solution A. These observations are in agreement with electrospraying theory ${ }^{14,15}$, since the electrical conductivity was considerably enhanced by increasing the absolute salt concentration four times (solution B) or by adding extra nitric acid (solution C). According to a deposition diagram describing the surface morphology of ESD-derived YSZ coatings as a function of initial droplet size, precursor concentration and substrate temperature ${ }^{13}$, particle formation prior to droplet landing due to homogeneous precipitation occurred already at substrate temperatures higher than $200{ }^{\circ} \mathrm{C}$ for droplets of $5 \mu \mathrm{m}$ at precursor solute concentrations from 1 to $100 \mathrm{mM}$. These results were obtained using a solvent mixture of butyl carbitol and ethanol (1:1) and a large nozzle-to-substrate distance of $60 \mathrm{~mm}$, whereas pure butyl carbitol and a small nozzle-to-substrate distance of $20 \mathrm{~mm}$ were used here. Nevertheless, it is reasonable to conclude from this diagram that grainy surface morphologies for precursor solutions $\mathrm{B}$ and $\mathrm{C}$ (Figures $6 \mathrm{f}+\mathrm{g}$ ) were formed by particle formation from homogeneous solute precipitation prior to droplet deposition on the substrate, since droplet sizes were significantly below $5 \mu \mathrm{m}$ and the substrate temperature of $400{ }^{\circ} \mathrm{C}$ was much higher than $200{ }^{\circ} \mathrm{C}$. An explanation for the differences in surface morphology between the supersaturated and acidic precursor solution combinations ( $\mathrm{B}$ and $\mathrm{C}$, respectively) is that precipitation kinetics are generally dependent on the particular phase of the $\mathrm{CaP}$ precipitate ${ }^{28}$. In a previous study, it was already shown that the crystal phase of ESD-deposited CaP coatings depended on precursor solution parameters such as acidity and absolute precursor concentration $^{10}$.

\subsection{DEPOSITION OF POROUS, RETICULAR COATINGS}

From the PDA measurements, it can be concluded that the hollow, micron-sized pits at the surface of reticular coating morphologies were derived from the electrospray droplets. 
Criteria for the formation of a reticular structure are amongst others: a) heterogeneous precursor solute precipitation at the edges of relatively large droplets using low precursor solution concentrations, and b) coalescence of droplet edges as a result of droplet spreading over the substrate surface. Droplets are only able to coalesce under very specific conditions controlled by droplet spreading rates/distances (as a function of the deposition temperatures), the number density of the droplets on the substrate surface (as a function of the liquid flow rate and the nozzle-to-substrate distance), and possibly the mutually repulsive forces of the positively charged spray droplets before discharge ${ }^{5}$. The submicron-porosity as shown in Figure 7, however, could not be correlated with the droplet dimensions. We suggest that several drying phenomena can be responsible for the presence of these submicron-sized pores. First of all, solvent boiling on the substrate surface during coating formation may cause this porosity. Second, in a previous study on ESD-deposited CaP coatings ${ }^{10}$, it was argued that $\mathrm{CO}_{2}$ gas is developed upon reaction between acid $\mathrm{HPO}_{4}{ }^{2-}$ and basic $\mathrm{CO}_{3}{ }^{2-}$ groups. In the third place, nitrate anions from the Ca-precursor $\left(\mathrm{Ca}\left(\mathrm{NO}_{3}\right)_{2} \cdot 4 \mathrm{H}_{2} \mathrm{O}\right)$ might decompose into gaseous oxides of nitrogen $\left(\mathrm{NO}_{\mathrm{x}}\right)$, thereby creating submicron-porosity in the deposited coatings.

Figure 9a revealed that reticular coating morphologies are composed of a dense, very thin underlayer (area II, see also Figure 8a), a submicron-porous intermediate layer of variable thickness depending on deposition time (area III), and a rough toplayer of either interconnected or separated, hollow doughnut-shapes (area IV). A constant growth rate was found for these graded coatings up to long deposition times of 8 hours yielding 25 $\mu \mathrm{m}$ thick coatings. This indicates that the decrease in electrical conductivity of the CaPcoated substrate as a result of deposition of an insulating ceramic layer was not sufficient to decrease the electrospraying current according to Ohm's law. Consequently, the deposition rate did not decelerate. Alternatively, droplet discharge rates can be affected by the decreased electrical conductivity of the CaP-coated substrate, thereby influencing droplet residence times after landing on the surface ${ }^{5}$. Other physical factors that change during deposition of porous, ceramic coatings on top of metallic substrates include the wettability (which influences droplet spreading behavior) and thermal conductivity (which influences the surface temperature) of the coated substrates.

\section{Conclusions}

PDA is a powerful technique to correlate spray characteristics with morphological features of the surface of ESD-derived CaP coatings. Variation of the deposition temperature and the nozzle-to-substrate distance showed that ESD of butyl carbitol solutions is a surface-controlled process without any significant solvent evaporation during droplet flight. The chemical composition of the precursor solutions and the mixing characteristics of the calcium and phosphate precursor components strongly influenced initial electrospray droplet sizes, precipitation kinetics of the $\mathrm{CaP}$ solute, and corresponding coating morphologies. Micron-sized surface features of these morphologies, such as doughnut-shapes and pores, were shown to correspond with the diameters of electrospray droplets, pointing out the potential of the ESD technique for synthesis of biomedical CaP coatings with controlled morphology. 


\section{References}

1. Ducheyne P, Qiu Q. Bioactive ceramics: the effect of surface reactivity on bone formation and bone cell function. Biomaterials 1999;20:2287-2303.

2. LeGeros RZ. Biodegradation and bioresorption of calcium phosphate ceramics. Clin Mater 1993;14:6588 .

3. de Bruijn JD, Davies JE, Klein CPAT, de Groot K, van Blitterswijk CA. Biological responses to calcium phosphate ceramics. In: Ducheyne P, Kokubo T, van Blitterswijk CA, eds. Bone-bonding biomaterials. Leiderdorp: Reed Healthcare Communications, 1993, p. 57.

4. Siebers MC, ter Brugge PJ, Walboomers XF, Jansen JA. Integrins as linker proteins between osteoblasts and bone replacing materials. A critical review. Biomaterials 2005;26:137-46.

5. Chen CH, Kelder EM, van der Put PJJM, Schoonman J. Morphology control of thin LiCoO films fabricated using the electrostatic spray deposition (ESD) technique. J Mater Chem 1996;6:765-771.

6. Taniguchi I, van Landschoot $\mathrm{RC}$, Schoonman J. Fabrication of $\mathrm{La}_{1-x} \mathrm{Sr}_{x} \mathrm{Co}_{1-y} \mathrm{Fe}_{y} \mathrm{O}_{3}$ thin films by electrostatic spray deposition. Solid State Ionics 2003;156:1-13.

7. Perednis D, Wilhelm O, Pratsinis SE, Gauckler LJ. Morphology and deposition of thin yttria-stabilized zirconia films using spray pyrolysis. Thin Solid Films 2005;474:84-95.

8. Berkland C, Park DW, Kim K. Controlling surface nano-structure using flow-limited field-injection electrostatic spraying (FFESS) of poly(D,L-lactide-co-glycolide). Biomaterials 2004;25:5649-5658.

9. Uematsu I, Matsumoto H, Morota K, Minagawa M, Tanioka A, Yamagata Y, Inoue K. Surface morphology and biological activity of protein thin films produced by electrospray deposition. J Colloid Interface Sci 2004;269:336-340.

10. Leeuwenburgh SCG, Wolke JGC, Schoonman J, Jansen JA. Influence of precursor solution parameters on chemical properties of calcium phosphate coatings prepared using Electrostatic Spray Deposition (ESD). Biomaterials 2004;25:641-649.

11. Leeuwenburgh SCG, Wolke JGC, Schoonman J., Jansen JA. Influence of deposition parameters on morphological properties of biomedical calcium phosphate coatings prepared using Electrostatic Spray Deposition. Thin Solid Films 2005;472:105-113.

12. Wilhelm O, Madler L, Pratsinis SE. Electrospray evaporation and deposition. J Aerosol Sci 2003;34:815836.

13. Wilhelm O, Pratsinis SE, Perednis D, Gauckler LJ. Electrospray and pressurized spray deposition of yttria-stabilized zirconia films. Thin Solid Films 2005;479:121-129.

14. Gaňán-Calvo AM, Davila J, Barrero A. Current and droplet size in the electrospraying of liquids. Scaling laws. J Aerosol Sci 1997;28:249-175.

15. Fernandez de la Mora J, Loscertales I. The current emitted by highly conducting taylor cones. J Fluid Mech 1997;260:155-184.

16. Hartman RPA, Brunner DJ, Camelot DMA, Marijnissen JCM, Scarlett B. Electrohydrodynamic atomization in te cone-jet mode: physical modeling of the liquid cone and jet. J Aerosol Sci 1999;30:823849 .

17. Heine $M C$, Pratsinis SE. Droplet and particle dynamics during flame spray synthesis of nanoparticles. Ind Eng Chem Res 2005;44:6222-6232. 
18. Hartman RPA, Borra JP, Brunner DJ, Marijnissen JCM, Scarlett B. The evolution of electrohydrodynamic sprays produced in the cone-jet mode, a physical model. J Electrostat 1999;47:143-170.

19. Tang K, Gomez A. On the structure of an electrostatic spray of monodisperse droplets. Phys Fluids 1994;6:2317-2332.

20. Charlesworth DH, Marshall WR. Evaporation from drops containing dissolved solids. AIChe J 1960;6:923.

21. Nesic S, Vodnik J. Kinetics of droplet evaporation. Chem Eng Sci 1991;46:527-537.

22. Messing GL, Zhang SC, Jayanthi GV. Ceramic powder synthesis by spray-pyrolysis. J Am Ceram Soc 1993;76:2707-2726.

23. Luo P, Nieh TH. Preparing hydroxyapatite powders with controlled morphology. Biomaterials 1996;17:1959-1964.

24. Perednis D. Thin film deposition by spray pyrolysis and the application in solid oxide fuel cells. PhD Thesis. ETH Zürich, Zürich, 2003.

25. Chen $\mathrm{CH}$, Kelder EM, Schoonman J. Unique porous $\mathrm{LiCoO}_{2}$ thin layers prepared by electrostatic spray deposition. J Mater Sci 1996;31:5437-5442.

26. Ajaev VS. Spreading of thin volatile liquid droplets ion uniformly heated surfaces. J Fluid Mech 2005;528:279-296.

27. Leeuwenburgh SCG, Wolke JGC, Schoonman J, Jansen JA. Influence of deposition parameters on chemical properties of calcium phosphate coatings prepared by using electrostatic spray deposition. J Biomed Mater Res 2005;74:275-284.

28. Elliott JC. Structure and chemistry of the apatites and other calcium orthophosphates. Amsterdam: Elsevier, 1994. 


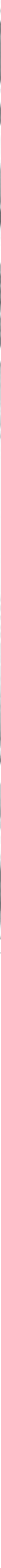




\section{Introduction}

The clinical success of orthopedic and dental implants is strongly affected by their physicochemical surface characteristics, since the actual interaction between biomaterials and the biological surroundings takes place at the exposed surface of an implant ${ }^{1}$. Consequently, research has focused onto surface modification of biomaterials, thereby creating entirely new surfaces which intend to improve the properties of a bulk implant ${ }^{2}$. Because of its similarity to the inorganic component of bone and teeth, synthetic calcium phosphate (CaP) ceramics are considered as candidate materials for bone-substituting applications. However, bulk CaP ceramics are brittle and relatively weak in comparison to implant metals such as titanium (Ti), and high-strength ceramics such as alumina and zirconia. As a coating, however, the excellent biological properties of $\mathrm{CaP}$ ceramics can be combined with the superior mechanical properties of metals ${ }^{3-8}$. For that purpose, Electrostatic Spray Deposition (ESD) can be an interesting alternative to conventional coating techniques such as plasma spraying ${ }^{3,4,7}$ or sputter deposition ${ }^{8}$, since ESD is a simple and versatile technique which allows deposition of $\mathrm{CaP}$ coatings with a wide variety of chemical ${ }^{9}$ and morphological $^{10}$ characteristics.

Generally, CaP coatings must adhere satisfactorily to the underlying substrate in order to maintain their bioactive functionality after surgical installation. In a preliminary study on mechanical properties of electrosprayed $\mathrm{CaP}$ coatings, we have measured a tensile adhesion strength of $36 \pm 5 \mathrm{MPa}$ for reticular, $2 \mu \mathrm{m}$ thick as-deposited ESD-coatings (mean of three coated substrates) according to a test method derived from ASTM C633 ${ }^{11,12}$. However, it has to be noticed that reliable data can only be obtained for coating thicknesses greater than $0.38 \mathrm{~mm}$ using this method ${ }^{13}$. This limitation is imposed because adhesive epoxy bonding agents are used in the test, which tend to penetrate into porosities of the coatings. Moreover, coatings do experience combined shear, bending, tensile, and compressive stresses in vivo, which make that measurement of tensile adhesion strength can be regarded as an oversimplification of the in vivo situation ${ }^{14}$. Therefore, other approaches are needed to evaluate the mechanical properties of porous ESD-coatings under various stress conditions.

In this study, the mechanical properties of reticular, electrosprayed $\mathrm{CaP}$ coatings have been characterized using a range of analysis techniques. First, the fatigue behavior of ESDcoatings was investigated using a three-point bending test method in Simulated Body Fluid under cyclic loading conditions in order to simulate the discontinous forces that act on an implant. Second, scratch testing was performed to obtain insight into the coating deformation mechanism under shear stress. Finally, the adhesion of ESD-coatings to the surface of dental implants was evaluated by implanting cylindrical as well as conical commercially pure titanium implants into an osseous environment (femoral condyle of goat cadavers), followed by electron microscopical and chemical microanalysis of the explants to determine coating maintenance.

\section{Materials and Methods}

\subsection{ELECTROSTATIC SPRAY DEPOSITION (ESD) PROCESS}

$\mathrm{CaP}$ coatings were deposited using downwards-facing electrosprays, which were gen- 
erated by means of a commercially available Electrostatic Spray Deposition (ESD) unit (Advanced Surface Technology, Bleiswijk, The Netherlands). A direct current voltage supply (Fug Elektronik GmbH, HCN 14-20000, Rosenheim, Germany) was used in order to generate a positive high potential difference between the nozzle and grounded substrate, which was heated by a heating plate (Eurotherm Controls 2216, Alphen a/d Rijn, The Netherlands). $\mathrm{Ca}$ and $\mathrm{P}$ precursor solutions were prepared by dissolving $\mathrm{Ca}\left(\mathrm{NO}_{3}\right)_{2} \cdot 4 \mathrm{H}_{2} \mathrm{O}$ (Merck) and $\mathrm{H}_{3} \mathrm{PO}_{4}\left(85 \mathrm{wt} \%\right.$, J.T. Baker) in butyl carbitol $\left(\mathrm{C}_{8} \mathrm{H}_{18} \mathrm{O}_{3}, 99 \%\right.$, Aldrich) at a fixed $\mathrm{Ca} / \mathrm{P}$ ratio of 1.8 . Both precursor solutions were pumped towards a single spraying nozzle (inner and outer diameter of 0.9 and $1.4 \mathrm{~mm}$, respectively) at an equal flow rate of $1.0 \mathrm{ml} / \mathrm{h}$ using a syringe pump (Kd Scientific 220, New Hope, PA, USA), yielding an effective flow rate of $2 . \mathrm{ml} / \mathrm{h}$ at the nozzle outlet.

\subsection{TEST SPECIMENS}

$\mathrm{CaP}$ coatings were electrosprayed onto 1) grit-blasted, unnotched gauge sections of Ti-6Al-4V bars $\left(180 \times 23 \times 3 \mathrm{~mm}\right.$, average surface roughness $\left.\mathrm{R}_{\mathrm{a}}=4.9 \mu \mathrm{m}\right)$ for fatigue testing, and onto 2) as-received, machined commercially pure Ti discs (diameter $12 \mathrm{~mm}$, thickness 1.5, average surface roughness $\mathrm{R}_{\mathrm{a}}=0.3 \mu \mathrm{m}$ ) for scratch testing. The deposition temperature was $350{ }^{\circ} \mathrm{C}$ for both substrate geometries in order to produce coatings with a reticular surface morphology ${ }^{10}$. Ti discs for scratch testing were coated at a nozzle-tosubstrate distance of $20 \mathrm{~mm}$, a potential difference of $6.2 \mathrm{kV}$, and a deposition time of 45 minutes, yielding a layer thickness of 2.0-2.5 $\mu \mathrm{m}$. Ti bars for fatigue testing were coated at a larger nozzle-to-substrate distance of $30 \mathrm{~mm}$ in order to ensure coverage of the entire bar width. The potential difference was $7.3 \mathrm{kV}$, and the deposition time was increased to 60 minutes, yielding a coating thickness of 1.5-2.0 $\mu \mathrm{m}$. Screw-shaped dental implants with two different geometries (Figure 1) were used for the implantation study:

- Conical, commercially pure Ti implants (Biocomp, Vught, The Netherlands) of $10 \mathrm{~mm}$ length ranged in diameter from $4.0 \mathrm{~mm}$ at the coronal part to 3.4 at the apical part, and contained two separate, threaded areas. These implants had already received a $50 \mu \mathrm{m}$ thick plasma-sprayed Ti coating (CAM Implants, Leiden, The Netherlands) to increase their average surface roughness $\mathrm{R}_{\mathrm{a}}$ to about $5.5 \mu \mathrm{m}$.

- Cylindrical, threaded commercially pure Ti implants (BTI, Vitoria, Spain) with a length of $10 \mathrm{~mm}$ and a diameter of $3.3 \mathrm{~mm}$. Only at the apical part, the implant diameter gradually decreased to $2.5 \mathrm{~mm}$. In contrast to conical implants (Biocomp), these cylindrical implants were self-tapping.

Figure 1: Conical (Biocomp) and cylindrical (BTI) dental implants.

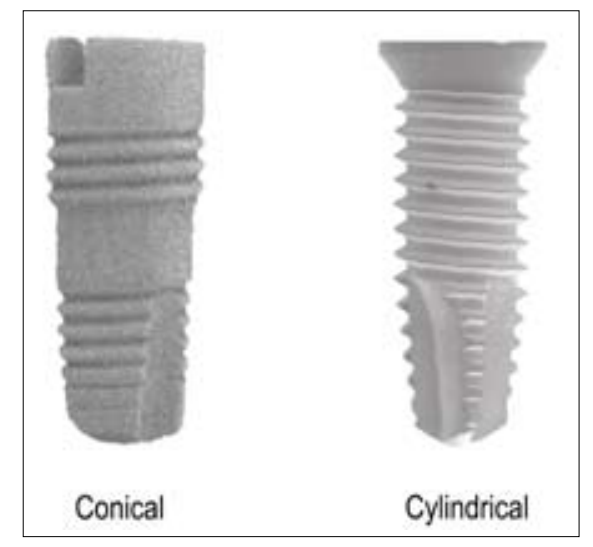


Both dental implant geometries were coated with a reticular, porous CaP layer using a cast $\mathrm{CoCr}$ implant holder ("negative") to ensure sufficient heating of the dental implants ("positive") by the flat heating plate. Implants were coated in three runs (in turns of $120^{\circ}$ ) of 45 minutes at a deposition temperature of $470{ }^{\circ} \mathrm{C}$ (conical implant) or $440{ }^{\circ} \mathrm{C}$ (cylindrical implant) and at a nozzle-to-substrate distance of $20 \mathrm{~mm}$, producing reticular coatings with a thickness of 2.0-2.5 $\mu \mathrm{m}$. Light and electron microscopy were used to ensure complete coverage of the implants by the CaP coatings. In total, 6 conical (Biocomp) and 6 cylindrical (BTI) implants were prepared for implantation.

All ESD-coated Ti discs, bars, and dental implants were either left untreated or subjected to additional heat-treatments at $500{ }^{\circ} \mathrm{C}$ or $700{ }^{\circ} \mathrm{C}$ for 2 hours at controlled heating and cooling rates of $100^{\circ} \mathrm{C}$ per hour. Untreated coatings were designated as amorphous calcium phosphate (ACP), whereas heat-treated coatings were designated as carbonate apatite (CA, heat-treated at $\left.500{ }^{\circ} \mathrm{C}\right)$, or carbonated hydroxyapatite $\left(\mathrm{CHA}\right.$, heat-treated at $\left.700{ }^{\circ} \mathrm{C}\right)$. The chemical and crystallographic structure of the resultant coatings have been discussed in a previous study on electrosprayed $\mathrm{CaP}$ coatings ${ }^{15}$. Briefly, the major structural difference between $\mathrm{CA}$ (heat-treated at $500{ }^{\circ} \mathrm{C}$ ) and $\mathrm{CHA}$ (heat-treated at $700{ }^{\circ} \mathrm{C}$ ) coatings was the presence of $\mathrm{OH}^{-}$groups in the apatitic lattice of $\mathrm{CHA}$ coatings after heat-treatment at 700 ${ }^{\circ} \mathrm{C}$, whereas $\mathrm{CA}$ coatings did not reveal $\mathrm{OH}^{-}$absorptions and displayed a higher carbonate content. Consequently, CHA coatings were slightly more crystalline than CA coatings.

\subsection{FATIGUE TESTING}

Fatigue testing was performed on untreated ACP- and heat-treated CA-coatings according to a three-point bending method (ASTM E855) using an MTS testing machine. Test specimens were positioned on two supports (separation distance $108 \mathrm{~mm}$ ) and loaded centrally with a hemispherical indenter, while the coatings were facing downward. The load amplitude was set at $390 \mathrm{~N}$ corresponding to a mid-specimen deflection of $2 \mathrm{~mm}$, which gave rise to bending stresses of about $280-300 \mathrm{MPa}^{16,17}$. Each specimen $(n=2)$ was subjected to $10^{6}$ load cycles at a frequency of $7 \mathrm{~Hz}$, corresponding to a testing time of 40 hours. In an attempt to mimic the in vivo environment, all tests were performed under wet conditions in a container filled with Simulated Body Fluid. Ionic concentrations of SBF were almost equal to human plasma ${ }^{18}: 142.0 \mathrm{mM} \mathrm{Na}^{+}, 5.0 \mathrm{mM} \mathrm{K}^{+}, 1.5 \mathrm{mM} \mathrm{Mg}^{2+}, 2.5 \mathrm{mM}$ $\mathrm{Ca}^{2+}, 147.8 \mathrm{mM} \mathrm{Cl}^{-}, 4.2 \mathrm{mM} \mathrm{HCO}_{3}{ }^{2-}, 1.0 \mathrm{mM} \mathrm{HPO}_{4}{ }^{2-}$, and $0.5 \mathrm{mM} \mathrm{SO}_{4}^{2-}$. Tris- $\mathrm{HCl}$ served as a buffer to maintain a constant $\mathrm{pH}$ value of 7.4 , whereas the temperature was kept at 25 ${ }^{\circ} \mathrm{C}$. In order to separate the influence of coating dissolution in SBF from the effect of cyclic loading, coated bars were also immersed in SBF (coating facing downwards) without cyclic loading for a similar time of 40 hour.

After the fatigue tests, all CaP-coated bars were thoroughly rinsed with distilled water and subsequently analyzed using Scanning Electron Microscopy (SEM, Jeol, SEM6310, Tokyo, Japan), reflection Fourier-Transform InfraRed spectroscopy (FTIR, Perkin Elmer, Spectrum One, Groningen, The Netherlands), thin-film X-Ray Diffraction (XRD, Panalytical, PW3710, Almelo, The Netherlands), and Energy Dispersive Spectroscopy (EDS, Noran Instruments, Voyager, Middleton WI, USA).

\subsection{SCRATCH TESTING}

Scratch tests were performed on ACP-, CA-, and CHA-coatings by using a Universal Surface Tester (UST, Innowep GmbH, Würzburg, Germany). This apparatus enabled separate measurement of plastic and elastic deformation by scanning three times over exactly 
Figure 2: Schematic drawing of the sharp scratch diamond.

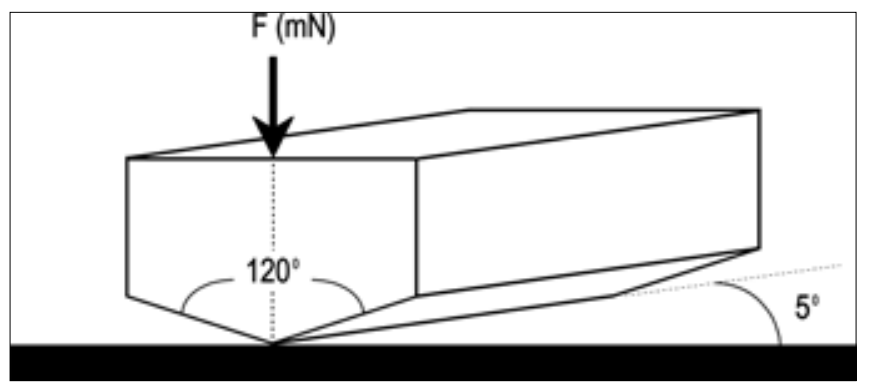

the same track ${ }^{19,20}$. The first and third scans were performed in the profilometer mode at a minimum vertical force of $1.0 \mathrm{mN}$, whereas the actual scratch was imposed onto the coating surface during the second scan, in which the force was increased along the scratch path. The difference in recorded height profile between the third and second scan equals the reversible elastic deformation, whereas the difference between the first and third scan corresponds to permanent plastic deformation.

Two different styli were used to produce scratches on the test specimens: a steel ball stylus with a tip radius of $0.40 \mathrm{~mm}$ was used to determine the influence of a blunt type of indenter on the mechanical integrity of the coatings, whereas a scratch diamond was employed to examine the localized deformation induced by a very sharp stylus. This scratch diamond has a flat front with a tip angle of $120^{\circ}$, whereas the angle between the substrate surface and oblique bottom of the stylus was $5^{\circ}$ (Figure 2). Scratches of $0.50 \mathrm{~mm}$ length were produced in triplicate at a scanning speed of $0.10 \mathrm{~mm} / \mathrm{s}$, while the vertical force was increased in 10 steps from $1.0 \mathrm{mN}$ to $5,10,20,50$, and $100 \mathrm{mN}$ (maximum apparatus load). After testing, all scratched areas were analyzed by means of SEM and EDS.

\subsection{EXPLANTATION OF DENTAL SCREW IMPLANTS}

A goat cadaver model was used to evaluate the adhesion of electrosprayed ACP-, CA-, and CHA-coatings on the above described dental implants. After euthanasia of mature Saanen goats, femoral condyles were excised and stored in distilled water until the implants were installed. Holes were drilled into the trabecular bone of the exposed femoral condyles under continuous cooling using different drills up to a final diameter of $2.5 \mathrm{~mm}$ (cylindrical implants) or $3.6 \mathrm{~mm}$ (conical implants). As a consequence, cylindrical implants (BTI) were inserted into an undersized hole (implant diameter of $3.3 \mathrm{~mm}$ vs. hole diameter of $2.5 \mathrm{~mm}$ ). On the contrary, conical implants were inserted oversized at the upper coronal part (implant diameter of $4.0 \mathrm{~mm}$ vs. drill hole diameter of $3.6 \mathrm{~mm}$ ), press-fit at the smooth middle part, and undersized at the apical part (implant diameter of $3.2 \mathrm{~mm}$ vs. drill hole diameter of $3.6 \mathrm{~mm}$ ). The implants were inserted and immediately explanted by means of unscrewing, whereafter the implants were carefully brushed and cleaned in distilled water to remove adherent tissue debris. After drying the implants overnight at $40^{\circ} \mathrm{C}$, SEM and EDS were carried out on all explants.

\section{Results}

\subsection{FATIGUE TESTING}

Figures 3a-e show the scanning electron micrographs of electrosprayed CaP coatings 
before (Figure 3a) and after fatigue testing in SBF (Figures 3b-e). The original surface morphology of ACP-coatings consisted of a reticular network of interconnected, micronsized (surface) pores, and heat-treatment at $500{ }^{\circ} \mathrm{C}(\mathrm{CA})$ did not alter the surface morphology (Figure 3a). After soaking ACP-coatings in SBF for 40 hours, remnants of the original surface structure were still recognizable, but the coatings had dissolved considerably (Figure 3b). The tendency of ACP-coatings to dissolve in SBF was further accelerated by means of cyclic loading, after which coating remnants were only vaguely perceptible (Figure 3c). On the contrary, CA-coatings did not loose their reticular surface architecture, although surface pores were occasionally filled with globular precipitations after soaking in SBF only (Figure 3d) or cyclic loading (Figure 3e). The capacity of ESD-coatings to

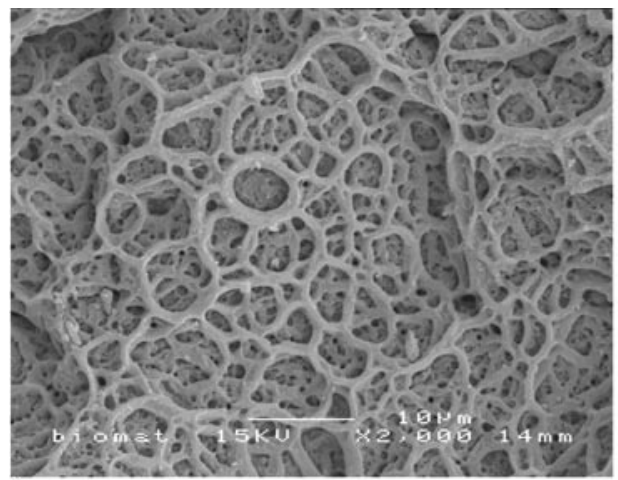

$3 \mathrm{a}$

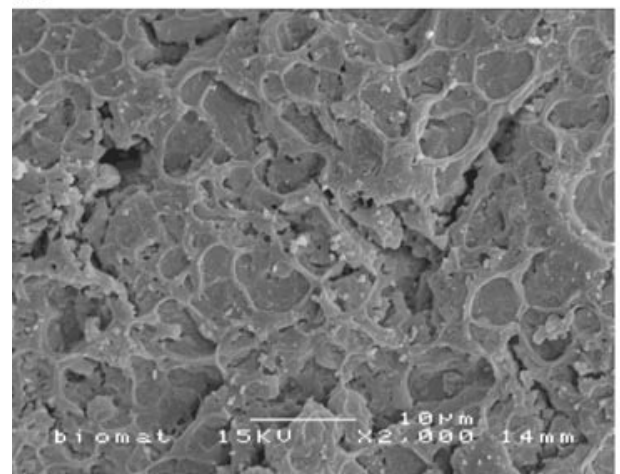

$3 \mathrm{~b}$

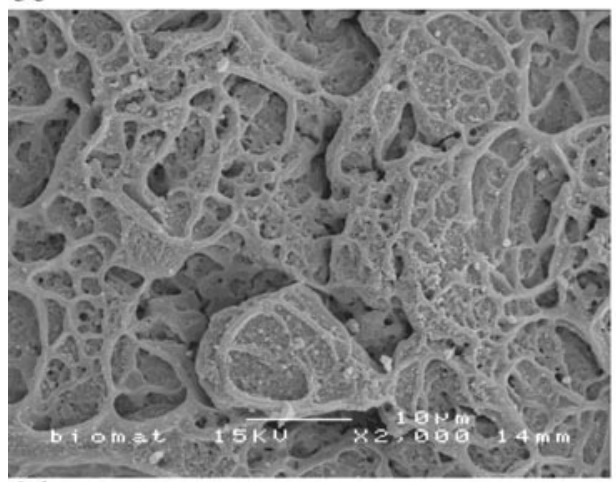

$3 \mathrm{~d}$
Figure 3: Scanning electron micrographs of electrosprayed CaP-coatings after deposition [a], after static immersion of an amorphous ACP-coating in $S B F[b]$, after cyclic loading of an amorphous ACP-coating in $S B F[c]$, after static immersion of a crystalline $C A$ coating in $S B F[d]$, and after cyclic loading of a crystalline CA-coating in $S B F[e]$.

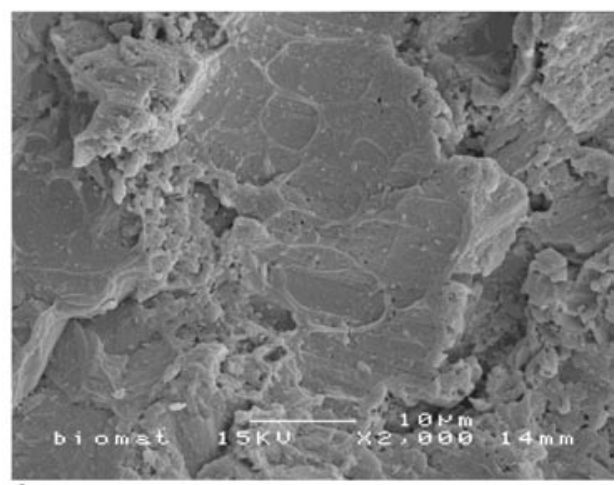

$3 \mathrm{c}$

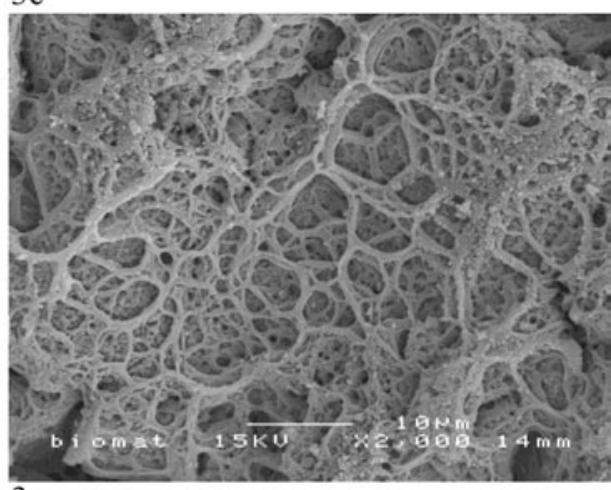

$3 \mathrm{e}$ 
induce $\mathrm{CaP}$ formation in vitro was already described in a previous paper on the calcification behavior of electrosprayed CaP coatings in $\mathrm{SBF}^{15}$.

The corresponding FTIR spectra of electrosprayed coatings before and after cyclic loading or soaking in SBF are shown in Figures 4a-b. ACP-coatings revealed broad, unresolved absorption bands at $1650 \mathrm{~cm}^{-1}\left(\mathrm{H}_{2} \mathrm{O}\right)$, between $1300-1500 \mathrm{~cm}^{-1}\left(\mathrm{CO}_{3}\right)$, and $900-1200$ $\mathrm{cm}^{-1}\left(\mathrm{PO}_{4}^{3-}\right)$, which are characteristic for amorphous ESD-derived CaP coatings (Figure 4a, lower spectrum $)^{21}$. After soaking in SBF, the intensity of these absorptions had decreased considerably (Figure 4a, middle spectrum), whereas absorption peaks had almost disappeared after cyclic loading (Figure 4a, upper spectrum). This indicates that amorphous ESD-coatings dissolved upon static immersion in SBF, whereas the dissolution rate was slightly accelerated when the coatings were also cyclically loaded in SBF. In contrast to these amorphous ESD-coatings, FTIR spectra of crystalline CA-coatings (Figure 4b, lower spectrum) did not show any significant alterations after static immersion in SBF (Figure 4b, middle spectrum), or upon cyclic loading (Figure 5b, upper spectrum). Sharp carbonate absorption peaks (at 1454, 1416, and $872 \mathrm{~cm}^{-1}$ ) and phosphate peaks/shoulders (at 1083, 1015, 960, and $561 \mathrm{~cm}^{-1}$ ) corresponded to a crystalline carbonate-containing CaP phase (Figure $4 \mathrm{~b}$, lower spectrum), the absorption peaks of which did not change in intensity after static or dynamic testing (Figure 4b, middle and upper spectrum, respectively). XRD of these crystalline ESD-coatings showed peaks at $25.8^{\circ}, 31.8^{\circ}$, and $32.9^{\circ} 2 \theta$, corresponding to the major reflections of the (carbonate) apatite structure (JCPDS File No. 9-432) (data not shown).

Figure 4: FTIR spectra of electrosprayed amorphous ACP [a] and crystalline CA-coatings [b] after deposition (lower spectra), after static immersion in SBF (middle spectra), and after cyclic loading in SBF (upper spectra).

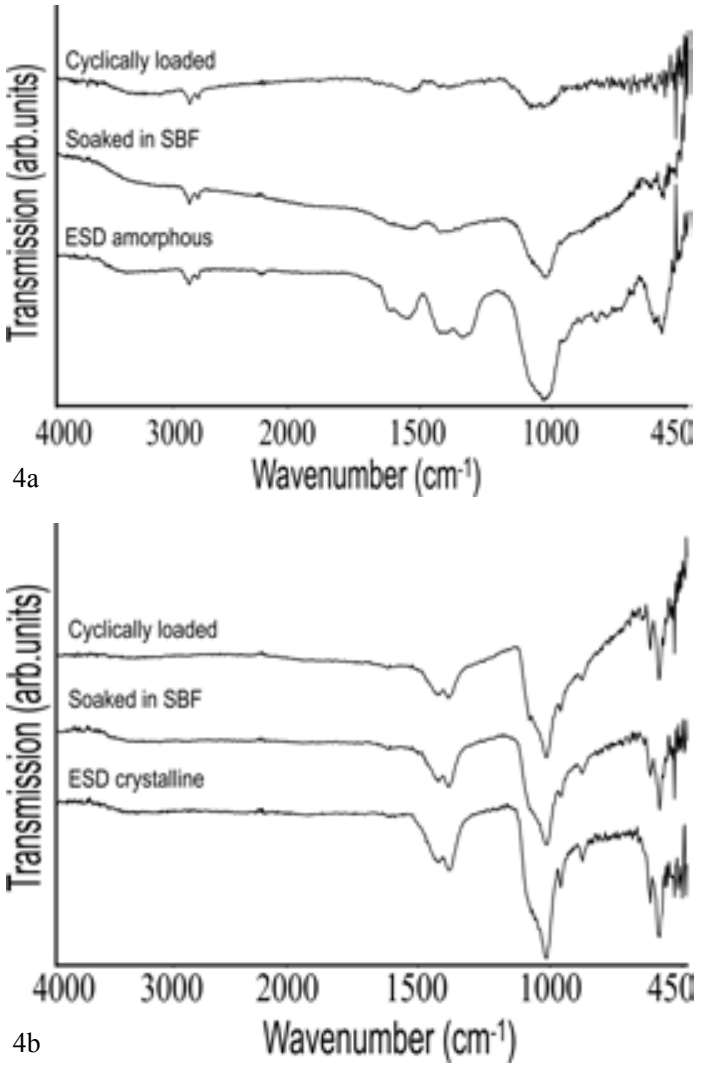




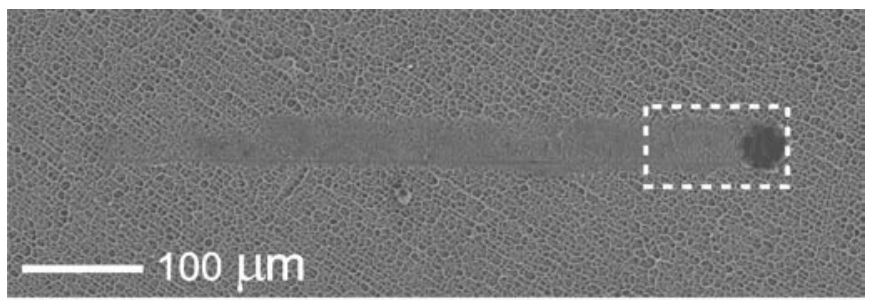

Figure 5: Scanning electron micrographs of a $0.50 \mathrm{~mm}$ scratch, produced by a ball stylus under a stepwise increasing load (final load $100 \mathrm{mN}$ ) on an amorphous ESD-coating (ACP) at low [a] and high [b] magnification.

$5 \mathrm{a}$

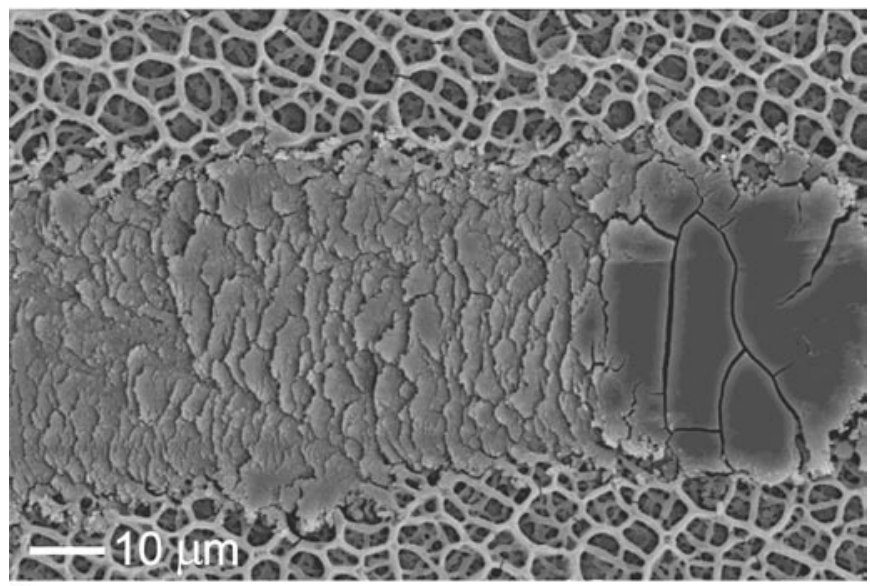

$5 \mathrm{~b}$

\subsection{SCRATCH TESTING}

Figures 5a-b show low- (Figure 5a) and high-magnification (Figure 5b) scanning electron micrographs of a $0.50 \mathrm{~mm}$ scratch, which was produced on reticular ACP-coatings by means of a blunt ball stylus (final load $100 \mathrm{mN}$ ). Generally, well-defined failure modes with clearly recognizable events along the track (such as delamination, chipping, or complete stripping of the coating) were not observed for any of the ESD-coatings using this ball stylus, which impeded unambiguous determination of the so-called critical load $\mathrm{L}_{\mathrm{c}}$ as a quantitative measure for coating adhesion. Instead, Figure 5a reveals clearly that the reticular surface structure of ACP-coatings was gradually deformed with increasing vertical load (from left to right). The endpoint of the scratch track was characterized by a clear spot resulting from an unavoidable bouncing movement of the stylus holder after the scratch was made, thereby compressing the local porous structure. The width of the scratch remained constant over the visible length of the scratch, indicating that the penetration depth of the ball stylus was also constant. From the ball stylus diameter $(0.40 \mathrm{~mm})$ and measured scratch width $(40-50 \mu \mathrm{m})$, the penetration depth was calculated to be about 0.5-0.6 $\mu \mathrm{m}$, which corresponded to the average plastic deformation value of $0.61 \mu \mathrm{m}$ as recorded by means of the profilometry capability of the UST apparatus. At higher magnification (Figure $5 \mathrm{~b}$ ), the ploughing mode of deformation can be observed in more detail. Pore walls of the reticular structure are spread out over the surface by the ball stylus into regularly stacked, overlapping $\mathrm{CaP}$ layers according to a ductile failure mode. However, the substrate was not exposed due to stripping of the coating. $\mathrm{Ca}$ and $\mathrm{P}$ signals were much more intense than $\mathrm{Ti}$ substrate peaks at the endpoint of the scratch track, as observed using EDS at an acceleration voltage of $15 \mathrm{kV}$.

Figures 6a-d show low (6a) and high-magnification (b-d) scanning electron micro- 
graphs of $0.50 \mathrm{~mm}$ scratches on various reticular ESD-coatings, which were produced by means of a scratch diamond (final load $100 \mathrm{mN}$ ). As before, it was impossible to determine quantitative values for the critical load $\mathrm{L}_{\mathrm{c}}$, since all ESD-coatings displayed a ductile deformation behavior characterized by progressive ploughing of the scratch diamond into the reticular coatings (Figure 6a). Well-defined failure modes were only observed at the very end of the scratches made on ACP-coatings at the maximum load of $100 \mathrm{mN}$. The scratch diamond had completely penetrated through the ACP-coating at this location, and large coating fragments occasionally delaminated from the Ti substrate, as shown in the tilted micrograph of the scratch endpoint (Figure 6b). At these delaminated areas, $\mathrm{Ca}$ and $\mathrm{P}$ signals were not detected anymore by means of EDS. Final scratch widths on CA-coatings were comparable to ACP-coatings, but delamination was not observed anymore (Figure 6c). Scratches made on CHA-coatings were considerably narrower than on CHA and CAcoatings ( $10 \mu \mathrm{m}$ for CHA vs. $20 \mu \mathrm{m}$ for ACP and CA-coatings, and delamination was never observed on CHA-coatings (Figure 6d). Chemical microanalysis of the deepest part of the scratches by the EDS technique revealed that the Ti substrate was still partly covered with the CHA-coating, as significant $\mathrm{Ca}$ and $\mathrm{P}$ peaks were still detected.

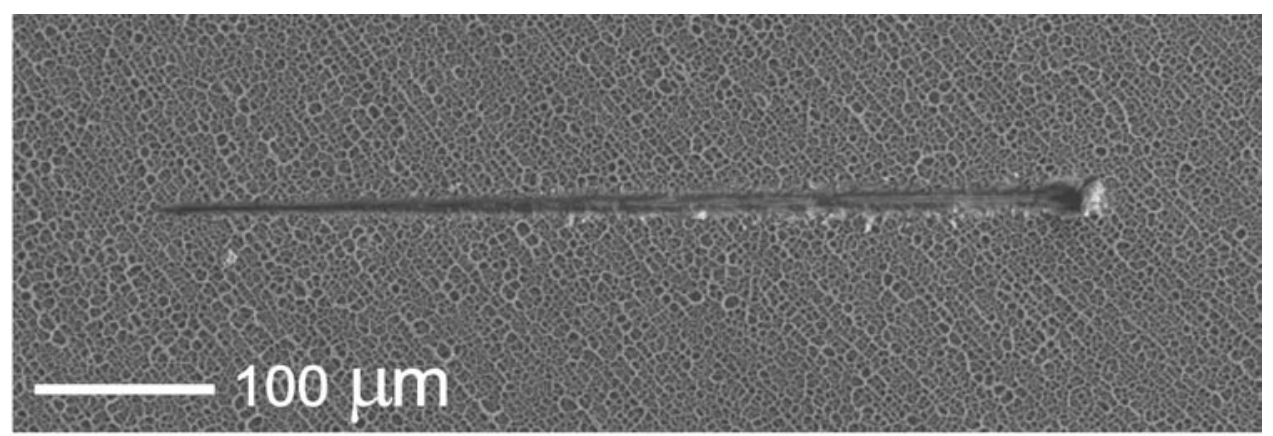

$6 \mathrm{a}$

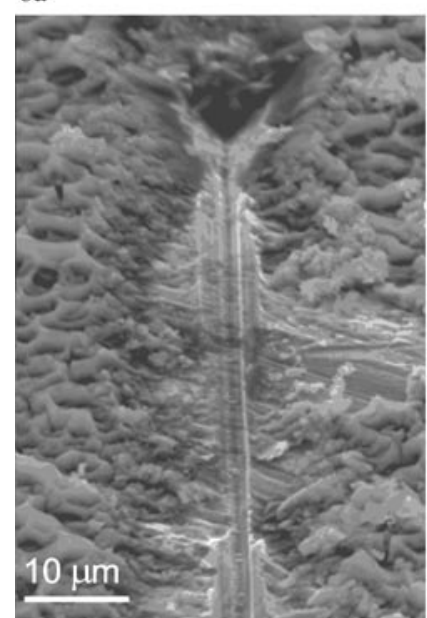

$6 \mathrm{~b}$

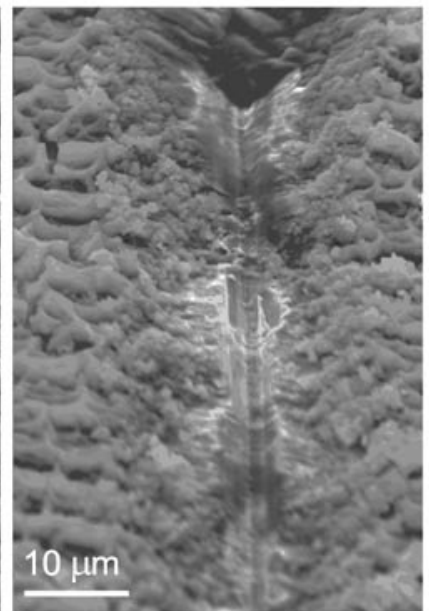

$6 \mathrm{c}$

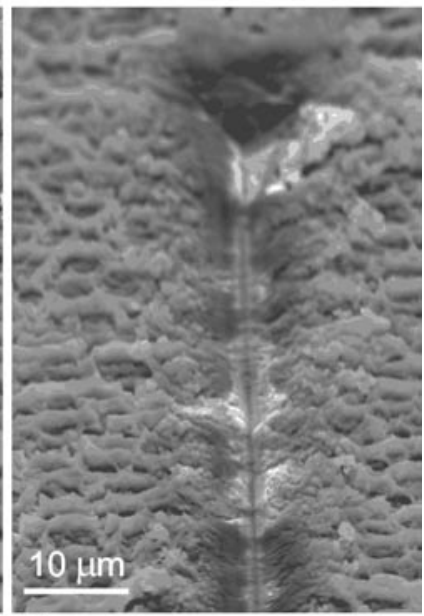

$6 \mathrm{~d}$

Figure 6: Scanning electron micrographs of $0.50 \mathrm{~mm}$ scratches produced on various electrosprayed coatings by means of a sharp scratch diamond under a stepwise increasing load (final load $100 \mathrm{mN}$ ) at low [a] and high magnification [b-d]: [a] ACP-coating; [b] tilted $\left(60^{\circ}\right)$ scratch endpoint on ACP-coating; [c] tilted $\left(60^{\circ}\right)$ scratch endpoint on CA-coating; [d] tilted $\left(60^{\circ}\right)$ scratch endpoint on CHA-coating. 
Figure 7a shows typical scratch test height profiles produced on CHA-coatings using a sharp scratch diamond which was loaded up to $100 \mathrm{mN}$. Initially, all three scans were almost overlapping, but during the first loading step (after a horizontal scratch distance of $0.075 \mathrm{~mm}$ corresponding to a vertical load of $10.9 \mathrm{mN}$ ), the second and third scans started to deviate from the first scan as a result of deformation. Many fine roughness peaks of the first scan were absent after the second and third scan, corresponding to a smoothening of the reticular coating. The corresponding elastic, plastic and total deformations of this scratch are depicted in Figure $7 \mathrm{~b}$. Elastic deformations started at slightly negative values, which was attributed to small positioning errors due to the unavoidable bouncing movement of the stylus holder upon scratch initiation. From a scratching distance of $0.075 \mathrm{~mm}$ onward, elastic deformation started to increase linearly up to final values of about $1.0 \mu \mathrm{m}$. Elastic deformations were identical for all coated and uncoated substrates, indicating that elastic deformation was mainly related to the underlying substrate. Plastic deformation was about $0.7-0.8 \mu \mathrm{m}$ after the first loading step, but this ploughing depth did not increase any further along the remaining scratch path. The average plastic deformation along the entire scratch track for this CHA-coating was calculated to be $0.76 \mu \mathrm{m}$.
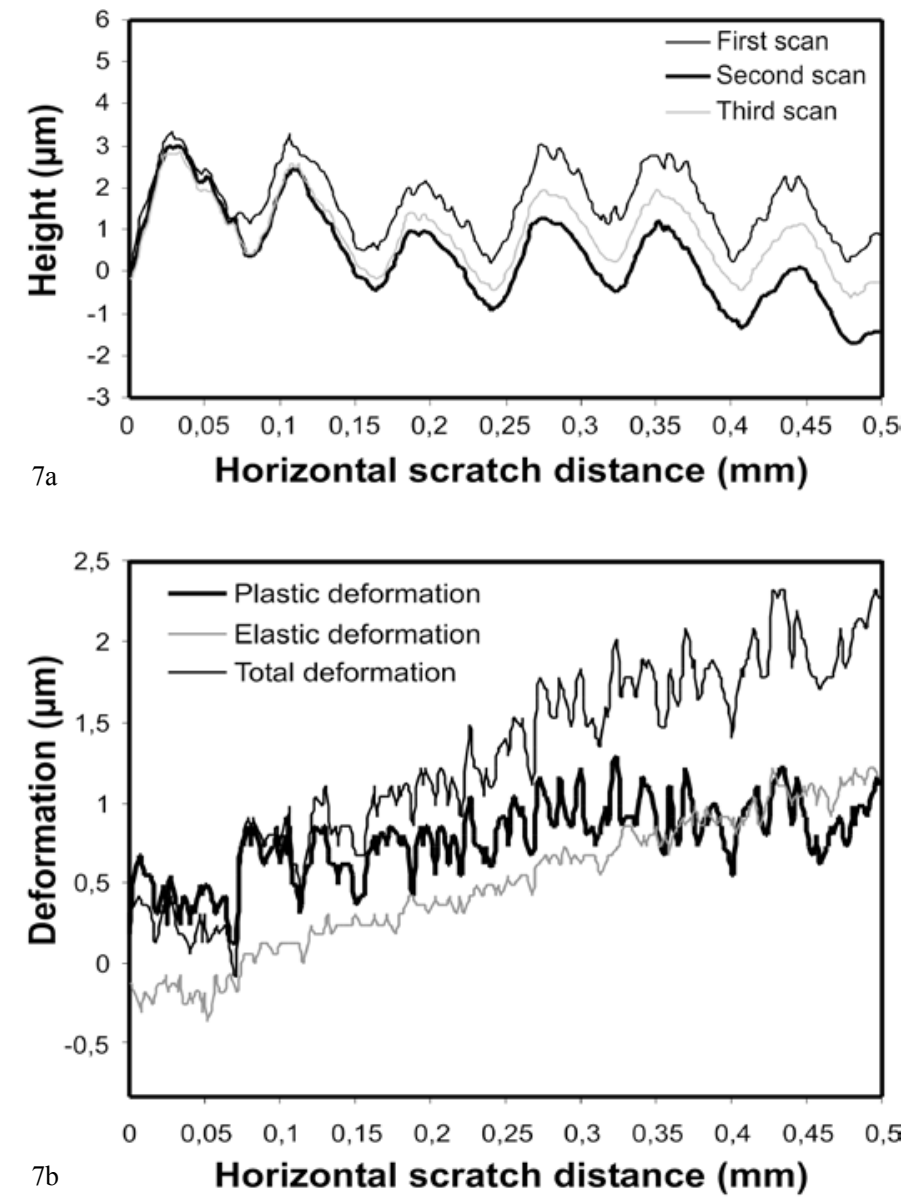

Figure 7: Scratch test height profiles [a] and corresponding deformations [b], produced by a scratch diamond under a stepwise increasing load (final load $100 \mathrm{mN}$ ) on $\mathrm{CHA}$ coatings. 
Figure 8: Average plastic deformation of scratches, produced by a scratch diamond under a stepwise increasing load up to various final loads (from 5 to $100 \mathrm{mN}$ ) on several electrosprayed coatings (ACP, $C A$, and $C A$ ).

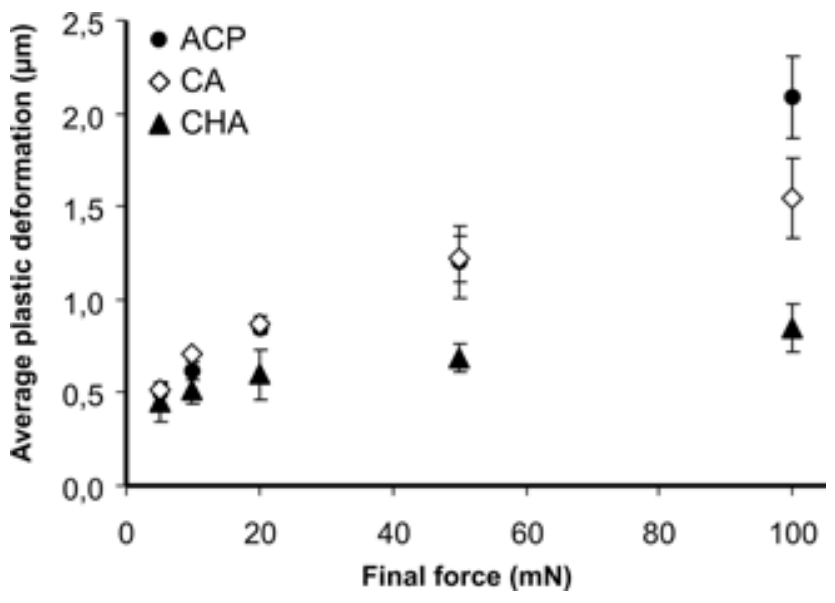

These average plastic deformations (mean \pm SD) are plotted in Figure 8 against the final vertical load for ACP (circles), CA (diamonds), and CHA coatings (triangles). Initially, all ESD coatings were plastically deformed at equal levels of about $0.4-0.5 \mu \mathrm{m}$ under a vertical load of $5 \mathrm{mN}$. However, at the highest final load of $100 \mathrm{mN}$, ACP-coatings (circles) were penetrated more than $2.0 \mu \mathrm{m}$ by the scratch diamond, whereas CA-coatings (diamonds) revealed a lower ploughing depth of about $1.5 \mu \mathrm{m}$. CHA-coatings (triangles) were more resistant to plastic deformation than ACP- and CA-coatings, as reflected by the low ploughing depths for CHA coatings. In order to obtain more evidence for this latter statement, some of the earlier scratched ACP-coatings were heat-treated at $700{ }^{\circ} \mathrm{C}$ and subsequently scratched again on previously unscratched areas. Observed plastic scratch deformations decreased towards exactly the same values as found earlier for the CHAcoatings, that were not scratched prior to heat-treatment.

\subsection{EXPLANTATION OF DENTAL SCREW IMPLANTS}

Figures 9a-h show the SEM-images of threaded parts of conical (left column, Biocomp) and cylindrical (right column, BTI) dental Ti implants before (Figures 9a+b) and after (Figures $9 \mathrm{c}-\mathrm{h}$ ) implantation into the trabecular bone of femoral condyles of goat cadavers. Asdeposited, reticular ESD-coatings were deposited homogeneously over the entire surface of conical (Figure 9a) as well as cylindrical (Figure 9b) implants. In some cases, proper analysis of explanted conical implants by means of SEM and EDS was hampered by the fact that these roughened implants were difficult to clean. As a result, a thin, adherent layer of proteinaceous tissue debris was remaining on the surface. Still, it can be concluded that the typical reticular coating morphology was not maintained after explantation of both conical and cylindrical ACP-coated dental implants (Figures 9c and 9d, respectively). Heattreated, crystalline CA-coatings also lost most of the reticular surface architecture following im- and explantation, as shown in Figures 9e+f. However, conical implants (Figure 9e) clearly revealed remnants of the original reticular CA-coating, the pores of which were partly filled with organic debris. The reticular morphology could still be recognized on the surface of conical CHA-coated implants (Figure 9g), whereas CHA-coatings were only removed from the peaks of the very sharp screw threads of cylindrical implants (Figure 9h). The remaining parts of the implants were still covered with an adherent $\mathrm{CHA}$-layer, which was also slightly deformed and/or filled with tissue debris. Ca and P signals of CHA-coated 


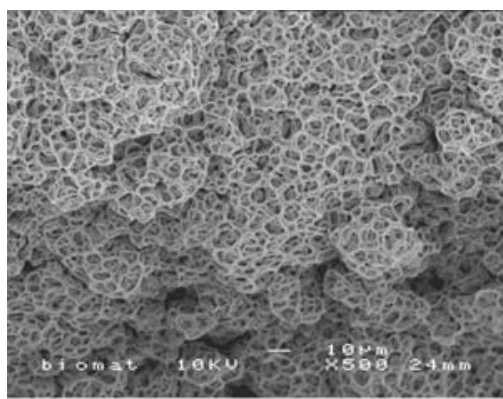

$9 \mathrm{a}$

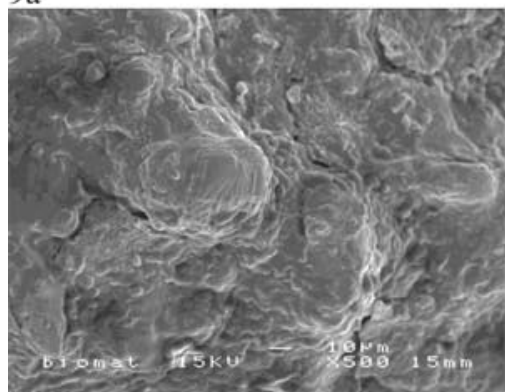

$9 \mathrm{c}$

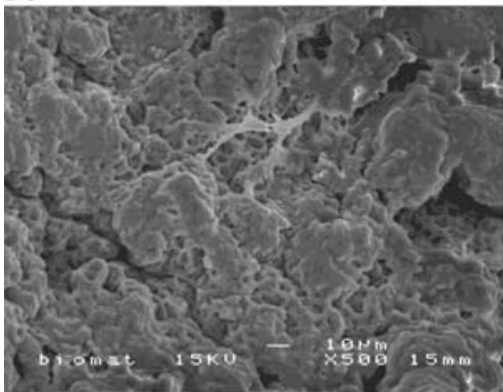

$9 \mathrm{e}$

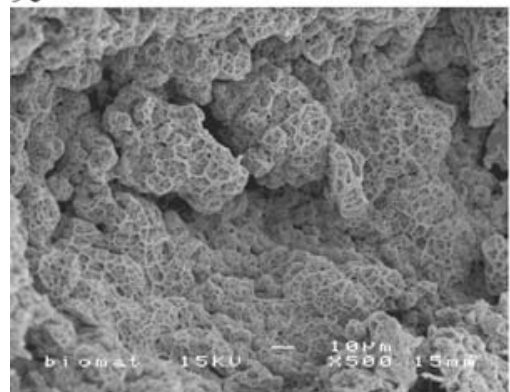

$9 \mathrm{~g}$

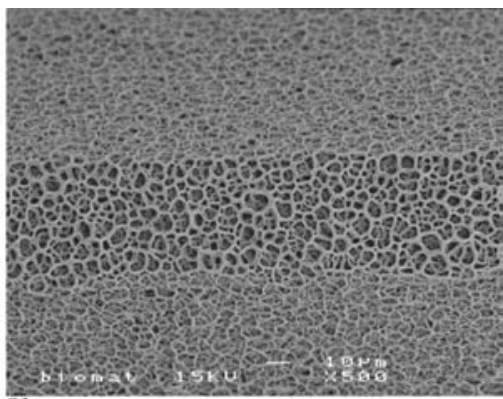

$9 \mathrm{~b}$

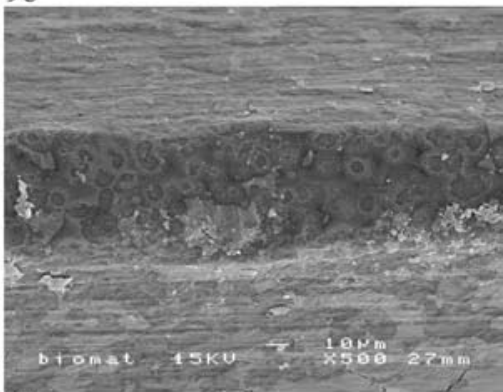

$9 d$

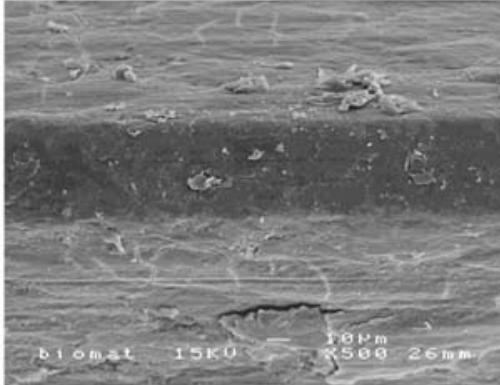

$9 f$

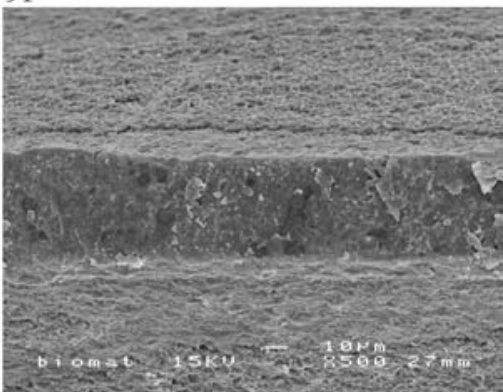

$9 \mathrm{~h}$

Figure 9: Scanning electron micrographs of threaded parts of conical (left column, Biocomp) and cylindrical (right column, BTI) dental Ti implants before implantation [a+b] and after explantation [c-h] from trabecular bone of femoral condyles of goat cadavers: [a] conical implant before implantation; [b] Cylindrical implant before implantantation; [c] explanted ACP-coated conical implant; [d] explanted ACP-coated cylindrical implant; [e] explanted CA-coated conical implant; [f] explanted CA-coated cylindrical implant; [g] explanted CHA-coated conical implant; [h] explanted CHA-coated cylindrical implant. 
implants were more intense than ACP- and CHA-coatings, as observed using EDS.

Further, ESD-coatings were much less deformed at the apical parts than at the threaded middle and coronal parts. Evidently, this is the consequence of the implant geometry, i.e. the apical part of both implant geometries was undersized and thus less subjected to plastic deformation by means of shear stresses. ESD-coatings within the grooves perpendicular to the screw threads remained largely intact.

\section{Discussion}

The aim of the current study was to investigate the mechanical properties of reticular, electrosprayed $\mathrm{CaP}$ coatings using a range of analysis techniques. Preliminary tensile testing (ASTM C633) revealed an adhesion strength of $36 \pm 5 \mathrm{MPa}$ under tensile stresses. However, this method is invalid for thin, porous coatings ${ }^{13}$. Therefore, alternative methods were selected to evaluate the mechanical properties of ESD-derived coatings, including fatigue testing, scratch testing, and implantation of ESD-coated dental implants into femoral condyles of goat cadavers.

\subsection{FATIGUE TESTING}

The fatigue behavior of ESD-derived CaP coatings was investigated using a cyclic, three-point bending test method (ASTM E855) in SBF. XRD, FTIR, and SEM analyses revealed that ACP-coatings gradually dissolved upon static immersion in SBF, while coating dissolution was slightly accelerated due to cyclic loading. On the contrary, crystalline CA ESD-coatings did not show any significant alterations in coating structure and morphology after cyclic loading in SBF. Clemens et al. ${ }^{16}$ and Wolke et al. ${ }^{17}$ also observed that crystallization of plasma-sprayed and sputtered $\mathrm{CaP}$ coatings increased their resistance to crack formation and fatigue failure. The highly porous and compliant structure of the tested ESD-coatings was expected to ensure a relatively high bending flexibility, low amounts of internal stresses, and therefore a low tendency towards crack formation and coating degradation as a result of cyclic loading.

\subsection{SCRATCH TESTING}

Scratch testing using a blunt ball stylus revealed a ductile failure mode of reticular $\mathrm{CaP}$ coatings. This ductile failure mode was described by $\mathrm{Bull}^{22}$ as a failure mechanism characterized by small areas of uncovered substrate which are confined within the scratch track, whereas brittle failure is more extensive and often extends beyond the limits of the scratch track. Bull stated that there is a requirement for ductile failure for the best scratch adhesion, since critical loads $\mathrm{L}_{\mathrm{c}}$ for ductile failure are much higher than those observed for brittle materials. Indeed, using a blunt ball stylus with a diameter in the same size range as a conventional Rockwell C stylus $(0.8 \mathrm{~mm}$ for the ball stylus vs. a tip diameter of $0.4 \mathrm{~mm}$ for Rockwell C), the maximum apparatus load of $100 \mathrm{mN}$ was by far not enough to delaminate the coating. Still, the reticular surface structure of these ESD-coatings appeared to be fragile and was severely deformed during the scratch tests. Wang et al..$^{23}$ reported the same effect for fragile OCP-coatings with flake-like morphologies, which displayed lower $\mathrm{L}_{\mathrm{c}}$ values for initial deformation as compared to denser CA-coatings, while $\mathrm{L}_{\mathrm{c}}$ values for total delamination were comparable to the CA-coatings. These findings emphasize that caution should always be taken in determining critical load values $\mathrm{L}_{c}$ as a quantitative measure- 
ment for coating adhesion, since adhesion and mechanical strength (cohesion) of coatings are strictly separated phenomena. Without unambiguous definition of a well-defined failure event (such as total coating delamination) by means of a scanning electron micrograph, which illustrates the particular failure mode, determination of $\mathrm{L}_{c}$ values is a rather arbitrary method of quantifying coating adhesion. Scratch testing is a good comparative test in order to obtain qualitative information on the major failure modes ${ }^{23,24}$. Nevertheless, the scratch testing method is less suitable to acquire absolute values of critical loads $\left(\mathrm{L}_{\mathrm{c}}\right)$ due to its dependence on numerous experimental parameters related to the testing system and specific coating-substrate system ${ }^{23-25}$. As a consequence, it is hardly possible to compare rough, dense plasma-sprayed with flat, reticular electrosprayed coatings in a quantitative way using the scratch test method because of the enormous differences in terms of roughness, thickness, morphology, crystallinity, homogenity, etc. For example, plasma-sprayed coatings have a much higher average surface roughness (typically more than $4.0 \mu \mathrm{m}$ ) and coating thickness (typically about $50 \mu \mathrm{m}$ ). Scratch testing of electrosprayed coatings on top of roughened Ti-substrates ( $\mathrm{R}_{\mathrm{a}}$ of about 1-1.5 $\mu \mathrm{m}$ ) was impossible using the ball stylus, since this coating was only scratched at the roughness peaks und remained intact at the roughness valleys.

Using a sharp scratch diamond, ductile failure modes were also dominant for ESD-coatings with the exception of amorphous ACP-coatings, which displayed spallation of small coating fragments around the very end of the maximum apparatus load at $100 \mathrm{mN}$ (Figure 6b). Spallation is the result of total delamination (adhesive failure) due to a compressive stress field around the moving stylus ${ }^{26}$, and typically occurs for poorly adhering coatings ${ }^{22}$. After heat-treatment of as-deposited ESD-coatings, the resistance to plastic deformation by the highly destructive scratch diamond stylus was enhanced most effectively for CHAcoatings. Delamination did not occur for both types of heat-treated coatings, but instead only simple ploughing through the coating material was observed, similar to observations made by $\mathrm{Wu}^{19}$ and Vaugh et al. ${ }^{27}$. They produced microscratches onto soft, ductile metallic coatings (Al-coated Si-substrates ${ }^{19}$ and $\mathrm{Cu}$-coated polymeric substrates ${ }^{27}$ ) using conical diamond styli with tip diameters between 1-10 $\mu \mathrm{m}$ at vertical loads of up to $40 \mathrm{mN}$. In this study, electrosprayed ACP and CA-coatings were completely penetrated by means of the scratch diamond at the final load of $100 \mathrm{mN}$, while similar scratch testing for CHA was terminated with the scratch diamond tip remaining in the $\mathrm{CaP}$ layer.

Consequently, reticular electrosprayed CaP coatings can be described as ductile coatings with a good interfacial adhesion to the Ti substrate, but with a poor mechanical strength of the rather fragile superficial pore walls. Additional heat-treatment at $700{ }^{\circ} \mathrm{C}$ is necessary to restrict ploughing deformation into ESD-prepared CaP coatings.

\subsection{EXPLANTATION OF DENTAL SCREW IMPLANTS}

A recent study by Manders et al. ${ }^{28}$ has proven the osteoconductive capacity of porous, electrosprayed CaP coatings. Still, the mechanical behavior of these coatings, when applied to dental implants screws, was not addressed before. The current study shows that dental implants with complex surface geometries can be homogeneously coated with reticular CaP coatings using ESD, although local differences in nozzle-to-substrate distances, surface temperature, and/or the electric field (in terms of preferential landing effects ${ }^{29}$ ) were supposed to hamper controlled deposition of these surface morphologies onto curved substrates. Therefore, the adhesion of porous, electrosprayed $\mathrm{CaP}$ coatings was evaluated in an osseous environment by means of implantation and immediate explantation of ESD- 
coated dental implant screws. This method appears to be a simple but valuable strategy to qualitatively characterize the adhesion of calcium phosphate coatings in an appropriate manner. However, it should be realized that CaP-coatings were deformed twice during implantation as well as explantation in this test, which of course does not correspond to the real clinical situation where the implant is left in place after installation. Moreover, it was shown that differences in implantation procedure and implant geometry greatly affect the final mechanical behavior of electrosprayed CaP-coatings on dental implants. Conical implants could not be screwed out of the femoral condyles without slipping, since they were not self-tapping in contrast to the self-tapping, cylindrical implants. Finally, differences in roughness were large between both implant geometries $\left(\mathrm{R}_{\mathrm{a}}\right.$ values of 0.2 and $5.5 \mu \mathrm{m}$ for cylindrical and conical implants, respectively).

Still, it can be concluded that the mechanical strength of amorphous ACP- and crystalline CA-coatings was not sufficient to withstand the shear and compressive forces applied onto the typical superficial pore wall structure. ACP- and CA-coated implants were covered with dense layers of $\mathrm{CaP}$, which most likely originated from the compressed remnants of the reticular coatings. In contrast to ACP- and CA-coatings, reticular structures of CHAcoatings were clearly recognizable after explantation. These findings confirm the results of scratch testing, where CHA-coatings were shown to be more resistant to plastic deformation by shear stresses. Generally, it can be concluded that heat-treatment at $700{ }^{\circ} \mathrm{C}$ significantly increased both adhesion and mechanical strength of electrosprayed $\mathrm{CaP}$ coatings to a degree where reticular surface structures were not easily deformed anymore and could be (partially) maintained upon implantation and subsequent implant retrieval. Adhesion of CHA-coatings can be improved as the result of oxidation of the Ti substrate (as observed using XRD) after heat-treatment at $700{ }^{\circ} \mathrm{C}$, which is suggested to act as an oxidic transition layer between non-oxide $\mathrm{Ti}$ substrates and oxidic $\mathrm{CaP}$ ceramic coatings. Improved mechanical strength of CHA-coatings can be related to various processes that occur upon heat-treatment of ESD-coatings. FTIR analysis revealed that heat-treatment at $700{ }^{\circ} \mathrm{C}$ resulted into decomposition of carbonate groups into $\mathrm{OH}^{-}$groups ${ }^{15}$ for $\mathrm{CHA}$ coatings, which corroborates the results of El Feki et al. ${ }^{30}$. Carbonate anions are known to hamper crystal growth as compared to carbonate-free hydroxyapatite by disturbing the structural stability of the apatitic lattice, which can be an explanation for the higher crystallinity and improved mechanical properties of CHA coatings as compared to CA coatings. The nucleation of apatite crystals in an otherwise amorphous matrix deviates crack propagating through the ceramic, thereby slowing down or inhibiting further crack propagation. Furthermore, a decrease in submicron-porosity - and correspondingly - an increase in specific surface area due to heat-treatment at $700{ }^{\circ} \mathrm{C}$ is expected to lead to microstructural compaction of the coating and thus to an increased resistance against plastic deformation.

\section{Conclusions}

Mechanical properties of reticular, electrosprayed CaP coatings were characterized using a range of analyzing techniques. It was observed for all these techniques that reticular ESD-coatings need to be crystallized in order to ensure sufficient interfacial adhesion to the substrate and mechanical strength of the superficial pore wall structure for applications where shear and compressive stresses are imposed onto the implant surface. Amorphous ESD-coatings dissolved rapidly during fatigue testing under wet conditions, and were eas- 
ily deformed by shear stresses during scratch testing or unscrewing of ESD-coated dental implants from femoral condyles of goat cadavers. On the contrary, crystalline coatings heat-treated at $700{ }^{\circ} \mathrm{C}$ were resistant to fatigue as well as plastic ploughing deformation by means of various scratch styli, whereas the fragile surface structure of ESD-coatings was maintained to a large extent after unscrewing of dental implants coated with crystalline carbonated hydroxyapatite coatings. This latter method of unscrewing previously implanted dental screws from osseous tissue of goat cadavers was successfully introduced as a simple method to assess the adhesion and mechanical strength of biomedical CaP-coatings under conditions that mimic possible clinical situations as close as possible. From the results, it was concluded that interfacial adhesion of crystalline carbonated hydroxyapatite ESD-coatings to the Ti substrate was sufficient, but that mechanical strength of the superficial architecture of ESD-coatings needs to be optimized for applications where high shear stresses are imposed onto the fragile coating surface of reticular ESD-morphologies.

\section{References}

1. Ducheyne P, Qiu Q. Bioactive ceramics: the effect of surface reactivity on bone formation and bone cell function. Biomaterials 1999;20:2287-2303.

2. Wagner WC. A brief introduction to advanced surface modification technologies. J Oral Implantol 1992;18:231-235.

3. de Groot K, Geesink R, Klein CP, Serekian P. Plasma sprayed coatings of hydroxylapatite. J Biomed Mater Res 1987;21:1375-1381.

4. Dhert WJ. Retrieval studies on calcium phosphate-coated implants. Med Prog Technol 1994;20:143154.

5. Lacefield WR. Current status of ceramic coatings for dental implants. Implant Dent 1998;7:315-322.

6. Lacefield WR. Materials characteristics of uncoated/ceramic-coated implant materials. Adv Dent Res 1999;13:21-26.

7. D'Antonio JA, Capello WN, Manley MT, Geesink R. Hydroxyapatite femoral stems for total hip arthroplasty. Clin Orthop Relat Res 2001;393:101-111.

8. $\quad$ Yang $Y$, Kim KH, Ong JL. A review on calcium phosphate coatings produced using a sputtering process - an alternative to plasma spraying. Biomaterials 2005;26:327-337.

9. Leeuwenburgh SCG, Wolke JGC, Schoonman J, Jansen JA. Influence of deposition parameters on chemical properties of calcium phosphate coatings prepared by using electrostatic spray deposition. J Biomed Mater Res 2005;74:275-284.

10. Leeuwenburgh SCG, Wolke JGC, Schoonman J, Jansen JA. Influence of deposition parameters on morphological properties of biomedical calcium phosphate coatings prepared using electrostatic spray deposition. Thin Solid Films 2005;472:105-113.

11. Wolke JGC, de Blieck-Hogervorst JMA, Dhert WJA, Klein CP, de Groot K. Studies to the thermal spraying of apatite bioceramics. J Thermal Spray Technol 1992;1:75-82.

12. Dong ZL, Khor KA, Quek CH, White TJ, Cheang P. TEM and STEM analysis on heat-treated and in vitro plasma-sprayed hydroxyapatite/Ti-6Al-4V composite coatings. Biomaterials 2002;24:97-105. 
13. Rohanizadeh $R$, LeGeros RZ, Harsono M, Bendavid A. Adherent apatite coating on titanium substrate using chemical deposition. J Biomed Mater Res 2005;72:428-438.

14. Haman JD, Chittur KK, Crawmer DE, Lucas LC. Analytical and mechanical testing of high velocity oxyfuel thermal sprayed and plasma sprayed calcium phosphate coatings. J Biomed Mater Res 1999;48:856860 .

15. Leeuwenburgh SCG, Wolke JGC, Siebers MC, Schoonman J, Jansen JA. In vitro and in vivo reactivity of porous calcium phosphate coatings deposited using Electrostatic Spray Deposition (ESD). Biomaterials $2006 ; 27: 3368-3378$.

16. Clemens JAM, Wolke JGC, Klein CP, de Groot K. Fatigue behavior of calcium phosphate coatings with different stability under dry and wet conditions. J Biomed Mater Res 1999;48:741-748.

17. JGC Wolke, van der Waerden JP, de Groot K, Jansen JA. Stability of radiofrequency magnetron sputtered calcium phosphate coatings under cyclically loaded conditions. Biomaterials 1997;18:483-488.

18. Lu X, Leng Y. Theoretical analysis of calcium phosphate precipitation in simulated body fluid. Biomaterials 2005;26:1097-1108.

19. Wu TW. Microscratch and load relaxation tests for ultra-thin films. J Mater Res 1991;6:407-426.

20. Feddes B, Wolke JGC, Weinhold WP, Vredenberg AM, Jansen JA. Adhesion of calcium phosphate ceramic on polyethylene (PE), polystyrene (PS), polytetrafluoroethylene (PTFE), polydimethylsiloxane (PMDS), and poly-L-lactic acid (PLLA). J Adhesion Sci Technol 2004;18:655-672.

21. Leeuwenburgh $S$, Wolke J, Schoonman J, Jansen J. Electrostatic spray deposition (ESD) of calcium phosphate coatings. J Biomed Mater Res 2003;66:330-334.

22. Bull SJ. Failure modes in scratch adhesion testing. Surf Coat Technol 1991;50:25-32.

23. Wang J, Layrolle P, Stigter M, de Groot K. Biomimetic and electrolytic calcium phosphate coatings on titanium alloy: physicochemical characteristics and cell attachment. Biomaterials 2004;25:583-592.

24. Takahashi K, Hayakawa T, Yoshinari M, Hara H, Mochizuki C, Sato M, Nemoto K. Molecular precursor method for thin calcium phosphate coating on titanium. Thin Solid Films 2005;484:1-9.

25. Steinmann PA, Tardy Y, Hintermann HE. Adhesion testing by the scratch method: the influence of intrinsic and extrinsic parameters on the critical load. Thin Solid Films 1987;154:333-349.

26. Burnett PJ, Rickerby DS. The relationship between hardness and scratch adhesion. Thin Solid Films 1987; 154:403-416.

27. Vaughn GD, Frushour BG, Dale WC. Scratch indentation, a simple adhesion test method for thin films on polymeric supports. J Adhesion Sci Technol 1994;8:635-650.

28. Manders PJD, Wolke JGC, Jansen JA. Bone supportive behaviour of calcium phosphate electrostatic spray deposition coated oral implants. An experimental study in goats. Clin Oral Implants Res 2006 (in press).

29. Chen CH, Kelder EM, van der Put PJJM, Schoonman J. Morphology control of thin LiCoO films fabricated using the electrostatic spray deposition (ESD) technique. J Mater Chem 1996;6:765-771.

30. El Feki H, Rey C, Vignoles M. Carbonate ions in apatites: infrared investigations in the $v_{4} \mathrm{CO}_{3}$ domain. Calcif Tissue Int 1991;49:269-274. 



\section{Introduction}

Bioactive calcium phosphate $(\mathrm{CaP})$ ceramics have been widely studied for orthopedic and dental applications due to their osteoconductive properties ${ }^{1-3}$. Generally, this phenomenon of bioactivity is determined by both chemical factors - such as the crystal phase and molecular structure of the material - and physical factors, such as surface roughness and porosity $^{4-5}$. CaP ceramics are too brittle for use as bulk material under loaded conditions, which makes that $\mathrm{CaP}$ ceramics are frequently applied as coatings onto the surface of metallic implant materials in order to combine the mechanical strength of metals with the excellent biological properties of $\mathrm{CaP}$ ceramics $^{6-9}$. For that purpose, Electrostatic Spray Deposition (ESD) is a versatile technique enabling deposition of $\mathrm{CaP}$ coatings with a wide variety of controlled surface properties in terms of coating chemistry and morphology. In view of the above mentioned relationship between $\mathrm{CaP}$ surface properties and bioactivity, ESD is a powerful tool in research on the fundamental relationship between the chemical and physical nature of $\mathrm{CaP}$ coatings and their biological performance in vitro and in vivo.

Briefly, the basic principle of ESD is the generation of a spray of charged, micron-sized droplets. This is accomplished by means of electrostatic atomization of precursor solutions that contain inorganic precursor salts. These spray droplets are directed towards a grounded and heated substrate as a result of the applied potential difference. After complete solvent evaporation, a thin inorganic layer is left onto the substrate surface. Several studies have shown already that inorganic ${ }^{10-12}$, polymeric ${ }^{13}$ as well as protein coatings ${ }^{14}$ can be deposited using ESD with various surface architectures.

In previous studies, biomedical CaP coatings were deposited with defined chemical ${ }^{15}$ and morphological characteristics ${ }^{16}$. Specifically, a unique reticular coating morphology was obtained, characterized by a three-dimensional, interconnected pore network with variable pore size. This coating morphology offers the advantage of creating an implant surface with an increased and controllable surface area. As a result, phenomena such as $\mathrm{CaP}$ coating dissolution rate and incorporation of osteoinductive proteins might be controlled by tailoring the surface morphology.

The ability to form apatite precipitation layers in Simulated Body Fluid (SBF) or in animal models has been regarded as the evidence of bioactivity for bioceramics ${ }^{3}$. Therefore, the objective of the current study was to investigate dissolution and/or precipitation reactions of porous, electrosprayed $\mathrm{CaP}$ coatings in a classical in vitro test by immersing ESD-coated titanium (Ti) substrates with various crystal phases (amorphous calcium phosphate, carbonate apatite, carbonated hydroxyapatite, and $\beta$-tricalcium phosphate) in SBF. Since in vitro assays cannot completely mimic the in vivo situation, identical CaP coatings were also evaluated in vivo after subcutaneous implantation in the back of goats in order to gain insight in the dissolution and compositional behaviour of porous ESD-prepared $\mathrm{CaP}$ coatings.

\section{Materials and Methods}

\subsection{SPECIMEN PREPARATION}

Commercially pure Ti discs (thickness $1.5 \mathrm{~mm}$, diameter $12 \mathrm{~mm}$ ) were either left asmachined (in vitro study, average roughness $\mathrm{R}_{\mathrm{a}}=0.3-0.4 \mu \mathrm{m}$ ) or $\mathrm{Al}_{2} \mathrm{O}_{3}$-blasted on one side prior to coating deposition to increase the surface roughness for the samples tested 
in vivo $\left(\mathrm{R}_{\mathrm{a}}=1.9-2.2 \mu \mathrm{m}\right)$. Coatings were deposited onto the Ti substrates by means of a commercially available Electrostatic Spray Deposition unit (Advanced Surface Technology, Bleiswijk, The Netherlands). The following porous ESD-coatings with equal surface morphology (Figure 1) but different chemical characteristics (Figures 2-3) were prepared for the in vitro and in vivo studies (coating thickness 2.0-2.5 $\mu \mathrm{m}$ ):

- Amorphous calcium phosphate (ACP)

- Carbonate apatite (CA)

- Carbonated hydroxyapatite (CHA)

- $\quad \beta$-Tricalcium phosphate $(\beta$-TCP)

All depositions were carried out for 45 minutes at a substrate temperature of $350{ }^{\circ} \mathrm{C}$, a nozzle-to-substrate distance of $20 \mathrm{~mm}$, and a liquid flow rate of $2.0 \mathrm{ml} / \mathrm{h}$ at the outlet of a novel two-component nozzle, which was described previously ${ }^{15}$. ACP, CA, and CHA coatings were prepared using precursor solutions with a $\mathrm{Ca} / \mathrm{P}$ ratio of $1.8\left(\mathrm{Ca}\left(\mathrm{NO}_{3}\right)_{2} \cdot 4 \mathrm{H}_{2} \mathrm{O}\right.$ and $\mathrm{H}_{3} \mathrm{PO}_{4}$ were precursors for $\mathrm{Ca}$ and $\mathrm{P}$, respectively), whereas solutions with a lower $\mathrm{Ca} / \mathrm{P}$ ratio of 1.4 were employed to prepare the $\beta$-TCP coatings. After coating deposition, all coated Ti substrates were heat-treated for 2 hours in air at $400{ }^{\circ} \mathrm{C}(\mathrm{ACP}), 500{ }^{\circ} \mathrm{C}$ (CA), and $700{ }^{\circ} \mathrm{C}(\mathrm{CHA}$ and $\beta$-TCP). Uncoated Ti substrates were also used as a reference material for both in vitro and in vivo studies. CaP-coated substrates were characterized using Scanning Electron Microscopy (SEM, Jeol, SEM6310, Tokyo, Japan), reflection Fourier-Transform InfraRed spectroscopy (FTIR, Perkin Elmer, Spectrum One, Groningen, The Netherlands), thin-film X-Ray Diffraction (XRD, Panalytical, PW3710, Almelo, The Netherlands), and Energy Dispersive Spectroscopy (EDS, Noran Instruments, Voyager, Middleton WI, USA).

\subsection{IN VITRO SOAKING EXPERIMENT}

In vitro experiments were carried out in conventional SBF with an ionic composition almost equal to human plasma ${ }^{17}$. Ionic concentrations of this SBF are $142.0 \mathrm{mM} \mathrm{Na}^{+}, 5.0$ $\mathrm{mM} \mathrm{K}^{+}, 1.5 \mathrm{mM} \mathrm{Mg}^{2+}, 2.5 \mathrm{mM} \mathrm{Ca}^{2+}, 147.8 \mathrm{mM} \mathrm{Cl}^{-}, 4.2 \mathrm{mM} \mathrm{HCO}_{3}^{2-}, 1.0 \mathrm{mM} \mathrm{HPO}_{4}^{2-}$, and $0.5 \mathrm{mM} \mathrm{SO}_{4}^{2-}$. Tris- $\mathrm{HCl}$ served as buffer to maintain a constant $\mathrm{pH}$ value of 7.4. The coated and uncoated substrates (three specimens per time period per type of $\mathrm{CaP}$ coating) were immersed in $4 \mathrm{ml}$ of SBF for 1, 2, 4, 8, and 12 weeks. In total, $75 \mathrm{CaP}$-coated discs were soaked in SBF: 15x ACP, 15x CA, 15x CHA, 15x $\beta$-TCP, and 15 uncoated Ti discs. SBF temperature was kept at $37^{\circ} \mathrm{C}$ using a water bath and replaced with freshly prepared SBF every week. After the various immersion times, the specimens were removed from SBF, washed thoroughly with MilliQ water $(3 \mathrm{x})$ and dried at $50^{\circ} \mathrm{C}$. Subsequently, all specimens were characterized using SEM, XRD, FTIR, and EDS.

\subsection{IN VIVO SUBCUTANEOUS IMPLANTATION}

Five adult goats with a mean body weight of about 50-60 kg were used in this study. CaP-coated implants, as described above, were implanted subcutaneously in the back of the goats in four surgical sessions. Surgery was performed under local anesthesia. Before surgery, the skin was shaved, washed, and disinfected with iodine. During each surgical session, five longitudinal incisions of about $1.5 \mathrm{~cm}$ were made parallel to the spinal column in the specific recipient site. Lateral to these incisions, small subcutaneous pockets were created by blunt dissection with scissors. The implants were inserted into these pockets and the wounds closed using Vicryl 3-0.

Four implantation periods were used: 2, 4, 8, and 12 weeks. Four surgical areas were 
used as recipient sites (alternately the left or right flank and caudal or frontal). The various recipient sites (each site represented 1 implantation time) and $\mathrm{CaP}$ coatings in each recipient site were randomized according to a split plot design to exclude the effect of implantation location and possible variations in individual goats. Each goat received 20 discs, 10 in the left and 10 in the right side of the spinal column. In total, 100 implants were placed: 20 $x$ ACP, 20x CA, 20x CHA, $20 x \beta$-TCP, and 20 uncoated Ti discs.

At the end of each implantation period, a longitudinal incision was made on both sides of the vertebral column, whereafter the implants were exposed and retrieved including their surrounding tissue. After removal, 40 discs were used for physicochemical characterization of the coatings, whereas the remaining 60 discs were prepared for histological analysis. For physicochemical analysis, the explants were fixed in $4 \%$ phosphate-buffered formaldehyde solution ( $\mathrm{pH}$ 7.4), removed out of their surrounding tissue capsule, dehydrated in serial ethanol solutions, and examined by means of SEM, XRD, FTIR, and EDS. For histological evaluation, implants with the surrounding tissues were retrieved and fixed in $4 \%$ formaldehyde solution, dehydrated in serial ethanol series and embedded in methylmethacrylate (MMA). After polymerization, $10 \mu \mathrm{m}$ thick sections were prepared using a modified sawing microtome technique ${ }^{18}$. These sections were stained with methylene blue and basic fuchsin, and studied with a light microscope.

\section{Results}

\subsection{CaP COATING CHARACTERIZATION BEFORE IN VITRO/VIVO TESTING}

All ESD-prepared CaP-coatings revealed a porous, reticular surface morphology (Figure 1), which was not affected by the $\mathrm{Al}_{2} \mathrm{O}_{3}$-blasting pre-treatment. Two pore size regimes can be distinguished: 1) micron-sized, hollow pits with diameters of about $2-10 \mu \mathrm{m}$ at the surface of the coating, and 2) submicron-sized pores in the underlying coating layer. The coatings were crack-free after heat-treatment at $700{ }^{\circ} \mathrm{C}$.

The FTIR-spectra of ACP, CA, CHA, and $\beta$-TCP coatings are shown in Figure 2. ACP coatings were heat-treated at $400{ }^{\circ} \mathrm{C}$ in order to remove organic remnants resulting from solvent decomposition reactions ${ }^{19}$. As a consequence, carbonate groups were engaged in an amorphous solid as indicated by two broad $v_{3}$ carbonate absorptions at $1489 \mathrm{~cm}^{-1}$ and 1427

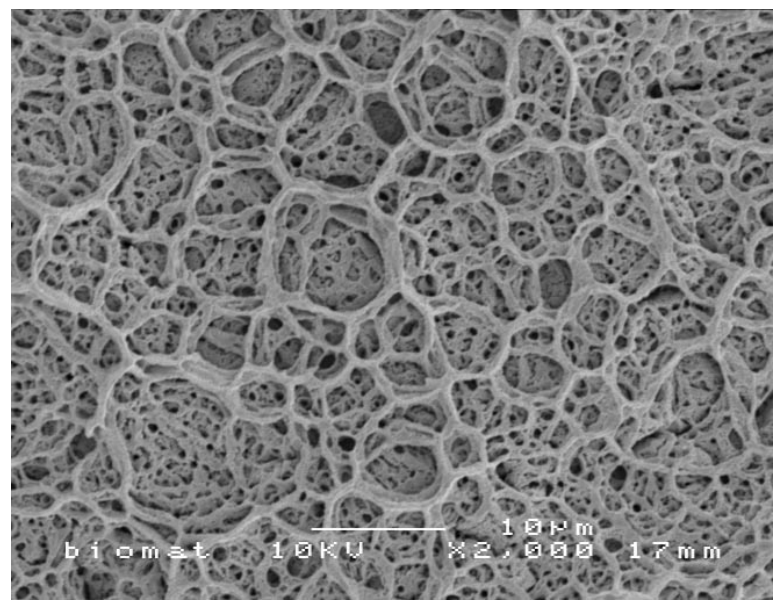

Figure 1: Scanning electron micrograph of the surface morphology of porous ESD-coatings before in vitro/vivo testing (equal surface morphology for $A C P, C A, C H A$, and $\beta-T C P)$. 
Figure 2: FTIR spectra of ESD-prepared ACP, CA, CHA, and $\beta$-TCP coatings before in vitro/vivo testing.

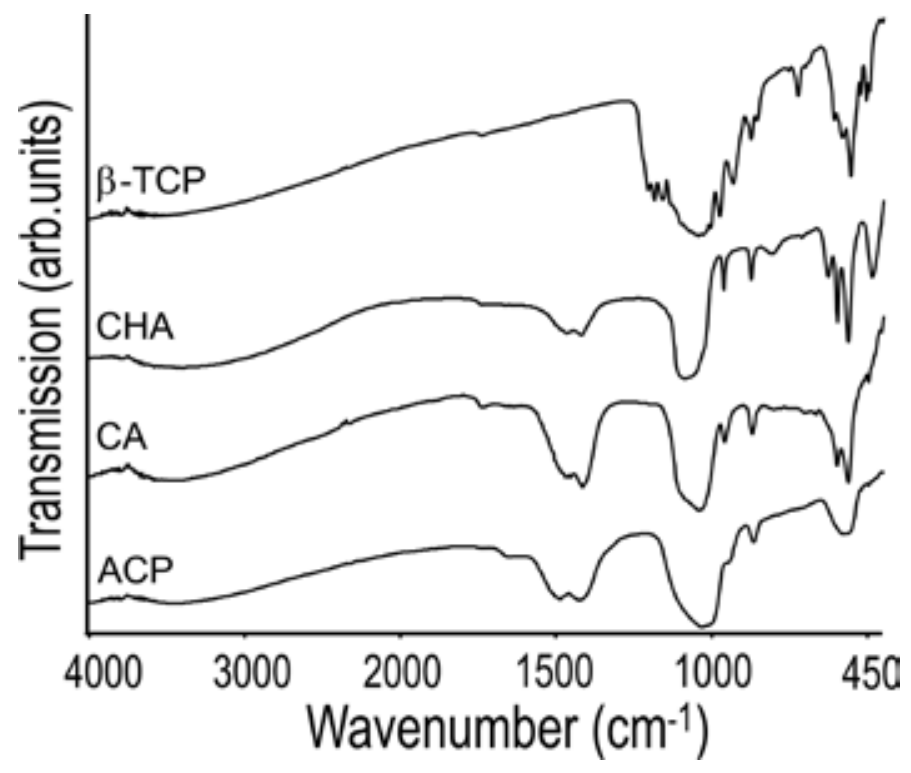

Figure 3: XRD patterns of ESD-prepared ACP, CA, $C H A$, and $\beta$-TCP coatings before in vitro/vivo testing.

$+=$ apatite

$\wedge=\beta-T C P$

$0=T i$

\# = rutile $\mathrm{TiO}_{2}$

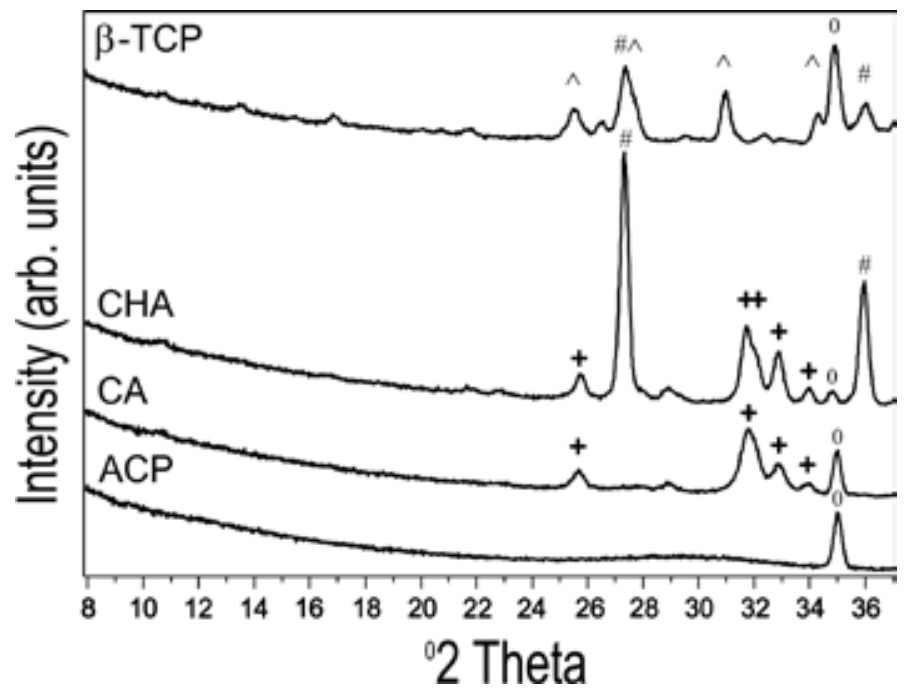

$\mathrm{cm}^{-1}$ which correspond to amorphous, carbonated CaP-ceramics. Absorption bands related to organic remnants were not observed anymore. Phosphate bands around $1035 \mathrm{~cm}^{-1}$ and $570 \mathrm{~cm}^{-1}\left(v_{3}\right.$ and $v_{4}$, respectively) remained broad single-phase bands, indicating a disordered environment. Heat-treatment at $500{ }^{\circ} \mathrm{C}$, however, induced the transformation into crystalline B-type carbonate apatite coatings, characterized by intense and well-defined absorption peaks ${ }^{20}$ at 1462, $1416\left(v_{3} \mathrm{CO}_{3}^{2-}\right), 1100,1038\left(v_{3} \mathrm{PO}_{4}^{3-}\right), 961\left(v_{1} \mathrm{PO}_{4}{ }^{3-}\right), 872\left(v_{2}\right.$ $\left.\mathrm{CO}_{3}{ }^{2-}\right), 600$ and $564\left(v_{4} \mathrm{PO}_{4}^{3-}\right) \mathrm{cm}^{-1}$. After heat-treatment at a higher temperature of $700{ }^{\circ} \mathrm{C}$, the intensity of the two carbonate absorptions (at 1464 and $1417 \mathrm{~cm}^{-1}$ ) decreased, whereas a sharp peak at $630 \mathrm{~cm}^{-1}$ was introduced corresponding to the libration mode ${ }^{21} \mathrm{of} \mathrm{OH}^{-}$. The FTIR spectrum of $\beta$-TCP coatings revealed intense, feature-rich absorption bands between 
900-1250 $\mathrm{cm}^{-1}$ and $450-650 \mathrm{~cm}^{-1}$ corresponding to $v_{3}$ and $v_{4}$ phosphate absorption modes of crystalline $\beta$-TCP, respectively ${ }^{22}$. No carbonate absorption peaks were observed.

The corresponding XRD patterns of ACP, CA, CHA, and $\beta$-TCP are depicted in Figure 3. ACP coatings displayed a broad maximum at about $30^{\circ} 2 \theta$ without any specific reflection lines characteristic for amorphous $\mathrm{CaP}$ solids. Upon heat-treatment at $500{ }^{\circ} \mathrm{C}$, reflection lines of CA coatings emerged at $25.7^{\circ}(002), 31.9^{\circ}(211$ and 112$), 32.9^{\circ}(300)$, and $34.0^{\circ} 2 \theta(202)$, comparable to JCPDS File $9-432$ of synthetic hydroxyapatite. CaP diffraction peaks were more intense for CHA coatings after heat-treatment at $700{ }^{\circ} \mathrm{C}$, and a distinct shoulder was observed at $32.1^{\circ} 2 \theta$ for the (112) reflection, suggesting that $\mathrm{CHA}$ coatings were slightly more crystalline than CA coatings. Severe oxidation of the Ti substrate was observed at $27.4^{\circ} 2 \theta$ corresponding to rutile $\left(\mathrm{TiO}_{2}\right)$. The XRD-pattern of the $\beta$-TCP coatings was characterized by reflections at $25.6^{\circ}, 27.8^{\circ}, 31.0^{\circ}$, and $34.3^{\circ} 2 \theta$ corresponding to JCPDS File 9-169, whereas less rutile formation was observed as compared to CHA coatings.

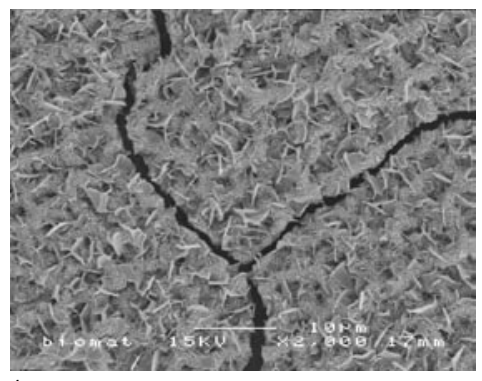

$4 \mathrm{a}$

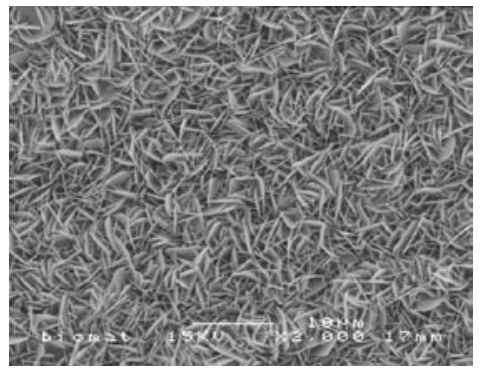

$4 \mathrm{~b}$

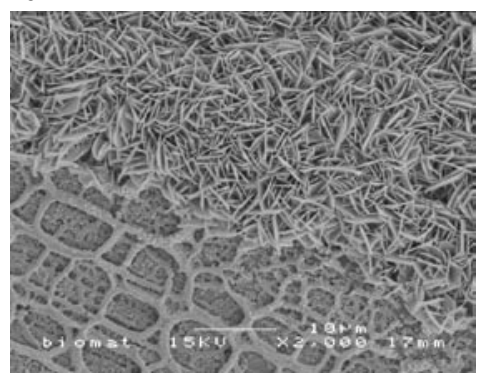

$4 \mathrm{c}$

Figure 4: Scanning electron micrographs of $A C P[a], C A[b]$, and $\beta-T C P[c]$ coatings after soaking in SBF for 1 week.

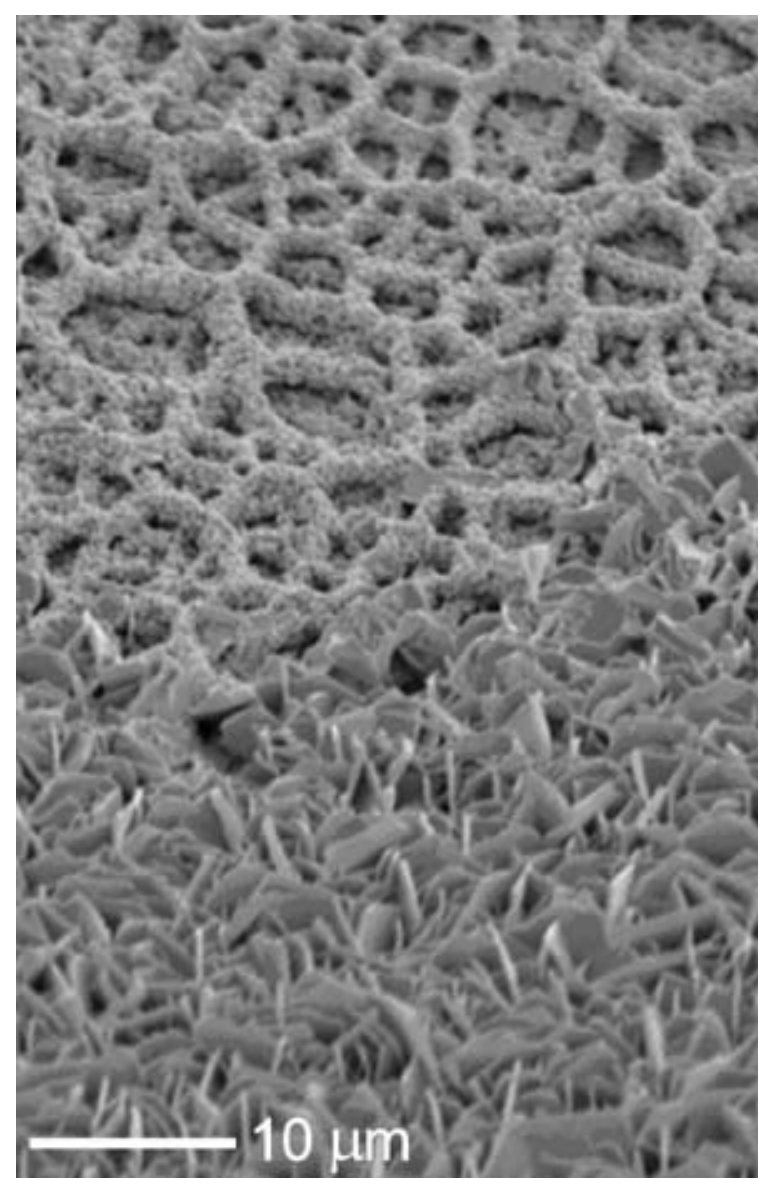

Figure 5: Tilted $\left(45^{\circ}\right)$ scanning electron micrograph of $\beta$-TCP after 2 weeks in SBF. Bar size $10 \mu \mathrm{m}$. 
$\mathrm{Ca} / \mathrm{P}$ ratios for $\mathrm{ACP}, \mathrm{CA}$, and $\mathrm{CHA}$ coatings ranged between 2.1 and 2.3 (as determined by EDS), whereas $\mathrm{Ca} / \mathrm{P}$ ratios of $\beta$-TCP coatings were about 1.4-1.5.

\subsection{IN VITRO SOAKING EXPERIMENT}

Figures $4 \mathrm{a}-\mathrm{c}$ and 5 show the scanning electron micrographs of various CaP-coated specimens after soaking in SBF for 1-2 weeks. After 1 week of immersion, ACP coatings displayed a crackled appearance and sparse formation of flakes with dimensions of up to 2 $\mu \mathrm{m}$, which nucleated both inside hollow surface pits and on top of the pore walls (Figure 4a). Reminiscents of the porous coating morphology were still visible, but the pore wall structure was severely degraded. On the contrary, CA and CHA coatings were completely covered with a homogeneous layer of flakes, as shown for CA coatings after 1 week in SBF (Figure 4b). $\beta$-TCP-coatings, however, were heterogeneously covered with CaP-flakes after 1 week (Figure 4c).

After 2 weeks in SBF, ACP coatings were completely covered with CaP flakes, but severe cracking was observed in the precipitated layer resulting into poor adherence and delamination of the calcified ACP coating. On the contrary, $\mathrm{CaP}$ precipitation layers on CA and CHA coatings after 2 weeks in SBF were homogeneous, adherent, and increased in thickness with soaking time. $\beta$-TCP coatings were gradually overgrown with CaP flakes, but after 2 weeks in SBF the coverage of the underlying ESD-coatings was still incomplete, as shown from a tilted perspective in Figure 5. This heterogeneous coverage of $\beta$-TCP coatings by $\mathrm{CaP}$ calcifications maintained up to 8 weeks of soaking. Generally, flake-like calcifications were not observed anymore after 12 weeks of soaking, but instead, a dense and homogeneously covered CaP precipitation layer of about 12-14 $\mu \mathrm{m}$ thickness had developed on top of all $\mathrm{CaP}$ coatings. Uncoated $\mathrm{Ti}$ discs did not provoke any observable $\mathrm{CaP}$ precipitation for all soaking periods (data not shown).

Figures $6 a-b$ show the XRD-patterns of CA (Figure 6a) and $\beta$-TCP (Figure 6b) coated substrates before and after immersion in SBF. The XRD-patterns of CA after soaking in SBF were representative for the diffractograms of soaked ACP and CHA coatings. A phase mixture of octacalcium phosphate $\left(\mathrm{OCP}, \mathrm{Ca}_{8} \mathrm{H}_{2}\left(\mathrm{PO}_{4}\right)_{6} \cdot 5 \mathrm{H}_{2} \mathrm{O}\right)$ and $\mathrm{CA}$ was observed after 2 weeks of immersing CA coatings in SBF (Figure 6a). Typical reflection lines at $9.5^{\circ}(200$ and 010$), 16.0^{\circ}, 24.3^{\circ}, 25.9^{\circ}, 31.6^{\circ}$, and $33.7^{\circ} 2 \theta$ were assigned to OCP $[1,8]$, whereas peaks/shoulders at $22.9^{\circ}, 25.8^{\circ}, 28.0^{\circ}, 29.0^{\circ}, 31.7^{\circ}, 32.0^{\circ}, 32.8^{\circ}$, and $34.0^{\circ} 2 \theta$ could be attributed to CA (JCPDS File 9-432). After 12 weeks of immersion, OCP peaks were hardly visible anymore, whereas the intensity of apatitic reflections had increased significantly and Ti peaks had disappeared completely from the diffractograms. $\beta$-TCP coatings gradually dissolved during time, as indicated by a strong decrease in intensity of $\beta$-TCP peaks at $25.6^{\circ}, 27.8^{\circ}, 31.0^{\circ}$ and $34.3^{\circ} 2 \theta$ after 2 weeks in SBF. At this time point, a complex diffractogram was recorded revealing the simultaneous presence of $\beta$-TCP traces, and precipitated phases OCP and CA. After 12 weeks, Ti substrate peaks and $\beta$-TCP coating peaks had disappeared completely, OCP peaks were almost absent, and CA reflections had become dominant, yielding a diffraction pattern comparable to synthetic hydroxyapatite (JCPDS File 9-432).

Several authors have already pointed out the possibility of misidentifying OCP as apatitic $\mathrm{CaP}$ phases when using XRD only because of structural similarity between apatite and $\mathrm{OCP}^{3,17,23}$. However, unique and low-angle (200) and (010) OCP peaks near $9.5^{\circ} 2 \theta$ were observed in the current study after short soaking periods for all specimens (1-2 weeks in $\mathrm{SBF}$ ). Furthermore, the initial presence of OCP was also confirmed by means of FTIR. 


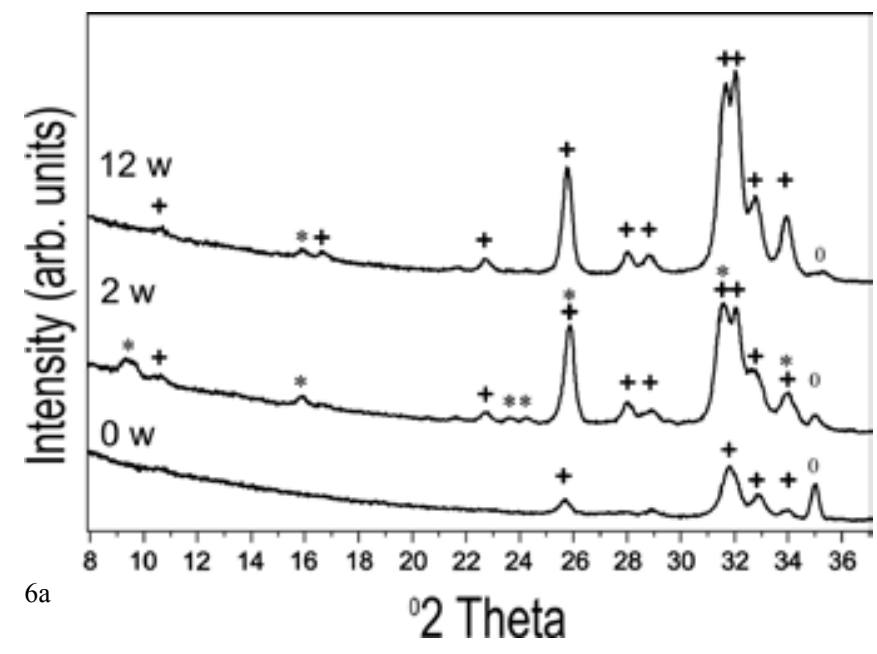

Figure 6: XRD patterns of $C A[a]$ and $\beta-T C P[b]$ coat ings after 0,2 , and 12 weeks of soaking in $S B F$.

$$
\begin{aligned}
& +=\text { apatite } \\
& *=O C P \\
& \wedge=\beta-T C P \\
& 0=T i \\
& \#=\text { rutile } \mathrm{TiO}_{2}
\end{aligned}
$$

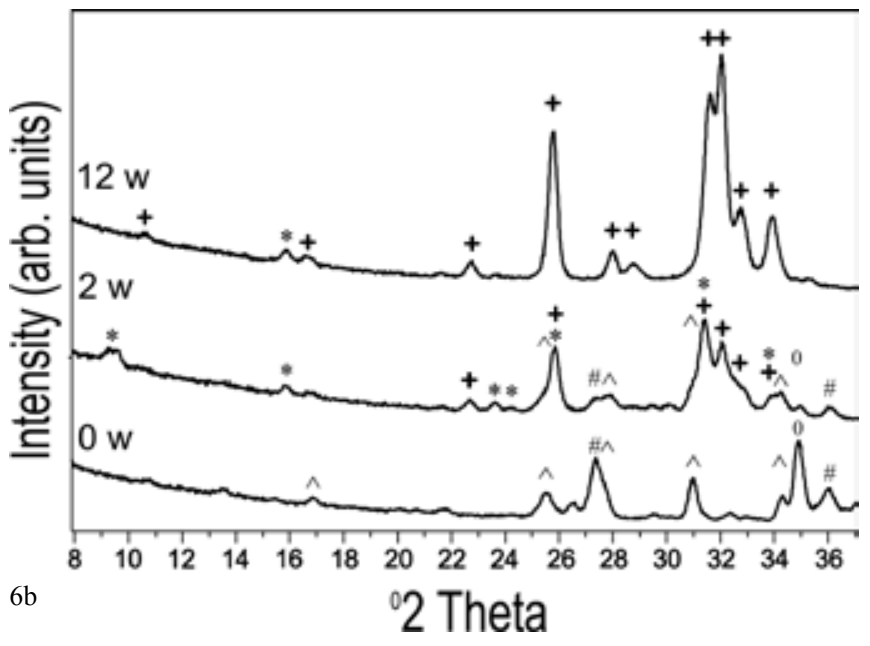

Figure 7 shows a typical FTIR-spectrum in the $v_{4}$ phosphate domain from 1300 to $800 \mathrm{~cm}^{-1}$ of a CA-coating after 1 week of immersion in SBF, the features of which are characteristic for other soaked specimens after 1 to 2 weeks in SBF. Small but sharp absorptions at 1110, $1077,1055,1035 \mathrm{~cm}^{-1}$, and shoulders at 912,1128 , and $1128 \mathrm{~cm}^{-1}$ correspond to $\mathrm{HPO}_{4}{ }^{2-}$ groups of OCP $[8,20,22]$. These sharp features gradually disappeared from the $v_{4}$ phosphate domain with increasing soaking time for all $\mathrm{CaP}$ coatings.

$\mathrm{Ca} / \mathrm{P}$ ratios (as determined by the EDS technique) of apatitic coatings (ACP/CA/CHA) decreased from initial values of 2.1-2.3 towards 1.6-1.7 within the first two weeks of soaking, whereafter the values increased again to 1.8-1.9 after 4 weeks of soaking. From 4 to 12 weeks of soaking, $\mathrm{Ca} / \mathrm{P}$ ratios remained constant at about 1.8-2.0. $\beta$-TCP coatings exhibited a different dependence of $\mathrm{Ca} / \mathrm{P}$ ratios on soaking time due to the heterogeneous precipitation of OCP on top of the $\beta$-TCP surface. OCP-covered areas were characterized by a gradual increase in $\mathrm{Ca} / \mathrm{P}$ ratio from 1.4-1.5 towards 1.8-1.9 after 12 weeks of soaking, whereas $\mathrm{Ca} / \mathrm{P}$ ratios of exposed $\beta$-TCP coating parts did not change, maintaining ratios of about 1.5. 


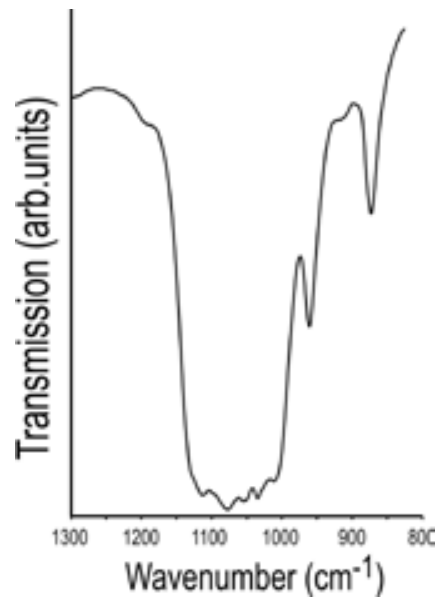

Figure 7: FTIR spectrum of the $v_{4}$ phosphate domain from 1300 to $800 \mathrm{~cm}^{-1}$ of a CA coating after 1 week of immersion in $S B F$.

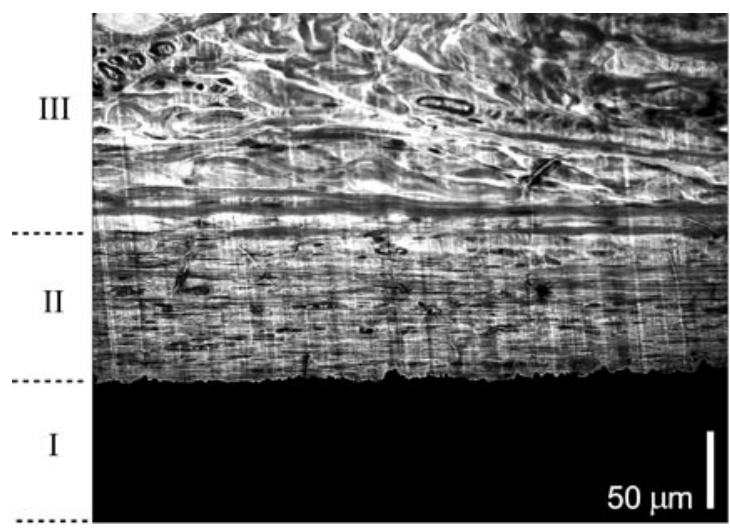

Figure 8: Light micrograph of a histological section of a CA-coated Ti implant after 2 weeks of subcutaneous implantation. $\mathrm{I}=\mathrm{Al}_{2} \mathrm{O}_{3}$-blasted Ti disc, $\mathrm{II}=$ fibrous capsule in close contact with the coated surface, and III = surrounding tissues.

\subsection{IN VIVO SUBCUTANEOUS IMPLANTATION}

At retrieval of the implants, macroscopical signs of infection reactions were not observed at the surgical sites. Histological analysis revealed a histocompatible tissue behaviour of all specimens at all implantation times. After two weeks of implantation, all coated and uncoated Ti-specimens (Figure 8, zone I) were surrounded by a fibrous tissue capsule irrespective of the type of CaP coating, which was characterized by 15-20 cell layers of aligned fibrocytes/fibroblasts yielding a capsule thickness of about $80 \mu \mathrm{m}$ (Figure 8, zone II). This capsule was almost free of inflammatory cells and was surrounded by blood vessels, connective and/or fat tissue, etc. (Figure 8, zone III). After longer implantation times, the capsules became denser but remained a constant thickness. An intimate contact was established between the implant surfaces and surrounding fibrous capsules, which closely followed the roughness profile of the blasted implant surfaces.

Examination by means of SEM showed that the implants were still covered with a thin, adherent layer of proteinaceous tissue debris - especially after longer implantation periods - even though the implants were removed from their surrounding capsules after retrieval. As compared to other ESD-coatings, poor adhesion of this surrounding proteinaceous layer was observed around ACP coatings for all time periods, occasionally accompanied by detachment of the tissue debris layer from the underlying ACP-coated Ti implant. This phenomenon complicated interpretation of the SEM-images and prevented proper analysis by means of FTIR spectroscopy. Still, certain trends could be deduced from SEM- and EDS-analysis.

All ESD-prepared CaP coatings degraded gradually at a dissolution rate depending on the specific chemical phase. After 12 weeks, it was hardly possible anymore to discern ACP- or CA-coated parts due to coverage by tissue debris and/or severe coating degradation, as shown in Figure 9a for a CA coating. CHA coatings were chemically more stable 


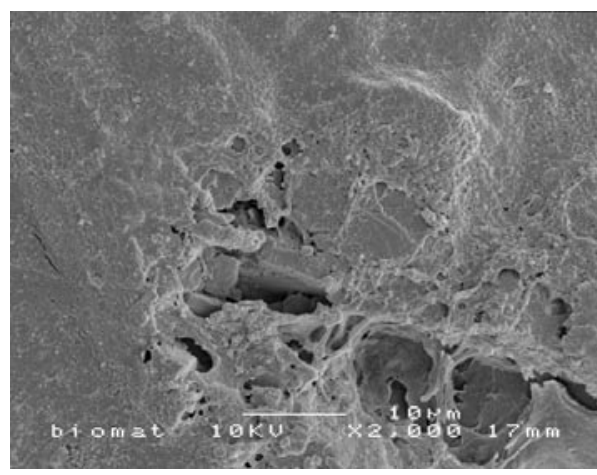

$9 \mathrm{a}$

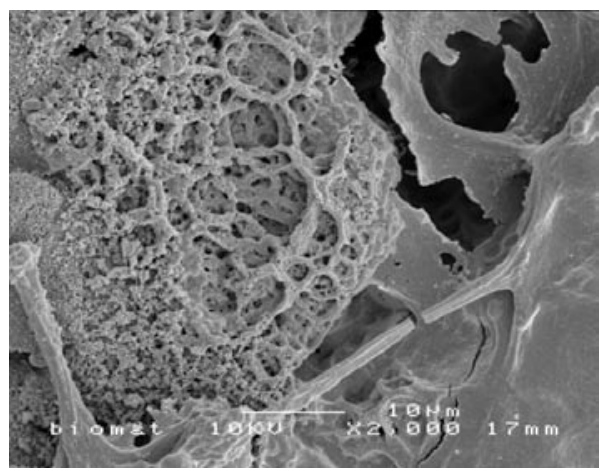

$9 \mathrm{c}$

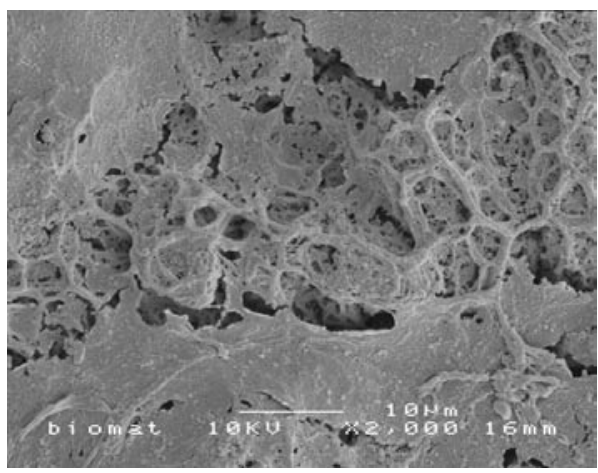

$9 \mathrm{~b}$

Figure 9: Scanning electron micrographs of $C A[a]$, CHA [b], and $\beta-T C P[c]$ coatings after subcutaneous implantation for 12 weeks.

than ACP and CA coatings upon subcutaneous implantation, as indicated by the clear presence of the porous coating morphology underneath the fibrous tissue debris after 12 weeks of subcutaneous implantation (Figure 9b). Remnants of $\beta$-TCP coatings were also still present after 12 weeks in vivo (Figure 9c), but in contrast to CHA coatings the surface morphologies of $\beta$-TCP coatings became highly disintegrated and granular.

Figures $10 \mathrm{a}-\mathrm{c}$ show the $\mathrm{X}$-ray diffractograms corresponding to $\mathrm{CA}, \mathrm{CHA}$, and $\beta$-TCP coatings before and after subcutaneous implantation for 2-12 weeks. As a result of blasting the $\mathrm{Ti}$ substrates with slightly $\mathrm{SiO}_{2}$-contaminated $\mathrm{Al}_{2} \mathrm{O}_{3}$ grains, minor substrate peaks at $25.5^{\circ}$ and $26.6^{\circ} 2 \theta$ remained present after all implantation periods for all implants. No information could be obtained on ACP coatings using XRD, since these coatings did not exhibit any diffraction peaks (Figure 3 ). Figure 10 a shows that reflection peaks at $31.9^{\circ}$ (211 and 112), $32.9^{\circ}(300)$, and $34.0^{\circ} 2 \theta$ (202), corresponding to the CA coating, disappeared within 4 weeks, whereas similar reflections were still observed for CHA coatings up to the final implantation time of 12 weeks (Figure 10b). $\beta$-TCP diffraction maxima gradually disappeared within 8 weeks of subcutaneous implantation $\left(27.8^{\circ}, 31.0^{\circ}\right.$ and $34.3^{\circ} 2 \theta$ peaks, Figure 10c). This means that the dissolution rate of $\beta$-TCP coatings was in between the degradation rates of soluble CA (and ACP) and stable CHA coatings, since characteristic $\beta$-TCP reflections were still present after 4 weeks, whereas reflections of CA coatings had disappeared already at that implantation time. Generally, low-angle diffraction peaks of OCP were not detected by means of XRD. 
Figure 10: XRD patterns of

$C A[a], C H A[b]$, and $\beta-T C P$

[c] coatings after $0,2,4,8$,

and 12 weeks of subcutaneous

implantation.

$+=$ apatite

$\wedge=\beta-T C P$

$0=T i$

\# = rutile $\mathrm{TiO}_{2}$
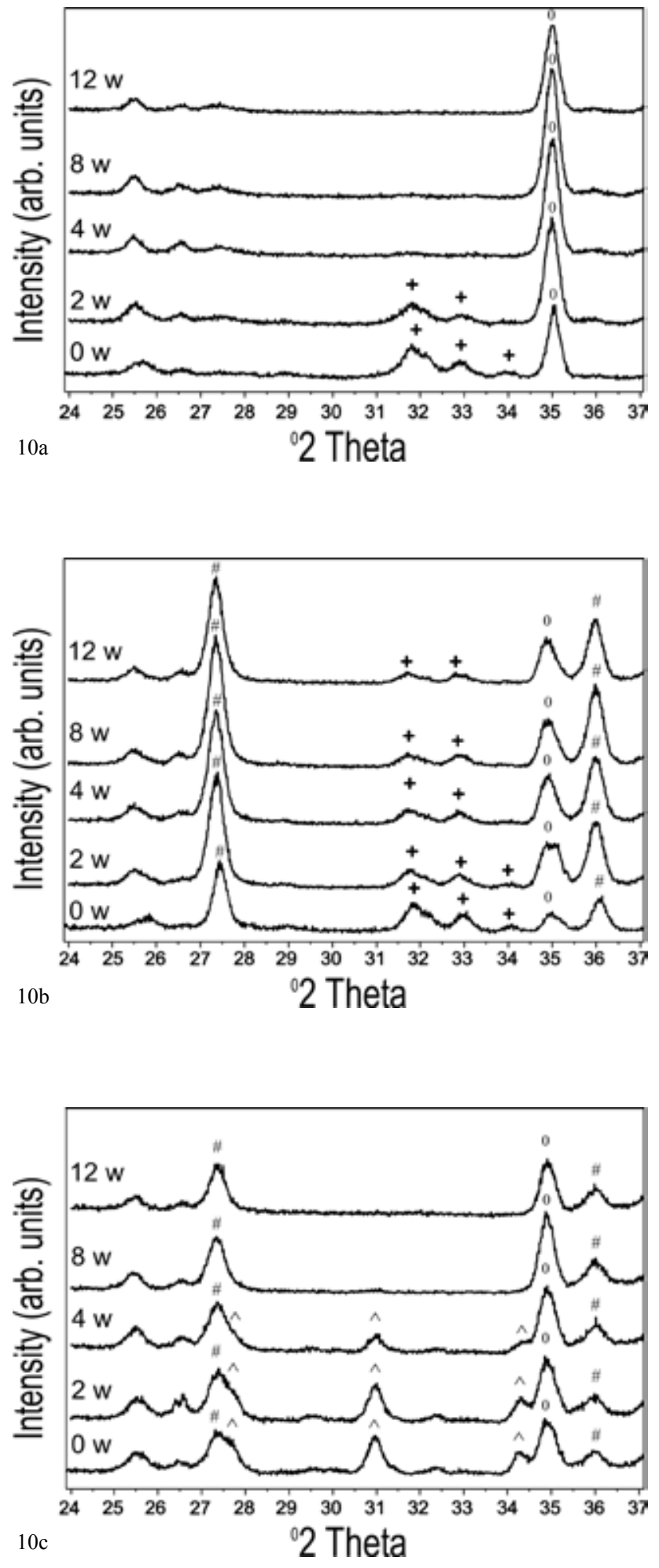


\section{Discussion}

The aim of the current study was to investigate the reactivity of porous, ESD-prepared $\mathrm{CaP}$ coatings with various crystal phases in terms of dissolution and/or precipitation reactions under in vitro and in vivo conditions.

\subsection{CaP COATING CHARACTERIZATION BEFORE IN VITRO/VIVO TESTING}

Several crystalline (CA, CHA, and $\beta$-TCP) and amorphous (ACP) electrosprayed CaPcoatings were tested in vitro and in vivo. The major structural difference between crystalline coatings $\mathrm{CA}$ (heat-treated at $500{ }^{\circ} \mathrm{C}$ ) and $\mathrm{CHA}$ (heat-treated at $700{ }^{\circ} \mathrm{C}$ ) was the presence of $\mathrm{OH}^{-}$groups into the apatitic lattice of $\mathrm{CHA}$ coatings after heat-treatment at $700{ }^{\circ} \mathrm{C}$, whereas CA coatings displayed higher carbonate contents without the presence of any $\mathrm{OH}^{-}$ absorptions. These results are in line with observations of El Feki et al. ${ }^{21}$, who found that $\mathrm{OH}^{-}$ions are formed and occupied A-sites after partial decomposition of type B carbonate ions according to the reaction:

$$
\mathrm{CO}_{3}^{2-}+\mathrm{H}_{2} \mathrm{O} \rightarrow \mathrm{CO}_{2}+2 \mathrm{OH}^{-}
$$

This phenomenon also explains the evolution of the (112) reflection shoulder in the diffraction pattern for CHA coatings after heat-treatment at $700{ }^{\circ} \mathrm{C}$, resulting from reduced peak broadening for CHA coatings as compared to CA coatings. Carbonate anions are known to hamper crystal growth as compared to carbonate-free hydroxyapatite ${ }^{22}$. Another striking observation was made with respect to the degree of oxidation of the underlying Ti substrate, which appeared to be more severe for CHA as compared to $\beta$-TCP coatings, although both types of coatings were heat-treated at $700{ }^{\circ} \mathrm{C}$. No solid explanation was found for this phenomenon, but it should be realized that all Ti-substrates were completely covered with 2-2.5 $\mu \mathrm{m}$ thick CaP coatings, which makes it reasonable to assume that the differences in oxidation layer thickness did not considerably alter the final in vitro and in vivo reactions.

\subsection{IN VITRO SOAKING EXPERIMENT}

A highly bioactive behaviour was observed for crystalline apatitic coatings (CA and $\mathrm{CHA}$ ), which induced the formation of a precipitation layer consisting of densely packed $\mathrm{CaP}$ flakes on top of apatitic coatings within the first 2 weeks of immersion in SBF. FTIR and XRD analyses revealed that all precipitation layers initially consisted of octacalcium phosphate (OCP) with its typical flake-like morphology, and $\mathrm{Ca} / \mathrm{P}$ ratios of OCP-covered apatitic coatings had decreased from 2.1-2.3 to values of about 1.6-1.7 as a result of the low $\mathrm{Ca} / \mathrm{P}$ ratio of OCP (1.33). Several authors mentioned already that OCP formation is a common feature in either simulated or real physiological environments ${ }^{3,23-26}$. However, unique low-angle $\left(<10^{\circ} 2 \theta\right)$ diffraction peaks of OCP are often ignored or are difficult to detect with XRD due to: a) the low angle of incidence of thin-film XRD when analyzing coatings, b) preferential orientation of OCP crystals on surfaces ${ }^{27}$, and/or c) small sizes in directions of the $(h 00)$ planes $^{28}$. A recent theoretical analysis of $\mathrm{CaP}$ precipitation in SBF by Lu et al. ${ }^{17}$ demonstrated that the nucleation rate of OCP is substantially higher than that of hydroxyapatite in SBF at a physiological $\mathrm{pH}$ of 7.4, while hydroxyapatite is thermodynamically the most stable phase in SBF. Iijama et al. ${ }^{28}$ and Nelson et al. ${ }^{29}$ proved that the presence of carbonate anions in surrounding fluids greatly affects the chemical nature and 
morphology of $\mathrm{CaP}$ precipitates. Nelson et al. ${ }^{29}$ suggested that nucleation of OCP seeds was favoured energetically in the presence of carbonate at concentrations lower than $10 \mathrm{mM}$. Moreover, subsequent conversion rates of OCP towards apatite were reduced by carbonate ions disturbing the crystallization of apatitic $\mathrm{CaP}$ phases ${ }^{22,28}$, which might explain the initial stabilization of OCP precipitates on carbonated ESD-coatings (ACP, CA, and CHA) under conditions where apatite is the expected precipitation bulk phase. Our findings support the statement made by Xin et al. ${ }^{3}$ that it should be reconsidered whether apatite formation is a suitable criterion to judge bioactivity of biomaterials, since misidentification of OCP for apatite might have confused theoretical considerations on in vitro bioactivity and distracted the attention from other $\mathrm{CaP}$ phases such as OCP.

With time, OCP precipitation layers became more apatitic in nature, as reflected by a) the gradual loss of OCP low-angle reflection peaks (XRD), b) the corresponding loss of degeneracy in the $v_{4}$ phosphate absorption domain (FTIR), and c) an increase in $\mathrm{Ca} / \mathrm{P}$ ratio from 1.6-1.7 to 1.8-1.9. OCP and apatite reveal close structural similarities, since the OCP structure is composed of apatite layers separated by hydrated layers ${ }^{22,23}$. The OCP $\rightarrow$ apatite transition is mostly a hydrolytic solid-state reaction ${ }^{24}$ :

$$
5 \mathrm{Ca}_{8} \mathrm{H}_{2}\left(\mathrm{PO}_{4}\right)_{6} \cdot 5 \mathrm{H}_{2} \mathrm{O} \rightarrow 8 \mathrm{Ca}_{5}\left(\mathrm{PO}_{4}\right)_{3} \mathrm{OH}+6 \mathrm{H}_{3} \mathrm{PO}_{4}+17 \mathrm{H}_{2} \mathrm{O}
$$

This gradual phase transformation from OCP to more basic apatitic $\mathrm{CaP}$ phases is a well-known phenomenon since Brown et al. ${ }^{30}$, and has been observed by several authors in vitro and in vivo after long periods of immersion ${ }^{23-31}$. Actually, OCP has been frequently proposed as a mandatory precursor phase for the formation of non-stoichiometric, biological apatites ${ }^{22,24,31}$. This process was described as a long-term mineralization process yielding phase mixtures richer in apatite with higher $\mathrm{Ca} / \mathrm{P}$ ratios than the transient OCP phase after maturation of biological calcifications ${ }^{25}$.

Amorphous $\mathrm{CaP}$ (ACP) displayed a delayed precipitation of poorly adherent $\mathrm{CaP}$ layers as compared to crystalline apatite coatings, whereas heterogeneous calcification was observed on $\beta$-TCP coated substrates for immersion periods of up to 8 weeks, indicating that $\beta$-TCP and ACP coatings exhibit a poor ability of inducing calcification in SBF as compared to crystalline apatitic coatings. FTIR and XRD analyses showed that ACP coatings were amorphous, exposing a chemically unstable surface with a high solubility to the surrounding body fluid, which initially might have reduced the calcifying tendency of ACP coatings after 1 week of immersion in SBF. Eventually, the high solubility of ACP led to deterioration of the porous coating morphology, crack formation, and most likely $\mathrm{CaP}$ dissolution at the interface between the coating and the substrate, which explains the poor adherence between calcified ACP coatings and the underlying Ti substrates. The observed poor ability of sintered $\beta$-TCP to induce CaP formation in vitro corroborates with a recent comparative study of Xin et al., who also observed that $\beta$-TCP did not readily induce OCP calcification in vitro and in vivo ${ }^{3}$. As before, this can be caused by the chemically unstable surface of $\beta$-TCP coatings, which might prevent the formation of OCP nuclei on soluble $\mathrm{CaP}$ phases in vitro. Another factor is the absence of carbonate ions in $\beta$-TCP coatings, which can stimulate OCP formation under specific conditions depending on the $\mathrm{Ca} / \mathrm{P}$ ratio and carbonate concentration of the surrounding fluids ${ }^{28}$. 


\subsection{IN VIVO SUBCUTANEOUS IMPLANTATION}

Gradual degradation was observed for all ESD-coatings using XRD and SEM techniques, as indicated by a continuous decrease in intensity of $\mathrm{CaP}$ reflection peaks and gradual deterioration of the porous coating structure. After 4 weeks of subcutaneous implantation, no CaP reflection peaks were observed for ACP and CA coatings, but remnants of the original porous coating structure were still recognizable using SEM for both ACP and CA, emphasizing that SEM is more sensitive in detecting amorphous and/or poorly crystalline $\mathrm{CaP}$ ceramics in degradation studies. Thin-film XRD gives general information on the crystal nature of the entire implant surface, whereas SEM provides local details on the morphology of retrieved CaP-coated implants. Although ACP coatings were characterized as amorphous, disordered solids using XRD and FTIR (Figures 2 and 3), the partial maintenance of the porous coating morphology up to 4-8 weeks of subcutaneous implantation suggests that the heat-treatment at $400{ }^{\circ} \mathrm{C}$ still had resulted into a chemical stabilization of this ceramic coating in terms of nucleation of $\mathrm{CaP}$ crystallites with sizes below the detection limit of thin-film XRD. Nevertheless, the occasional detachment of surrounding layers of fibrous tissue debris from ACP coatings suggests that the surface of ACP coatings was still chemically unstable enough to hamper the establishment of a close contact between the tissue capsule and the implant surface. After 12 weeks, ACP and CA coatings could hardly be discerned anymore resulting from severe coating degradation and coverage by surrounding fibrous tissue debris.

CHA coatings were heat-treated at a higher temperature of $700{ }^{\circ} \mathrm{C}$ and consequently revealed a lower dissolution rate than $\mathrm{ACP}$ and $\mathrm{CA}$, maintaining typical apatitic reflection peaks and the original porous coating morphology up to 12 weeks of implantation. As before, this effect was attributed to the decreased content of crystal growth inhibiting $\mathrm{CO}_{3}{ }^{2-}$ ions and the corresponding formation of $\mathrm{OH}^{-}$groups after heat-treatment at $700{ }^{\circ} \mathrm{C}$ for CHA coatings. XRD analysis revealed that $\beta$-TCP coatings were degraded completely after 8 weeks at an intermediate dissolution rate in between the rates for CA and CHA, although globular remnants of the reticular surface morphology were still observed by means of SEM after 12 weeks of implantation (Figure 9c). As before, SEM appears to be more sensitive than XRD in detecting degrading $\mathrm{CaP}$ coatings. $\beta$-TCP coatings were heat-treated at a higher temperature $\left(700^{\circ} \mathrm{C}\right)$ than $\mathrm{CA}$ coatings $\left(500^{\circ} \mathrm{C}\right)$, which might have resulted into formation of relatively large $\beta$-TCP crystals.

Generally, no signs of CaP mineralization were observed, but instead, coating dissolution was found for all ESD-coatings according to a gradual degradation mechanism without delamination of large coating fragments. Wolke et al. ${ }^{32}$ demonstrated that amorphous sputter-coatings gradually disappeared upon subcutaneous implantation in rabbits. Crystalline, $0.1 \mu \mathrm{m}$ thick hydroxyapatite sputter-coatings disappeared after 8 weeks, while thicker (1 and $4 \mu \mathrm{m}$ ) hydroxyapatite coatings were maintained until 12 weeks. In contrast to these perfectly dense CaP-coatings, dissolution of porous ESD-coatings was accelerated by their very high specific surface, which increased the surface reactivity of thermodynamically stable phases such as CA and CHA. In that way, control over the specific surface area of ESD-coatings (in terms of morphology/porosity) can be regarded as an added tool in order to control degradation rates of $\mathrm{CaP}$ coatings as compared to variation of coating chemistry only, which might be of interest for applications which require sustained drug delivery profiles of incorporated biological agents such as growth factors.

Finally, histological evaluation demonstrated that all implanted ESD-coatings evoked a biocompatible soft tissue reaction upon subcutaneous implantation for periods between 
2 and 12 weeks. In response to surgical trauma and implant positioning, a normal wound healing process was observed, characterized by the formation of a thin fibrous capsule around the implants without the occurrence of a serious inflammatory reaction. Since degradation of ESD-prepared CaP-coatings proceeded according to a gradual dissolution process, CaP release products did not provoke any foreign-body responses or other undesired tissue reactions, which might have been triggered by detached CaP-coating fragments ${ }^{33,34}$.

\subsection{COMPARISON BETWEEN IN VITRO AND IN VIVO STUDIES}

The current subcutaneous in vivo study was characterized by degradation of ESD-prepared $\mathrm{CaP}$ coatings, the outcome of which was directly opposed to the in vitro soaking experiment, where abundant OCP/CA calcification of identical ESD-coatings was observed. The same tendencies were described recently by Xin et al. ${ }^{3}$, who also found less CaP formation in vivo than in vitro under almost similar in vitro and in vivo conditions. This discrepancy is inherent in the impossibility to copy the immensely complex in vivo environment by an in vitro model such as soaking in SBF. First of all, it should be realized that in vivo wound healing processes are always associated with a local decrease in $\mathrm{pH}^{35}$, which inhibits CaP precipitation, whereas freshly prepared SBF solutions are buffered at neutral $\mathrm{pH}$ while performing in vitro soaking studies. Furthermore, the static in vitro conditions as employed in the current study (refreshment of SBF solutions on a weekly basis) are completely different from the constant physiological circulation of body fluids. Ramila et al. ${ }^{36}$ observed that apatite precipitation rate and morphology were different for static and dynamic immersion of sol-gel bioglass discs in SBF, and Duan et al. ${ }^{37}$ reported that nucleation of apatite in a dynamic soaking experiments could only be detected in the internal pore surface of porous CaP ceramics, where flow rates of SBF were lower than the outer surface. Another major experimental difference between in vitro and in vivo studies is the presence of various biological compounds, such as proteins, in the in vivo environment. Proteins are known to interact with CaP ceramics as promotor and/or inhibitor of mineral crystal formation $^{38}$. Several authors have already shown that serum proteins such as albumin can have an inhibitory effect on $\mathrm{CaP}$ crystallization in vitro, which could increase the solubility of protein-coated $\mathrm{CaP}$ ceramics over protein-free $\mathrm{CaP}$ under in vitro conditions ${ }^{39,40}$.

\section{Conclusions}

Various ESD-prepared, porous CaP coatings were a) soaked in SBF for time periods up to 12 weeks (in vitro), and b) implanted subcutaneously in goats for identical time periods (in vivo). In vitro, a highly bioactive behaviour was observed for all ESD-coatings, characterized by the deposition of a CaP precipitation layer on ESD-coatings. In vivo, on the contrary, all ESD-coatings degraded gradually at a dissolution rate depending on the specific chemical phase, thereby enabling synthesis of $\mathrm{CaP}$ coatings with a tailored degradation rate. The difference between the in vitro and in vivo results can be related to the intrinsically different experimental conditions for in vitro and in vivo studies (composition and static vs. dynamic exchange of simulated/extracellular body fluids, presence of proteins, etc.). 


\section{References}

1. Elliott, JC. Structure and chemistry of the apatites and other calcium orthophosphates. Amsterdam: Elsevier, 1994.

2. Yang $Y$, Kim KH, Ong JL. A review on calcium phosphate coatings produced using a sputtering process - an alternative to plasma spraying. Biomaterials 2005;26:327-337.

3. Xin R, Leng Y, Chen J, Zhang Q. A comparative study of calcium phosphate formation on bioceramics in vitro and in vivo. Biomaterials 2005;26:6477-6486.

4. $\quad$ Ducheyne P, Qiu Q. Bioactive ceramics: the effect of surface reactivity on bone formation and bone cell function. Biomaterials 1999;20:2287-2303.

5. LeGeros RZ. Biodegradation and bioresorption of calcium phosphate ceramics. Clin Mater 1993;14:6588 .

6. Lemons JE. Hydroxyapatite coatings. Clin Orthop Relat Res 1988;235:220-223.

7. Klein CPAT, Patka P, Wolke JGC, de Blieck-Hogervorst JM, de Groot K. Long-term in vivo study of plasma-sprayed coatings on titanium alloys of tetracalcium phosphate, hydroxyapatite and alpha-tricalcium phosphate. Biomaterials 1994;15:146-50.

8. Ban S, Maruno S. Morphology and microstructure of electrochemically deposited calcium phosphates in a modified simulated body fluid. Biomaterials 1998;19:1245-1253.

9. Wang J, Layrolle P, Stigter M, de Groot K. Biomimetic and electrolytic calcium phosphate coatings on titanium alloy: physicochemical characteristics and cell attachment. Biomaterials 2005;25:583-592.

10. Chen CH, Kelder EM, van der Put PJJM, Schoonman J. Morphology control of thin LiCoO films fabricated using the electrostatic spray deposition (ESD) technique. J Mater Chem 1996;6:765-771.

11. Perednis D, Wilhelm O, Pratsinis SE, Gauckler LJ. Morphology and deposition of thin yttria-stabilized zirconia films using spray pyrolysis. Thin Solid Films 2005;474:84-95.

12. Huang J, Best SM, Bonfield W, Brooks RA, Rushton N, Jayasinghe SN, Edirisinghe MJ. In vitro assessment of the biological response to nano-sized hydroxyapatite. J Mater Sci Mater Med 2004;15:441445 .

13. Berkland C, Pack DW, Kim K. Controlling surface nano-structure using flow-limited field-injection electrostatic spraying (FFESS) of poly(D,L-lactide-co-glycolide). Biomaterials 2004;25:5649-5658.

14. Uematsu I, Matsumoto H, Morota K, Minagawa M, Tanioka A., Yamagata Y, Inoue, K. Surface morphology and biological activity of protein thin films produced by electrospray deposition. J Colloid Interface Sci 2004;269:336-340.

15. Leeuwenburgh SCG, Wolke JGC, Schoonman J, Jansen JA. Influence of deposition parameters on chemical properties of calcium phosphate coatings prepared by using electrostatic spray deposition. J Biomed Mater Res 2005;74:275-284.

16. Leeuwenburgh SCG, Heine MC, Wolke JGC, Pratsinis SE, Schoonman J, Jansen JA. Morphology of calcium phosphate coatings for biomedical applications deposited using Electrostatic Spray Deposition. Thin Solid Films 2006;503:69-78.

17. Lu X, Leng Y. Theoretical analysis of calcium phosphate precipitation in simulated body fluid. Biomaterials 2005;26:1097-1108. 
18. van der Lubbe HB, Klein CP, de Groot $K$. A simple method for preparing thin (10 microM) histological sections of undecalcified plastic embedded bone with implants. Stain Technol 1988;63:1171-1176.

19. Layrolle P, Ito A, Tateishi T. Sol-gel synthesis of amorphous calcium phosphate and sintering into microporous hydroxyapatite bioceramics. J Am Ceram Soc 1998;81:1421-1428.

20. Koutsopolous S. Synthesis and characterization of hydroxyapatite crystals: a review study on the analytical methods. J Biomed Mater Res 2002;62:600-612.

21. El Feki H, Rey C, Vignoles M. Carbonate ions in apatites: infrared investigations in the $v_{4} \mathrm{CO}_{3}$ domain. Calcif Tissue Int 1991;49:269-274.

22. LeGeros RZ. Calcium phosphate in oral biology and medicine. Basel: Karger, 1991.

23. Leng Y, Chen J, Qu S. TEM study of calcium phosphate precipitation of HA/TCP ceramics. Biomaterials $2003 ; 24: 2125-2131$.

24. Eidelman N, Chow LC, Brown WE. Calcium phosphate phase transformation in serum. Calcif Tissue Int 1987;41:18-26

25. Mikroulis D, Mavrilas D, Kapolos J, Koutsoukos PG, Lolas C. Physicochemical and microscopical study of calcific deposits from natural and bioprosthetic heart valves. Comparison and implications for mineralization mechanism. J Mater Sci Mater Med 2002;13:885-889.

26. Sauer GR, Wuthier RE. Fourier Transform Infrared characterization of mineral phases formed during induction of mineralization by collagenase-released matrix vehicles in vitro. J Biol Chem 1988;263:1371813724.

27. Lu X, Leng Y. TEM study of calcium phosphate precipitation on bioactive titanium surfaces. Biomaterials 2004;25:1779-1786.

28. Iijima $M$, Kamemizu $H$, Wakamatsu $N$, Goto T, Doi Y, Moriwaki Y. Effects of $\mathrm{CO}_{3}^{2-}$ ion on the formation of octacalcium phosphate at $\mathrm{pH} 7.4$ and $37^{\circ} \mathrm{C}$. J Cryst Growth 1994;135:229-234.

29. Nelson DGA, Barry JC, Shields CP, Glena R, Featherstone JDB. Crystal morphology, composition, and dissolution behaviour of carbonated apatites prepared at controlled $\mathrm{pH}$ and temperature. $J$ Colloid Interface Sci 1989;130:467-479.

30. Brown WE, Smith JP, Lehr JR, Frazier AW. Crystallography of octacalcium phosphate. Nature 1962;196:1050-1054.

31. Ban $S$, Jinde T, Hasegawa J. Phase transformation of octacalcium phosphate in vivo and in vitro. Dent Mater J 1992;11:130-140.

32. Wolke JGC, van der Waerden JPCM, Schaeken HG, Jansen JA. In vivo dissolution behaviour of various $R F$ magnetron-sputtered Ca-P coatings on roughened titanium implants. Biomaterials 2003;24:26232629 .

33. Haman JD, Chittur KK, Crawmer DE, Luca LC. Analytical and mechanical testing of high velocity oxy-fuel thermal sprayed and plasma sprayed calcium phosphate coatings. J Biomed Mater Res (Appl Biomater) 1999;48:856-860.

34. Gross KA, Ray N, Rokkum M. The contribution of coating microstructure to degradation and particle release in hydroxyapatite coated prostheses. J Biomed Mater Res 2002;63:106-114.

35. Wong MEK, Hollinger JO, Pinero GJ. Integrated processes responsible for soft tissue healing. Oral Surg Oral Med Oral Patol Oral Radiol Endod 1996;82:475-492. 
37. Duan YR, Zhang ZR, Wang CY, Chen JY, Zhang XD. Dynamic study of calcium phosphate formation of porous HA/TCP ceramics. J Mater Sci Mater Med 2004;15:1205-1211.

38. Combes $C$, Rey C. Adsorption of proteins and calcium phosphate biomaterials bioactivity. Biomaterials 2002;23:2817-2823.

39. Cazalbou S, Combes C, Eichert D, Rey C, Glimcher MJ. Poorly crystalline apatites: evolution and maturation in vitro and in vivo. J Bone Miner Metab 2004;22:310-317.

40. Kim HM, Himeno T, Kokubo T, Nakamura T. Process and kinetics of bonelike apatite formation on sintered hydroxyapatite in a simulated body fluid. Biomaterials 2005;26:4366-4373. 



\section{Summary}

I

Calcium phosphate $(\mathrm{CaP})$ ceramics are widely studied for orthopedic and dental applications due to their bioactive properties. Generally, bioactive materials interact with surrounding bone, resulting into the formation of a chemical bond to this tissue ("bonebonding"). This phenomenon of bioactivity is determined mainly by chemical factors such as the crystal phase and molecular structure of the material - as well as physical factors, such as surface roughness and porosity. $\mathrm{CaP}$ ceramics are too brittle for use as bulk material under loaded conditions, which makes that $\mathrm{CaP}$ ceramics are frequently applied as coatings onto the surface of metallic implant materials in order to combine the mechanical strength of metals with the excellent biological properties of $\mathrm{CaP}$ ceramics. For that purpose, Electrostatic Spray Deposition (ESD) is a versatile technique, enabling deposition of inorganic coatings with a wide variety of controlled surface properties in terms of coating chemistry and morphology ${ }^{1,2}$. Briefly, the basic principle of ESD is the generation of a so-called electrospray out of organic solvents containing inorganic precursors. This is accomplished by pumping this liquid through a nozzle which is connected to a high voltage supply. As a result, a spray consisting of charged, micron-sized droplets is formed, which are attracted towards the grounded and heated substrate as a result of the applied potential difference. Consequently, the droplets impinge onto the heated substrate, where they lose their charge. After complete solvent evaporation, a thin layer is left onto the substrate surface.

In view of the above mentioned influence of $\mathrm{CaP}$ surface properties on bioactivity, ESD can be a powerful tool in research on the fundamental relationships between the physicochemical nature of $\mathrm{CaP}$ coatings and their biological performance in vitro and in vivo. In chapter one, a brief overview is presented of $\mathrm{CaP}$ ceramics, ceramic coating techniques, as well as principles and applications of electrospraying.

\section{II}

In chapter two of this thesis, the feasibility of the ESD technique was investigated for biomedical purposes, i.e., deposition of CaP coatings onto commercially pure titanium (Ti) substrates. By varying the deposition parameters, CaP coatings with various surface morphologies were successfully synthesized using this recently developed deposition process. Coating morphologies ranged from rough films made of fractal agglomerates to unique reticular coating morphologies with an interconnected porous network. X-Ray Diffraction (XRD) and FTIR (Fourier-Transform Infrared Spectroscopy) analyses showed that as-deposited $\mathrm{CaP}$ coatings were amorphous. After heat-treatment in air using infrared radiation, these amorphous coatings were transformed into crystalline AB-type carbonate apatite coatings, for which carbonate anions replaced both hydroxyl and phosphate groups. Carbonate ions were suggested to originate from the organic solvents which were used for electrospraying, since these solvents were the only organic component in the precursor solutions. This carbonate apatite crystal phase was particularly interesting due to its chemical resemblence to bone mineral. Consequently, it was concluded that the feasibility of the ESD technique was proven for the deposition of thin $\mathrm{CaP}$ coatings with a defined surface morphology. 
III

In order to be able to deposit $\mathrm{CaP}$ coatings with tailored chemical properties, the influence of precursor solution-related deposition parameters on the resultant chemical characteristics of electrosprayed $\mathrm{CaP}$ coatings was investigated in chapter three. It was shown by means of XRD, FTIR, and Energy Dispersive Spectroscopy (EDS) that the relative $\mathrm{Ca} / \mathrm{P}$ ratio in the precursor solution, the absolute precursor concentration, the acidity of the precursor solution, and the type of Ca-precursor strongly affected the chemical nature of the deposited $\mathrm{CaP}$ coatings. Various crystal phases and phase mixtures were obtained such as carbonate apatite, $\alpha / \beta$-tricalcium phosphate, $\mathrm{Mg}$-substituted whitlockite, monetite, $\beta / \gamma$-pyrophosphate, and calcite. It was shown that carbonate plays an essential role in the chemical mechanism of coating formation. Carbonate is formed due to a decomposition reaction of organic solvents. Depending on deposition conditions, carbonate anions a) react with acidic phosphate groups, b) are incorporated into apatitic $\mathrm{CaP}$ phases, and c) react with excessive $\mathrm{Ca}^{2+}$ cations in case of phosphate-deficient precursor solutions.

\section{IV}

The relationship between physical, apparatus-related deposition parameters and the chemical characteristics of ESD coatings was studied by means of XRD, FTIR, and EDS in chapter four. The results revealed that the chemical characteristics of $\mathrm{CaP}$ coatings, deposited using the ESD technique, were strongly dependent on the deposition temperature, the nozzle-to-substrate distance, the liquid flow rate, and the geometry of the spraying nozzle. By investigating the influence of the deposition temperature, information was obtained on the chemical formation mechanism of electrosprayed $\mathrm{CaP}$ coatings. CaP coatings were not formed merely due to solvent evaporation, but a chemical reaction was needed to synthesize the coatings. This reaction involved thermal decomposition of the organic solvent butyl carbitol into carbonate ions via formation of intermediate oxalate ions. The amount of carbonate incorporation (and correspondingly the $\mathrm{Ca} / \mathrm{P}$ ratios of the deposited coatings) was shown to: a) decrease with increasing nozzle-to-substrate distance, b) decrease with increasing liquid flow rate, and c) decrease by making use of a novel two-component nozzle geometry.

\section{$\mathrm{V}$}

In comparison to conventional deposition methods, such as sputter deposition and plasma-spraying, the ESD technique offers the possibility to deposit ceramic coatings with a wide variety of surface morphologies. Therefore, a Scanning Electron Microscopical (SEM) study was performed in chapter five to investigate the influence of several apparatus-related deposition parameters on the final morphology of electrosprayed CaP coatings. By changing the nozzle-to-substrate distance, the precursor liquid flow rate, and the deposition temperature, a broad diversity of coating morphologies was obtained, which varied from relatively dense to highly porous, reticular morphologies. Generally, droplet-like features were recognizable in terms of separated rings, doughnut-shapes, or interconnected pores, reflecting that electrospray droplets were the building units of the various coating morphologies using the ESD technique. The formation of various morphologies was suggested in the literature to be the result of an equilibrium between the rates of $\mathrm{CaP}$ solute precipitation, solvent evaporation, and droplet spreading on the substrate surface. 
VI

Various formation mechanisms have been suggested in the literature to explain the characteristic surface morphologies obtained using ESD. However, these models are merely based on observations using Scanning Electron Microscopy (SEM), and in some cases the models are contradictory. Therefore, in situ measurements of droplet sizes and velocities were performed in chapter six using Phase Doppler Anemometry during coating formation at high temperatures in order to correlate morphological features of the deposited $\mathrm{CaP}$ coatings with corresponding electrospray characteristics. Generally, it was shown that micron-sized surface features of these morphologies, such as doughnut-shapes and pores, corresponded to the diameters of electrospray droplets. By varying physical, apparatus-related parameters such as the nozzle-to-substrate distance and the deposition temperature, it was observed that electrosprayed butyl carbitol droplets did not shrink during droplet flight towards the heated substrate. Nevertheless, coatings with a different surface morphology were obtained, varying from microporous structures with coalesced pore walls to isolated rings on top of dense or grainy underlayers. This indicated that ESD of butyl carbitol solutions was a surface-controlled process without any significant solvent evaporation during droplet flight. The chemical composition of the precursor solutions and the mixing characteristics of the calcium and phosphate precursor components strongly influenced the initial droplet sizes, precipitation kinetics of the $\mathrm{CaP}$ solute, and subsequent coating morphology. Unique, reticular coatings were deposited at a deposition rate of 3.2 $\mu \mathrm{m} /$ hour, which had a graded structure consisting of a dense underlayer, a submicronporous intermediate layer, and a roughened toplayer revealing droplet-derived features such as isolated rings or coalesced, hollow surface pits.

\section{VII}

Mechanical properties of CaP coatings, deposited using the ESD technique, have been characterized in chapter seven using a range of analytical techniques, including tensile testing (according to ASTM C633), fatigue testing (ASTM E855), and scratch testing using blunt and sharp scratch styli. Moreover, a simple explantation procedure was successfully introduced using ESD-coated, screwed dental implants to characterize the mechanical performance of $\mathrm{CaP}$ coatings under conditions that mimic clinical situations as close as possible. Generally, all analysis techniques revealed that ESD-coatings need to be crystallized in order to ensure interfacial adhesion to the substrate and sufficient mechanical strength of the superficial reticular structure. Crystalline carbonated hydroxyapatite coatings (heattreated at $700{ }^{\circ} \mathrm{C}$ ) were resistant to fatigue as well as to plastic ploughing deformation by means of various scratch styli. The fragile surface structure of ESD-coatings was maintained to a large extent after unscrewing CHA-coated dental implants from femoral condyles of goat cadavers. From these experiments, it was concluded that interfacial adhesion of crystalline carbonated hydroxyapatite ESD-coatings to the Ti substrate was sufficient, but that mechanical strength of the superficial architecture of ESD-coatings needs to be optimized for applications where high shear and compressive stresses are imposed onto the fragile coating surface.

\section{VIII}

In chapter eight, the dissolution and/or precipitation behavior of electrosprayed porous $\mathrm{CaP}$ coatings was investigated a) in vitro after soaking in Simulated Body Fluid (SBF) for several time periods $(2,4,8$, and 12 weeks), and b) in vivo after subcutaneous implanta- 
tion of CaP coated implants in the back of goats for identical time periods. Physical and chemical properties of coatings were characterized before and after in vitro/vivo testing by means of SEM, XRD, FTIR, and EDS. Moreover, part of the explants was prepared for light-microscopical evaluation of the tissue response. In vitro, all apatitic ESD-coatings induced the formation of homogeneous and adherent $\mathrm{CaP}$ precipitation layers. Amorphous $\mathrm{CaP}$, however, displayed a delayed precipitation of poorly adherent $\mathrm{CaP}$ layers, whereas heterogeneous calcification was observed on top of $\beta$-TCP coated substrates, indicating that $\beta$-TCP and amorphous $\mathrm{CaP}$ coatings exhibit a poor ability of inducing calcification in $\mathrm{SBF}$ as compared to crystalline apatitic coatings. Initially, all precipitation layers consisted of octacalcium phosphate (OCP) with a typical flake-like morphology, but gradually the OCP phase hydrolyzed into dense carbonate apatite (CA) layers with increasing soaking time. In vivo, no adverse tissue reactions (toxic effects/inflammatory cells) were observed using light microscopy, and all coatings became surrounded by a dense, fibrous tissue capsule after implantation. All ESD-coatings degraded gradually at a dissolution rate depending on the chemical phase (order of relative solubility: amorphous $\mathrm{CaP} \approx$ carbonate apatite $>\beta$-TCP $>$ carbonated hydroxyapatite), thereby enabling synthesis of $\mathrm{CaP}$ coatings with a tailored degradation rate.

\section{Closing remarks and future perspective}

In this thesis, the suitability of the ESD technique was studied for biomedical purposes, i.e., deposition of CaP coatings onto Ti substrates. Using ESD, which is a simple and cheap deposition method for inorganic and organic coatings, it was possible to obtain thin $\mathrm{CaP}$ layers with an extremely wide range of chemical and morphological characteristics. Various CaP phases and phase mixtures were deposited and a broad diversity of coating morphologies was produced by varying deposition parameters related to the ESD-apparatus and/or the precursor solutions. Electrosprayed $\mathrm{CaP}$ coatings were shown to be biocompatible to soft tissue in this thesis, while the osteoconductive nature of electrosprayed $\mathrm{CaP}$ coatings was also proven in vivo ${ }^{3}$. Particular interest was given to a unique, reticular coating morphology consisting of a porous network of variable pore size. This specific coating morphology offers the possibility of varying the specific surface area of electrosprayed $\mathrm{CaP}$ coatings to a large extent. Consequently, the degradation rate of $\mathrm{CaP}$ coatings as well as the incorporation and subsequent release of biological agents (such as growth factors) can be influenced by chemical as well as physical coating properties using the ESD technique. In that way, control over the biological activity of drug-releasing CaP-coatings can be improved significantly as compared to conventional coating techniques, which lack this chemical and morphological variability.

Still, several problems need to be solved in order to achieve this final goal of depositing biologically active, drug-releasing CaP coatings onto implant surfaces. First of all, upscaling is necessary to coat large implant surfaces, since coating areas are restricted to a few square centimeters using the current set-up. Several strategies can be followed to overcome the restricted production rate and deposition area of the ESD-process. In chapter one of this thesis, an electrospraying set-up is described ${ }^{4}$ for which the number of spraying sources is increased to 250 nozzles $/ \mathrm{cm}^{2}$. Electrospraying deposition rates and covering areas can be increased even more, if these upscaled multiplexed nozzle systems are used in combination with a substrate holder connected to a computer-controlled XY-table. 
Second, relatively high temperatures are currently employed during coating deposition $\left(>300{ }^{\circ} \mathrm{C}\right)$ as well as subsequent heat-treatments $\left(>50{ }^{\circ} \mathrm{C}\right)$, which impede co-deposition of organic molecules. High temperatures are required to decompose the precursor solvents and salts and to form the final amorphous $\mathrm{CaP}$ compound, whereas additional heat-treatments are necessary to produce coatings with sufficient crystallinity and mechanical stability in vivo. A possible solution for this drawback related to the high processing temperatures is electrospraying of stable suspensions and sols, which contain crystalline $\mathrm{CaP}$ nano-particles. Starting from these suspensions and sols, a crystalline $\mathrm{CaP}$ ceramic is formed prior to spray generation. As a result, high temperatures during coating deposition and additional heat-treatments can be avoided. Further, the mechanical strength of $\mathrm{CaP}$ coatings can be increased by co-deposition of an organic protein component such as collagen $^{5}$ when a strong physicochemical interaction is established between the inorganic and organic composite phases. Moreover, deposition rates can be enhanced significantly as compared to electrospraying of dissolved precursor salts, since the solubility of precursor salts is not a limiting factor anymore when using stable suspensions and sols.

Another benefit of this suspension- and sol-based approach can be improved reproducibility as compared to synthesis starting from dissolved precursor salts, which react towards solid $\mathrm{CaP}$ compounds after spray generation. In chapters three and four, it was shown that $\mathrm{Ca} / \mathrm{P}$ ratios of the dissolved precursor salts do not correspond to $\mathrm{Ca} / \mathrm{P}$ ratios of deposited coatings. This phenomenon depends on the mixing time of the $\mathrm{Ca}$ and $\mathrm{P}$ precursors as described in chapter 4 , which makes that the geometry of the spraying nozzle is a critical process parameter. As a consequence, process control and reproducibility is complicated for the deposition of complex inorganic materials, such as carbonate apatite, by electrospraying of dissolved $\mathrm{Ca}$ and $\mathrm{P}$ precursor salts. On the contrary, compositional and crystallographic alterations of the solid $\mathrm{CaP}$ ceramic are not expected after spray generation during electrospraying of stable suspensions and sols.

Finally, it is possible to coat implants with complex geometries without using cast holders ("negatives") if coating deposition occurs at low temperatures. These cast holders are used to ensure heat conduction to curved implant surfaces for processing at high temperatures. 


\section{Samenvatting}

\section{I}

Calciumfosfaat $(\mathrm{CaP})$ keramiek wordt veelvuldig toegepast in de tandheelkundige en orthopedische chirurgie vanwege de zogenaamde bioactiviteit van dit biomateriaal. Bioactieve materialen gaan een interactie aan met omliggend botweefsel, waardoor een sterke binding ontstaat tussen levend bot en het synthetische implantaatoppervlak. $\mathrm{CaP}$ keramiek is van zichzelf te bros om te kunnen fungeren als lastdragend implantaat, maar dit probleem wordt dikwijls omzeild door $\mathrm{CaP}$ keramiek als dunne deklaag op mechanisch sterke metalen aan te brengen. Op deze wijze kan de mechanische sterkte van biometalen gecombineerd worden met de gunstige biologische eigenschappen van $\mathrm{CaP}$ keramiek. De ESD-techniek ("Electrostatic Spray Deposition”) is een veelbelovend hulpmiddel voor dit doeleinde, omdat de fysische en chemische oppervlakte-eigenschappen van keramische deklagen sterk gevariëerd kunnen worden met behulp van deze veelzijdige techniek $^{1,2}$. De ESD-techniek maakt gebruik van het principe van electrosprayen, waarbij een calciumfosfaat-houdende oplossing door een spuitnaald op hoogspanning verneveld wordt. Deze electrospray bestaat uit kleine, geladen druppels, die door het aangebrachte electrische veld naar een verhit substraat worden getransporteerd. Aangekomen op dit substraat verliezen de druppels hun lading, en vervolgens ontstaat een dunne keramische laag op het substraatoppervlak door verdamping van het oplosmiddel.

Omdat de mate van bioactiviteit van een CaP deklaag sterk samenhangt met diens oppervlakte-eigenschappen, biedt de variabiliteit van de ESD-techniek grote voordelen bij het onderzoek naar het verband tussen de fysisch-chemische eigenschappen van $\mathrm{CaP}$ deklagen en hun uiteindelijke biologische effectiviteit. Hoofdstuk 1 van dit proefschrift is een introductie tot $\mathrm{CaP}$ keramiek, de wijze waarop CaP deklagen aangebracht kunnen worden, en de hoofdprincipes en toepassingen van electrosprayen.

\section{II}

Om te beginnen werd in hoofdstuk 2 een studie uitgevoerd naar de toepasbaarheid van de ESD-techniek voor biomedische doeleinden. Het bleek dat het daadwerkelijk mogelijk was om CaP deklagen met verschillende oppervlaktestructuren aan te brengen op titanium (Ti) substraten door de instelparameters van de ESD-techniek te variëren. De oppervlaktestructuur van de aangebrachte deklagen liep uiteen van ruw en korrelig tot uiterst poreus. Gebruikmakend van analyse-technieken zoals röntendiffractie en infraroodspectroscopie kon vastgesteld worden dat de gedeponeerde deklagen amorf waren, maar onder invloed van infraroodstraling transformeerden tot een kristallijne, carbonaathoudende apatietdeklagen. Het carbonaat verving daarbij zowel hydroxyl- als fosfaatgroepen. Omdat er buiten het organische oplosmiddel geen enkele organische component in het electrospray-proces aanwezig was, namen wij aan dat het ingebouwde carbonaat afkomstig was van het oplosmiddel. Carbonaatapatiet is een veelbelovende kristalstructuur voor synthetisch $\mathrm{CaP}$ keramiek, omdat het overeenkomt met de minerale fase van menselijk bot en tanden. Samenvattend bracht deze haalbaarheids-studie ons tot de conclusie dat de ESD-techniek zeer geschikt is voor het aanbrengen van dunne $\mathrm{CaP}$ deklagen met een gedefiniëerde oppervlaktestructuur.

III

Om de samenhang te doorgronden tussen de instelvariabelen van het ESD-proces 
en de chemische eigenschappen van de gevormde deklagen, werd in hoofdstuk 3 met behulp van röntgendiffractie, infraroodspectroscopie en elementanalyse onderzoek verricht naar de relatie tussen de gebruikte uitgangsvloeistoffen en de chemie van de $\mathrm{CaP}$ coatings. Parameters zoals de verhouding tussen calcium $(\mathrm{Ca})$ en fosfor $(\mathrm{P})$, de absolute zoutconcentratie, de zuurtegraad, en het soort Ca-zout hadden alle een grote invloed invloed op de chemische eigenschappen van de CaP deklagen. Als gevolg van deze variatie in uitgangsoplossingen werden kristalfasen en fasenmengsels van o.a. carbonaatapatiet, $\alpha / \beta$-tricalciumfosfaat, magnesiumhoudend whitlockiet, monetiet, $\beta / \gamma$-pyrofosfaat en calciet gevormd. Daarbij hadden carbonaationen, ontstaan door verbrandingsreacties van het organisch oplosmiddel, een essentiële functie. Al naar gelang de reactieomstandigheden reageerden carbonaationen met zure fosfaatgroepen, werden ingebouwd in de apatietstructuur, en sloegen neer in de vorm van calciet wanneer er sprake was van een tekort aan fosfaat in de uitgangsvloeistof.

\section{IV}

Voortbordurend op hoofdstuk 3 onderzochten wij in hoofdstuk 4 de relatie tussen de chemische eigenschappen van de $\mathrm{CaP}$ deklagen en de fysische parameters van de ESDopstelling zelf, zoals de depositietemperatuur, de afstand tussen de spuitnaald en het substraat, de vloeisnelheid van de uitgangsoplossingen en de geometrie van de spuitnaald. Door deklagen bij verschillende depositietemperaturen op Ti aan te brengen, kregen wij een indruk van de wijze waarop de $\mathrm{CaP}$ coatings chemisch gezien ontstonden. Het bleek dat het oplosmiddel niet alleen verdampte, maar tevens een chemische reactie aanging met het $\mathrm{CaP}$ als gevolg van thermische ontleding van het organisch oplosmiddel butyl carbitol via oxalaat tot carbonaatgroepen. De mate van carbonaatinbouw - en dienovereenkomstig de $\mathrm{Ca} / \mathrm{P}$ verhouding van de deklagen - nam af met toenemende afstand tussen spuitnaald en substraat en toenemende vloeisnelheid van de uitgangsoplossingen. Bovendien bleken naalden met gescheiden vloeistoftoevoer voor $\mathrm{Ca}$ en $\mathrm{P}$ eveneens tot minder carbonaatinbouw en lagere $\mathrm{Ca} / \mathrm{P}$ verhoudingen te leiden.

\section{V}

Een groot voordeel van het ESD-proces ten opzichte van conventionele dunnelaagtechnieken (zoals plasmaspuiten en sputterdepositie) is de mogelijkheid om keramische deklagen met een grote variatie in oppervlaktestructuur te vormen. Om deze unieke eigenschap van de ESD-techniek verder uit te diepen, werd in hoofdstuk 5 een electronenmicroscopisch onderzoek verricht naar de wijze waarop fysische, apparaatgerelateerde procesparameters de oppervlaktestructuur van CaP deklagen bepalen. Afhankelijk van de afstand tussen spuitnaald en substraat, de vloeistofsnelheid en de depositietemperatuur bleek de oppervlaktestructuur van de gevormde $\mathrm{CaP}$ coatings uiteen te lopen van vrijwel massief en vlak tot uiterst poreus. Daarbij waren druppelgerelateerde elementen, zoals afzonderlijke ringen, "doughnuts" of samengevloeide poriën altijd duidelijk herkenbaar aan het oppervlak van de deklagen. Dit duidt op het feit dat de electrospray-druppels de bouweenheden waren van de verschillende oppervlaktestructuren. In de literatuur wijt men de vorming van de verschillende structuren aan het evenwicht tussen de snelheden van CaP precipitatie, verdamping van het oplosmiddel en spreiding van de druppels over het substraatoppervlak. 
Verschillende mechanismes zijn geopperd in de literatuur over ESD-deklagen om de vorming van de karakteristieke oppervlaktestructuren te verklaren. Deze modellen zijn louter gebaseerd op electronenmiscropisch onderzoek, en in sommige gevallen spreken ze elkaar tegen. Daarom hebben wij in hoofdstuk 6 de grootte en snelheid van de electrospray-druppels gemeten met behulp van de zogenaamde "Phase Doppler Anemometry" techniek om een verband te vinden tussen oppervlaktestructuur van de gevormde deklagen en de gemeten kenmerken van de overeenkomstige electrosprays. De typische micrometer-kenmerken van de deklagen, zoals poriën en "doughnuts", hadden een vergelijkbare diameter als de gemeten afmetingen van de druppels. Deze druppels bleken nauwelijks te krimpen tijdens het transport naar het verhit substraat, ongeacht de depositietemperatuur en afstand tussen spuitnaald en substraat. Desondank werden uiteenlopende deklagen gevormd onder deze verschillende omstandigheden, resulterend in microporeuze lagen met samengevloeide poriewanden tot korrelige of massieve lagen afgedekt door geïsoleerde ringen. Dit duidt erop dat ESD een oppervlakte-gecontroleerd proces is zonder enige verdamping van het oplosmiddel butyl carbitol tijdens transport van de druppels naar het substraat. De chemische samenstelling van de uitgangsvloeistoffen en de wijze van vermenging van de calcium- en fosfaatgroepen had een grote invloed op zowel de grootte van de druppels, de precipitatiesnelheid van het $\mathrm{CaP}$, als de uiteindelijke oppervlaktestructuur van de $\mathrm{CaP}$ deklagen. Unieke deklagen met een poreus netwerk groeiden met een snelheid van $3.2 \mu \mathrm{m} /$ uur, waarbij drie verschillende lagen onderscheden konden worden: een massieve onderlaag, een poreuze tussenlaag met poriën kleiner dan 1 $\mu \mathrm{m}$, en een ruwe toplaag bestaande uit druppel-gerelateerde elementen zoals geïsoleerde ringen of samengevloeide holtes.

\section{VII}

In hoofdstuk 7 stonden de mechanische eigenschappen van poreuze ESD-coatings centraal. Daartoe hebben wij zowel trektesten (volgens ASTM C633), vermoeiingsproeven (volgens ASTM E855) als krastesten uitgevoerd op de CaP deklagen. Bovendien hebben we met succes een simpele methode geïntroduceerd om het mechanisch gedrag van $\mathrm{CaP}$ deklagen te verifiëren onder omstandigheden die de tandheelkundige praktijk zoveel mogelijk nabootsen. Daarbij werden met $\mathrm{CaP}$ bedekte, tandheelkundige schroefimplantaten in en uit het kniebot van geitenkadavers geschroefd en vervolgens met electronenmicroscopie geëvalueerd. In het algemeen toonden al deze methoden aan dat ESD-coatings door verhitting gekristalliseerd dienen te worden om de hechting en mechanische sterkte van de $\mathrm{CaP}$ deklagen te waarborgen. Kristallijne deklagen van carbonaathoudend hydroxyapatiet (CHA, verhit op $700{ }^{\circ} \mathrm{C}$ ) waren bestand tegen vermoeiing en vertoonden relatief weinig blijvende vervorming na het aanbrengen van krassen door zowel scherpe als botte kraspennen. De kwetsbare oppervlakte-structuur van deze hoogverhitte CaP deklagen bleef eveneens grotendeels gehandhaafd na het verwijderen van deze CHA deklagen uit het kniebot van geitenkadavers. Ondanks dat de hechting van ESD-deklagen voldoende lijkt te zijn, was de hoofdconclusie van deze studie dat de mechanische sterkte van de tamelijk fragiele oppervlaktestructuur van ESD-deklagen verbeterd moet worden voor mogelijke toepassingen waarbij de deklagen blootgesteld worden aan grote schuif- en drukspanningen. 


\section{VIII}

Hoofdstuk acht was een onderzoek naar het biologische gedrag van de poreuze ESDdeklagen onder in vitro en in vivo omstandigheden. Bij het in vitro onderzoek hebben we verschillende soorten CaP deklagen gedurende 2, 4, 8 en 12 weken ondergedompeld in zogenaamde lichaams-simulerende vloeistoffen (Simulated Body Fluid, SBF). Dezelfde deklagen werden gedurende identieke tijdsperiodes onderhuids in de rug van geiten geïmplanteerd om de in vitro met de in vivo studie te kunnen vergelijken. De deklagen werden met electronenmiscroscopie, röntgendiffractie, infraroodspectroscopie en elementanalyse bestudeerd na afloop van zowel in vitro als in vivo studies. Bovendien hebben we een deel van de geïmplanteerde deklagen geprepareerd voor lichtmicroscopie om een indruk te krijgen van de reactie van zacht weefsel op de $\mathrm{CaP}$ deklagen. In vitro bleken kristallijne apatietdeklagen de vorming van een homogene en goed hechtende mineralisatielaag op te wekken. Amorfe $\mathrm{CaP}$ deklagen vertoonden daarentegen een vertraagde calcificatie, terwijl heterogene mineralisatie plaatsvond op deklagen met de kristalfase $\beta$-tricalciumfosfaat. Hieruit valt te concluderen dat $\beta$-tricalciumfosfaat en amorfe $\mathrm{CaP}$ deklagen minder snel $\mathrm{CaP}$ neer laten slaan in lichaams-simulerende vloeistoffen dan apatietdeklagen. Aanvankelijk bestond de calcificatielaag uit vlokken van de octacalciumfosfaat-fase, maar deze octacalciumfosfaat-fase zette in de loop van de tijd om tot massieve carbonaathoudende apatietlagen. In vivo werden geen nadelige weefselreacties waargenomen met lichtmicroscopie, en alle implantaten waren ingekapseld door een dunne laag bindweefsel. De deklagen degradeerden geleidelijk met een snelheid die afhing van de specifieke chemische fase (volgorde van oplosbaarheid: amorf $\mathrm{CaP} \approx$ carbonaatapatiet $>\beta$-tricalciumfosfaat $>$ carbonaathoudend hydroxyapatiet). Dit verschijnsel biedt mogelijkheden in de ontwikkeling van $\mathrm{CaP}$ deklagen met een gedefiniëerde afbraaksnelheid.

\section{Slotopmerkingen en toekomstperspectief}

In dit proefschrift is de potentie van de ESD-techniek voor biomedische doeleinden onderzocht. ESD is een simpel en goedkoop proces, waarmee dunne $\mathrm{CaP}$ deklagen met een enorme verscheidenheid aan oppervlakte-eigenschappen aangebracht kunnen worden op Ti substraten. Door de diverse procesparameters van de ESD-techniek structureel te variëren, waren wij in staat om verschillende chemische fasen en fasenmengsels te produceren met een breed spectrum aan oppervlaktestructuren. Deze CaP deklagen waren biocompatibel in zacht weefsel, en de ESD-deklagen blijken ook botgeleidend gedrag in vivo te vertonen ${ }^{3}$. We waren met name geïnteresseerd in unieke deklagen die bestonden uit een poreus netwerk met variabele poriegrootte. Deze bijzondere oppervlaktestructuur biedt de mogelijkheid om het specifieke oppervlakte van CaP deklagen te variëren, waardoor de afbraaksnelheid en de inbouw en afgifte van biologische moleculen (zoals groeihormonen) door zowel chemische als fysische eigenschappen van de deklagen beïnvloed kan worden. Op die manier kan de controle over de biologische activiteit van $\mathrm{CaP}$ deklagen die medicijnen afgeven sterk verbeteren ten opzichte van conventionele depositie-technieken die deze variabiliteit ontberen.

Toch zijn er nog heel wat problemen te overwinnen voordat het uiteindelijke doel bereikt kan worden, te weten de productie van biologisch actieve CaP deklagen met een gecontroleerde afgifte van medicijnen. Ten eerste moet het proces opgeschaald worden 
om grote implantaten te kunnen bedekken, want momenteel kunnen we de CaP deklagen slechts aanbrengen over een oppervlakte van een aantal vierkante centimeters. Verschillende opties zijn mogelijk om de beperkingen qua productiesnelheid en bedekkingsoppervlak te overwinnen. In hoofdstuk 1 van dit proefschrift werd een opgeschaalde electrosprayopstelling besproken ${ }^{4}$ waarbij maar liefst 250 spuitnaalden per $\mathrm{cm}^{2}$ zijn ingebouwd. De depositiesnelheid en bedekkingsgraad kan nog verder worden verhoogd door dit type opgeschaalde, meervoudige naaldsystemen te combineren met een computergestuurde, beweegbare substraathouder.

Verder maken de hoge temperaturen tijdens het depositieproces $\left(>300{ }^{\circ} \mathrm{C}\right)$ en de eropvolgende hittebehandelingen $\left(>500{ }^{\circ} \mathrm{C}\right)$ het sprayen van organische moleculen onmogelijk. Deze hoge procestemperaturen zijn nodig om de reactie tot stand te brengen tussen de opgeloste uitgangszouten en de ontledingsproducten van het organische oplosmiddel, terwijl de hittebehandeling voor de CaP kristallisatie en mechanische stabiliteit verantwoordelijk is. Dit probleem valt te omzeilen door stabiele suspensies en sols van kristallijne $\mathrm{CaP}$ nanodeeltjes te versprayen. Op deze wijze zijn de processen van $\mathrm{CaP}$ kristallisatie en electrosprayen gescheiden, en kunnen hoge procestemperaturen vermeden worden. Door organische eiwitmoleculen (zoals collageen) met de keramische $\mathrm{CaP}$ component te vermengen, kan de mechanische sterkte van dergelijke composietdeklagen aanzienlijk toenemen, mits deze organische en minerale bestanddelen een sterke fysischchemische interactie met elkaar aangaan ${ }^{5}$. Bovendien zullen hogere productiesnelheden mogelijk zijn bij het versprayen van suspensies ten opzichte van het sprayen van opgeloste zouten, aangezien de oplosbaarheid van de precursorzouten dan geen beperkende factor meer is.

De reproduceerbaarheid van deze op suspensies gebaseerde aanpak zal naar verwachting beter zijn dan de conventionele methode uitgaande van opgeloste zouten. In hoofdstuk 3 en 4 van dit proefschrift wordt beschreven dat de verhouding tussen $\mathrm{Ca}$ en $\mathrm{P}$ van de gevormde deklagen niet overeenkomt met de verhoudingen van de opgeloste $\mathrm{Ca}$ en $\mathrm{P}$ uitgangschemicaliën. Dit verschijnsel hangt samen met de vermenging van de $\mathrm{Ca}$ en $\mathrm{P}$ componenten (hoofdstuk 4), waardoor het ontwerp van de spuitnaald een belangrijke invloedsfactor wordt. Procescontrole en reproduceerbaarheid voor de ESD-techniek is dan ook lastig voor complexe anorganische materialen zoals carbonaatapatiet. De samenstelling en kristalstructuur van $\mathrm{CaP}$ keramiek zal daarentegen naar verwachting niet veranderen tijdens het electrosprayen van stabiele suspensies en sols.

Tenslotte zou het mogelijk moeten kunnen zijn om implantaten met complexe geometrieën op eenvoudige wijze te voorzien van een CaP deklaag zonder gebruikmaking van gegoten houders ("negatieven"). Deze houders zijn in de huidige opstelling wel nodig om de implantaten gelijkmatig te kunnen verhitten bij hoge temperaturen. 


\section{References / Referenties}

1. van Zomeren AA, Kelder EM, Marijnissen JCM, Schoonman J. The production of thin films of LiMn $\mathrm{O}_{4}$ by electrospraying. J Aerosol Sci 1994;25:1229-1235.

2. Chen CH, Kelder EM, van der Put PJJM, Schoonman J. Morphology control of thin LiCoO, films fabricated using the electrostatic spray deposition (ESD) technique. J Mater Chem 1996;6:765-771.

3. Siebers MC, Wolke JGC, Walboomers XF, Leeuwenburgh SCG, Jansen JA. Bioactivity of porous Electrostatic Spray Deposition (ESD)-derived calcium phosphate coatings. An in vivo study in a goat model. Clinical Oral Implants Research 2006 (in press).

4. Deng W, Klemic JF, Li X, Reed MA, Gomez A. Increase of electrospray throughput using multiplexed microfabricated sources for the scalable generation of monodisperse droplets. JAerosol Sci 2006;37:696714.

5. Fan $Y$, Duan K, Wang R. A composite coating by electrolysis-induced collagen self-assembly and calcium phosphate mineralization. Biomaterials 2005;26:1623-1632. 


\section{Dankwoord}

Een promotie wordt in de bijbehorende dankwoorden dikwijls vergeleken met een sportieve prestatie zoals het het beklimmen van een Alpenpas. Uit eigen ervaring weet ik echter dat je je als wielrenner in het hooggebergte heel wat radelozer kunt voelen dan tijdens een promotietraject. Deze positieve constatering heb ik met name te danken aan de directe of indirecte steun van velen. Een wetenschappelijke promotie is uiteindelijk toch vooral mensenwerk, en dankzij deze hartverwarmende hulp zijn de afgelopen jaren een heerlijke tijd voor me geweest.

Allereerst wil ik een welgemeend dankwoord uitspreken naar prof. John Jansen. Beste John, ik ben je enorm dankbaar voor alles wat je voor me betekend hebt in de afgelopen tijd. Jij liet me vrij om mijzelf ook op muzikaal gebied te ontwikkelen naast dit promotieonderzoek, wat van onschatbaar belang is geweest voor mijn levensgeluk. Ruimdenkend ben je ook geweest in de vakkundige wijze waarop je mij hebt begeleid. De vrijheid en het geschonken vertrouwen vormen de basis voor de totstandkoming van dit proefschrift. Dit neemt niet weg dat ik bijzonder veel van je heb geleerd op wetenschappelijk en nietwetenschappelijk gebied. Ik heb grote bewondering voor de manier waarop je in staat bent om de vele, uiteenlopende aspecten van een modern hoogleraarschap met zin voor kwaliteit uit te voeren. Je oprechtheid als mens en academicus kan daarbij velen tot voorbeeld strekken.

Dankzij het enthousiasme en de meedenkendheid van prof. Joop Schoonman ben ik in de biomateriaalkunde terechtgekomen, en ik ben u daar nog altijd erg dankbaar voor. Op uw afdeling heb ik de ESD-techniek geleerd, en ik heb de samenwerking van de laatste jaren tussen de vakgroepen Biomaterialen en Anorganische Chemie altijd als stimulerend ervaren. Gedurende deze periode heb ik veel gehad aan uw nauwkeurige correcties van de manuscripten, en na al die jaren vind ik het dan ook erg bijzonder dat $u$ nu mijn tweede promotor bent.

Een bijzonder woord van dank verdient mijn directe begeleider Joop Wolke. Beste Joop, ik heb door de jaren heen altijd erg genoten van onze samenwerking. Je bent voor mij zonder meer de ideale begeleider geweest, en jij hebt me definitief voor de biomaterialen gewonnen. Ondanks dat de afgelopen jaren niet bepaald gemakkelijk voor je zijn geweest, kon ik altijd bij je terecht en ik waardeer deze hulpvaardige houding ten diepste. Niet veel afdelingen zijn gezegend met zo'n eerlijk mens zoals jij.

I would like to thank prof. Sotiris Pratsinis for giving me the opportunity to perform PDA-measurements at the Particle Technology Laboratory of the ETH Zürich (Switzerland). These experiments comprise a valuable part of this thesis, which resulted into a published paper, and this collaboration has been a good example of the importance and benefits of scientific collaboration. Diese Messungen wären unmöglich gewesen ohne den kundigen Assistenz von Martin Heine, und ich möchte Dich denn auch herzlich danken für Deine Hilfe während der Experimente und bei der Korrektur.

Het ESD-team was afgelopen jaren niet compleet zonder mijn kamergenoot Marijke Siebers, en ik wil je dan ook heel hartelijk danken voor de fijne samenwerking door de jaren heen. Dankzij jouw biologisch werk weten we nu ook dat mijn materiaalkundige geploeter zin heeft gehad. Vele andere collega's van de afdeling Biomaterialen (Anne, Chris-vanorthopedie, Corinne, Dennis, Edwin Ooms, Edwin van der Wal, Esther, Harry, Henriëtte, Frank, Jack, Jacky, Johan, Juliëtte, Jurgen, Ken, Lise, Manal, Martijn, Meike, Natasja, Olga, Peter, Petra, Remco, Vincent, Walter, Weibo, Wouter, Yong Gang) wilde ik bedanken 
voor de sociale werksfeer en hulpvaardigheid, zodat werk zelden als een verplichting heeft aangevoeld. Anja verdient daarbij een speciale vermelding voor de strakke organisatie van het lab, waardoor ik mij kon richten op experimenten in plaats van op het vinden van schoon glaswerk. Met Bas Feddes was het altijd prettig en stimulerend discussiëren, en aan onze geslaagde uitwisseling tussen pianolessen en de heerlijke vlucht naar Texel bewaar ik goede herinneringen. In het bijzonder wilde ik kamergenoten Quinten, Diederik en natuurlijk strijdmakker Jeroen bedanken voor het plezier op de werkkamer en tijdens onze verkenningen van de Nijmeegse restaurants.

Louis Winnubst dank ik hartelijk voor alle betrokkenheid gedurende de afgelopen jaren. Jouw ruime ervaring met keramische materialen hebben mijn blikveld op biomaterialen zonder enige twijfel verruimd. In het bijzonder wilde ik je danken voor de mogelijkheid die je mij hebt geboden om namens de Nederlandse Keramische Verening aan het congres van de Europese Keramische Vereniging in Portoroz (Slovenië) deel te nemen. Ik heb genoten van dit congres, en hoop dat we nog vaker gezamenlijke wetenschappelijke activiteiten zullen ontplooien.

Jan Marijnissen heeft mij in de eerste jaren van dit promotie-onderzoek veel bijgeleerd over de wondere wereld van het electrosprayen, waarvoor ik je veel dank verschuldigd ben. Het verschijnsel electrosprayen is tamelijk complex, en ik heb je geboden hulp en aanstekelijk enthousiasme altijd bijzonder gewaardeerd. Dankzij het technisch inzicht en de meedenkende instelling van Ben Meester konden vele nieuwe ideeën op ESD-gebied verwezenlijkt worden, en ik hoop voor de toekomst op een prettige voortzetting van deze samenwerking. Henk Looij verzorgde het ontwerp van de omslag, en ik ben erg blij met het fraaie resultaat: een beter visitekaartje voor dit onderzoek kan ik me niet wensen.

Frank Peters, je had er waarschijnlijk nooit op gerekend ooit nog eens in een proefschrift terecht te komen. Zo zie je maar weer, Gods wegen zijn uiterst ondoorgrondelijk. Toch is jouw indirecte inbreng in deze wetenschappelijke creatie van niet te onderschatten belang geweest, want de piano - en jouw stimulerende rol daarbij - vormde de voor mij noodzakelijke afwisseling waardoor dit proefschrift mede tot stand is gekomen. In dat verband wil ik de heren Bach JS, Rachmaninov SV, Radiohead et al. eveneens danken voor al het moois dat zij de wereld schonken; hun grootsheid is een onuitputtelijke bron van steun en inspiratie.

Paranimfomanen Bastiaan van Meeteren en Roel Schierbeek wilde ik ontzettend bedanken voor alle relativering, humor en betrokkenheid door de jaren heen. Jullie kennen beide het gevoel van een herfstig-verregende Mekelweg, ontploffen op de Keutenberg en de schoonheid van kunst, en dat maakt jullie tot heel bijzondere en waardevolle vrienden.

$\mathrm{Na}$ onze opwindende trektocht van Azië naar Europa (dank voor de prachtige tijd!) was reisgenoot Martijn Prins ook nog eens zo barmhartig om mij de laatste computerkwellingen bij de lay-out van dit proefschrift te besparen. Heel erg bedankt daarvoor, en het resultaat ziet er perfect uit. Ook niet-Delftenaren hebben ervoor gezorgd dat ik de laatste jaren de dingen in hun juiste verhouding kon blijven zien, en in dat verband wil ik met name Erik, Herman, Mariska, Nina en Vincent noemen. Dank voor alles !

Bovenal wilde ik mijn familie danken voor hun onbegrensde liefde en steun. Jullie vormen een stabiele basis op wie ik altijd kan terugvallen, en dat is waar het leven uiteindelijk om draait. Pepijn, Imme en Isa zijn daarbij ware aanwinsten voor dit familiegeluk. In het bijzonder wilde ik tot slot mijn lieve ouders bedanken. De grote kunst van het leven is het respecteren en waarderen van de medemens, en die kunst beheersen jullie als geen ander. Jullie zijn prachtmensen, en ik geniet volop van jullie wijsheid, inspiratie en liefde.

Dank! 


\section{Curriculum vitae}

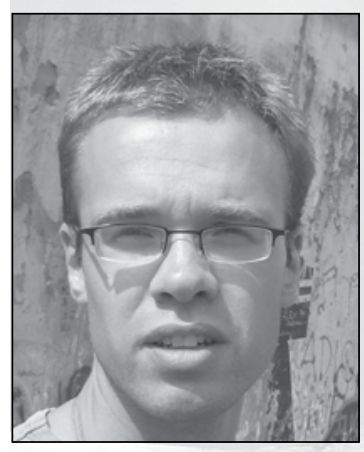

Sander Leeuwenburgh werd op 22 juli 1977 geboren te Gouda. In 1995 behaalde hij het eindexamen op het Coornhert Gymnasium in Gouda, waarna hij Materiaalkunde ging studeren aan de Technische Universiteit Delft. Tijdens deze studie verbleef hij een half jaar aan de ETH in Zürich (Zwitserland) en volgde een stage van 4 maanden bij het biomedisch bedrijf Isotis te Bilthoven. In april 2001 besloot hij zijn studie aan de TU Delft met een afstudeerstage bij de vakgroep Anorganische Chemie van prof. dr. Joop Schoonman (met lof).

Vervolgens begon hij in deeltijd zijn promotie-onderzoek bij de vakgroep Biomaterialen van prof. dr. John Jansen aan het Medisch Centrum van de Radboud Universiteit Nijmegen. Daarnaast studeerde hij piano aan het conservatorium van Arnhem, waar hij in 2005 afstudeerde (met onderscheiding). Het promotie-onderzoek werd december 2005 afgesloten, en de resultaten ervan zijn beschreven in dit proefschrift.

Van januari tot en met maart 2006 was hij te gast bij de afdeling Bioengineering van prof. dr. Antonios Mikos aan de Rice University in Houston (Verenigde Staten). Daarna reisde hij gedurende vier maanden van Tibet naar Nederland. In september 2006 trad hij als post-doc in dienst bij de afdeling Biomaterialen van prof. dr. John Jansen aan het Medisch Centrum van de Radboud Universiteit Nijmegen. 


\section{Publications related to this thesis}

1. Leeuwenburgh S, Wolke J, Schoonman J, Jansen J. Electrostatic Spray Deposition (ESD) of calcium phosphate coatings. J Biomed Mater Res 2003;66:330-334.

2. Leeuwenburgh SCG, Schoonman J, Wolke JGC, Jansen JA. Electrostatic Spray Deposition (ESD) of calcium phosphate coatings for biomedical applications. Tijdschrift voor Klei, Glas en Keramiek 2003;24:21-22.

3. Leeuwenburgh SCG, Wolke JGC, Schoonman J, Jansen JA. Influence of precursor solution parameters on chemical properties of calcium phosphate coatings prepared using Electrostatic Spray Deposition (ESD). Biomaterials 2004;25:641-649.

4. Leeuwenburgh SCG, Wolke JGC, Schoonman J, Jansen JA. Influence of deposition parameters on chemical properties of calcium phosphate coatings prepared by using electrostatic spray deposition. J Biomed Mater Res 2005;74:275-284.

5. Leeuwenburgh SCG, Wolke JGC, Schoonman J, Jansen JA. Deposition of calcium phosphate coatings with defined chemical properties using the Electrostatic Spray Deposition technique. J Europ Ceram Soc 2006;26:487-493.

6. Leeuwenburgh SCG, Wolke JGC, Schoonman J., Jansen JA. Influence of deposition parameters on morphological properties of biomedical calcium phosphate coatings prepared using Electrostatic Spray Deposition. Thin Solid Films 2005;472:105-113.

7. Leeuwenburgh SCG, Heine MC, Wolke JGC, Pratsinis SE, Schoonman J, Jansen JA. Deposition of biomedical calcium phosphate coatings with defined chemical and morphological properties using the Electrostatic Spray Deposition technique. Tijdschrift voor Klei, Glas en Keramiek 2005;26:13-14.

8. Leeuwenburgh SCG, Heine MC, Wolke JGC, Pratsinis SE, Schoonman J, Jansen JA. Morphology of calcium phosphate coatings for biomedical applications deposited using Electrostatic Spray Deposition. Thin Solid Films 2006;503;69-78.

9. Leeuwenburgh SCG, Wolke JGC, Siebers MC, Schoonman J, Jansen JA. In vitro and in vivo reactivity of porous, electrosprayed calcium phosphate coatings. Biomaterials 2006;27:33683378 .

10. Leeuwenburgh SCG, Wolke JGC, Lommen L, Pooters T, Schoonman J, Jansen JA. Mechanical properties of porous, electrosprayed calcium phosphate coatings. J Biomed Mater Res 2006 (published online).

\section{OTHER PUBLICATIONS}

1. Leeuwenburgh SCG, Layrolle P, Barrère F, de Bruijn J, Schoonman J, van Blitterswijk CA, de Groot K. Osteoclastic resorption of biomimetic calcium phosphate coatings in vitro. J Biomed Mater Res 2001;56:208-215. 
2. Siebers MC, Walboomers XF, Leeuwenburgh SCG, Wolke JGC, Jansen JA. Electrostatic spray deposition (ESD) of calcium phosphate coatings, an in vitro study with osteoblast-like cells. Biomaterials 2004;25:2019-2027.

3. Siebers MC, Matsuzaka K, Walboomers XF, Leeuwenburgh SCG, Wolke JGC, Jansen JA. Osteoclastic resorption of calcium phosphate coatings applied with electrostatic spray deposition (ESD), in vitro. J Biomed Mater Res 2005;74:570-580.

4. Siebers MC, Walboomers XF, Leeuwenburgh SCG, Wolke JGC, Jansen JA. The influence of crystallinity of Electrostatic Spray Deposition (ESD)-derived coatings on osteoblast-like cell behavior. J Biomed Mater Res 2006;78:258-267.

5. Siebers MC, Walboomers XF, Leeuwenburgh SCG, Wolke JGC, Boerman OC, Jansen JA. TGF- $\beta 1$-release from a porous Electrostatic Spray Deposition (ESD)-derived calcium phosphate coating. Tissue Eng 2006 (published online).

6. Siebers MC, Wolke JGC, Walboomers XF, Leeuwenburgh SCG, Jansen JA. Bioactivity of porous Electrostatic Spray Deposition (ESD)-derived calcium phosphate coatings. An in vivo study in a goat model. Clin Oral Implants Res 2006 (in press).

7. Siebers MC, Walboomers XF, Leeuwenburgh SCG, Wolke JGC, Jansen JA. The behavior of osteoblast-like cells on various substrates with functional blocking of integrin- $\beta 1$ and integrin- $\beta 3$. Submitted to J Biomed Mater Res 2006. 

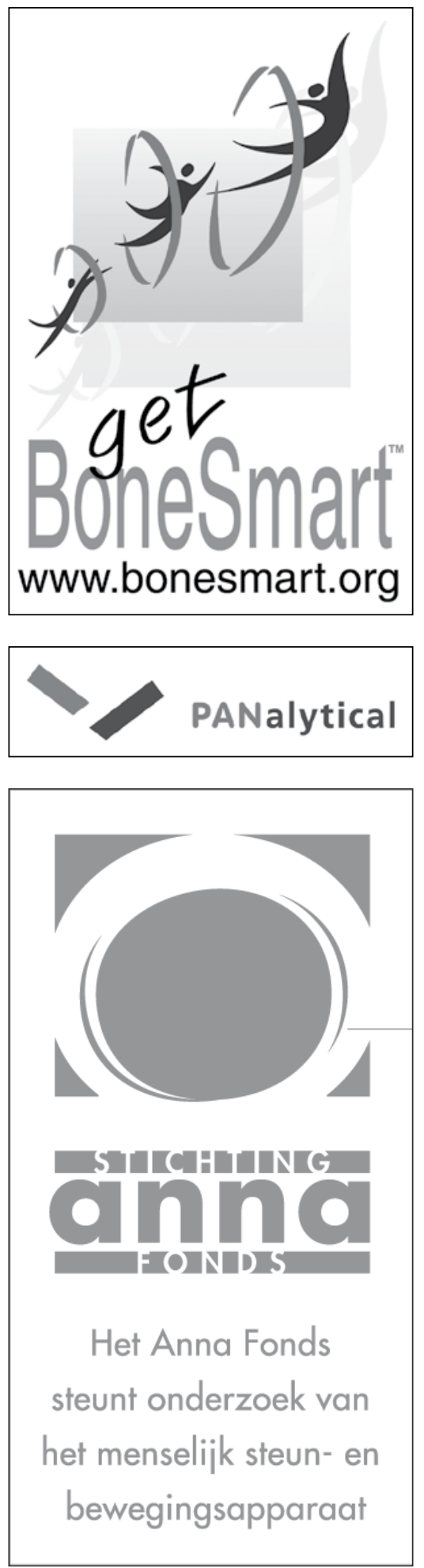

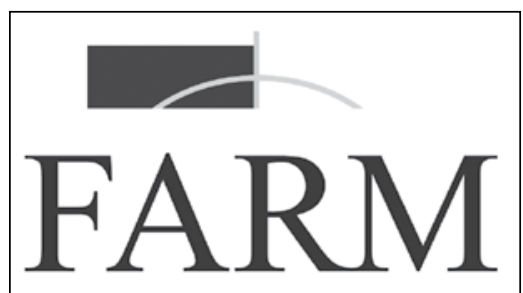

Foundation for Advancement in Research in Medicine, Inc.
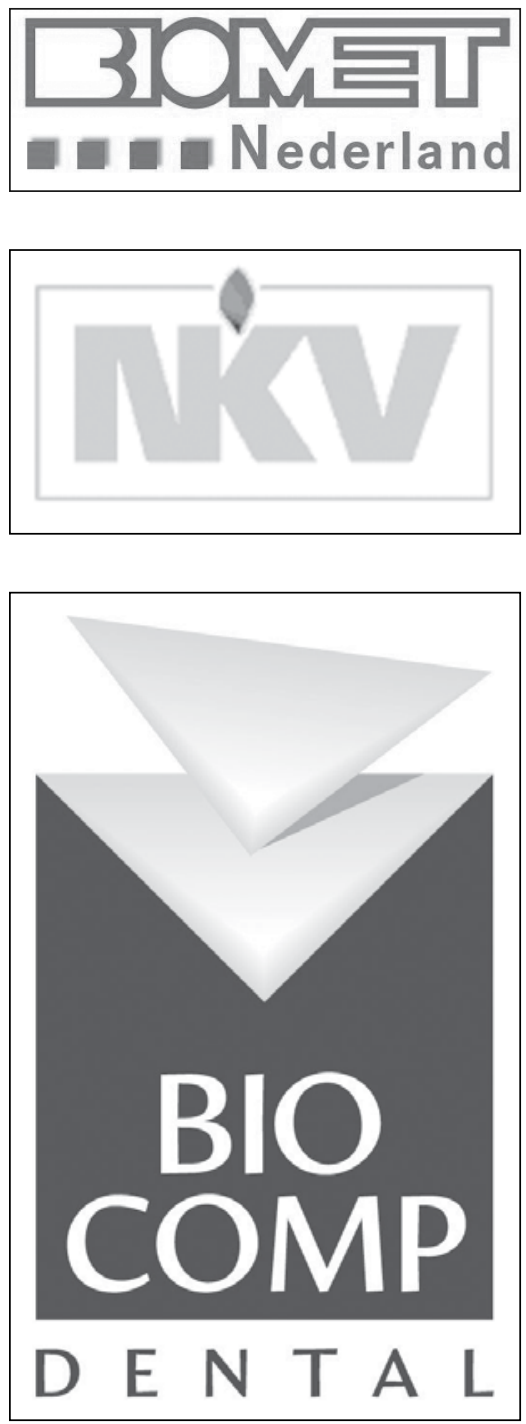